\title{
The Characterisation and Performance of Magnetron Sputter Coatings on Minting Dies
}

\author{
By \\ David Alexander McLean \\ B.Eng \\ A thesis submitted to \\ the Faculty of Graduate Studies and Research \\ in partial fulfillment of \\ the requirements for the degree of \\ Master of Applied Science \\ Ottawa-Carleton Institute for Mechanical and Aerospace Engineering \\ Department of Mechanical and Aerospace Engineering \\ Carleton University \\ Ottawa, Ontario \\ Canada \\ April 2010@
}




$\begin{array}{ll}\begin{array}{l}\text { Library and Archives } \\ \text { Canada }\end{array} & \begin{array}{l}\text { Bibliothèque et } \\ \text { Archives Canada }\end{array} \\ \begin{array}{l}\text { Published Heritage } \\ \text { Branch }\end{array} & \begin{array}{l}\text { Direction du } \\ \text { Patrimoine de l'édition }\end{array} \\ \begin{array}{l}395 \text { Wellington Street } \\ \text { Ottawa ON K1A ON4 } \\ \text { Canada }\end{array} & \begin{array}{l}395, \text { rue Wellington } \\ \text { Ottawa ON K1A ON4 } \\ \text { Canada }\end{array}\end{array}$

Your file Votre référence

ISBN: 978-0-494-68624-9

Our file Notre référence

ISBN: $978-0-494-68624-9$

NOTICE:

AVIS:

The author has granted a nonexclusive license allowing Library and Archives Canada to reproduce, publish, archive, preserve, conserve, communicate to the public by telecommunication or on the Internet, loan, distribute and sell theses worldwide, for commercial or noncommercial purposes, in microform, paper, electronic and/or any other formats.

The author retains copyright ownership and moral rights in this thesis. Neither the thesis nor substantial extracts from it may be printed or othenwise reproduced without the author's permission.

L'auteur a accordé une licence non exclusive permettant à la Bibliothèque et Archives Canada de reproduire, publier, archiver, sauvegarder, conserver, transmettre au public par télécommunication ou par l'Internet, prêter, distribuer et vendre des thèses partout dans le monde, à des fins commerciales ou autres, sur support microforme, papier, électronique et/ou autres formats.

L'auteur conserve la propriété du droit d'auteur et des droits moraux qui protège cette thèse. $\mathrm{Ni}$ la thèse ni des extraits substantiels de celle-ci ne doivent être imprimés ou autrement reproduits sans son autorisation.

In compliance with the Canadian Privacy Act some supporting forms may have been removed from this thesis.

While these forms may be included in the document page count, their removal does not represent any loss of content from the thesis.
Conformément à la loi canadienne sur la protection de la vie privée, quelques formulaires secondaires ont été enlevés de cette thèse.

Bien que ces formulaires aient inclus dans la pagination, il n'y aura aucun contenu manquant. 


\begin{abstract}
Enhancing the performance of various tools and mechanical parts through the use of thin films has been given much attention recently. Thin films have many different uses including: reducing friction, protecting from corrosion and increasing hardness and wear resistance. The Royal Canadian Mint has adopted the magnetron sputter ion plating technique to apply a new $\mathrm{Cr}-\mathrm{Ti}-\mathrm{N}$ based multi-component hard coating and thereby replace their Cr-plating process. Apart from showing improvements to the performance of their minting dies, this change is also more environmentally friendly.

The purpose of this thesis is to further characterise this new coating which has shown superior performance. The structure of coatings applied using the magnetron sputter ion plating technique was reviewed along with the hardness and performance analysis of thin-film coatings. Hardness performance of the film on minting dies, including hardness testing and thin-film hardness models, are reviewed. The die performance is discussed in terms of surface wear encountered during the minting process. Two test dies made from air-hardening tool steel are coated and analysed for their hardness performance. Three numismatic coin dies are also analysed at different stages of their lifetime to compare the surface wear at those stages and evaluate the performance of the coating.

Both nano- and micro-indentation hardness testing was used to obtain hardness data on the two test dies. The Korsunsky thin-film hardness model was selected to best represent both sets of hardness data. The thin-film hardness model parameters and film hardness were simultaneously calibrated using both nano- and micro-indentation test data. The film hardness was determined to be about $2672 H V$. The film hardness was then successfully predicted using only the micro-indentation data and the method was demonstrated on two additional dies with the same composition. The hardness performance of the die was linked to the adhesion of the film. In particular, poor adhesion led to an early decrease in measured hardness as indent test weight was increased.
\end{abstract}




\section{Acknowledgements}

I would like to thank Professor Xin Wang for his support, guidance and infinite patience.

I would also like to thank Dr. Xianyao Li for his direction and support, as well as the staff at the Royal Canadian Mint who have been exceptionally helpful.

I would like to thank the Ontario Centre for Excellence and the Royal Canadian Mint for providing the funding to undertake this project.

More thanks are due to Dr. Qi Yang, Institute for Aerospace Research, National Research Council (NRC) of Canada for volunteering his time performing nanoindentation testing on some of the test specimens.

Finally, I want to thank all of my family and friends for their encouragement and support in this endeavour from beginning to end. 


\section{Table of Contents}

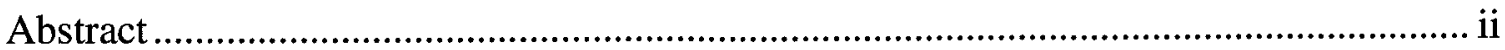

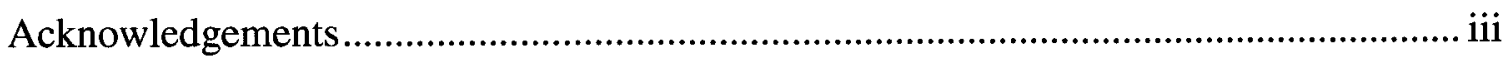

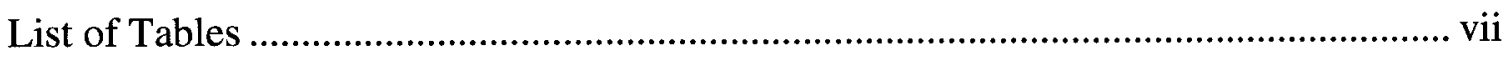

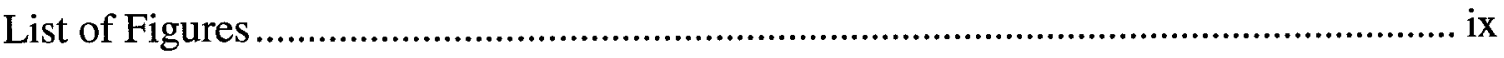

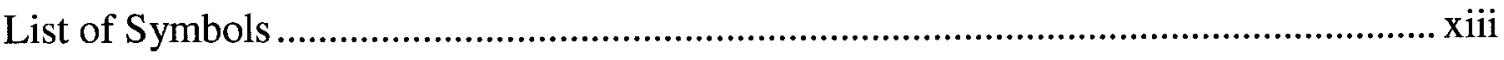

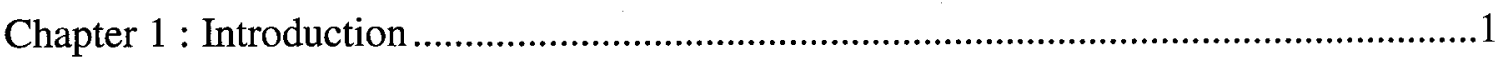

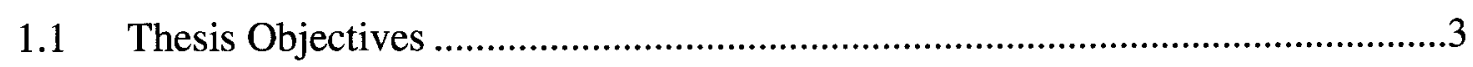

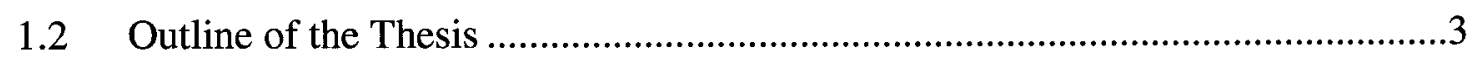

Chapter 2 : Literature Review and Background .................................................

2.1 Structure of the Coated Die ......................................................................4

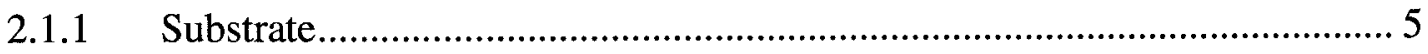

2.1.2 Intermediate and Film Layers ......................................................... 5

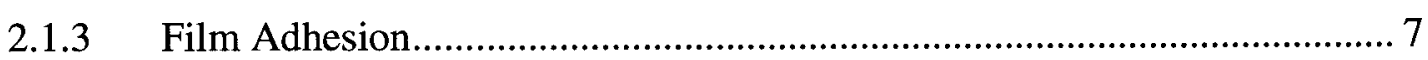

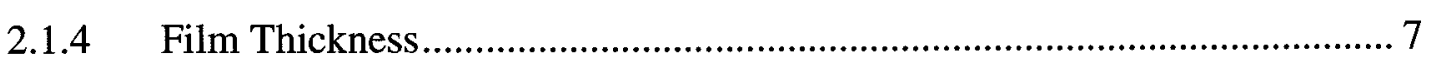

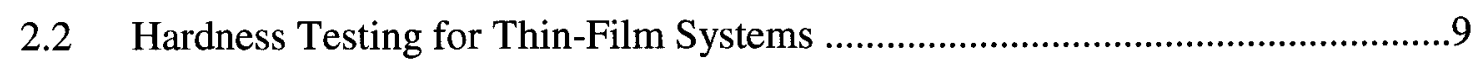

2.2.1 Micro-Indentation Hardness Testing ................................................ 9

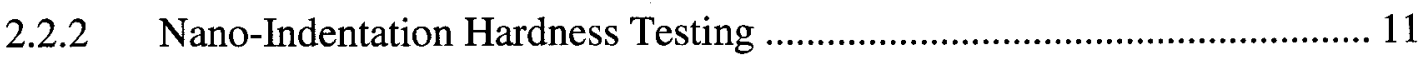

2.3 Thin-Film Hardness Models................................................................14

2.3.1 Hardness Models for Thin-Film Coated Systems ................................... 15

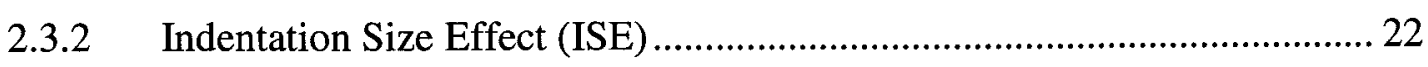

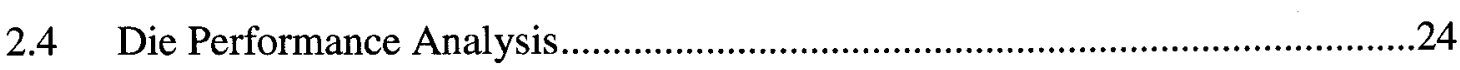

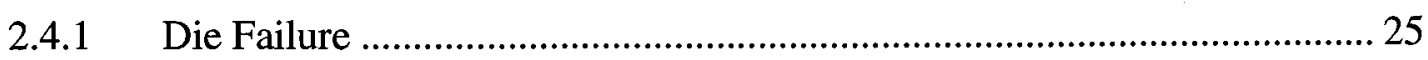

Chapter 3 : Hardness Testing, Procedures and Results.............................................36

3.1 Micro-Indentation Testing of the Substrate ............................................36

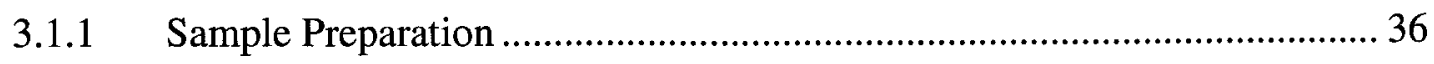

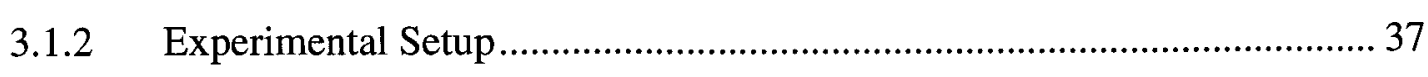

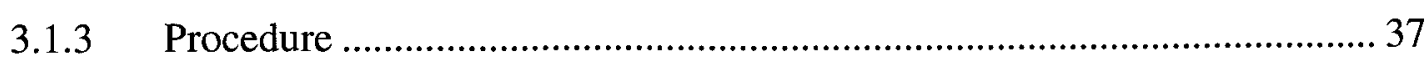




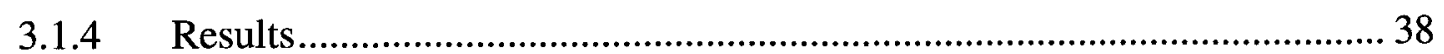

3.2 Nano-Indentation Testing of the Coated System ..............................................38

3.2.1 Sample Preparation ................................................................................ 39

3.2.2 Experimental Setup............................................................................ 39

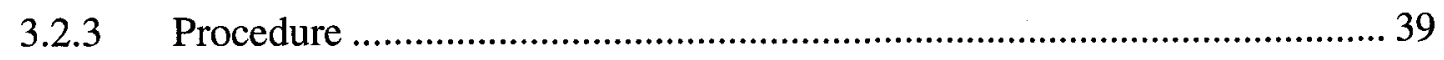

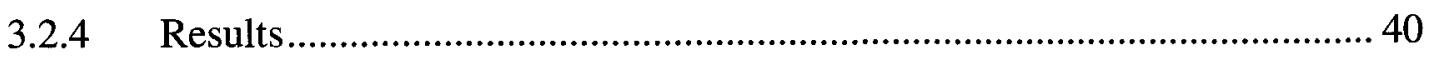

3.3 Micro-Indentation Testing of the Coated System ..............................................41

3.3.1 Sample Preparation and Experimental Setup............................................. 41

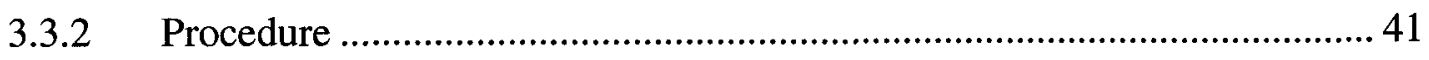

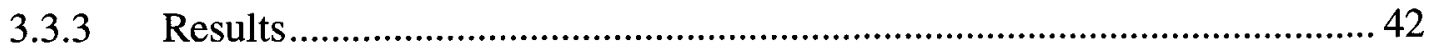

3.4 Determination of the Film Thickness..............................................................42

3.4.1 Sample Preparation and Experimental Setup............................................. 43

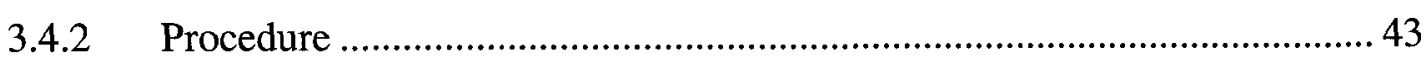

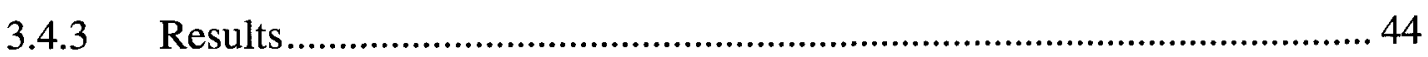

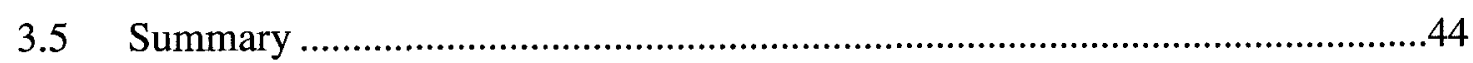

Chapter 4 : Characterisation of the Sputter Coating ..........................................................83

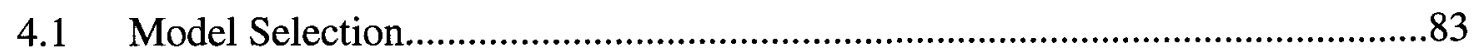

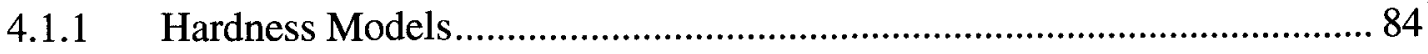

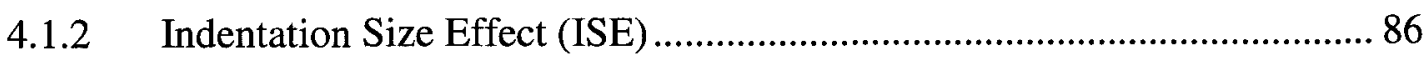

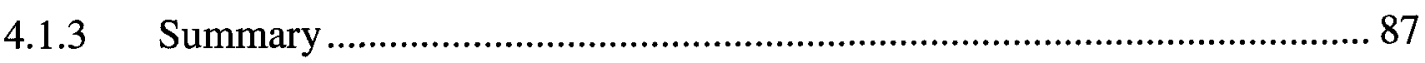



4.2.1 Hardness Using No Indentation Size Effect .......................................... 89

4.2.2 Hardness Using the Meyer or Thomas Indentation Size Effect................... 89

4.2.3 Summary of Substrate Hardness Values...................................................... 91

4.3 Calibration of the Film Parameters Using Nano- and Micro-Indentation Test Data 91



4.3.2 Algorithm ......................................................................................... 92

4.3.3 Calibration of the Model and Film Parameters.......................................... 95

4.3.4 Summary and Selection of Model and Indentation Size Effect.................. 96

4.4 Prediction of Film Hardness Using Micro-Indentation Data .............................97 
4.4.1 Korsunsky/No Indentation Size Effect ...................................................... 97

4.4.2 Korsunsky/Meyer.................................................................................. 99

4.5 Demonstration of the Predictive Method .........................................................100

4.6 Summary and Conclusions .............................................................................100

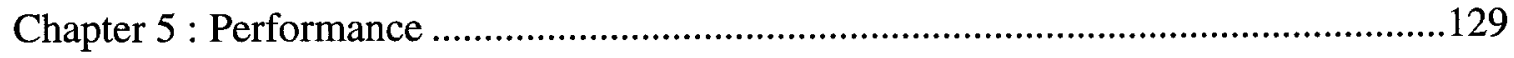

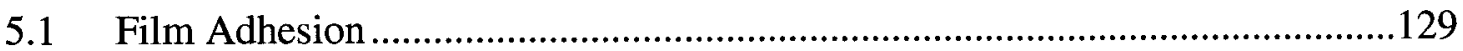

5.1.1 Experimental Setup and Procedure ........................................................ 129

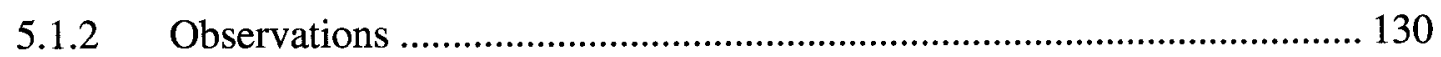

5.2 Surface Cracking Observed During Indentation Testing ................................131

5.3 Performance of the Film Surface in Numismatic Coining Operations .............132

5.3.1 Samples........................................................................................... 133

5.3.2 Observations and Surface Wear........................................................ 134

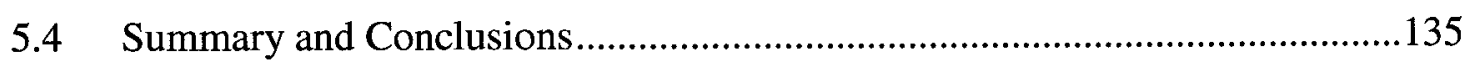

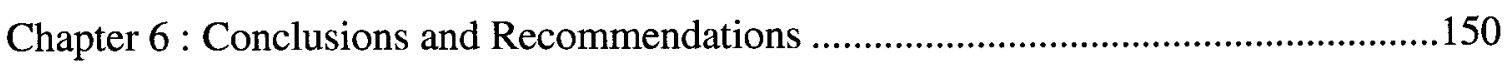

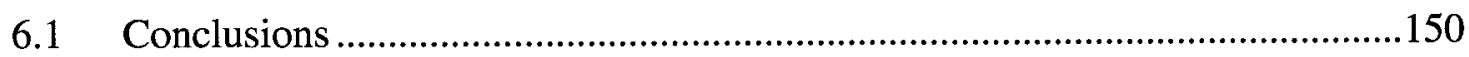

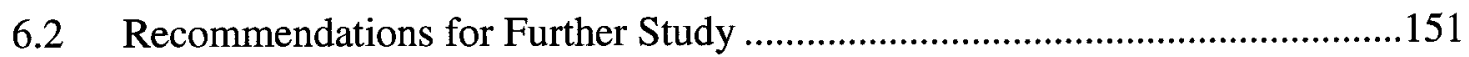

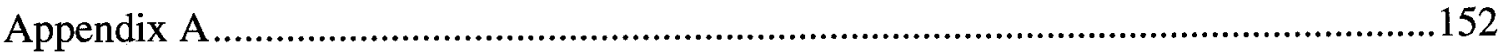

The Closed-Field Unbalanced Magnetron Sputter Ion Plating Process.......................152

Overview of Unbalanced Magnetron Sputtering of Minting Dies..............................155

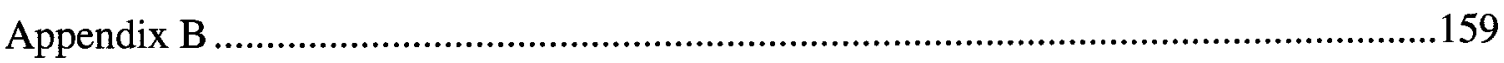

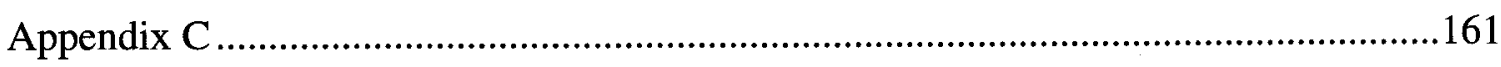

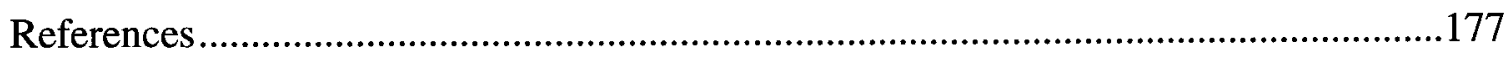




\section{List of Tables}

Table 3.1: Indentation diagonals and hardness measurements of micro-indentation tests performed on uncoated $57 X$......

Table 3.2: Indentation diagonals and hardness measurements of micro-indentation tests performed on uncoated $X 7$. . .49

Table 3.3: Nomenclature of nano-indentation hardness tests performed on test dies $57 X$ and $X 7$...............53

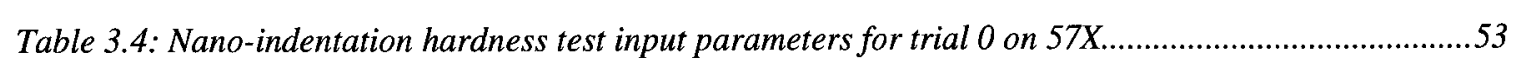

Table 3.5: First 30 entries of load-penetration data for trial 0 on $57 X$.......................................................54

Table 3.6: Nano-indentation results for trials 0 to 4 on $57 \mathrm{X}$...................................................................55

Table 3.7: Nano-indentation results for trials 1 to 4 on $X 7$.......................................................................56

Table 3.8: Summary of hardness values obtained from nano-indentation testing at a load of $20 \mathrm{mN}$............56

Table 3.9: Micro-indentation test data from coated $57 \mathrm{X}$..........................................................................57

Table 3.10: Micro-indentation test data for coated $X 7$..........................................................................61

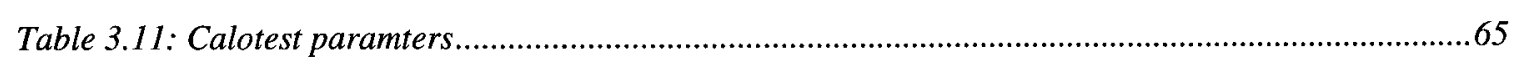

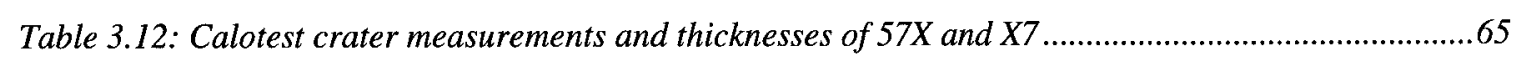

Table 4.1: Sample material properties used for preparation of Figure 4.1 for model selection.................102

Table 4.2: Sample model parameters used for preparation of Figure 4.1 for model selection...................102

Table 4.3: Absolute hardness and ISE parameter from Meyer ISE ........................................................103

Table 4.4: Absolute hardness and ISE parameter from Thomas ISE .......................................................103

Table 4.5: Summary of substrate hardness model parameters being used in the thin-film analysis...........103

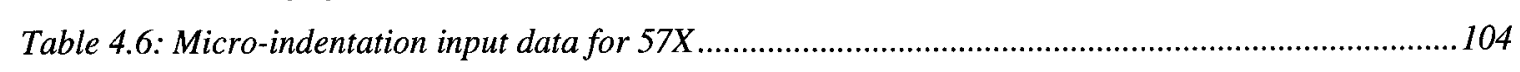

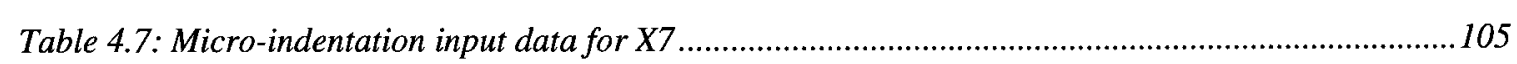

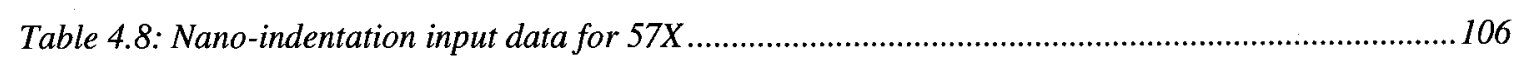

Table 4.9: Nano-indentation input data for X7 ....................................................................................... 106

Table 4.10: Summary of parameters to be calibrated simultaneously for all 6 selected combinations of model and indentation size effect ..................................................................................................... 107

Table 4.11: Initial search space used for calibration of the model parameters..........................................107

Table 4.12: Calibrated parameters for 57X and X7 using Korsunsky/No ISE .........................................108

Table 4.13: Calibrated parameters for 57X and X7 using Puchi-Cabrera/No ISE...................................108

Table 4.14: Calibrated parameters for $57 X$ and $X 7$ using Korsunsky/Meyer ............................................108

Table 4.15: Calibrated parameters for 57X and X7 using Puchi-Cabrera/Meyer...................................108

Table 4.16: Calibrated parameters for $57 X$ and $X 7$ using Korsunsky/Thomas........................................109

Table 4.17: Calibrated parameters for $57 X$ and $X 7$ using Puchi-Cabrera/Thomas .................................109

Table 4.18: Predicted film hardness values for $57 X$ and $X 7$ using Korsunsky/No ISE .............................110 
Table 4.19: Predicted film hardness values for $57 \mathrm{X}$ and $\mathrm{X} 7$ using Korsunsky/Meyer .............................110

Table 4.20: Micro-indentation test data and algorithm input for 100278-6X..........................................111

Table 4.21: Micro-indentation test data and algorithm input for 100278-6X.........................................111 


\section{List of Figures}

Figure 2.1: Structure of a multi-component film (Teer, et al., 2006) ..........................................................27

Figure 2.2: Film microstructure showing nano-layers of coating (Teer, et al., 2006).................................27

Figure 2.3: Rockewell-C indent showing good coating adhesion on the left and poor coating adhesion on

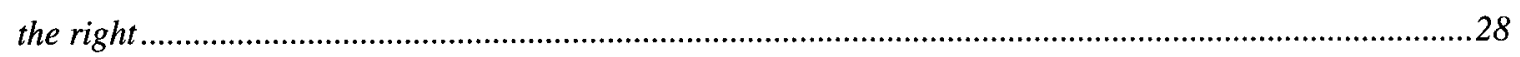

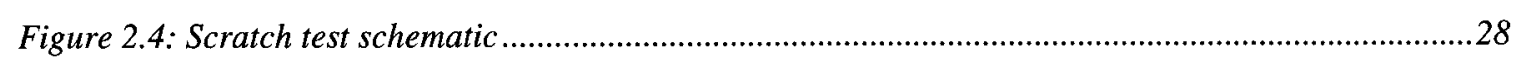

Figure 2.5: CSM Instruments calotest apparatus.................................................................................29

Figure 2.6: Calotest crater showing layers of coating and substrate (CSM-Instruments, 2009).................29

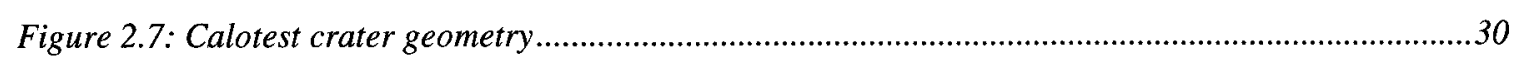

Figure 2.8: Calotest crater showing geometry (CSM-Instruments, 2009) ....................................................30

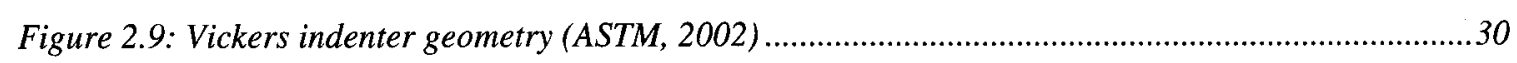

Figure 2.10: Knoop indenter geometry (ASTM, 2002) .......................................................................

Figure 2.11: Typical nano-indentation loading and unloading curve (Pharr, et al., 1992) .......................31

Figure 2.12: Equivalence of indentation diagonals for Vickers and Berkovich indenter tips.......................31

Figure 2.13: Load-carrying areas for J-H model(Jönsson, et al., 1984) ....................................................32

Figure 2.14: Illustration of zones affected by microhardness indentation (Chicot, et al., 1995)..................32

Figure 2.15: Piling failure from plastic deformation of the substrate (Lin, et al., 2006)..............................33

Figure 2.16: Pin-hole defect in substrate (Lin, et al., 2006) ......................................................................33

Figure 2.17: Starburst scratches on used GML die .................................................................................33

Figure 2.18: Flaking failure of coating due to poor adhesion ..................................................................34

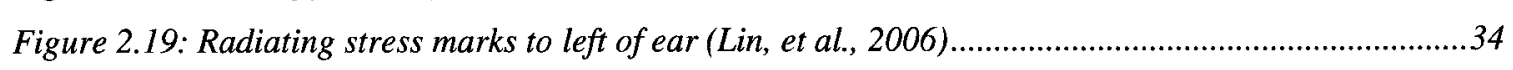

Figure 2.20: Failure of blank due to inclusions (Lin, et al., 2006) ...........................................................34

Figure 2.21: Failure of GML die from material ploughing into die surface ................................................35

Figure 2.22: Adhesion of blank material on GML die ...........................................................................35

Figure 3.1: Test dies $57 X$ and $X 7$ polished to mirror-like surface ..........................................................66

Figure 3.2: Micro-indentation apparatus ........................................................................................67

Figure 3.3: Sample micro-indentation test field from uncaoted $57 \mathrm{X}$........................................................68

Figure 3.4: Sample micro-indentation test field from uncoated $X 7$......................................................68

Figure 3.5: Measured substrate hardness of 57X displayed against indent diagonal.................................69

Figure 3.6: Measured substrate hardness of $X 7$ displayed against indent diagonal....................................70

Figure 3.7: Comparison of substrate hardness data for $57 X$ and $X 7$ showing similar trend and magnitude

Figure 3.8: CSM Instruments nano-indentation tester resting on a vibration isolation table .....................72

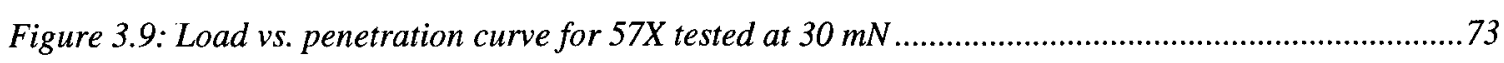


Figure 3.10: Load vs. penetration curves for nano-indentation trials 1 to 4 performed on $57 \mathrm{X}$ at at test weight of $20 \mathrm{mN}$.

Figure 3.11: Load vs. penetration curves for nano-indentation trials 1 to 4 performed on X7 at at test weight of $20 \mathrm{mN}$...

Figure 3.12: Measured micro-indentation hardness of $57 \mathrm{X}$ plotted against indent size...............................76

Figure 3.13: Measured micro-indentation hardness of $X 7$ plotted against indent size...............................77

Figure 3.14: Measured micro-indentation hardness of $57 X$ and X7 plotted against indent size showing a

similar trend and magnitude throughout indentation range......

Figure 3.15: Coated and uncoated hardness plotted against indent diagonal showing the hardness values converging at high indent sizes.....

Figure 3.16: Steel ball position relative to the motor output shaft and specimen surface.

Figure 3.17: Crater on 57X resulting from calotest showing abraded film and substrate with measurements

Figure 3.18: Crater on $X 7$ resulting from calotest showing abraded film and substrate with measurement 82

Figure 4.1: Comparison of thin-film hardness models.. .112

Figure 4.2: Effect $k$ and $X$ parameter variation on Korsunsky thin-film hardness model.........................113

Figure 4.3: Effect $k$ and $X$ parameter variation on Puchi-Cabrera thin-film hardness model...................114

Figure 4.4: Combined micro-indentation data for $57 X$ and X7 showing fit of Meyer ISE for both sets of data..

Figure 4.5: Thomas indentation size effect representation of the substrate hardness profile for 57X........116

Figure 4.6: Thomas indentation size effect representation of the substrate hardness profile for $X 7$.. .117

Figure 4.7: Flowchart illustrating the process for calibrating the model and film parameters using nanoand micro-indentation test data .

Figure 4.8: Korsunsky/No ISE calibrated hardness profile for 57X.

Figure 4.9: Korsunsky/No ISE calibrated hardness profile for X7.

Figure 4.10: Korsunsky/Meyer calibrated hardness profile for $57 X$

Figure 4.11: Korsunsky/Meyer calibrated hardness profile for $X 7$

Figure 4.12: Calibrated and predicted hardness profiles for 57X using Korsunsky/No ISE showing close agreement despite removal of nano-indentation test data.

Figure 4.13: Calibrated and predicted hardness profiles for X7 using Korsunsky/No ISE showing close agreement despite removal of nano-indentation test data.

Figure 4.14: Calibrated and predicted hardness profiles for 57X using Korsunsky/Meyer showing close agreement between the two curves despite the removal of the nano-indentation data for the predicted curve

Figure 4.15: Calibrated and predicted hardness profiles for X7 using Korsunsky/Meyer showing close agreement between the two curves despite the removal of the nano-indentation data for the predicted curve 
Figure 4.16: Predicted hardness profile for 100278-6X when using model parameters calibrated from X7

Figure 4.17: Predicted hardness profile for 100278-7X when using model parameters calibrated from X7

Figure 5.1: Rockwell-C indenter.

Figure 5.2: Carl Zeiss Axiovert 200 Max inverted microscope equipped with Sony ExwaveHAD video camera.

Figure 5.3: Rockwell-C indent \#1 on X7 showing good adhesion (5x magnification).

Figure 5.4: Rockwell-C indent \#1 on X7 showing good adhesion and a small chip in the lower right (10x magnification)

Figure 5.5: Rockwell-C indent \#1 on X7 close-up of chip at bottom right of indent crater and showing circumferential cracking (50x magnification)..

Figure 5.6: Rockwell-C indent \#1 on X7 close-up of damage at upper right edge of indent crater (100x magnification)

Figure 5.7: Rockwell-C indent \#2 on X7 showing good adhesion (5x magnification).

Figure 5.8: Rockwell-C indent \#2 on X7 showing good adhesion and a small chip in the upper left (10x magnification)

Figure 5.9: Rockwell-C indent \#2 on X7 close-up of chip at upper left of indent crater and showing circumferential cracking (50x magnification)

Figure 5.10: Rockwell-C indent \#2 on X7 close-up of damage at upper edge of indent crater (100x magnification)

Figure 5.11: Rockwell-C indent \#1 on 57X showing poor film adhesion (5x magnification).

Figure 5.12: Rockwell-C indent \#1 on 57X showing the film lifting from the substrate near the edge of the indent crater (10x magnification).

Figure 5.13: Rockwell-C indent \#1 on 57X showing area at upper edge of crater where coating has delaminated from the substrate under high deformation (50x magnification).

Figure 5.14: Rockwell-C indent \#1 on 57X showing circumferential cracking and film delaminating from the substrate (50x magnification).

Figure 5.15: Rockwell-C indent \#2 on 57X showing primarily poor film adhesion (5x magnification) ..... 142 Figure 5.16: Rockwell-C indent \#2 on 57X primarily poor adhesion with a small section of well-adhered coating near the left side (10x magnification).

Figure 5.17: Rockwell-C indent \#2 on 57X showing some well-adhered coating with circumferential cracking and some chipping of the coating (50x magnification).

Figure 5.18: Rockwell-C indent \#2 on 57X showing chipping of the coating at the edge of crater with coating visible within the crater (50x magnification).

Figure 5.19: Calibrated hardness profiles for $57 X$ and X7 using Korsunsky/No ISE and shown on the same plot. 
Figure 5.20: Cracking occurring inside indent performed during micro-indentation testing of the thin-film system (Jönsson, et al., 1984).

Figure 5.21: GML dies use for surface analysis [from left to right: new and unused die (104819X8), failed die due to striking collar (104819-26X), failed die due to surface wear (104819-7X)] ….........................144

Figure 5.22: Flat surface of $X 8$ (10x magnification) ..........................................................................145

Figure 5.23: Flat surface of X8 (100x magnification) ........................................................................145

Figure 5.24: Recessed ' $F$ ' of $X 8$ showing film fully covering flat surface up to the edges (5x magnification)

Figure 5.25: Recessed ' $F$ ' of X8 showing some clearly visible film inside recessed area (10x magnification)

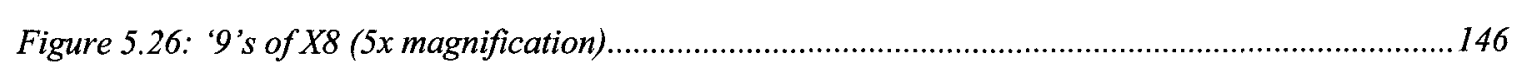

Figure 5.27: Edge of ' 9 's on X8 (10x magnification) ........................................................................146

Figure 5.28: Surface inside sunken area of leaf (10x magnification) ...................................................146

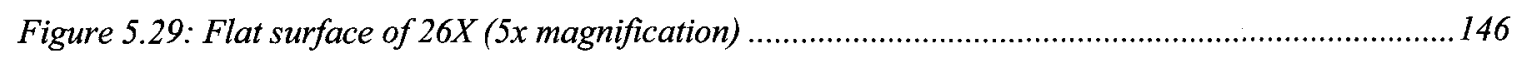

Figure 5.30: Flat surface of $26 X$ (100x magnification) ......................................................................... 147

Figure 5.31: Deep scratch on surface of $26 X$ (5x magnification) ...........................................................147

Figure 5.32: Scratches at the edge of '9's on 26X (50x magnification) ..................................................147

Figure 5.33: Starburst scratches visible on the flat surface of $26 X$ (100x magnification) .......................... 147

Figure 5.34: Coin material adhering to the flat surface of $26 X$ (50x magnification) ................................148

Figure 5.35: Crack at a vein in the recessed leaf of $26 X$ (10x magnification) ...........................................148

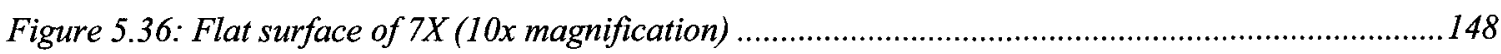

Figure 5.37: Starburst scratches and corrosion near ' 9 's of $7 X$ (10x magnification) ..............................148

Figure 5.38: Crack at leaf tip of $7 X$ causing removal of die from coin production (10x magnification).... 149

Figure 5.39: Crack in film at leaf tip on $7 X$ showing corrosion of substrate and adhesion of coin material (50x magnification)

Figure 5.40: Corrosion at the bottom of recessed ' 9 ' on $7 X$ where the film poorly covered the substrate or has been worn away (5x magnification).

Figure 5.41: Surface inside recessed leaf on $7 X$ showing small crack near leaf vein and smooth bright

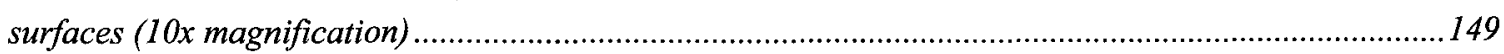

Figure A.1: Arrangement of magnets in a magnetron (Sproul, 1996)..................................................156

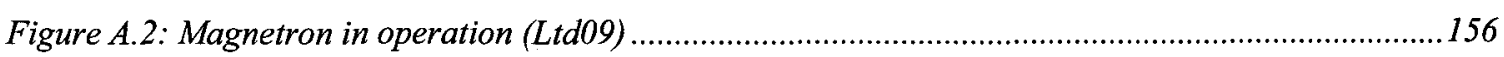

Figure A.3: Distribution of plasma for various magnetron configurations (Kelly, et al., 2000).................157

Figure A.4: Four magnetron closed field arrangement (Ltd09) .....................................................157

Figure A.5: Various magnetron configurations (Kelly, et al., 2000) ..................................................158 


\section{List of Symbols}

\begin{tabular}{|c|c|}
\hline Symbol & Description \\
\hline$A$ & Total load-supporting area under the indenter; Projected contact area \\
\hline$a$ & $\begin{array}{l}\text { Fraction of the film involved in an indentation test; radius of cylindrical } \\
\text { indenter }\end{array}$ \\
\hline$A_{f}$ & Load-supporting area of the film under the indenter \\
\hline$a_{m}$ & Meyer indentation size effect parameter \\
\hline$A_{s}$ & $\begin{array}{l}\text { Surface area of indent; load-supporting area of the substrate under the } \\
\text { indenter }\end{array}$ \\
\hline$b$ & Thomas indentation size effect parameter; burger's vector \\
\hline$C_{1}$ & Jönsson \& Hogmark constant for plastic deformation \\
\hline$C_{2}$ & Jönsson \& Hogmark constant for brittle fracture \\
\hline$D$ & Penetration depth of the indenter/indent depth \\
\hline$d$ & Length of indent diagonal \\
\hline$D_{f}$ & Calotest crater diameter at the film surface \\
\hline$D_{s}$ & Calotest crater diameter at the substrate surface \\
\hline$E_{f}$ & Young's modulus of the film \\
\hline$E_{i}$ & Young's modulus of the indenter \\
\hline$E_{r}$ & Reduced Young's modulus \\
\hline$E_{s}$ & Young's modulus of the substrate \\
\hline$G_{f}$ & Through thickness fracture toughness of the film \\
\hline$H_{\text {of }}$ & Absolute film hardness \\
\hline$H_{0 s}$ & Absolute substrate hardness \\
\hline$H_{c}$ & Composite/measured hardness \\
\hline$h_{c}$ & Indenter contact depth \\
\hline$H_{f}$ & Film hardness \\
\hline$h_{m}$ & Maximum penetration of the indenter \\
\hline$h_{p}$ & Plastic depth/indent depth \\
\hline$h_{r}$ & Elastic recovery depth \\
\hline$H_{s}$ & Substrate hardness \\
\hline$H V$ & Vickers hardness number \\
\hline$k_{K}$ & Korsunsky model parameter \\
\hline$k_{P C}$ & Puchi-Cabrera model parameter \\
\hline$n$ & Meyer indentation size effect parameter \\
\hline$P$ & Test weight \\
\hline$R$ & Calotest ball radius \\
\hline$S$ & Stiffness during initial unloading of indenter \\
\hline$t$ & Film thickness \\
\hline
\end{tabular}




$\begin{array}{cl}V & \text { Total volume of material affected by indentation } \\ V_{f} & \text { Volume of film affected by indentation } \\ V_{s} & \text { Volume of substrate affected by indentation } \\ W_{f} & \text { Work of deformation of the film } \\ W_{s} & \text { Work of deformation of the substrate } \\ W_{t_{t}} & \text { Total work of deformation } \\ X_{K} & \text { Korsunsky model parameter } \\ X_{P C} & \text { Puchi-Cabrera model parameter } \\ & \\ \alpha & \text { Indenter face angle; empirical parameter for Nix \& Gao indentation size effect } \\ \alpha_{B e r k o v i c h} & \text { Angle formed between the indenter face and the indenter's axis } \\ \beta & \text { Relative indent depth } \\ \beta_{O P} & \text { Oliver-Pharr correction factor } \\ \varepsilon & \text { Parameter accounting for deformation of surrounding material during } \\ & \text { indentation and relates } h_{m} h_{c} \text { and } h_{r} \\ \theta & \text { Angle between conical indenter and material surface } \\ \kappa & \text { Parameter describing the geometry of the indenter } \\ \lambda_{1} / \lambda_{2} & \text { Empirical parameters describing crack length } \\ \mu & \text { Shear modulus } \\ \nu & \text { Poisson's ratio (of the film) } \\ \xi & \text { Indenter semi-angle } \\ \rho_{s} & \text { Density of statistically stored dislocations } \\ \varphi & \text { Error function } \\ \chi & \text { Interference parameter }\end{array}$

\section{Subscripts}

$f \quad$ Film property

$s \quad$ Substrate property

c Film-substrate composite property

JH Jönsson \& Hogmark model

CL Chicot \& Lessage model

BR Burnette \& Rickerby model

$B \quad$ Bykov model

K Korsunsky model

PC Puchi-Cabrera model

$N \quad$ No indentation size effect

$M \quad$ Meyer indentation size effect

$T \quad$ Thomas indentation size effect 


\section{Chapter 1 : Introduction}

The minting of coinage in various forms has been in existence worldwide for ages. Written reports of research and development stretch back at least to the 1700 s when Britain was producing the world's first steam-struck coins (Selgin, 2003). At the time, the steam powered coinage presses aided in reducing counterfeit coins as well as significantly reducing manufacturing costs. Mints around the world today are businesses and as in any business, increasing productivity and decreasing downtime are very important. In addition, security and counterfeit protection remain a concern as more and more technology becomes available to the general public. Despite development as far back as the 1700s, information pertaining to minting dies has been difficult to find. For a long time, mints worldwide have been manufacturing coin dies from shallow hardening water quenching die steels of mainly plain carbon type (Conran, 1995). Recently, new technology has been considered and incorporated at many mints around the world. For increased die life in particular, the new technologies include new materials, heat treatments and surface coatings (Conran, 1995), (Yasbandha, 2000), (Rodríguez, et al., 1996). Conran (1995) and Yasbandha (2000) were concerned particularly with the properties of the material to be selected for minting dies at the Royal Australian Mint. Their concerns included such factors as: machinability, hobability, polishability, availability, hardenability, coatability, impact strength and coinability. The Royal Canadian Mint (RCM) participates in many research and development projects as it strives to maintain its place as a world leader in minting technology (Teer, et al., 2006).

Although Conran reports that the first vacuum heat treatment furnace was installed in 1979 at the Royal Australian Mint, it was not until the installation of a two (2) bar pressure quench vacuum furnace late in 1988 that major research activity was conducted to evaluate the suitability of different materials for their minting dies (Conran, 1995). The RCM similarly uses a variety of heat treatments on their minting dies, depending on the application, in order to provide it with the best combination of properties. Once 
hobbed and machined, a die must be heat treated to increase its hardness. Hardness and toughness are both particularly important to the longevity of minting dies. Hardness is especially important in resisting deformation and abrasion (Callister, 2000) to maintain coin and die quality.

The selection of die material is also critical to the production of a quality minting die. In the past, the RCM has used an oil-quenching tool steel for the production of minting dies but has recently moved to an air-hardening tool steel. The reason for the change includes many of the factors included in Conran and Yasbandha's research such as coatability and impact strength. In particular, the RCM's strategy is to use a combination of a strong tool steel base which can effectively support a hard thin-film coating to achieve a die with superior overall quality. The tool steel is used for strength and toughness while the hard coatings are used for high hardness and wear resistance (Teer, et al., 2006).

For years, hard Cr-plating has been used to protect and extend the life of minting dies, particularly proof dies (Leu, et al., 2004). Unfortunately the chromic acid required in the Cr-plating process has been found to be detrimental to both personal health and the environment which has fuelled the search for other coating processes. Surface treatment for all kinds of applications, including minting dies, is currently an area of active research. Ion implantation techniques have been suggested as a surface treatment for various applications including minting dies (Rodríguez, et al., 1996). Mints around the world are currently researching ion plating techniques, in particular physical vapour deposition (PVD) techniques, for depositing various hard coatings on minting dies. Leu et al. (2004) are among the researchers that have been looking at diamond-like coatings (DLC) prepared by the filtered cathodic arc technique. Several mints, including RCM, have been working together to investigate the use of a hard Cr-Ti-N based PVD coating for minting dies which has demonstrated superior performance (Murata, 2008). As a result of innovative spirit and the aforementioned health concerns, the RCM opted to fully eliminate the Cr-Plating process in 2005 and make use of this hard PVD coating for all of their numismatic coin dies (Teer, et al., 2006). The RCM has also implemented and used this PVD coating for circulation coin dies. 


\subsection{Thesis Objectives}

The main objective of this thesis is to further our understanding of this particular hard CrTi-N based coating through experimentation and modelling. Although it has shown superior performance over Cr-plated dies, there remain several aspects of the film which have not yet been fully characterised. In particular, the aim of this research is to experimentally determine the hardness of this new film and to evaluate methods to reliably estimate the hardness of the film without the need for special nano-indentation hardness testing. In addition to the systematic hardness testing, other aspects of film performance will be examined with particular concentration on any link to the hardness and wear performance of the film.

\subsection{Outline of the Thesis}

This thesis is organized into 6 different chapters of which this first chapter introduces the motivation and objectives of the current research. Chapter 2 is a literary review of the structure of coatings applied by magnetron sputtering and thin-film hardness models. Chapter 2 also provides background information about micro- and nano-indentation hardness testing, particularly in relation to testing thin films. Chapter 3 details the experiments and results obtained from micro- and nano-indentation hardness testing performed on two test dies. It also details the measurement of the film thickness of the two dies for use with the aforementioned thin-film hardness models. Chapter 4 presents the analysis of the data detailed in Chapter 3 and discusses the significance of the results. In particular, the hardness of the film is determined using the thin-film hardness models and the ability to use the thin-film hardness models to predict the film hardness is assessed. Chapter 5 presents an analysis of other factors describing die performance such as film adhesion, cracking during indentation testing and surface wear. The first two of these factors are related to the hardness analysis performed in Chapter 4. Chapter 6 presents a summary of the major conclusions made in this thesis as well as recommendations to supplement and continue the research. 


\section{Chapter 2 : Literature Review and Background}

This chapter discusses the structure and testing of thin films applied by magnetron sputter ion plating techniques. In particular, the structure of the film applied to a minting die is discussed as well as the effect of the coating process on the structure of the substrate. For further reference, a detailed review of the magnetron sputter ion plating process is presented in Appendix A. Micro- and nano-indentation hardness testing is then discussed for application to thin-film hardness testing. This is followed by a review of common thin-film hardness models in the literature which use the film and substrate hardness values to model the measured hardness during micro- and nano-indentation testing. This chapter ends with a discussion of failure modes of thin-films in practice and some key observations of surface wear. As this discussion is focussed on minting operations, a short glossary of minting terminology can be found in Appendix B.

\subsection{Structure of the Coated Die}

Specialised thin films are used to enhance many different aspects of a material surface such as hardness, frictional coefficient, chemical protection and wear resistance. In recent years, a lot of research has been done concerning the properties and behaviour of films applied for wear resistance and high hardness. TiN is a common choice for increasing the wear resistance for industrial parts (Stallard, et al., 2006), (Mayrhofer, et al., 2002). Some common coatings increasing the hardness and wear resistance include diamond-like carbon (DLC) (Huang, et al., 2001), (Leu, et al., 2004) and TiAlN (Oliveira, et al., 2006), (Sproul, et al., 1993), (Vlasveld, et al., 2002), as well as various other nitride coatings (Cooke, et al., 2003), (Sproul, et al., 1993). Most thin films deposited by PVD methods are made up at least two layers, including some sort of intermediate layer between the substrate and film. The film layer itself may be composed of many smaller layers as in Figure 2.1. The structures of both the substrate and coating layers can have an impact not only on the properties of the individual layers but also their 
interaction. As interest in multi-component coatings increases, some authors have been investigating the addition of quaternary components to further improve coating performance (Yang, et al., 2002), (Yang, et al., 2008). The RCM is similarly investigating variations of their $\mathrm{Cr}-\mathrm{Ti}-\mathrm{N}$ based coating to improve the performance of their dies. The coating is applied using the closed-field unbalanced magnetron sputter ion plating (CFUBMSIP) method (see Appendix A) using a Teer Coatings Ltd. UDP 650/4. This substrate-film system can be broken down into three basic components: substrate, intermediate layer and film.

\subsubsection{Substrate}

During coating application, the substrate is held at a bias voltage to attract the charged particles of coating material. The energy deposited on the substrate surface increases with the coating deposition rate and results in higher substrate temperatures (Oliveira, et al., 2006). One concern during coating application is the change in microstructure of the substrate due to the temperature of the process. Cases have been described where heat sinks were needed to help reduce the temperature of the substrates during the coating process (Sproul, et al., 1993). In the tests by Sproul et al. (1993), it was suggested that the poor performance of a $\mathrm{Ti}_{0.5} \mathrm{Al}_{0.5} \mathrm{~N}$ coating may be due to the reduction of applied target power to avoid substrate overheating. The manufacturer of the tool steel used for the dies suggests that PVD coatings could be applied from about $200-500{ }^{\circ} \mathrm{C}$ which is below the suggested minimum tempering temperature of $525{ }^{\circ} \mathrm{C}$. During the coating process and before the coating is applied, a sputter etch is used to remove contaminates at about $450-500{ }^{\circ} \mathrm{C}$ (Sproul, 1996). The coating process itself can be applied at temperatures as low as $150{ }^{\circ} \mathrm{C}$ (Teer, et al., 2006). Given these temperatures, there should not be any great change in the structure of the steel due to the PVD process.

\subsubsection{Intermediate and Film Layers}

The microstructure of the deposited film is highly dependent upon the conditions during sputtering. Oliveira et al. (2006) investigated the effects of using pure or composite 
targets in reactive (nitrogen) and inert gas flows on the structure and properties of TiAlN coatings. It was found that for both target configurations at low nitrogen partial pressures, a highly crystalline hcp titanium phase was deposited. Although occurring at different nitrogen flow rates for each configuration, it was found that increasing the nitrogen flow resulted in an amorphous structure. The results occurred at different flow rates due to the target configurations and voltages applied. The highly amorphous coating (high nitrogen flow) deposited from the pure targets achieved the highest hardness of the samples prepared. In the work done by Sproul et al. (1993), it was found that many structural properties did not match those determined by other authors. In particular, the $\operatorname{Ti}_{0.5} \mathrm{Al}_{0.5} \mathrm{~N}$ coating mentioned above had identical composition but was applied using a different target bias voltage. The film was found to have a fcc structure with lattice parameter of $4.165 \AA$ and underperformed in wear and hardness tests (Sproul, et al., 1993). Clearly, despite having the same composition, the small differences in the conditions during coating application have an effect on the deposited film structure and properties. Thorough cleaning and carful control of the conditions are required for consistent results.

The intermediate layer of the coating used in this thesis is deposited in two parts, a $\mathrm{Cr}$ adhesive layer and a reactively deposited columnar accommodating layer. The structure of the film is similar in nature to the coating reported in Yang et al. (2002) which used thicknesses of 0.2 and $0.3 \mu \mathrm{m}$ for the adhesive and accommodating layers respectively. Several authors have explained that applying this intermediate layer improves coating adhesion (Yang, et al., 2002), (Huang, et al., 2001), (Leu, et al., 2004). Reasons for the improved adhesion due to the intermediate layer include: accommodating the high stress induced from ion bombardment, different thermal expansion coefficients and different lattice parameters (Huang, et al., 2001). After depositing the $\mathrm{Cr}$ adhesive layer, the columnar layer is reactively applied with a graded composition with increasing concentration of nitrogen. The remainder of the film was deposited in nano-layers which also varied in composition. The complete film can be seen in Figure 2.1 while a micrograph of the nano-layered portion of the film can be seen in Figure 2.2. The composition and thickness of the layers was varied by controlling the voltages on the metallic targets and the substrate holder rotational speed (see Appendix A). Alternating 
layers in the film has several advantages over single-layered films including higher hardness and toughness. One possible cause of this enhancement is the difference in elastic properties of the adjacent layers which help to hinder the propagation of dislocations (Cooke, et al., 2003). The total thickness of the alternating layers in the coating reported in Yang et al. (2002) was about $4.0 \mu \mathrm{m}$. The nano-layered coating was reported to have even higher wear resistance than TiAlN coatings (Yang, et al., 2008). The total thickness of the coating used by the RCM is expected to be on the order of 1 to $4 \mu m$.

\subsubsection{Film Adhesion}

Adhesion of the film to the substrate is important to the film's performance and is commonly used as a performance indicator. One simple method for assessing the adhesion is by performing a Rockwell-C hardness test (Teer, et al., 2006)(Yang, et al., 2002). This test produces large deformations relative to the coating thickness so that the adhesion can be determined qualitatively by observing the area near the lip of the indent. Figure 2.3 shows two Rockwell-C indents with examples of both good and poor film adhesion. A commonly used method for quantifying the adhesion of a coating is the scratch test (CSM-Instruments, 2009) (Teer, et al., 2006) (Yang, et al., 2002). In the scratch test, a sharp tip made of hard material is dragged across the coating at a constant speed. The load on the scratch tool is increased as the scratch is performed. The load at which the coating first delaminates from the substrate is termed the critical load. This critical load is used to quantify the adhesion of various coatings to their substrates. Figure 2.4 taken from the manufacturer's website illustrates the process for a CSM scratch tester.

\subsubsection{Film Thickness}

The magnetron sputter coating process is expected to produce a uniform coating over the entire surface of the die. The growth of the film on the substrate is controlled by the magnetron power and substrate rotation speed during coating (Yang, et al., 2002). The 
thickness can be measured optically using a calotest which is performed by using a steel ball and abrasive solution to wear a small crater through the film and into the substrate. The calotest apparatus is shown in Figure 2.5. Figure 2.6 illustrates a typical crater for a coating-substrate system. It is necessary for the crater to fully penetrate the coating into the substrate to be able to measure the coating thickness. From the crater geometry in Figure 2.7, the following equations can be written where $A$ is the total crater depth, $B$ is the depth of penetration into the substrate and $\mathrm{R}$ is the radius of ball used for the test. The values of $D_{f}$ and $D_{s}$ are the diameter of the crater at the film and substrate surface respectively while $t$ is the film thickness. The film thickness is expressed in Equation 2.3. As mentioned earlier, the coating analysed in this thesis is expected to have a thickness on the order of about 1 to $4 \mu m$.

$$
\begin{gathered}
A=R-\frac{1}{2} \sqrt{4 R^{2}-D_{f}^{2}} \\
B=R-\frac{1}{2} \sqrt{4 R^{2}-D_{S}^{2}} \\
t=A-B=\frac{1}{2}\left(\sqrt{4 R^{2}-D_{s}^{2}}-\sqrt{4 R^{2}-D_{f}^{2}}\right)
\end{gathered}
$$

Alternatively, the thickness of the film can be determined from Equation 2.4 below with the measurement of $x$ and $y$ as in Figure 2.8. Equation 2.4 can be obtained from the manipulation Equation 2.3 and defining $x$ and $y$ as shown below.

$$
\begin{gathered}
t=\frac{x y}{2 R} \\
x=\frac{D_{f}+D_{s}}{2}, \quad y=\frac{D_{f}-D_{s}}{2}
\end{gathered}
$$




\subsection{Hardness Testing for Thin-Film Systems}

In general, a hardness test for a bulk material involves applying a test weight to an indenter of known geometry and measuring the size of the resulting indent. The hardness can be quantified from the measurement of a characteristic dimension of the indent. For a thin-film system, the resulting hardness measurement will be a combination of the hardness of the film and substrate (Jönsson, et al., 1984). In order to determine the hardness of the film alone, we must minimize or eliminate the effect of the substrate on the measurement. This can be done by reducing the size of the indent so that the indent depth is several times smaller than the thickness of the coating. Although it has been shown to be untrue, it was previously believed that film hardness could be measured at indents less than $1 / 10^{\text {th }}$ of the coating thickness (Tuck, et al., 2001). Due to the thickness of the coating evaluated in this thesis, conventional micro-indentation hardness testing for bulk materials is insufficient to accurately determine the hardness of the film. This section discusses the micro- and nano-indentation hardness testing theory used in this thesis.

\subsubsection{Micro-Indentation Hardness Testing}

Micro-indentation tests are defined by the ASTM standards for test forces of 1 to $1000 \mathrm{gf}$ (ASTM, 2002). Upon removal of the load, it is assumed that there is no elastic recovery of the material. To achieve ideal results, the surface of the specimen to be tested should be flat, level and appropriately smooth or polished. The machine must be protected from unnecessary vibrations during the application of the load. The ASTM standards also specify conditions for the speed and time duration of the application of the test weight (see ASTM E384 for further details). According to the standard, the indentation test apparatus must allow the user to select the location and measure the size of the indentation on the sample using a light microscope attachment. The hardness number can then be calculated based on the indenter geometry, test load and measured dimensions of the indent. 


\section{Indenter Geometry (ASTM, 2002)}

The ASTM standards have been written for micro-indentation hardness testing using Vickers and Knoop indenters. The Vickers indenter is a square-based pyramidal-shaped diamond indenter with an angle of $136^{\circ}$ between opposite faces. The Knoop indenter is a rhombic-based pyramidal-shaped indenter with edge angles of $172^{\circ} 30^{\prime}$ and $130^{\circ} 0$ '. The Vickers and Knoop indenter geometries can be seen in Figure 2.9 and Figure 2.10 respectively. Due to availability, the Knoop indenter was not used in any experiments and only the Vickers indenter will be discussed further. Using the geometry of a Vickers indenter, the penetration depth $(D)$ and the mean indent diagonal $(d)$ can be related by:

$$
D=d \frac{\tan \left(22^{\circ}\right)}{2 \sqrt{2}} \approx \frac{d}{7}
$$

\section{Calculation of Vickers Hardness Number (HV)}

The hardness number is defined as the ratio of the test weight to the surface area of the indent $\left(A_{s}\right)$. There are slight variations in the method by which the hardness number is calculated depending on the test parameters. In practise, the test loads $(P)$ are measured in $g f$ and the average indent diagonal $(d)$ is measured in $\mu m$. The equation for Vickers hardness number based on the surface area of the indent is given below in Equation 2.6 (ASTM, 2002).

$$
H V=1.000 \times 10^{3} \times \frac{P}{A_{S}}
$$

Substituting for $A_{s}$ in terms of the mean indent diagonal and the indenter face angle for a Vickers indenter $\left(\alpha=136^{\circ}\right)$, we get the following:

$$
H V=1000 \frac{P\left[2 \sin \left(\frac{\alpha}{2}\right)\right]}{d^{2}}
$$




$$
H V=1854.4 \frac{P}{d^{2}}
$$

Equation 2.7 is most commonly used for determining the Vickers hardness from microindentation tests where the quantities $P$ and $d$ are measured as mentioned above.

\section{Reporting Vickers Hardness Values}

When reporting hardness values it is conventional to indicate the type of hardness determined (using the symbol $H V$ for Vickers hardness) and the load at which it is determined. For a Vickers hardness of 1000 at $100 \mathrm{gf}$ load, the hardness would be reported as $1000 H V_{100}$. It is also acceptable to report the hardness using $k g f$ as in the ISO standards (ASTM, 2002). The hardness should then be reported as $1000 H V_{0.1}$. The ASTM standards suggest that the determination of hardness of a material should be done at the highest loading in order to achieve consistent results.

\subsubsection{Nano-Indentation Hardness Testing}

Although using indentation depths less than $1 / 10^{\text {th }}$ of the film thickness has often been used as the guideline for measuring thin-film hardness (Burnett, et al., 1987) it has been shown that the substrate can affect the hardness measurement at even smaller indentation depths (Tuck, et al., 2001). If this guideline were accurate, indentations no deeper than about $100 \mathrm{~nm}$ are required for the film that is 1 to $4 \mu \mathrm{m}$ thick. Using a Vickers indenter, this would require an indent such that the diagonal is $0.7 \mu m$. It has been reported that indents can only be reliably measured down to about $4 \mu m$ (Bykov, et al., 2003) so a much finer measurement is required. Nano-indentation hardness testing is a depth sensing process where load and displacement are measured to form an indentation profile as in Figure 2.11. Unlike the micro-indentation hardness test method, there is no need to optically measure the size of the indent. However, the data must be calibrated by the operator to determine the point at which the indenter first contacts the material surface. 
The Oliver-Pharr method is commonly used to extract the elastic properties from the load-displacement data.

\section{Indenter Geometry}

Nano-indentation testers often employ a Berkovich indenter tip for indentation testing. The Berkovich indenter is a triangular based pyramid shaped indenter made from diamond. The indenter faces of a perfect Berkovich indenter make an angle of $65.03^{\circ}$ with its axis $\left(\alpha_{\text {Berkovich }}\right)$. For a triangular indenter, the indent diagonal is an equivalent conical diameter as shown in Figure 2.12 and is given by Equation 2.8 below.

$$
d=4 D \tan \left(\alpha_{\text {Berkovich }}\right)
$$

Since nano-indentation testing records and reports the depth measurements, it is more useful to express the indent diagonal in terms of the indent depth as opposed to microindentation where the depth must be determined from the indent diagonal.

\section{Oliver-Pharr Method}

A common practice is to relate the Young's Modulus $(E)$ to the initial unloading slope of the nano-indentation load-penetration graph (Pharr, et al., 1992). The active assumption is that the contact area on the indenter does not change significantly during initial unloading. This is the case of a flat cylindrical punch for which the relevant equations have already been developed (Sneddon, 1965). The equations relating the load $(P)$ and the penetration depth $(D)$ are given below:

$$
\begin{gathered}
P=\frac{4 \mu a}{1-v} D \\
\frac{d P}{d D}=\frac{2}{\sqrt{\pi}} \sqrt{A} \frac{E}{1-v^{2}}
\end{gathered}
$$


Here $a$ is the radius of the cylinder, $\mu$ is the shear modulus, $v$ is the Poisson's ratio and $A$ is the projected contact area. Given an estimate of the Poisson's ratio, the Young's modulus can be determined from the slope of the graph at initial unloading. Pharr et al. (1992) have used a reduced elastic modulus to account for the deformation of the indenter.

$$
\frac{1}{E_{r}}=\frac{1-v^{2}}{E}+\frac{1-v_{i}^{2}}{E_{i}}
$$

Both Pharr et al. and Sneddon have shown that Equations 2.9 and 2.10 are not restricted to a flat cylindrical punch but are in fact general equations applicable to a solid of revolution. The use of non-axisymmetric indenters can be described using a modified version of Equation 2.10 (King, 1987). Using King's findings, Pharr et al. (1992) modified their equation with a constant $\left(\beta_{O P}\right)$ based on the shape of the indenter as shown in Equation 2.12.

$$
\begin{array}{ll}
\qquad \frac{d P}{d D}=\beta_{O P} & \frac{2}{\sqrt{\pi}} \sqrt{A} E_{r} \\
\text { circular } & 1.000 \\
\text { triangular } & 1.034 \\
\text { square } & 1.012
\end{array}
$$

Pharr et al. (1992) concluded that the errors were small enough that Equation 2.10 could be used without incurring large errors even when the indenter is not a body of revolution. 


\subsection{Thin-Film Hardness Models}

Thin films have been used extensively for a variety of reasons including: hardness, friction, wear and chemical resistance. With this increased usage, it was noticed that coated materials no longer acted as bulk materials. Furthermore, it was noticed that the even hardness properties of a bulk material can exhibit non-uniform behaviour, especially at small indents. When determining the hardness of a coated system through traditional hardness testing, it was found that the hardness varies significantly with the load applied and the size of the indent (Jönsson, et al., 1984). This phenomenon has also been observed at the RCM when attempting to quantify the hardness of their film. Jönsson et al. (1984) reported that the measured hardness is significantly influenced above a critical value of the ratio indent depth to film thickness $(D / t)$. This ratio is important in thin film analysis and is also known as relative indentation depth $(\beta)$. The critical value of $\beta$ was reported to vary approximately between 0.07 and 0.2 . Although it was known that the film hardness could be measured by decreasing the size of the indents with lower loads, the impression created by the indenter was either non-existent or too small to reliably define the hardness of the film. Before nano-indentation was readily available, several attempts were made to model and predict the hardness of coated systems using microindentation testing (Korsunsky, et al., 1998). Although nano-indentation hardness testing is now available, it is neither inexpensive nor practical for a manufacturing environment where timely feedback is required. The machines themselves are quite expensive and the time required to send out samples and have them returned incurs both extra time and expense. Furthermore, the exact point at which the substrate begins to affect the hardness measurement is unknown so the nano-indentation test still cannot guarantee direct measurement of the film hardness. Fortunately, several models have been developed which make use the bulk hardness values of the substrate and film to describe the apparent hardness of a thin-film system during testing as well as the variation of hardness noticed on the base materials. 


\subsubsection{Hardness Models for Thin-Film Coated Systems}

The following is a short summary of some prominent hardness models which were created to account for the difficulties encountered in thin-film hardness testing. These models range from the early 1970 s up to the present showing the phenomenon is still under investigation and an active area of research.

\section{Bückle Model}

Bückle first suggested a simple law of mixtures to describe a substrate-film system (Korsunsky, et al., 1998). The composite hardness (also known as measured or apparent hardness) can be expressed simply as:

$$
H_{c}=H_{s}+a\left(H_{f}-H_{s}\right)
$$

The value of $a$ represents the fraction of the film involved in the indentation which Bückle left as an empirical constant. $H_{c}, H_{s}$ and $H_{f}$ represent the hardness of the composite, the substrate and the film respectively. The remainder of the models presented in this section can be expressed mathematically in the same form as the Bückle model.

\section{Jönsson and Hogmark (J-H) Model}

The model proposed by Jönsson and Hogmark suggests that the composite hardness is composed of weighted contributions of the components (Jönsson, et al., 1984). The weightings are based on the fractions of the load-supporting areas of the components to the total indentation area as shown in Figure 2.13 and Equation 2.14 below.

$$
H_{c}=\frac{A_{f}}{A} H_{f}+\frac{A_{s}}{A} H_{s}
$$


The plastic deformation caused by the indentation causes the film to undergo cracking. The area of film enclosed by cracks under the indenter defines $A_{s}$ since it is supported only by the substrate and not the surrounding film. The area of film under the indenter that has not been separated from the surrounding film by cracking defines $A_{f}$ and is capable of supporting a portion of the indenter load. If rewritten in the same form as Bückle, the equation becomes:

$$
H_{c}=H_{s}+\frac{A_{f}}{A}\left(H_{f}-H_{s}\right)
$$

The areas can be expressed as a function of coating thickness $t$, indentation depth $D$ and a constant based on the deformation of the film. The film deformation constant $C$ is defined based on the predominant mode of cracking during deformation. When the film hardness is significantly higher than that of the substrate, brittle fracture will occur. If the film and substrate hardness values are reasonably similar, plastic deformation is expected. The full model is described by Equation 2.16 with the two definitions for the deformation constant $C$.

$$
\begin{gathered}
H_{c}=H_{s}+\left[2 C \frac{t}{D}-C^{2}\left(\frac{t}{D}\right)^{2}\right]\left(H_{f}-H_{s}\right) \\
C_{1}=\sin ^{2} 22^{\circ} \quad \text { plastic deformation } \\
C_{2}=2 \sin ^{2} 11^{\circ} \quad \text { brittle fracture }
\end{gathered}
$$

The authors noted that this model agreed well with the experimental data when $d>7 t$ (Jönsson, et al., 1984). In other words, the model is applicable when the relative indentation depth is greater than $1(\beta>1)$.

\section{Burnett and Rickerby (B-R) Model}

Burnett and Rickerby's analysis of previous methods concluded that inaccuracies were due to the nature of the models and neglecting the indentation size effect (ISE) (Burnett, 
et al., 1987), which will be discussed shortly. In particular, they found that the J-H model became very inaccurate for small indentations. The model proposed by Burnett and Rickerby is based on a model proposed by Sergeant (Burnett, et al., 1987). The model and a modified version including an interference parameter are shown respectively below in Equations 2.17 and 2.18.

$$
\begin{gathered}
H_{c}=\frac{V_{s}}{V} H_{s}+\frac{V_{f}}{V} H_{f} \\
H_{c}=\frac{V_{s}}{V} \chi^{3} H_{s}+\frac{V_{f}}{V} H_{f}
\end{gathered}
$$

The values $V, V_{s}$, and $V_{f}$ are the affected volumes of the total system, substrate and film respectively. The interference parameter in Equation 2.18 is represented by $\chi$. The model can be displayed neatly in the following form where the hardness values can be computed with the knowledge of the Young's modulus of the film $\left(E_{f}\right)$ (Puchi-Cabrera, et al., 2002). In this equation $t, d$ and $\xi$ represent the film thickness, indent diagonal and indenter semi-angle respectively.

$$
H_{c}=H_{s}+3\left(H_{f}-H_{s}\right)\left(\frac{H_{f}}{E_{f}}\right)^{\frac{1}{2}} \frac{t}{d} \tan ^{\frac{1}{3}} \xi
$$

\section{Chicot and Lesage (C-L) Model}

Like the B-R model, the C-L model is based on a volume law of mixtures (Chicot, et al., 1995). Four different cases of the affected volume described by the authors are shown in Figure 2.14. The four different cases are:

(1) The affected volume is contained within the film and the value of $a$ from Equation 2.13 is 1 since the value of $a$ should be limited to 1 .

(2) If the affected volume results in elastic deformation in the substrate but the indentation is still less than the film thickness then the value of $a$ is also 1 . 
(3) As the indentation approaches the film thickness, the substrate will begin to deform and the value of $a$ will decrease to less than 1 .

(4) As the indentation exceeds the coating thickness plastic deformation will exist in the substrate and the value of $a$ will be less than 1 .

The model is expressed in the literature (Chicot, et al., 1995) as:

$$
\begin{aligned}
H_{c}=\frac{3}{2} \tan ^{\frac{1}{3}} \xi \frac{t H_{f}^{\frac{3}{2}}}{d E_{f}^{\frac{1}{2}}}+\left(1-\frac{3}{2} \tan ^{\frac{1}{3}} \xi \frac{t H_{s}^{\frac{1}{2}}}{d E_{s}^{\frac{1}{2}}}\right) H_{s} \\
+\frac{3}{2} \tan ^{\frac{1}{3}} \xi \frac{t}{d}\left[\left(\frac{H_{s}}{E_{s}}\right)^{\frac{1}{2}} H_{f}-\left(\frac{H_{f}}{E_{f}}\right)^{\frac{1}{2}} H_{s}\right]
\end{aligned}
$$

In order to use this method, the Young's moduli $\left(E_{f}\right.$ and $\left.E_{s}\right)$ of both the components should be known in advance. In this equation $t, d$ and $\xi$ once again represent the film thickness, indent diagonal and indenter semi-angle respectively. As with the B-R model, this model can also be displayed neatly as shown below in Equation 2.21 (Puchi-Cabrera, et al., 2002).

$$
H_{c}=H_{s}+\frac{3 t}{2 d}\left[\left(\frac{H_{f}}{E_{f}}\right)^{\frac{1}{2}}+\left(\frac{H_{s}}{E_{s}}\right)^{\frac{1}{2}}\right] \tan ^{\frac{1}{3}} \xi\left(H_{f}-H_{s}\right)
$$

\section{Bykov et al. (B) Model}

Bykov et al. (2003) have recently proposed an alternative model which assumes that the system follows the additivity rule (Bykov, et al., 2003) and is mathematically identical to Bückle's model. Their model is shown below in Equation $2.22 \mathrm{a}$ and alternatively in $2.22 \mathrm{~b}$ using the relative indentation depth $(\beta)$. In their approach, they suggest that in order to get an accurate reading, the film must be pierced by the indenter (Bykov, et al., 
2003). In other words, they suggest that it is only valid for indentation depths greater than the coating thickness $(\beta>1)$.

$$
\begin{aligned}
& H_{c}=H_{s}+\left[1-\frac{(D-t)^{2}}{D^{2}}\right]\left(H_{f}-H_{s}\right) \\
& H_{c}=H_{s}+\left[1-\frac{(\beta-1)^{2}}{\beta^{2}}\right]\left(H_{f}-H_{s}\right)
\end{aligned}
$$

They concluded that it is able to detect the effect of the coating down to a thickness of 1.5 $\mathrm{nm}$ for hardened tool steel coated with diamond (Vickers hardness values of 1000 and $10000 H V$ respectively) (Bykov, et al., 2003). Although the simplicity in this method is attractive, the method has not been extensively examined and verified through experiment. According to this model, when the relative indentation depth $(\beta)$ is equal to 1 , the composite hardness should be equal to the film hardness. This is inconsistent with the observations of $\mathrm{J}-\mathrm{H}$ which found that the hardness measurement was affected at relative indentation depths as low as 0.07 .

\section{Korsunsky (K) Model}

In contrast to previously proposed methods based on areas or volumes, Korsunsky et al. (1998) proposed a method based on the energy expended during indentation. Their assumption is that the work of deformation can be broken into plastic deformation of the substrate and the deformation and fracture of the coating (Korsunsky, et al., 1998),(Puchi-Cabrera, et al., 2002). They derived an expression for the hardness of a material in terms of the total work of deformation, $W_{t o t}$ (Korsunsky, et al., 1998):

$$
\begin{gathered}
H_{c}=\frac{3 \kappa W_{t o t}}{D^{3}} \\
W_{t o t}=W_{s}+W_{f}
\end{gathered}
$$


In this equation, $\kappa$ is a parameter describing the geometry of the indenter, $D$ is the indent depth and $W_{s}$ and $W_{f}$ represent the work of deformation of the substrate and film respectively. The work of deformation of the substrate is given by:

$$
W_{s}=\frac{H_{S} D^{3}}{3 \kappa}
$$

The work of deformation of the film is dependent on the mode of deformation. The Korsunsky model addresses two cases, namely: fracture-dominated and plasticdominated deformation. For fracture-dominated deformation, the work of deformation is given by:

$$
W_{f}=\lambda_{1} G_{f} t D
$$

Where $t$ is the thickness of the film, $G_{f}$ is the through thickness fracture toughness of the film and $\lambda_{I}$ is an empirical parameter which describes the dependence of the crack length on the material pair and other properties of the film and substrate material combination. On the other hand, if plastic strain is dominant then the work of deformation is given by:

$$
W_{f}=\frac{\lambda_{2} H_{f} t^{2} D}{3 \kappa}
$$

Where $\lambda_{2}$ is similarly an empirical parameter. Now, substituting Equations 2.24 to 2.27 into 2.23 we can solve for the composite hardness as follows:

$$
H_{c}=H_{s}+\frac{\alpha \Delta H}{\beta^{2} t}
$$

Here, $\beta$ is relative indentation depth and expressions for the $\alpha A H$ term are given below for fracture and plastic-dominated deformation modes respectively:

$$
\alpha \Delta H=3 \kappa \lambda_{1} G_{c}
$$




$$
\alpha \Delta H=\lambda_{2} H_{f} t
$$

The model written below in Equation 2.31 was created by addressing the boundary conditions. As the relative indentation depth $\beta$ becomes very large, the composite hardness approaches the substrate hardness and vice-versa (Korsunsky, et al., 1998).

$$
H_{c}=H_{s}+\frac{H_{f}-H_{s}}{1+\beta^{2} \frac{t}{\alpha}}=H_{s}+\frac{H_{f}-H_{s}}{1+k_{K} \beta^{2}}
$$

$k_{K}$ represents a material parameter. This particular model was later refined by replacing the exponent of the relative indentation depth by the general exponent $X_{K}$. The modified model (Tuck, et al., 2001) is given below.

$$
H_{c}=H_{S}+\frac{1}{1+k_{K} \beta^{X_{K}}}\left(H_{f}-H_{s}\right)
$$

\section{Puchi-Cabrera (PC) Model}

One of the most recent models was proposed by Puchi-Cabrera (Beegan, et al., 2008). The model is based on four assumptions (Puchi-Cabrera, 2002), namely:

(1) The substrate begins affecting the measured hardness at relative indentations depths of 0.07 to 0.2 .

(2) For relative indentation depths less than 0.07 , the hardness of the film is dominant and for relative indentation depths greater than 0.2 , the hardness is a result of the mixture.

(3) The hardness of the mixture is assumed to be constant except for possible indentation size effect of the substrate.

(4) The composite hardness is given by a linear law of mixtures based on volume fractions. 
The resulting model is given by Equation 2.33 where $k_{P C}$ and $X_{P C}$ are material parameters describing the changes in hardness.

$$
H_{c}=H_{s}+\left(H_{f}-H_{s}\right) e^{-k_{P C} \beta^{X_{P C}}}
$$

\subsubsection{Indentation Size Effect (ISE)}

It has been found that the measured hardness for a bulk material is dependent on load (Chicot, et al., 1995). Many authors have acknowledged the indentation size effect (ISE) as a factor in the determination of the hardness of thin-film systems (Chicot, et al., 1995), (Korsunsky, et al., 1998), (Puchi-Cabrera, et al., 2002), (Beegan, et al., 2008). Most authors using the thin-film hardness models presented above have suggested the use of an ISE as a further refinement. An ISE model relates the measured hardness for a range of indentation sizes to the absolute hardness of a material. Several different ISE models are available to accommodate for the inconsistent hardness measurements observed. This section summarizes three commonly used ISE models found in material hardness research. In each of the following models, $H_{0}$ represents the absolute hardness of the material while $H$ represents the hardness measured through testing. Once again, $d$ represents the average of the indentation diagonals.

\section{Thomas Model}

Thomas proposed a linear ISE model based on the indentation diagonal (Chicot, et al., 1995), (Puchi-Cabrera, et al., 2002), (Korsunsky, et al., 1998). In this model, expressed in Equation 2.34 below, the constant describing the behaviour of the curve is given as $b$. As the indentation diagonal increases with increasing load the second term will diminish and the measured hardness will approach the absolute hardness. This is expected as ASTM micro-indentation test standards indicate that more consistent results are obtained at higher test loads. 


$$
H=H_{0}+\frac{b}{d}
$$

\section{Meyer Model}

Meyer suggested a power relationship between the measured hardness, absolute hardness and indentation diagonal. The ISE appears in two forms, relating the indentation diagonal to the hardness as in Equation 2.35 (Korsunsky, et al., 1998), (Puchi-Cabrera, et al., 2002) and the load as in Equation 2.36 (Chicot, et al., 1995). The former of these two expressions will be used in this thesis. The hardness is constant when the value of the exponent $n$ is 2 .

$$
\begin{gathered}
H=H_{0} d^{n-2} \\
P=a_{m} d^{n}
\end{gathered}
$$

\section{Strain Gradient Plasticity (MSG) Model}

A further ISE model was developed primarily by Nix and Gao (1998) based on strain gradient plasticity theory. It has been described as a multiscale method linking the microscale notion of statistically stored dislocations and the mesoscale notion of plastic strain and strain gradient (Beegan, et al., 2008). The ISE model is presented below as defined by Nix and Gao (Nix, et al., 1998).

$$
\frac{H}{H_{0}}=\sqrt{1+\frac{h^{*}}{h_{c}}}
$$

In Equation 2.37, $h_{c}$ is the contact depth while $h^{*}$ is expressed below in Equation 2.38. Unlike the other ISE models, the absolute hardness is specifically defined as in Equation 2.39 below (Nix, et al., 1998). 


$$
\begin{gathered}
h^{*}=\frac{81}{2} b \alpha^{2} \tan ^{2} \theta\left(\frac{\mu}{H_{O}}\right)^{2} \\
H_{O}=3 \sqrt{3} \alpha \mu b \sqrt{\rho_{s}}
\end{gathered}
$$

In the above two equations, $b$ is the Burger's vector, $\alpha$ is an empirical constant $(0.2$ to $0.5), \theta$ is the angle between the conical indenter and the surface of the indented material and $\mu$ is the shear modulus of the material. In order to calculate the absolute hardness we also require the density of statistically stored dislocations, $\rho_{S}$.

\subsection{Die Performance Analysis}

The performance of a minting die is ideally measured by the number of coins which can be successfully struck before failure. The inability of the die to create an accurate coin constitutes its failure. The type of failure observed on a coin can often be related to the failure of a particular part of the die (Lin, et al., 2006). Thus the reason for removal of a die should be recorded on an ongoing basis to accurately characterise the performance of a die. Though the thorough field testing of a die to characterise its performance is ideal, studies of this nature require a lot of planning and equipment time in order to collect and correlate all the data. As a business, a mint cannot afford the downtime for such detailed experiments and so it must either fit these experiments into its daily operations or determine other methods for predicting the performance of a die. As a result, other indicators are often used for determining or predicting the performance of various aspects of a minting die. Adhesion, hardness and wear resistance are characteristics of a thinfilm coated die that are used to evaluate performance. The adhesion and hardness performance of a coated die have already been discussed. This section will discuss the wear failures which can be noticed on the die surface. 


\subsubsection{Die Failure}

There are several different mechanisms responsible for the failure of the coin die (Costello, 2009). Lin et al. (2006) classified die failures into two main categories: (1) not directly determined by the coating and (2) observed on the die coating. In addition to this, inclusions in the blank can play a role in the die surface wear. During the high stress striking process, the blank material flows against the die surface where hard inclusions in the blank can be dragged across the surface of the die causing surface damage (Lin, et al., 2006).

\section{Not Directly Determined by the Coating}

Lin et al. (2006) have listed failures belonging to the first category as: die sinking from plastic deformation, die settling caused by neck expansion, die cracks caused by chips or machine conditions, and die crash. In particular, die sinking and die cracks can affect the coating and cause surface related failures. Die sinking will cause excessive deformation of the relatively brittle coating. The pilling failure described by Lin et al. (2006) is shown in Figure 2.15. Cracks and other defects in the die substrate can locally increase the deformation of the coating and provide failure initiation sites. For example, a typical pinhole defect in the substrate causing failure of the film is shown in Figure 2.16.

\section{Observed on the Die Coating}

The two modes listed by Lin et al. (2006) for the second category are abrasive and adhesive surface wear. In particular, the abrasive wear of the coating can be seen in the form of starburst scratches (Teer, et al., 2006) as in Figure 2.17. Adhesion related failures include flaking of the coating and radiating stress marks as in Figure 2.18 and Figure 2.19 respectively. Lin et al. (2006) reported that other authors (Martin, et al., 2000) have mentioned problems with micro-cracks in the coating where blank material would first begin to adhere in the area. After continued striking, blank material can be 
forced into the cracks and along the coating-substrate interface causing the coating to separate from the substrate.

\section{Inclusions in the Blank}

As mentioned earlier, hard inclusions in the blank material can be shattered and ploughed into the coating surface during striking. The resulting damage appears as starburst scratches or deep gouges in the die surface. In addition to die surface damage, inclusions in the blank can also mar the surface of the blank or adhere to the surface of the die. Figure 2.20, Figure 2.21 show failures in the coin and die due to inclusions in the blank (Lin, et al., 2006) or other foreign materials in between the die and blank during striking. Blank material can also accumulate on the die surface as in Figure 2.22 and be transferred to another blank or distort the surface of other coins. 


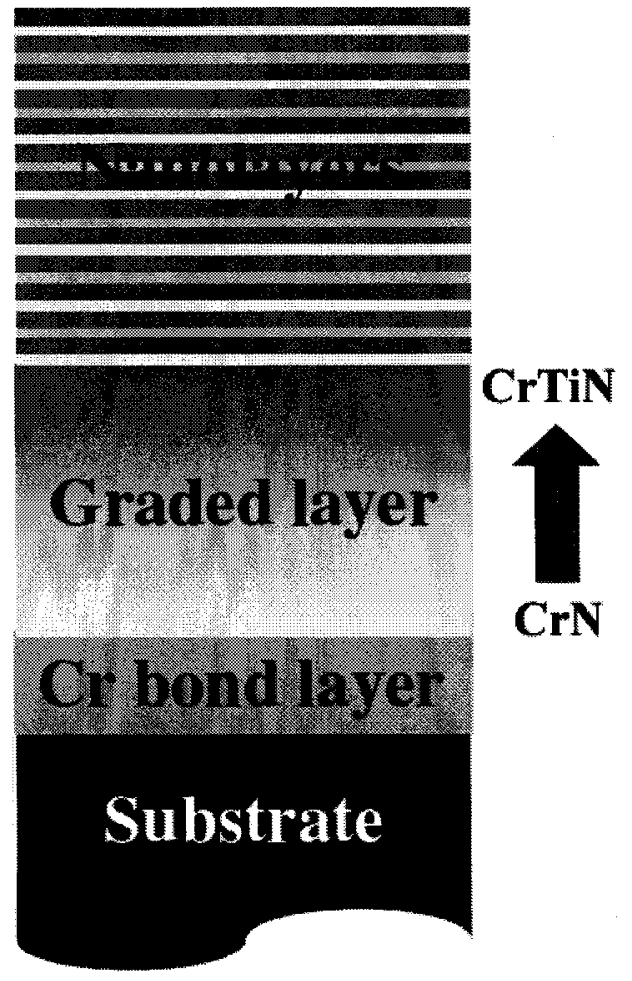

Figure 2.1: Structure of a multi-component film (Teer, et al., 2006)

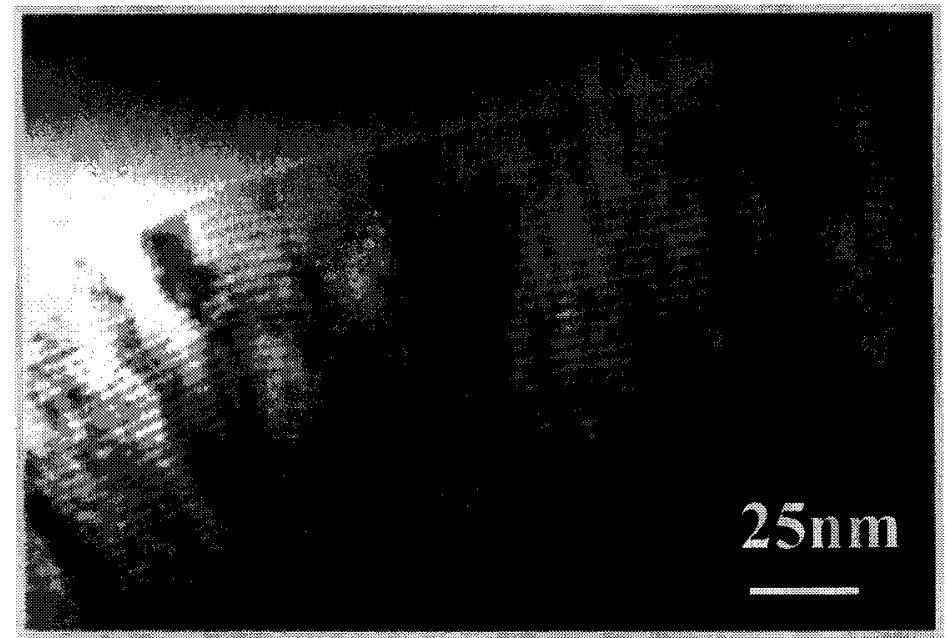

Figure 2.2: Film microstructure showing nano-layers of coating (Teer, et al., 2006) 

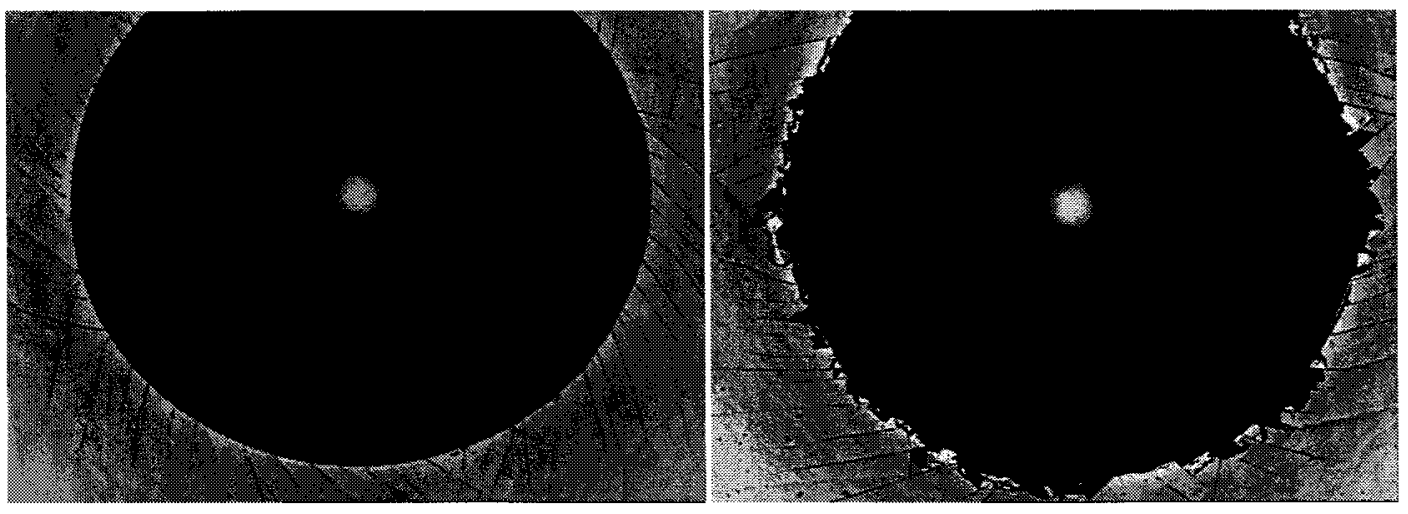

Figure 2.3: Rockewell-C indent showing good coating adhesion on the left and poor coating adhesion on the right

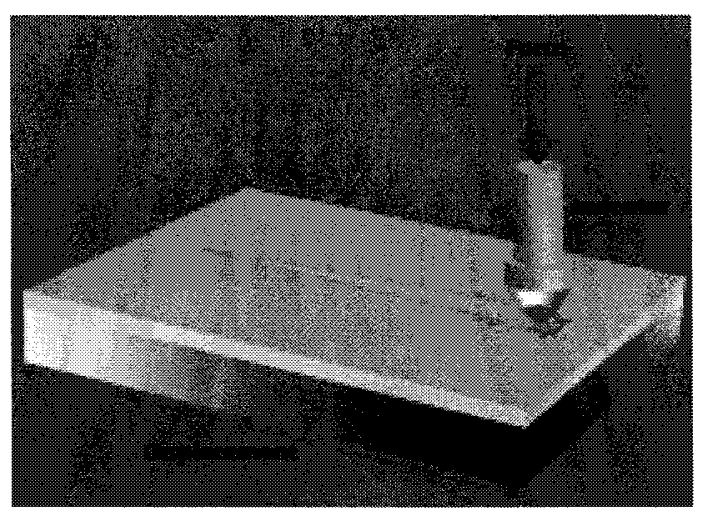

Figure 2.4: Scratch test schematic 


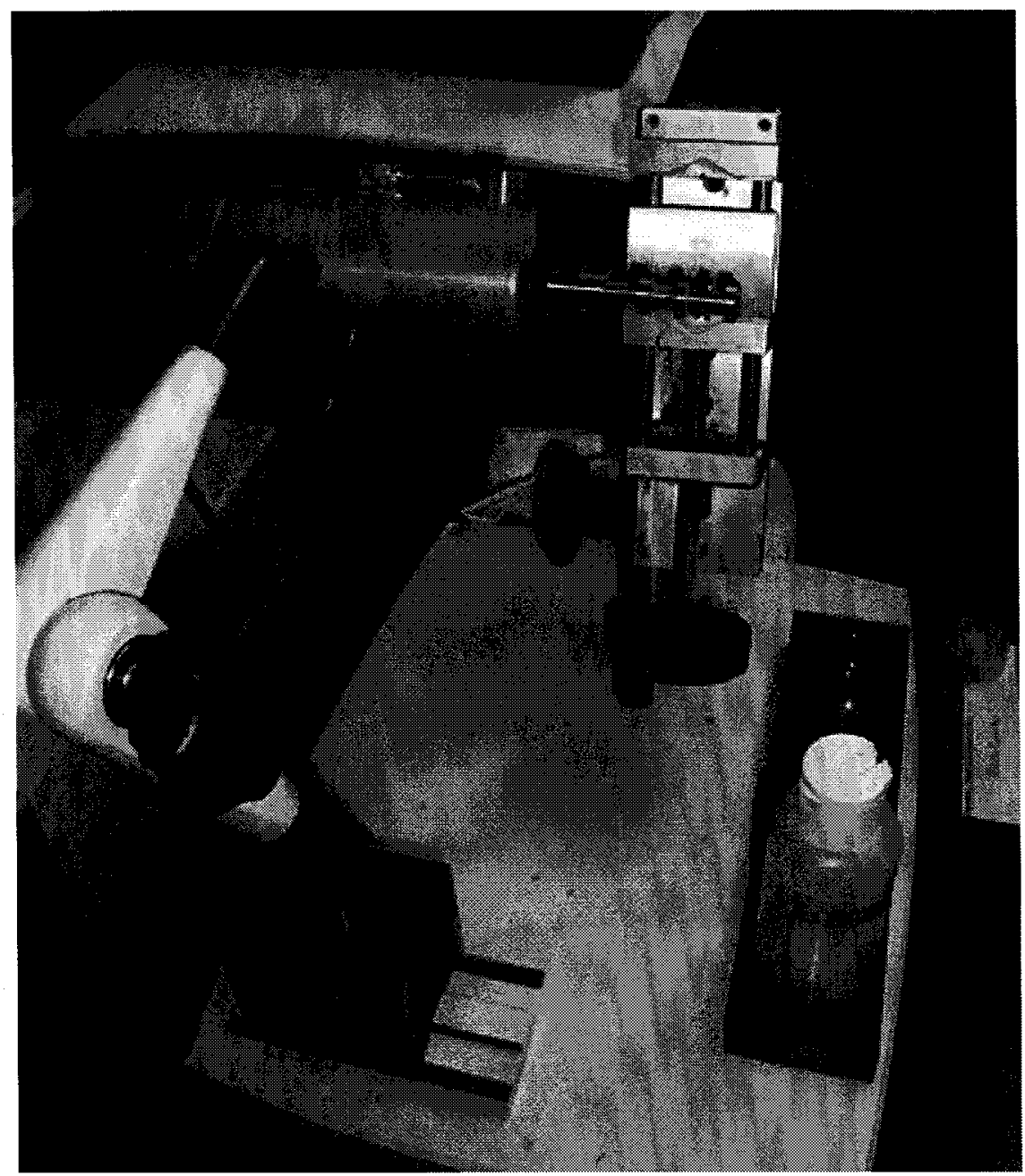

Figure 2.5: CSM Instruments calotest apparatus

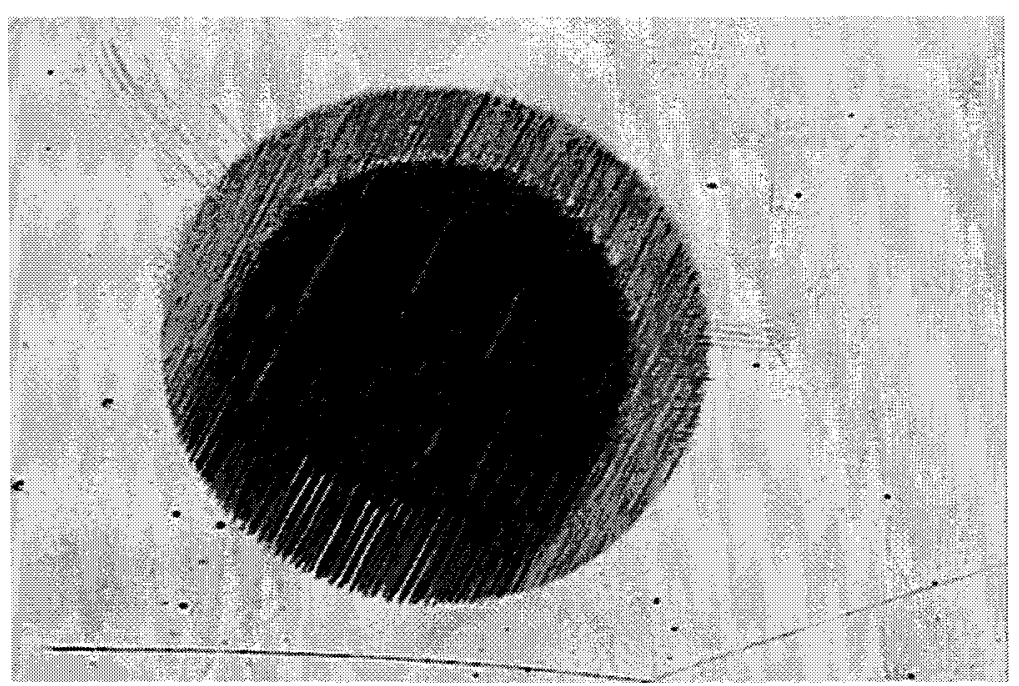

Figure 2.6: Calotest crater showing layers of coating and substrate (CSM-Instruments, 2009) 


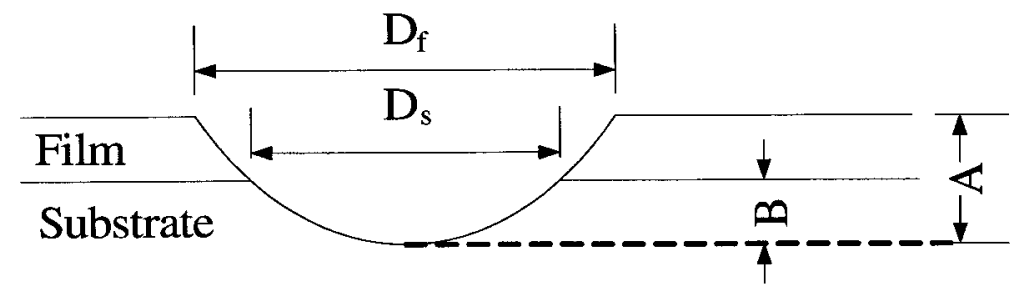

Figure 2.7: Calotest crater geometry

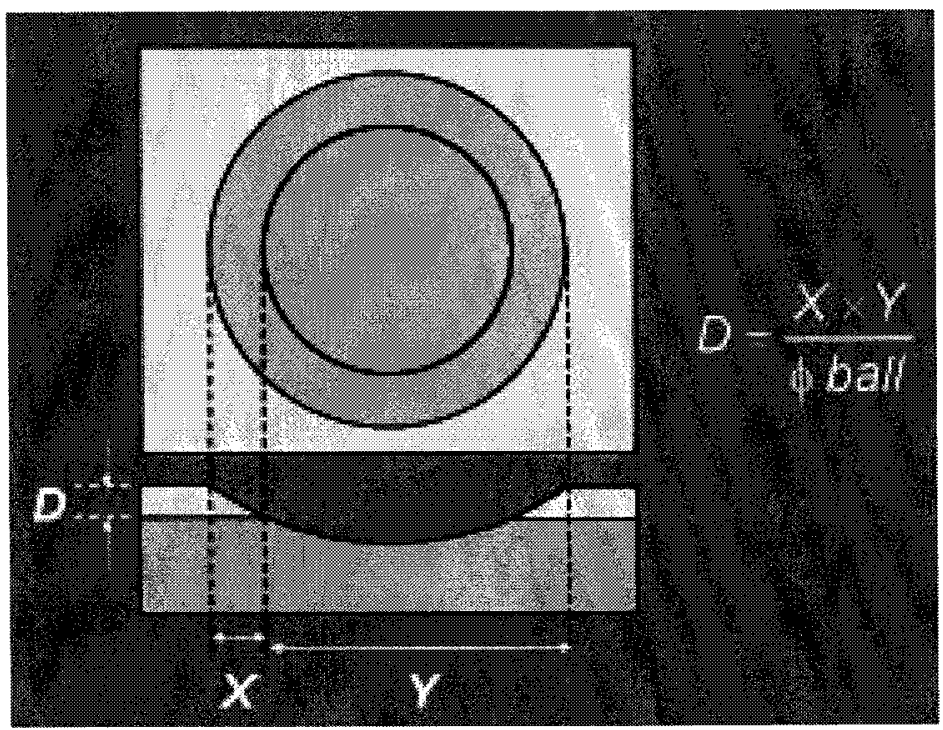

Figure 2.8: Calotest crater showing geometry (CSM-Instruments, 2009)

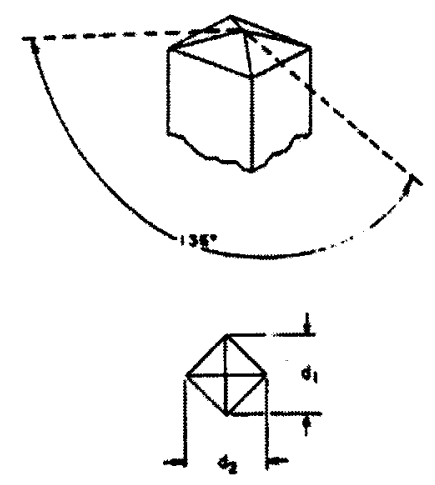

Figure 2.9: Vickers indenter geometry (ASTM, 2002) 


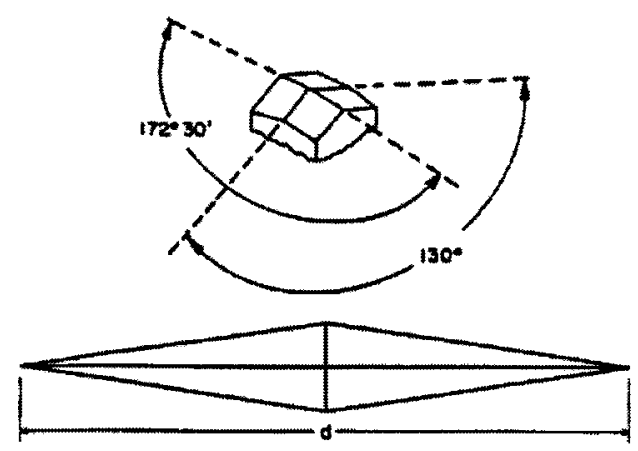

Figure 2.10: Knoop indenter geometry (ASTM, 2002)

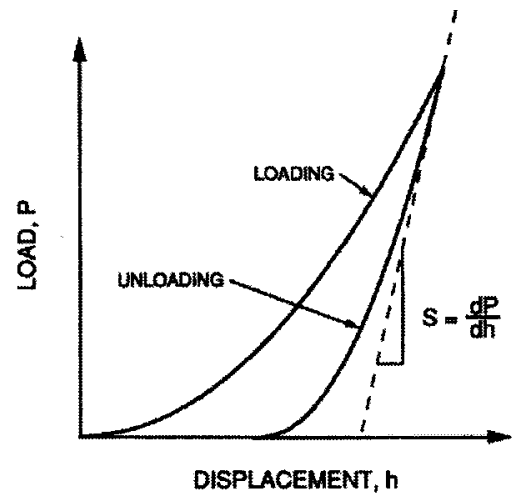

Figure 2.11: Typical nano-indentation loading and unloading curve (Pharr, et al., 1992)

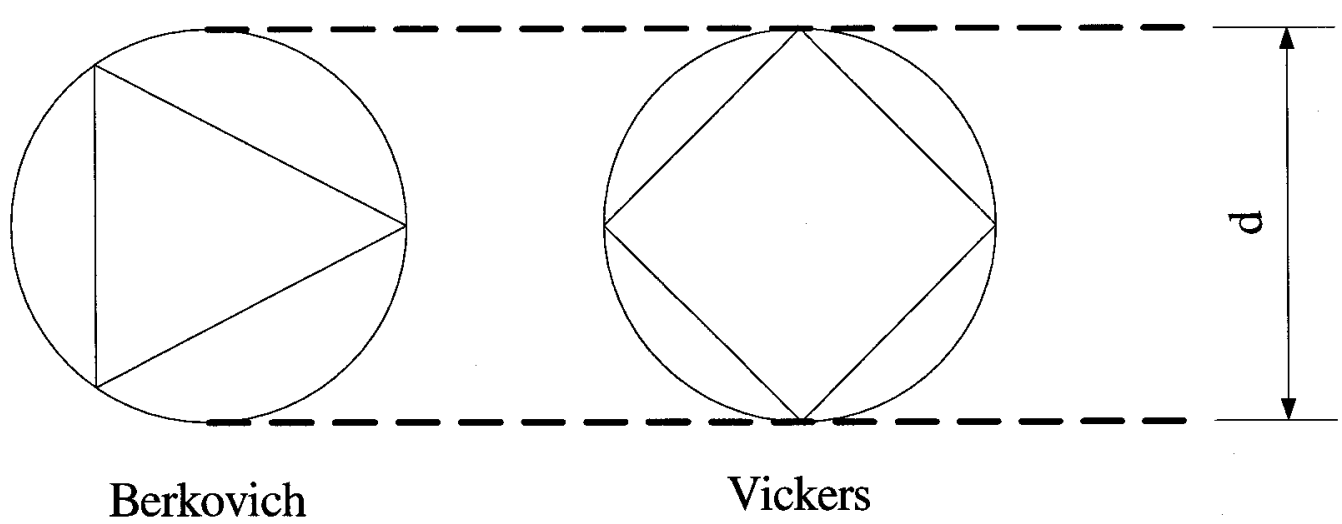

Figure 2.12: Equivalence of indentation diagonals for Vickers and Berkovich indenter tips 


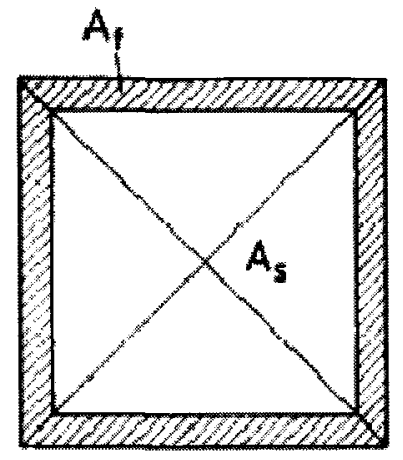

Figure 2.13: Load-carrying areas for J-H model(Jönsson, et al., 1984)

(1)

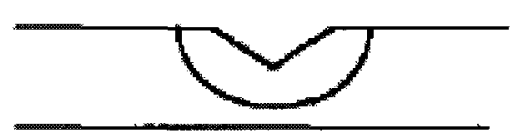

$H_{C}=H_{y} \quad(a=1)$

(3)

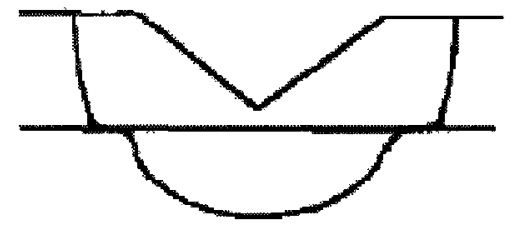

beginning of the plastic deformation of the substrate
(2) progression of the plastic zone

Filum

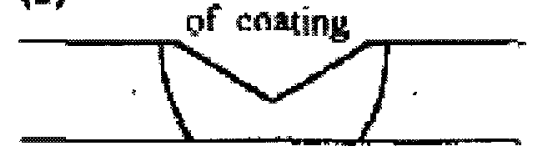

Eilastic seaction of the substrate

$$
d t=1 \ldots g=1
$$

(4)

Film

Suburate

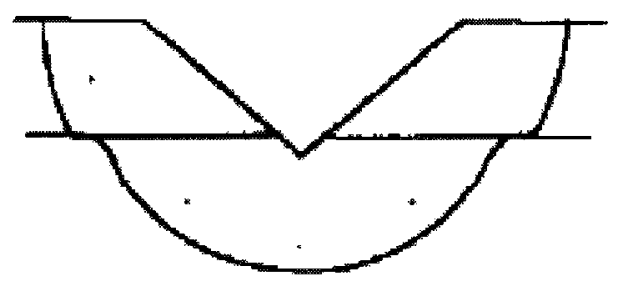

progression of plastic zone of the substrate and coxting

Figure 2.14: Illustration of zones affected by microhardness indentation (Chicot, et al., 1995) 


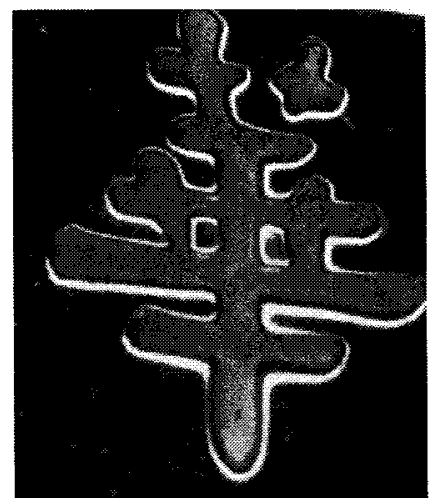

Figure 2.15: Piling failure from plastic deformation of the substrate (Lin, et al., 2006)

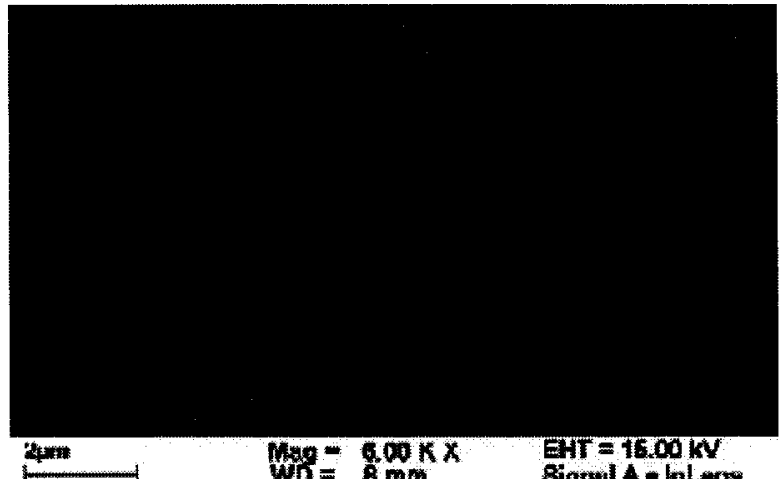

Figure 2.16: Pin-hole defect in substrate (Lin, et al., 2006)

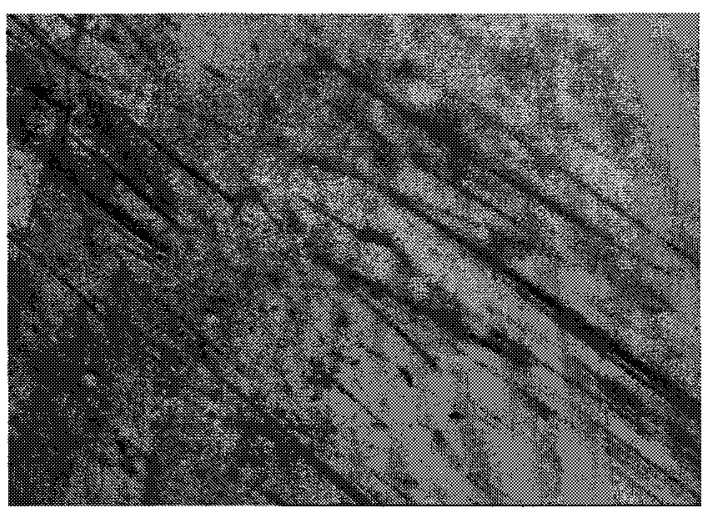

Figure 2.17: Starburst scratches on used GML die 


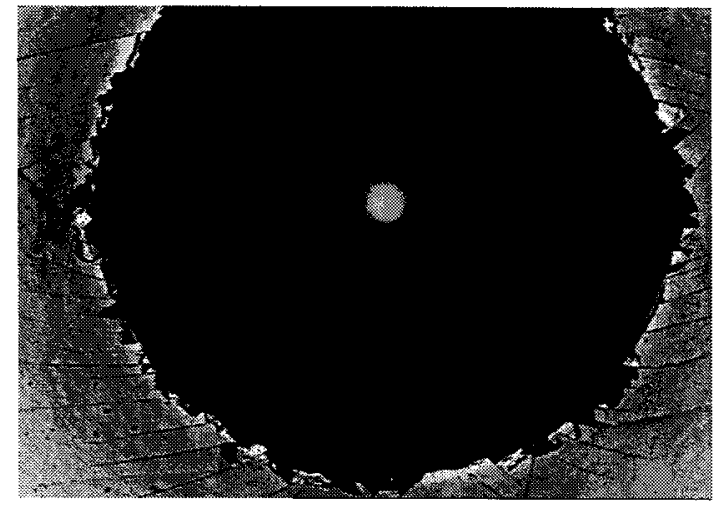

Figure 2.18: Flaking failure of coating due to poor adhesion

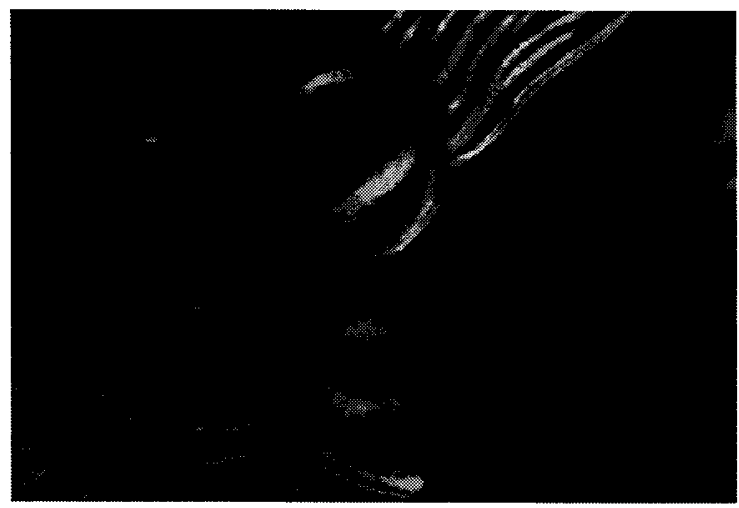

Figure 2.19: Radiating stress marks to left of ear (Lin, et al., 2006)

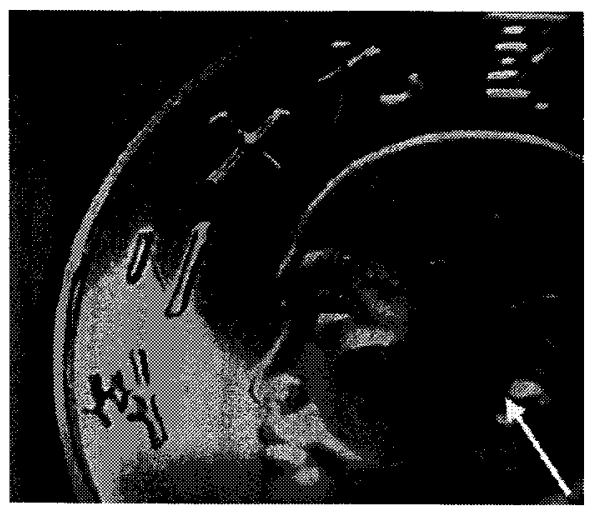

Figure 2.20: Failure of blank due to inclusions (Lin, et al., 2006) 


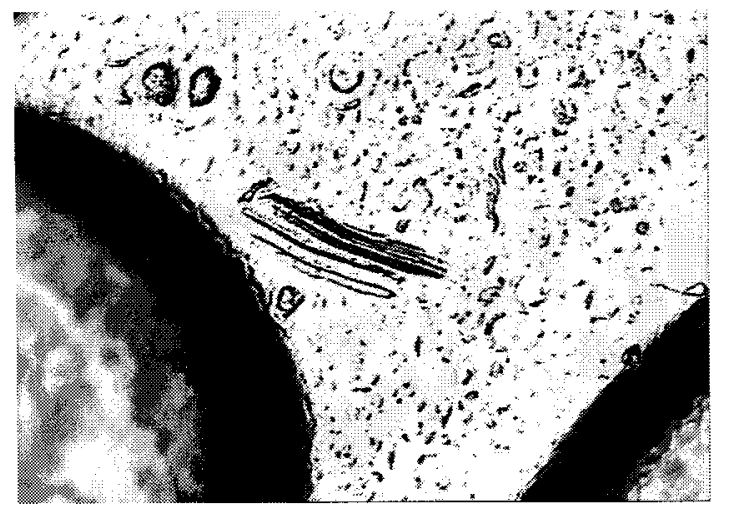

Figure 2.21: Failure of GML die from material ploughing into die surface

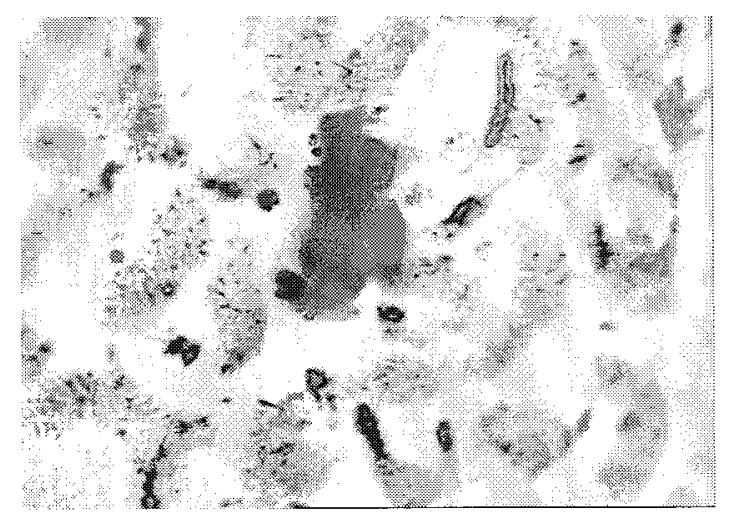

Figure 2.22: Adhesion of blank material on GML die 


\section{Chapter 3 : Hardness Testing, Procedures and Results}

This chapter presents the experimental setup, procedures and results of the hardness testing carried out on the thin-film system. The two test dies shown in Figure 3.1, with identification numbers 104027-57X and 104027X7 (hereafter referred to as 57X and X7 respectively), were used for all testing reported in this section. A thorough investigation of the substrate-film system hardness was conducted on both the micro and nano scales. First, the substrate hardness properties were examined through micro-indentation testing. Second, the coated system was examined using nano- and micro-indentation to provide measurement over a wide range of values. Finally, the thickness of the film was measured optically through calotests. The experiments are addressed chronologically in four groups: micro-indentation testing of the substrate, nano-indentation testing of the system, micro-indentation of the system and calotesting of the system. For consistency, the uncoated test dies will be referred to as the substrates and the coated dies as (coated) systems.

\subsection{Micro-Indentation Testing of the Substrate}

This section outlines the procedures and results for the micro-indentation testing of the substrate material. The micro-indentation tests described here were performed prior to the application of the hard PVD coating. Testing was performed over a wide range of test weights to determine a hardness profile of the substrate independent of the effect of the film.

\subsubsection{Sample Preparation}

The substrates (test dies 57X and X7) were made from soft annealed air-hardening tool steel. They were cut and prepared from steel rods using a high speed lathe and the top and bottom surfaces machined to be flat and level. The substrate was heat treated in a 
vacuum heat treatment furnace to a Rockwell-C hardness of about $58 \mathrm{HRC}$. After heat treatment, the top surface was polished to a mirror-like finish to minimise surface roughness and remove any scale or other surface irregularities.

\subsubsection{Experimental Setup}

A Leica VMHT MOT micro-indentation hardness tester (shown in Figure 3.2) equipped with a Vickers indenter tip was used for all micro-indentation tests performed on the substrates. The tester was equipped with an adjustable specimen holder, an optical light microscope and a control unit with touch screen interface. The microscope eyepiece, with built-in measuring equipment, was connected to the control unit so that measurements of the indent diagonals could be made directly. The control unit allowed the user to control the test parameters such as test weight and dwell time in accordance with ASTM standards (ASTM, 2002). The machine was placed on a hard marble table top to reduce the effect of vibrations on the tests.

\subsubsection{Procedure}

The 100X optical zoom lens was used for selecting the location of the indent and measuring the subsequent indentation diagonals of all indents. The micro-indentation tester was calibrated using a test piece, with a hardness of $597 \mathrm{HV} V_{0.015}$, before performing any micro-indentation tests on the substrates. The calibration was performed by setting the zero position of the eyepiece and measuring the indent diagonals produced using a 15 $g f$ test load.

The substrate surface was cleaned with isopropyl alcohol and a lint-free cloth and placed on the specimen holder. It was then adjusted into position under the $100 \mathrm{X}$ optical zoom lens. The hardness of each substrate was measured using at least 8 separate indents for test weights of $5,10,15,25,50,100$ and $200 \mathrm{gf}$. Additionally, 8 indents were made at a test weight of $1 \mathrm{gf}$ for $57 \mathrm{X}$. Each indentation test was physically separated by about 5 indent diagonals to minimise any interference which is in excess of the minimum of 3 
suggested in ASTM standard E384 (ASTM, 2002). Examples of the indentation test fields for both $57 \mathrm{X}$ and $\mathrm{X} 7$ can be seen in Figure 3.3 and Figure 3.4 respectively. The indent diagonals ( $d_{1}$ and $d_{2}$ as in Figure 2.9) and hardness of the material as reported by the micro-indentation tester were recorded for each measurement. In order to ensure consistency, 4 measurements were made per indent for test weights of 1 and $5 g$ on $57 \mathrm{X}$. It was found that 2 measurements of each indent were sufficient. The remainder of the indent diagonals on both substrates (57X and X7) were measured only twice for each indent.

\subsubsection{Results}

Indentation data were obtained for each substrate (57X and X7) which included test weight, indent diagonals and hardness. The data recorded for $57 \mathrm{X}$ are presented in Table 3.1 while the data recorded for $\mathrm{X} 7$ are presented in Table 3.2. A total of 78 indentations were performed on $57 \mathrm{X}$ while 80 indents were performed on $\mathrm{X} 7$. Figure 3.5 and Figure 3.6 show the measured hardness against the average indent diagonal for $57 \mathrm{X}$ and $\mathrm{X} 7$ respectively. The measurements for both $57 \mathrm{X}$ and $\mathrm{X} 7$ are very consistent at higher test weights. The larger indent sizes occurring at higher test loads reduce the effect of measurement error, particularly since the indent term is squared when determining the hardness from Equation 2.7. The data is combined in Figure 3.7 to illustrate that the measurements for each test die are consistent.

\subsection{Nano-Indentation Testing of the Coated System}

Nano-indentation testing was performed on the coated system in order to obtain precise hardness measurements at very low loading conditions. The nano-indentation test results will provide a far more accurate representation of the actual film hardness than is available from micro-indentation. As nano-indentation testing is a delicate and precise operation, it was performed prior to other tests on the coated system to ensure the smoothest surface conditions. 


\subsubsection{Sample Preparation}

After completion of the micro-indentation testing, the surfaces of substrates $57 \mathrm{X}$ and $\mathrm{X} 7$ were cleaned using isopropyl alcohol and a lint free cloth. The hard PVD coating was then applied to the substrate using a Teer Coatings Ltd. UDP650/4 magnetron sputter ion plating system. Both substrates were coated using the same equipment and process. To ensure a smooth surface, the surfaces were buffed after coating to remove asperities.

\subsubsection{Experimental Setup}

A CSM Instruments nano-indentation hardness tester equipped with a Berkovich indenter tip was used to perform the nano-indentation tests. The tester was equipped with a microscope and control unit for the user to setup the machine for the tests. With the specimen on the specimen holder, the machine can be adjusted using the control unit to perform indentations perpendicular to the specimen surface. The nano-indentation tester rested on an air-cushion vibration isolation table. The machine can be seen atop the vibration isolation table in Figure 3.8 .

\subsubsection{Procedure}

The surface of the coated system was cleaned using isopropyl alcohol and a lint free cloth. The coated system was placed into position beneath the microscope where a flat and level portion of the surface was selected for the indentations. Since a value for the Poisson's ratio was required to perform the test, the operator suggested that a value of 0.25 should be used for this type of coating. A total of 9 nano-indentation tests were performed with 5 being on $57 \mathrm{X}$ and 4 on X7. A first test was performed on $57 \mathrm{X}$ at a test load of $30 \mathrm{mN}$ and loading rate of $60 \mathrm{mN} / \mathrm{min}$. Although still a valid result, the operator indicated that lowering the test load and loading rate to $20 \mathrm{mN}$ and $40 \mathrm{mN} / \mathrm{min}$ respectively may yield more useful results so the remainder of the trials were conducted at these conditions. In total, 4 indentations were performed on each of $57 \mathrm{X}$ and $\mathrm{X} 7$ at the 
lower loading conditions. Table 3.3 illustrates the naming convention used for all nanoindentation tests performed. The input test conditions for all trials are summarised in Table 3.4. For each indentation, the machine recorded data points at time intervals during indentation where each point included: time, indentation depth and indenter load.

\subsubsection{Results}

The nano-indentation tester output both raw load-penetration data and a summary of important data points. The tester automatically analysed the load-penetration data for key points on the curve and calculated the hardness properties of the system. The results are presented below in two parts; the raw load-penetration data and the summary of the hardness analysis.

For each indentation test, the machine recorded 1000 data points. It is not practical for the complete results to be shown in this thesis. The first 30 entries of T0_57X (30 mN test on 57X) are given in Table 3.5 to show a sample of the recorded data. The full results are plotted in Figure 3.9 to Figure 3.11 showing that each test followed the expected trend from Figure 2.11. The first trial on 57X (T0_57X) is shown in Figure 3.9. Plots of the load vs. penetration data for trials T1_57X through T4_57X can be seen in Figure 3.10 while load vs. penetration plots for trials T1_X7 to T4_X7 can be seen in Figure 3.11. Although some noise is present in the measurements, smooth curves are produced for all trials indicating that no binding, irregularities or excessive vibrations disturbed the test.

The nano-indentation tester used the Oliver-Pharr method (see Section 2.2.2) to determine various surface properties from the load-penetration data, including the hardness. The results of indentation trials T0_57X to T4_57X are shown in Table 3.6 while trials T1_X7 to T4_X7 are shown in Table 3.7. The results here include depths for various points on the load-penetration curve such as indent depth $\left(H_{0}\right)$ and maximum penetration $\left(H_{c}\right)$. The hardness values measured from indentations performed at $20 \mathrm{mN}$ (T1_57X to T4_57X and T1_X7 to T4_X7) are summarised in Table 3.8. The average hardness for $57 \mathrm{X}$ and $\mathrm{X} 7$ at the $20 \mathrm{mN}$ load differed by about $88 \mathrm{HV}$. Despite the precise 
measurements made by the nano-indentation tester, the individual hardness measurements for 57X varied between 2352.9 and 2671.1 $H V$ while those for X7 varied between 2260.1 and $2613.4 \mathrm{HV}$.

\subsection{Micro-Indentation Testing of the Coated System}

Micro-indentation hardness tests were performed on the coated system only after the nano-indentation hardness testing had been completed. The nano-indentation test indents were small in comparison with the micro-indentations so that they did not significantly contribute to the surface roughness. Further to that, only 9 nano-indentation tests were performed in total (5 on 57X and 4 on X7). Very little of the surface was affected and no issues were encountered during testing. The micro-indentation testing was used to determine the hardness profile of the thin-film coated system for a variety of different test loads and to subsequently assess the fit of various thin-film system hardness models.

\subsubsection{Sample Preparation and Experimental Setup}

The coated systems (test dies 57X and X7) used in Section 3.2 were used for microindentation testing without any additional preparation. The experimental setup for microindentation testing of the coated system is identical to the experimental setup used in the micro-indentation testing of the uncoated dies (see Section 3.1.2).

\subsubsection{Procedure}

The micro-indentation tester was calibrated as described in Section 3.1.3 before performing any tests on the coated system. The coated system was placed on the specimen holder of the indenter and adjusted into position for the micro-indentation test under the 100X optical zoom lens. The hardness of each test die was measured using 5 separate indents for test weights of 5, 10, 15, 25, 50, 100 and $200 \mathrm{gf}$. The hardness of each coated system was also tested using 3 indents for test weights of 300 and $500 \mathrm{gf}$. Once again, every effort was made to ensure that each indentation test was physically 
separated by about 5 indentation diagonals to minimise any interference. Due to the small size of the indents, the indent diagonals $\left(d_{1}\right.$ and $\left.d_{2}\right)$ were measured four times for each indent performed at test weights of 5 and $10 \mathrm{~g} f$ to ensure consistency. For test weights of $15 \mathrm{~g} f$ or greater the indent diagonals were only measured twice as the dimension was large enough to be consistently measured. The hardness calculated by the micro-indentation tester based on the measured indent diagonals was recorded along with the measured diagonals and test weight for each indent.

\subsubsection{Results}

A total of 41 indents were performed on each of the coated systems. As with the microindentation testing of the substrate, the precision of the measurements increased as the indent size increased. The measured data with averaged indent diagonals and hardness are shown in Table 3.9 for $57 \mathrm{X}$ and Table 3.10 for X7. The hardness is plotted against the average indent diagonal for $57 \mathrm{X}$ in Figure 3.12 and $\mathrm{X} 7$ in Figure 3.13. In both figures, the hardness is about $2200 \mathrm{HV}$ for small indents and approaches an asymptote near $750 \mathrm{HV}$.

The data are plotted together in Figure 3.14 to compare the two sets. In general, the 57X hardness values are consistently lower than the $\mathrm{X} 7$ hardness values at the same indent size. The hardness values of $57 \mathrm{X}$ at indent sizes of about $4 \mu \mathrm{m}$ are significantly lower than those of X7. Additionally, the hardness data of $57 \mathrm{X}$ near this point deviate from the trend indicating possible errors in measurement or inconsistency of the film. The coated hardness data are also plotted together with the uncoated hardness data in Figure 3.15 to show that the apparent hardness approaches the substrate hardness at large indent sizes.

\subsection{Determination of the Film Thickness}

The thickness of the film in a thin-film coated system is an important parameter used by the hardness models discussed in Section 2.3. This section describes the calotest 
experiments that were performed on the test dies in order to determine the film thicknesses.

\subsubsection{Sample Preparation and Experimental Setup}

After micro-indentation testing of the coated system, no additional preparation of the specimens was necessary. The calotests were performed using a CSM instruments calotester. The test setup consisted of a sample holder, a $25.4 \mathrm{~mm}$ diameter steel ball, an electric motor and a control unit. The output shaft of the motor is grooved so that the steel ball stays in position during the test. The apparatus is shown in Figure 2.5. The sample is held near the motor output shaft so that the steel ball can rest on both the sample and shaft as shown in Figure 3.16. The angle and distance between the sample surface and motor output shaft is not specified in the user's manual however they must be adjusted carefully so that the ball does not fall from the apparatus during testing. The motor rotates as shown in Figure 3.16 to ensure that the ball maintains constant contact with the surface of the sample.

\subsubsection{Procedure}

The test conditions including motor speed, test duration and ball diameter commonly used for this test at the RCM were selected and are summarised in Table 3.11. The test die was placed in the calotester's sample holder and adjusted into position near the motor output shaft. The steel ball was cleaned with isopropyl alcohol and a lint-free cloth before placing it to rest between the surface of the coated system and the grooves of the motor output shaft. The test parameters were input into the motor control unit. Two drops of an abrasive solution ( 0.1 micron (blue) diamond solution) were dropped onto the steel ball immediately before the test was started. Once complete, the test die and steel ball were once again cleaned using isopropyl alcohol and a lint-free cloth. The wear crater was measured under a microscope to determine the film thickness. 


\subsubsection{Results}

One calotest was performed on each test die with each test successfully abrading the surface through the film layer into the substrate below. The resulting craters with measurements are shown in Figure 3.17 and Figure 3.18 for $57 \mathrm{X}$ and $\mathrm{X} 7$ respectively. The film thickness can be found by applying Equation 2.4 from Section 2.1.4 to the measurements. Both thicknesses are within the expected range of 1 to $4 \mu \mathrm{m}$. The film thicknesses are $2.18 \mu \mathrm{m}$ for $57 \mathrm{X}$ and $2.59 \mu \mathrm{m}$ for X7. The measurements and thicknesses for $57 \mathrm{X}$ and $\mathrm{X} 7$ are summarised in Table 3.12.

\subsection{Summary}

The experiments were successful in acquiring consistent measurements for the various parameters which describe the hardness of the thin-film system. The hardness profile of the substrate was isolated and measured using micro-indentation testing. The coated system hardness profile was obtained through micro- and nano-indentation testing for a wide range of test weights. Finally the film thickness was determined so that the hardness profile of the thin-film system can be modelled. 

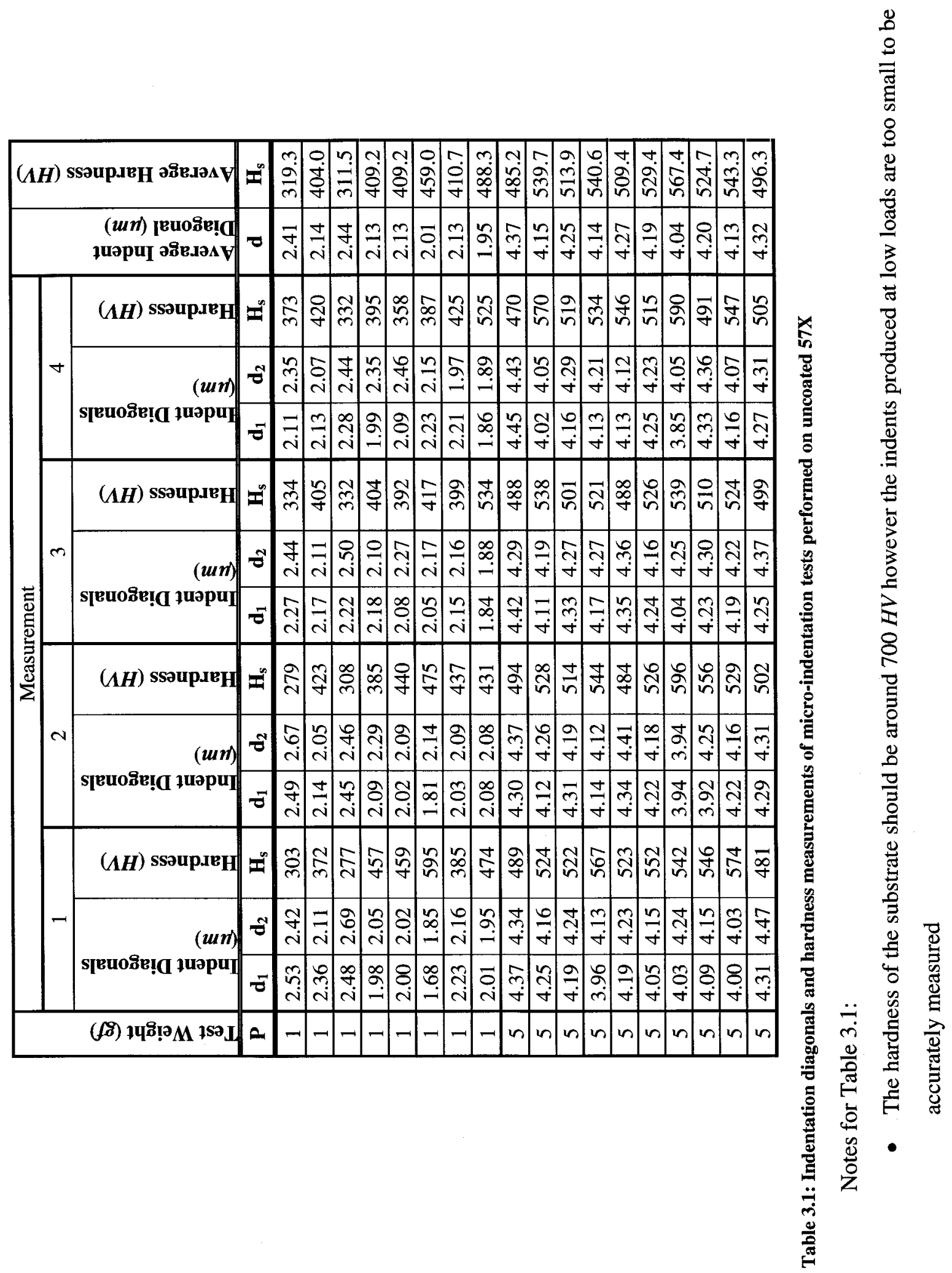


\begin{tabular}{|c|c|c|c|c|c|c|c|c|}
\hline \multirow[b]{3}{*}{ 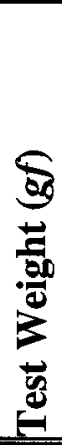 } & \multicolumn{6}{|c|}{ Measurement } & \multirow[b]{3}{*}{ 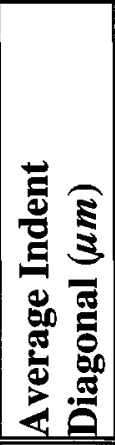 } & \multirow{3}{*}{ 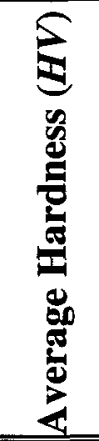 } \\
\hline & \multicolumn{3}{|c|}{1} & \multicolumn{3}{|c|}{2} & & \\
\hline & \multicolumn{2}{|c|}{ 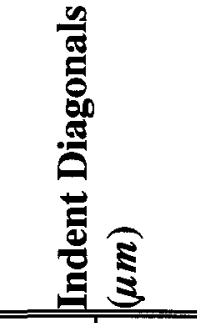 } & \multirow[t]{2}{*}{ 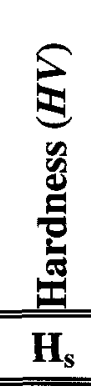 } & \multicolumn{2}{|c|}{ 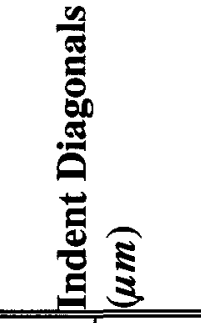 } & \multirow[t]{2}{*}{ 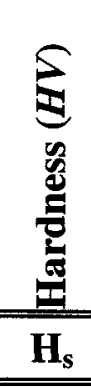 } & & \\
\hline $\mathbf{P}$ & $d_{1}$ & $\mathbf{d}_{2}$ & & $d_{1}$ & $\mathbf{d}_{2}$ & & d & $\mathbf{H}_{\mathrm{s}}$ \\
\hline 10 & 5.23 & 5.52 & 643 & 5.38 & 5.40 & 63 & 5.38 & 40. \\
\hline 10 & & & & 6 & & & & 4.0 \\
\hline 10 & 5.34 & 564 & 615 & 48 & 5.6 & & 2 & 508.6 \\
\hline 10 & 0 & 5.24 & 667 & .48 & 5.4 & & 6 & 645.5 \\
\hline 10 & & & 620 & 45 & 5.4 & & -1 & - \\
\hline 10 & 5.34 & 5.44 & 638 & .32 & 5.50 & & 40 & 35.9 \\
\hline 10 & 5.3 & 5.34 & 649 & 5.21 & 5. & & 2 & 55.2 \\
\hline 10 & 5.3 & 5.3 & 659 & 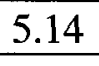 & 5. & & 2 & 0 \\
\hline 10 & 5.16 & 5.16 & 697 & 5.27 & 5.21 & & 5.20 & 685.8 \\
\hline 10 & 5.2 & 5.24 & 679 & 5.39 & 5.4 & & 5.31 & 657.7 \\
\hline 15 & 6.28 & 37 & 696 & 6.24 & 6.41 & & 3 & 95.3 \\
\hline 15 & 0.26 & 6.21 & 715 & 6.30 & 6.42 & & 6.30 & 701.4 \\
\hline 15 & 6.2 & 6. & 689 & 6.42 & 6.4 & & 6.40 & 680.2 \\
\hline 15 & 6.49 & 6.44 & 666 & 6.44 & 6.45 & & 6.46 & 667.6 \\
\hline 15 & 6.34 & 6.34 & 692 & 6.24 & 6.34 & & 6.32 & 697.5 \\
\hline 15 & 6.42 & 6.52 & 665 & 6.19 & 6.5 & & 6.41 & 677.0 \\
\hline 15 & 6.23 & 6.33 & 705 & 6.23 & 6.25 & & 6.26 & 709.8 \\
\hline 15 & 6.25 & 6.32 & 705 & 6.34 & 6.24 & 70 & 6.29 & 703.6 \\
\hline 15 & 6.23 & 6.17 & 724 & 6.34 & 6.16 & 71 & 6.23 & 717.8 \\
\hline 15 & 6.23 & 6.28 & 711 & 6.24 & 6.23 & 715 & 6.25 & 713.2 \\
\hline
\end{tabular}

Table 3.1 (cont.) 


\begin{tabular}{|c|c|c|c|c|c|c|c|c|}
\hline \multirow[b]{3}{*}{ 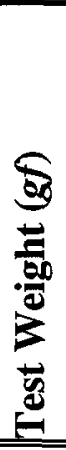 } & \multicolumn{6}{|c|}{ Measurement } & \multirow[b]{3}{*}{ 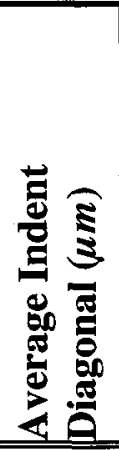 } & \multirow{3}{*}{ 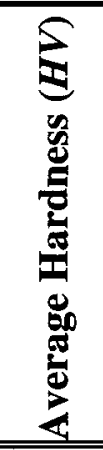 } \\
\hline & \multicolumn{3}{|c|}{1} & \multicolumn{3}{|c|}{2} & & \\
\hline & \multicolumn{2}{|c|}{ 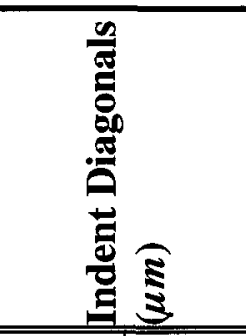 } & \multirow[t]{2}{*}{ 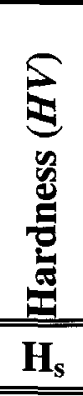 } & \multicolumn{2}{|c|}{ 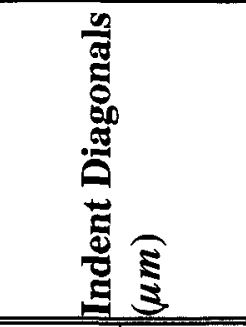 } & \multirow[t]{2}{*}{ 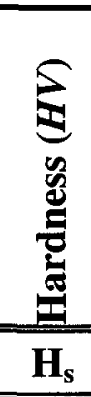 } & & \\
\hline $\mathbf{P}$ & $d_{1}$ & $d_{2}$ & & $d_{1}$ & $\mathbf{d}_{2}$ & & $\mathbf{d}$ & $\mathbf{H}_{\mathrm{s}}$ \\
\hline 25 & 8.30 & 8.28 & 675 & 8.00 & 8.17 & 709 & 8.19 & 691.6 \\
\hline 25 & 8.33 & 8.35 & 667 & 37 & 8.31 & 666 & 8.34 & 666.5 \\
\hline 25 & 8.12 & 8.06 & 709 & 8.36 & 8.21 & 675 & 8.19 & 691.6 \\
\hline 25 & 8.39 & 8.44 & 654 & 8.31 & 8.39 & 665 & 8.38 & 659.8 \\
\hline 25 & 8.20 & 8.01 & 706 & 8.35 & 8.31 & 667 & 8.22 & 686.5 \\
\hline 25 & 8.19 & 8.19 & 692 & 8.09 & 8.20 & 699 & 8.17 & 695.0 \\
\hline 25 & 8.22 & 8.06 & 699 & 7.95 & 8.15 & 715 & 8.10 & 707.5 \\
\hline 25 & 8.06 & 8.04 & 715 & 7.92 & 8.26 & 709 & 8.07 & 711.9 \\
\hline 25 & 8.04 & 8.11 & 711 & 7.92 & 8.26 & 709 & 8.08 & 709.7 \\
\hline 25 & 7.94 & 8.13 & 718 & 8.17 & 8.13 & 697 & 8.09 & 707.9 \\
\hline 50 & 12.74 & 12.69 & 574 & 12.70 & 12.34 & 592 & 12.62 & 582.4 \\
\hline 50 & 11.45 & 11.36 & 713 & 11.44 & 11.32 & 716 & 11.39 & 714.4 \\
\hline 50 & 11.25 & 11.56 & 713 & 11.40 & 11.53 & 706 & 11.44 & 709.1 \\
\hline 50 & 11.67 & 11.54 & 688 & 11.58 & 11.50 & 696 & 11.57 & 692.3 \\
\hline 50 & 11.95 & 11.86 & 654 & 11.82 & 12.03 & 652 & 11.92 & 653.1 \\
\hline 50 & 11.05 & 11.43 & 734 & 11.18 & 11.13 & 745 & 11.20 & 739.5 \\
\hline 50 & 11.22 & 11.33 & 729 & 11.23 & 11.31 & 730 & 11.27 & 729.7 \\
\hline 50 & 11.45 & 11.47 & 706 & 11.43 & 11.55 & 702 & 11.48 & 704.2 \\
\hline 50 & 11.34 & 11.43 & 715 & 11.29 & 11.36 & 723 & 11.36 & 719.1 \\
\hline 50 & 11.31 & 11.49 & 714 & 11.45 & 11.46 & 707 & 11.43 & 710.0 \\
\hline
\end{tabular}

Table 3.1 (cont.) 


\begin{tabular}{|c|c|c|c|c|c|c|c|c|}
\hline \multirow[b]{3}{*}{ 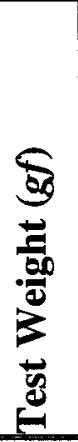 } & \multicolumn{6}{|c|}{ Measurement } & \multirow[b]{3}{*}{ 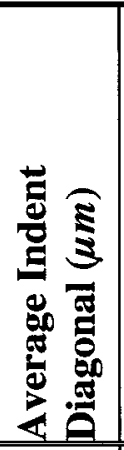 } & \multirow{3}{*}{ 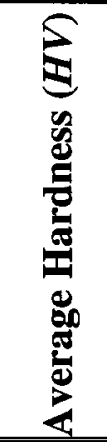 } \\
\hline & \multicolumn{3}{|c|}{1} & \multicolumn{3}{|c|}{2} & & \\
\hline & \multicolumn{2}{|c|}{ 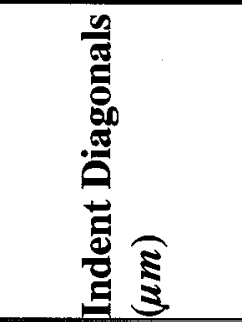 } & \multirow[t]{2}{*}{ 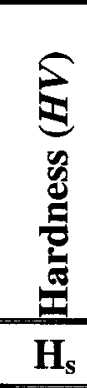 } & \multicolumn{2}{|c|}{ 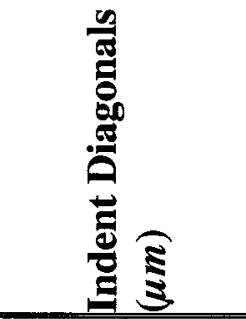 } & \multirow[t]{2}{*}{$\frac{\underset{\Xi}{\Xi}}{\mathbf{H}_{\mathbf{S}}}$} & & \\
\hline $\mathbf{P}$ & $d_{1}$ & $\mathbf{d}_{2}$ & & $d_{1}$ & $\mathrm{~d}_{2}$ & & d & $\overline{H_{s}}$ \\
\hline 100 & 15.92 & 5.86 & 735 & 15.97 & 15.94 & 729 & 5.92 & 731.4 \\
\hline 100 & 15.8 & 15.83 & 741 & 15.87 & 15.82 & 739 & 33 & 739.8 \\
\hline 100 & 16. & 16.06 & 721 & 15.92 & 16.11 & 723 & 3 & 722.1 \\
\hline 100 & 16 & 16.10 & 719 & 16.11 & 16.20 & 710 & 5.11 & 714.7 \\
\hline 100 & 15. & 15.91 & 734 & 15.85 & 15.87 & 73 & 38 & 735.4 \\
\hline 100 & 15 & 3 & 766 & 15.77 & 15.72 & 748 & 55 & 757.1 \\
\hline 100 & 16.02 & 16.17 & 716 & 16.07 & 16.20 & 712 & 2 & 714.1 \\
\hline 100 & 16.0 & 16.26 & 712 & 15.91 & 16. & 727 & 6 & 719.4 \\
\hline 100 & 16 & 16.02 & 720 & 16.17 & 16.22 & 707 & 2 & 713.4 \\
\hline 100 & 15.84 & 15.85 & 739 & 15.94 & 15.86 & 834 & .87 & 736.1 \\
\hline 200 & 22.93 & 23.29 & 694 & 23.16 & 23.42 & 684 & 3.20 & 689.1 \\
\hline 200 & 22.41 & 22.67 & 730 & 22.60 & 22.52 & 729 & 2.55 & 729.4 \\
\hline 200 & 22.60 & 22.78 & 721 & 22.60 & 22.88 & 71 & 2.72 & 718.8 \\
\hline 200 & 22.89 & 22.93 & 707 & 22.92 & 22.99 & 704 & 22.93 & 705.2 \\
\hline 200 & 22.96 & 22.99 & 702 & 22.89 & 23.02 & 704 & 22.97 & 703.2 \\
\hline 200 & 23.38 & 23.76 & 668 & 23.25 & 23.54 & 678 & 23.48 & 672.6 \\
\hline 200 & 23.36 & 23.51 & 675 & 22.95 & 23.32 & 693 & 23.29 & 684.0 \\
\hline 200 & 23.11 & 23.51 & 683 & 23.04 & 23.47 & 686 & 23.28 & 684.2 \\
\hline 200 & 22.69 & 23.31 & 701 & 22.70 & 23.32 & 700 & 23.01 & 700.8 \\
\hline 200 & 22.93 & 23.47 & 689 & 23.11 & 23.32 & 688 & 23.21 & 688.6 \\
\hline
\end{tabular}

Table 3.1 (cont.) 


\begin{tabular}{|c|c|c|c|c|c|c|c|c|}
\hline \multirow[b]{3}{*}{ 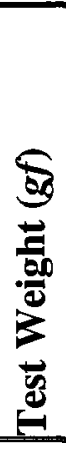 } & \multicolumn{6}{|c|}{ Measurement } & \multirow[b]{3}{*}{ 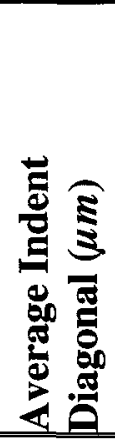 } & \multirow{3}{*}{ 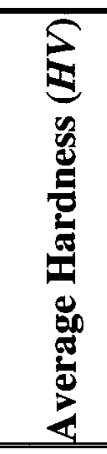 } \\
\hline & \multicolumn{3}{|c|}{1} & \multicolumn{3}{|c|}{2} & & \\
\hline & \multicolumn{2}{|c|}{ 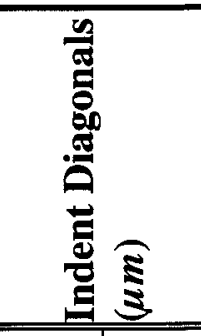 } & \multirow[t]{2}{*}{ 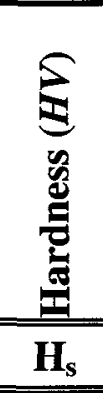 } & \multicolumn{2}{|c|}{ 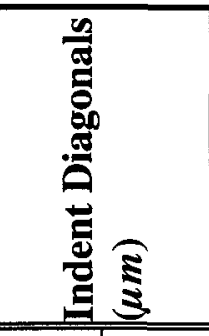 } & \multirow[t]{2}{*}{ 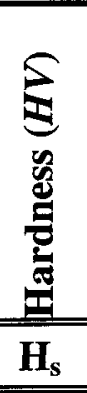 } & & \\
\hline $\mathbf{P}$ & $d_{1}$ & $\mathbf{d}_{2}$ & & $d_{1}$ & $d_{2}$ & & d & $\mathbf{H}_{\mathrm{s}}$ \\
\hline 5 & 4.64 & 5.27 & 8 & 4.43 & 4.52 & 163 & 4.72 & 417.1 \\
\hline 5 & 4.89 & 4.89 & 388 & 4.89 & 4.89 & 38 & 4.89 & 387.8 \\
\hline 5 & 4.52 & 4.82 & 425 & 4.67 & 4.84 & 4 & 4.71 & 417.5 \\
\hline 5 & 3.97 & 4.3 & 53 & 4.00 & 4. & & 2 & 545.6 \\
\hline 5 & 4.01 & 4.16 & 555 & 3.59 & 4.14 & 0 & 3.5 & 586.8 \\
\hline 5 & 3.87 & 4.09 & 585 & 3.84 & 3.98 & 60 & 3.95 & 595.8 \\
\hline 5 & 3.60 & 3.7 & 692 & 3.73 & 3.85 & 6 & 3.73 & 667.3 \\
\hline 5 & 3.71 & 3.9 & 631 & 3.50 & 3.79 & 69 & 3.74 & 662.9 \\
\hline 5 & 3.76 & 3.96 & 622 & 3.80 & 3.89 & 628 & 3.85 & 624.7 \\
\hline 5 & 3.64 & 3.71 & 687 & 3.78 & 3.96 & 619 & 3.77 & 651.5 \\
\hline 5 & 3.69 & 3.86 & 651 & 3.85 & 4.00 & 601 & 3.85 & 625.5 \\
\hline
\end{tabular}

Table 3.2: Indentation diagonals and hardness measurements of micro-indentation tests performed on uncoated X7 


\begin{tabular}{|c|c|c|c|c|c|c|c|c|}
\hline \multirow[b]{3}{*}{ 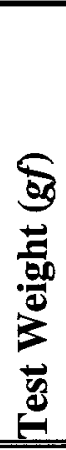 } & \multicolumn{6}{|c|}{ Measurement } & \multirow[b]{3}{*}{ 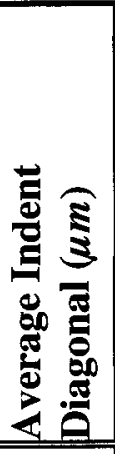 } & \multirow{3}{*}{ 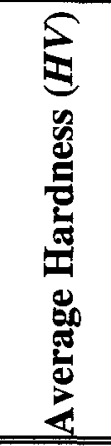 } \\
\hline & \multicolumn{3}{|c|}{1} & \multicolumn{3}{|c|}{2} & & \\
\hline & \multicolumn{2}{|c|}{  } & \multirow[t]{2}{*}{ 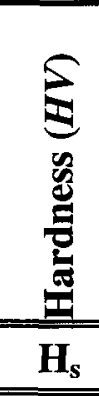 } & \multicolumn{2}{|c|}{ 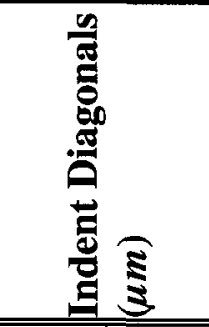 } & \multirow[t]{2}{*}{ 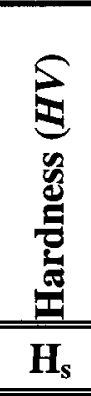 } & & \\
\hline $\mathbf{P}$ & $d_{1}$ & $\mathbf{d}_{2}$ & & $d_{1}$ & $\mathbf{d}_{2}$ & & d & $\mathbf{H}_{\mathrm{s}}$ \\
\hline 10 & 5.60 & & & & & 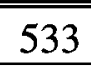 & & $\overline{556.0}$ \\
\hline 10 & 5.5 & 5.66 & & 5.80 & 5. & & 5.72 & 67.8 \\
\hline 10 & 5.6 & 6.05 & & & & & & 57.5 \\
\hline 10 & 0.36 & & & 43 & & & & 35.4 \\
\hline 10 & 5.00 & 5.31 & 97 & 5.07 & 5.2 & 70 & 5.15 & 99.9 \\
\hline 10 & 532 & 5.43 & & 38 & & & & 20.3 \\
\hline 10 & 5.25 & & & 5.00 & & & & 79.3 \\
\hline 10 & 4.56 & 4.72 & 2 & 4.92 & 4. & & 4.78 & 311.6 \\
\hline 10 & 4.82 & 4.89 & & & & & 4.90 & 71.6 \\
\hline 10 & 4.89 & 4.95 & 7 & 78 & & & & 63.7 \\
\hline 10 & 4.89 & 4.86 & 81 & 4.71 & 4.96 & 793 & 4.86 & 786.7 \\
\hline 10 & 4.90 & 4.85 & - & 4.93 & 4.94 & 761 & 4.91 & 770.8 \\
\hline 15 & 7.11 & 7.03 & 557 & 7.03 & 721 & $54{ }^{\circ}$ & 710 & 552.6 \\
\hline 15 & 6.51 & 7.06 & & 6.64 & & & & 95.8 \\
\hline 15 & 6.79 & 6.99 & & & & & & 65.2 \\
\hline 15 & 6.14 & & & & & & & 707.0 \\
\hline 15 & 6.10 & 6.24 & 1 & 5.98 & 6.25 & 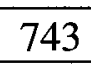 & 14 & 737.2 \\
\hline 15 & 5.65 & 5.8 & & & & & & 332.6 \\
\hline 15 & 6.01 & 6.38 & 125 & 0.14 & & 100 & 0.17 & 730.1 \\
\hline 15 & 5.68 & 5.85 & 836 & 5.61 & 5.83 & 849 & 5.74 & 843.5 \\
\hline 15 & 5.74 & 5.86 & 8 & 5.82 & 5.97 & 80 & 5.85 & 313.5 \\
\hline 15 & 5.90 & 5.86 & 805 & 5.94 & 5.87 & 797 & 5.89 & 801.1 \\
\hline 15 & 5.88 & 5.94 & 796 & 5.98 & 5.99 & 776 & 5.95 & 786.4 \\
\hline 15 & 5.72 & 5.82 & 836 & 5.74 & 5.87 & 827 & 5.79 & 830.4 \\
\hline
\end{tabular}

Table 3.2 (cont.) 


\begin{tabular}{|c|c|c|c|c|c|c|c|c|}
\hline \multirow[b]{3}{*}{ 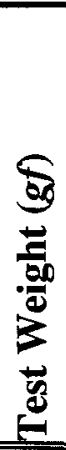 } & \multicolumn{6}{|c|}{ Measurement } & \multirow[b]{3}{*}{ 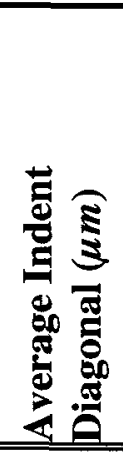 } & \multirow{3}{*}{ 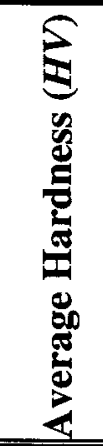 } \\
\hline & \multicolumn{3}{|c|}{1} & \multicolumn{3}{|c|}{2} & & \\
\hline & \multicolumn{2}{|c|}{ 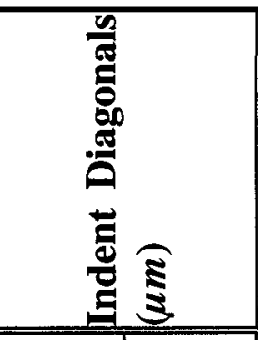 } & \multirow[t]{2}{*}{ 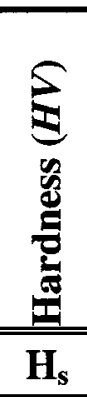 } & \multicolumn{2}{|c|}{ 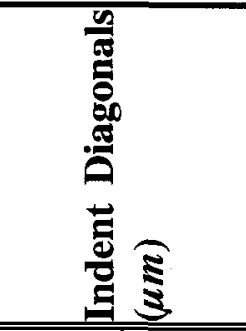 } & \multirow[t]{2}{*}{ 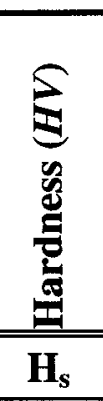 } & & \\
\hline $\mathbf{P}$ & $\mathbf{d}_{1}$ & $d_{2}$ & & $d_{1}$ & $\mathbf{d}_{2}$ & & d & $\mathbf{H}_{\mathrm{s}}$ \\
\hline 25 & 8.64 & 9.00 & 596 & 8.91 & 9.02 & 576 & 8.89 & 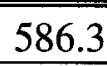 \\
\hline 25 & 8.76 & 9.11 & 581 & 8.87 & 9.00 & 581 & 8.94 & 580.7 \\
\hline 25 & 8.79 & 8.98 & 588 & 8.51 & 8.93 & 609 & 8.80 & 598.3 \\
\hline 25 & 7.95 & 8.04 & 725 & 7.89 & 8.04 & 731 & 7.98 & 728.0 \\
\hline 25 & 7.91 & 8.11 & 722 & 7.66 & 7.96 & 760 & 7.91 & 741.0 \\
\hline 25 & 7.64 & 7.96 & 762 & 7.64 & 7.91 & 767 & 7.79 & 764.4 \\
\hline 25 & 8.20 & 8.35 & 677 & 19 & 8.38 & 676 & 8.28 & 676.2 \\
\hline 25 & 8.03 & 7.98 & 723 & 7.73 & 7.91 & 758 & 7.91 & 740.5 \\
\hline 25 & 7.83 & 7.81 & 758 & 7.81 & 8.02 & 741 & 7.87 & 749.0 \\
\hline 25 & 7.86 & 7.89 & 748 & 7.75 & 7.93 & 754 & 7.86 & 750.9 \\
\hline 25 & 7.88 & 7.95 & 739 & 7.72 & 7.91 & 760 & 7.87 & 749.5 \\
\hline 25 & 7.84 & 8.05 & 734 & 7.81 & 7.64 & 778 & 7.84 & 755.2 \\
\hline 50 & 11.79 & 12.34 & 637 & 11.87 & 12.43 & 628 & 12.11 & 632.5 \\
\hline 50 & 11.34 & 11.83 & 691 & 11.83 & 11.85 & 661 & 11.71 & 675.9 \\
\hline 50 & 11.35 & 11.89 & 687 & 11.37 & 11.92 & 684 & 11.63 & 685.2 \\
\hline 50 & 11.22 & 11.20 & 738 & 11.14 & 11.58 & 718 & 11.29 & 728.1 \\
\hline 50 & 11.08 & 11.24 & 744 & 10.94 & 11.12 & 762 & 11.10 & 753.2 \\
\hline 50 & 11.54 & 11.45 & 702 & 11.52 & 11.43 & 704 & 11.49 & 702.9 \\
\hline 50 & 10.94 & 11.03 & 769 & 11.05 & 11.18 & 751 & 11.05 & 759.4 \\
\hline 50 & 10.73 & 11.02 & 784 & 10.97 & 11.02 & 767 & 10.94 & 775.4 \\
\hline 50 & 10.83 & 11.11 & 770 & 10.85 & 11.01 & 776 & 10.95 & 773.3 \\
\hline 50 & 10.99 & 10.91 & 773 & 10.89 & 11.03 & 772 & 10.96 & 772.6 \\
\hline 50 & 10.82 & 10.94 & 783 & 10.94 & 10.95 & 774 & 10.91 & 778.6 \\
\hline 50 & 10.74 & 10.91 & 791 & 10.78 & 11.03 & 780 & 10.87 & 785.4 \\
\hline
\end{tabular}

Table 3.2 (cont.) 


\begin{tabular}{|c|c|c|c|c|c|c|c|c|}
\hline \multirow[b]{3}{*}{ 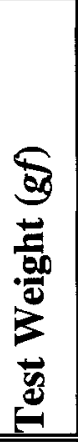 } & \multicolumn{6}{|c|}{ Measurement } & \multirow[b]{3}{*}{ 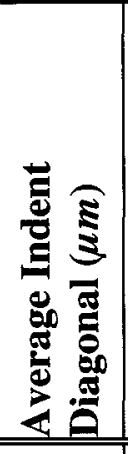 } & \multirow{3}{*}{ 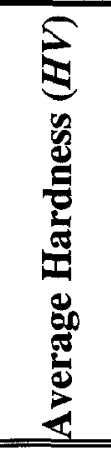 } \\
\hline & \multicolumn{3}{|c|}{1} & \multicolumn{3}{|c|}{2} & & \\
\hline & \multicolumn{2}{|c|}{ 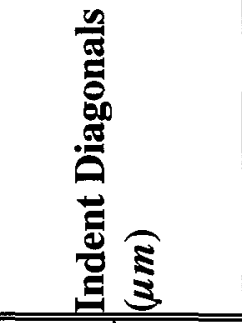 } & \multirow[t]{2}{*}{ 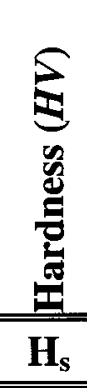 } & \multicolumn{2}{|c|}{ 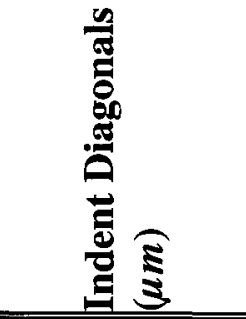 } & \multirow{2}{*}{ 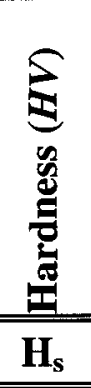 } & & \\
\hline $\mathbf{P}$ & $d_{1}$ & $\mathbf{d}_{2}$ & & $d_{1}$ & $d_{2}$ & & $d$ & $\mathbf{H}_{\mathrm{s}}$ \\
\hline 100 & 16.43 & 70 & 661 & 16.58 & 17.05 & 655 & 16.79 & $\bar{~} 657.6$ \\
\hline 100 & 16 & 16 & 672 & 3 & 1 & 685 & 3 & 678.5 \\
\hline 100 & 16 & 1677 & 679 & 16.33 & 16.90 & 672 & & 675.2 \\
\hline 100 & 15. & 15.89 & 748 & 15.79 & 16. & 72 & 5 & 737.9 \\
\hline 100 & 16 & 5 & 704 & 38 & 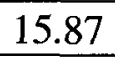 & 736 & 5 & 19.9 \\
\hline 100 & 15. & 16.08 & 742 & 15.73 & 16.02 & 73 & 84 & 739.1 \\
\hline 100 & 15.71 & 16.11 & 733 & 15.95 & 15.98 & 72 & 94 & 730.1 \\
\hline 100 & 158 & 16.0 & 728 & 15.87 & 16. & 7 & 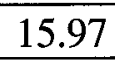 & 727.3 \\
\hline 100 & 15.75 & 15.75 & 748 & 15.73 & 15.93 & 740 & 15.79 & 743.8 \\
\hline 100 & 15.37 & 15.92 & 758 & 15.86 & 15.98 & 73 & 15.78 & 744.5 \\
\hline 100 & 15.6 & 15.93 & 743 & 15.67 & 15.64 & 75 & .73 & 749.9 \\
\hline 100 & 15.51 & 15.69 & 762 & 15.42 & 15.84 & 759 & 15.62 & 760.5 \\
\hline 100 & 15.68 & 16.18 & 731 & 15.68 & 15.82 & 747 & 15.84 & 739.1 \\
\hline 200 & 22.92 & 23.25 & 696 & 23.18 & 23.69 & 675 & 23.26 & 685.5 \\
\hline 200 & 23.32 & 23.51 & 676 & 22.75 & 23.08 & 706 & 23.17 & 691.1 \\
\hline 200 & 23.07 & 23.17 & 694 & 22.84 & 23.19 & 700 & 23.07 & 697.0 \\
\hline 200 & 22.64 & 23.06 & 710 & 22.89 & 23.33 & 694 & 22.98 & 702.3 \\
\hline 200 & 22.99 & 23.22 & 695 & 22.87 & 23.42 & 692 & 23.13 & 693.5 \\
\hline 200 & 22.57 & 22.79 & 721 & 22.55 & 22.93 & 717 & 22.71 & 719.1 \\
\hline 200 & 23.04 & 23.24 & 693 & 23.02 & 22.99 & 701 & 23.07 & 696.7 \\
\hline 200 & 23.21 & 23.07 & 693 & 23.11 & 23.31 & 688 & 23.18 & 690.5 \\
\hline
\end{tabular}

Table 3.2 (cont.) 


\begin{tabular}{|c|c|c|}
\hline Test Load & $\mathbf{5 7 X}$ & X7 \\
\hline $\mathbf{3 0} \mathbf{~ m N}$ & T0_57X & - \\
\hline $\mathbf{2 0} \mathbf{m N}$ & T1_57X to T4_57X & T1_X7 to T4_X7 \\
\hline
\end{tabular}

Table 3.3: Nomenclature of nano-indentation hardness tests performed on test dies 57X and X7

\begin{tabular}{|c|c|c|}
\hline & T0_57X & $\begin{array}{c}\text { T1_57X to T4_57X } \\
\text { T1_X7 to T4_X7 }\end{array}$ \\
\hline Maximum load & $30 \mathrm{mN}$ & $20 \mathrm{mN}$ \\
\hline Loading rate & $60 \mathrm{mN} / \mathrm{min}$ & $40 \mathrm{mN} / \mathrm{min}$ \\
\hline Unloading rate & $60 \mathrm{mN} / \mathrm{min}$ & $40 \mathrm{mN} / \mathrm{min}$ \\
\hline Poisson's ratio & 0.25 & 0.25 \\
\hline
\end{tabular}

Table 3.4: Nano-indentation hardness test input parameters for trial 0 on $57 \mathrm{X}$ 


\begin{tabular}{|c|c|c|}
\hline Time $(\boldsymbol{s})$ & $\mathbf{P}_{\mathbf{d}}(\mathbf{n m})$ & $\mathbf{F}_{\mathbf{n}}(\boldsymbol{m} \boldsymbol{N})$ \\
\hline 0 & 0 & 0 \\
\hline 0.0662 & 2.1727 & 0.0015 \\
\hline 0.1324 & 5.6769 & 0.0015 \\
\hline 0.1986 & 10.5688 & 0.0001 \\
\hline 0.2648 & 18.2302 & -0.0018 \\
\hline 0.3311 & 23.9314 & -0.0024 \\
\hline 0.3973 & 27.2036 & -0.0014 \\
\hline 0.4635 & 28.9556 & 0 \\
\hline 0.5297 & 30.9009 & 0.0024 \\
\hline 0.5959 & 33.2185 & 0.0062 \\
\hline 0.6621 & 34.0506 & 0.0105 \\
\hline 0.7283 & 34.0929 & 0.0151 \\
\hline 0.7945 & 33.1872 & 0.0201 \\
\hline 0.8607 & 34.1445 & 0.0241 \\
\hline 0.9269 & 35.3469 & 0.0278 \\
\hline 0.9931 & 36.6203 & 0.031 \\
\hline 1.0594 & 34.9633 & 0.038 \\
\hline 1.1256 & 34.4238 & 0.0435 \\
\hline 1.1918 & 36.724 & 0.0454 \\
\hline 1.258 & 36.9913 & 0.0492 \\
\hline 1.3242 & 37.1003 & 0.0537 \\
\hline 1.3904 & 37.6311 & 0.0589 \\
\hline 1.4566 & 38.9785 & 0.0619 \\
\hline 1.5228 & 39.6988 & 0.0651 \\
\hline 1.589 & 38.5472 & 0.0704 \\
\hline 1.6552 & 39.2781 & 0.0749 \\
\hline 1.7215 & 39.9735 & 0.0795 \\
\hline 1.7877 & 39.2757 & 0.0846 \\
\hline 1.8539 & 38.5597 & 0.091 \\
\hline 1.9201 & 38.0777 & 0.0971 \\
\hline & & \\
\hline
\end{tabular}




\begin{tabular}{|c|c|c|c|c|c|}
\hline \multirow[b]{2}{*}{ Main results } & \multicolumn{5}{|c|}{ Trial } \\
\hline & $\mathbf{0}$ & 1 & 2 & 3 & 4 \\
\hline HV (Vickers) & 2417.2 & 2567.5 & 2472.6 & 2671.1 & 2352.9 \\
\hline $\mathbf{H}(\mathbf{M P a})$ & 26084 & 27706 & 26682 & 28824 & 25390 \\
\hline $\mathbf{E}(G P a)$ & 269.76 & 280.25 & 296.36 & 310.15 & 286.02 \\
\hline \multicolumn{6}{|l|}{ Hypothesis } \\
\hline $\mathbf{v}$ & 0.25 & 0.25 & 0.25 & 0.25 & 0.25 \\
\hline \multicolumn{6}{|l|}{ Additional results } \\
\hline$P_{m}(m N)$ & 30.1 & 20.08 & 20.08 & 20.08 & 20.06 \\
\hline$h_{m}(n m)$ & 294.95 & 232.29 & 231.71 & 224.45 & 236.21 \\
\hline$S(\mathrm{mN} / \mathrm{nm})$ & 0.2883 & 0.2355 & 0.2508 & 0.25 & 0.2499 \\
\hline $\mathbf{h}_{\mathrm{c}}(n \mathrm{~nm})$ & 215.21 & 167.32 & 170.79 & 163.77 & 175.31 \\
\hline$h_{\mathrm{r}}(\mathrm{nm})$ & 190.55 & 147.04 & 151.64 & 144.15 & 155.95 \\
\hline$h_{p}(n m)$ & 147.47 & 110.71 & 117.06 & 105.78 & 122.56 \\
\hline $\mathbf{m}$ & 1.36 & 1.38 & 1.39 & 1.44 & 1.4 \\
\hline$\varepsilon$ & 0.76 & 0.76 & 0.76 & 0.76 & 0.76 \\
\hline $\mathbf{A}_{\mathrm{s}}\left(n m^{2}\right)$ & 1153845 & 724645.1 & 752645.6 & 696520.2 & 789916.8 \\
\hline
\end{tabular}

Table 3.6: Nano-indentation results for trials 0 to 4 on $57 X$ 


\begin{tabular}{|c|c|c|c|c|}
\hline \multirow[b]{2}{*}{ Main results } & \multicolumn{4}{|c|}{ Trial } \\
\hline & 1 & 2 & 3 & 4 \\
\hline HV (Vickers) & 2466.6 & 2613.4 & 2372.4 & 2260.1 \\
\hline $\mathbf{H}(M P a)$ & 26617 & 28201 & 25601 & 24389 \\
\hline $\mathbf{E}(G P a)$ & 296.27 & 313.66 & 311.2 & 299.3 \\
\hline \multicolumn{5}{|l|}{ Hypothesis } \\
\hline $\boldsymbol{v}$ & 0.25 & 0.25 & 0.25 & 0.25 \\
\hline \multicolumn{5}{|l|}{ Additional results } \\
\hline$P_{m}(m N)$ & 20.11 & 20.07 & 20.11 & 20.14 \\
\hline $\mathbf{h}_{\mathrm{m}}(\mathrm{nm})$ & 232.03 & 224.95 & 231.86 & 237.19 \\
\hline$S(\mathrm{mN} / \mathrm{nm})$ & 0.2512 & 0.2549 & 0.2662 & 0.2647 \\
\hline $\mathbf{h}_{\mathrm{c}}(\mathrm{nm})$ & 171.12 & 165.71 & 174.8 & 179.55 \\
\hline $\mathbf{h}_{\mathrm{r}}(n m)$ & 152 & 146.22 & 156.31 & 161.14 \\
\hline $\mathbf{h}_{\mathrm{p}}(\mathrm{nm})$ & 119.01 & 107.28 & 123.44 & 127.37 \\
\hline $\mathbf{m}$ & 1.38 & 1.47 & 1.44 & 1.41 \\
\hline$\varepsilon$ & 0.76 & 0.75 & 0.76 & 0.76 \\
\hline $\mathbf{A}_{\mathrm{s}}\left(n m^{2}\right)$ & 755402.4 & 711819.7 & 785617.9 & 825588.3 \\
\hline
\end{tabular}

Table 3.7: Nano-indentation results for trials 1 to 4 on X7

\begin{tabular}{|c|c|c|c|c|c|}
\hline \multirow[b]{2}{*}{ Die } & \multicolumn{4}{|c|}{ Trial } & \multirow{2}{*}{$\begin{array}{c}\text { Average } \\
\text { HV }\end{array}$} \\
\hline & 1 & 2 & 3 & 4 & \\
\hline $57 X$ & 2567.5 & 2472.6 & 2671.1 & 2352.9 & 2516.0 \\
\hline $\mathbf{X 7}$ & 2466.6 & 2613.4 & 2372.4 & 2260.1 & 2428.1 \\
\hline
\end{tabular}

Table 3.8: Summary of hardness values obtained from nano-indentation testing at a load of $20 \mathrm{mN}$ 


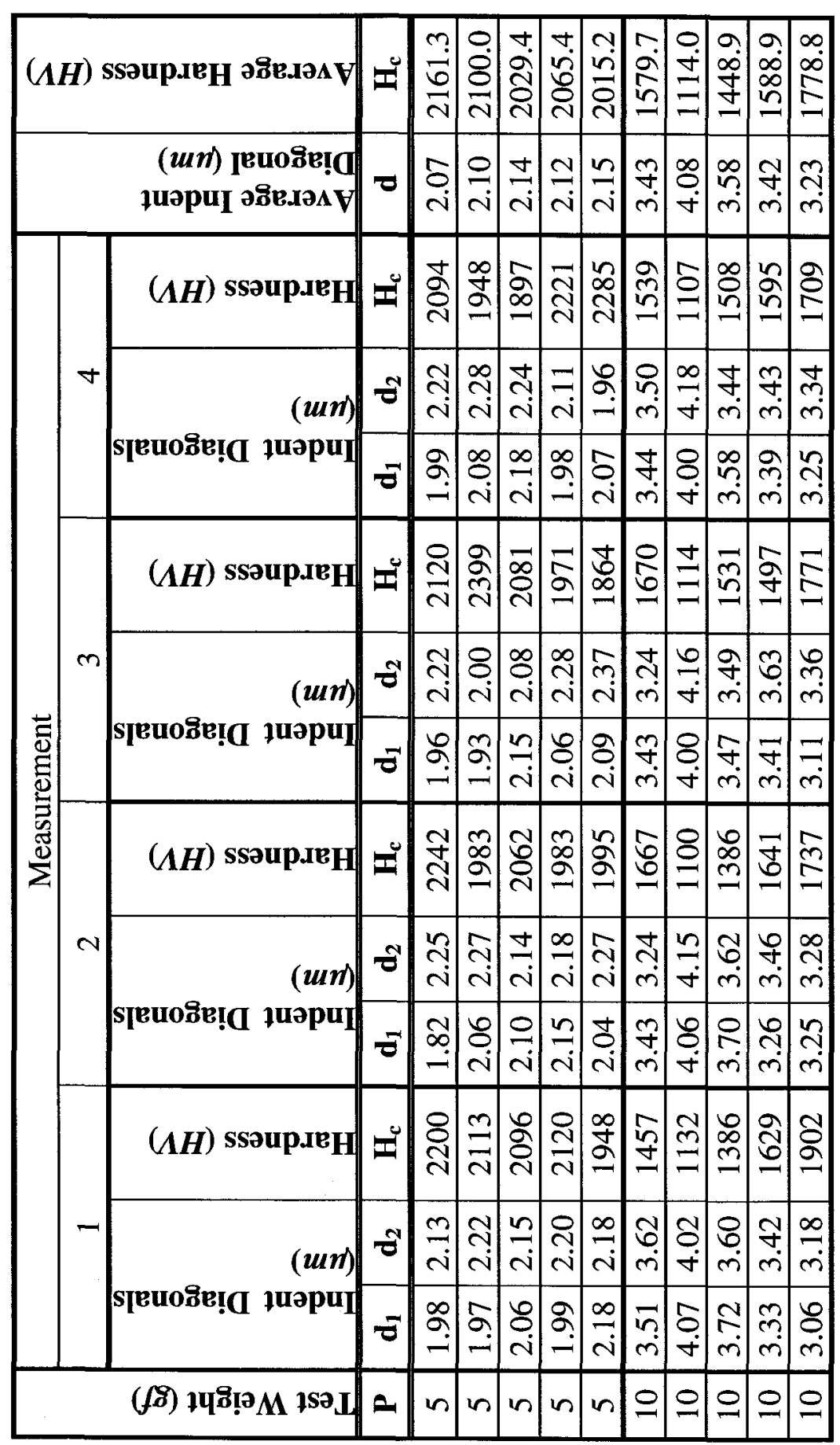

 


\begin{tabular}{|c|c|c|c|c|c|c|c|c|}
\hline \multirow[b]{3}{*}{ 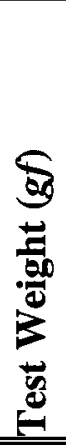 } & \multicolumn{6}{|c|}{ Measurement } & \multirow[b]{3}{*}{ 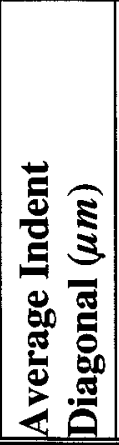 } & \multirow{3}{*}{ 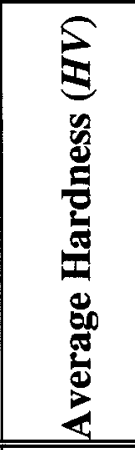 } \\
\hline & \multicolumn{3}{|c|}{1} & \multicolumn{3}{|c|}{2} & & \\
\hline & \multicolumn{2}{|c|}{ 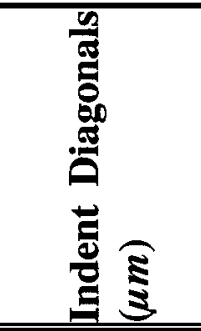 } & \multirow[t]{2}{*}{ 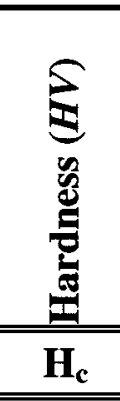 } & \multicolumn{2}{|c|}{ 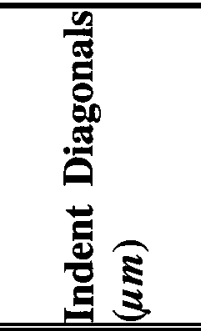 } & \multirow[t]{2}{*}{ 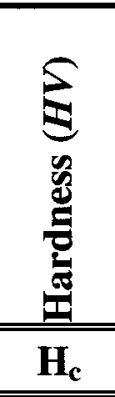 } & & \\
\hline $\mathbf{P}$ & $\mathbf{d}_{1}$ & $\mathbf{d}_{\mathbf{2}}$ & & $\mathbf{d}_{1}$ & $\mathbf{d}_{\mathbf{2}}$ & & d & $\mathbf{H}_{\mathbf{c}}$ \\
\hline 15 & 3.94 & 4.16 & 1692 & 4.07 & 4.09 & 1668 & 4.07 & 1683.3 \\
\hline 15 & 4.07 & 4.18 & 1637 & 4.01 & 4.04 & 1717 & 4.08 & 1675.1 \\
\hline 15 & 4.26 & 4.14 & 1575 & 4.30 & 4.29 & 1507 & 4.25 & 1541.8 \\
\hline 15 & 4.24 & 4.34 & 1510 & 4.24 & 4.27 & 1537 & 4.27 & 1523.8 \\
\hline 15 & 4.27 & 4.26 & 1528 & 4.23 & 4.22 & 1561 & 4.25 & 1543.6 \\
\hline 25 & 5.70 & 5.85 & 1390 & 5.74 & 5.71 & 1415 & 5.75 & 1402.2 \\
\hline 25 & 5.88 & 5.82 & 1355 & 5.89 & 5.70 & 1379 & 5.82 & 1367.5 \\
\hline 25 & 5.62 & 5.72 & 1443 & 5.64 & 5.53 & 1486 & 5.63 & 1463.9 \\
\hline 25 & 5.79 & 5.85 & 1367 & 5.73 & 5.70 & 1420 & 5.77 & 1393.7 \\
\hline 25 & 5.93 & 6.01 & 1300 & 5.81 & 5.96 & 1339 & 5.93 & 1319.5 \\
\hline
\end{tabular}

Table 3.9 (cont.) 


\begin{tabular}{|c|c|c|c|c|c|c|c|c|}
\hline \multirow[b]{3}{*}{ 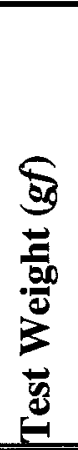 } & \multicolumn{6}{|c|}{ Measurement } & \multirow[b]{3}{*}{ 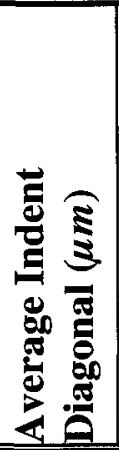 } & \multirow{3}{*}{ 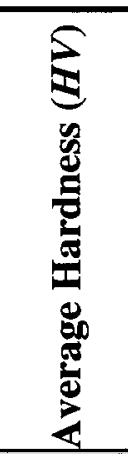 } \\
\hline & \multicolumn{3}{|c|}{1} & \multicolumn{3}{|c|}{2} & & \\
\hline & \multicolumn{2}{|c|}{ 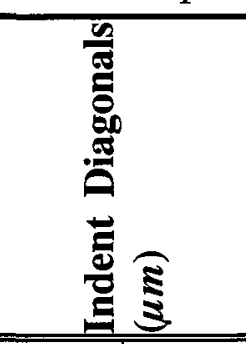 } & \multirow[t]{2}{*}{ 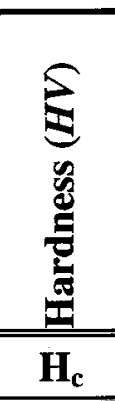 } & \multicolumn{2}{|c|}{ 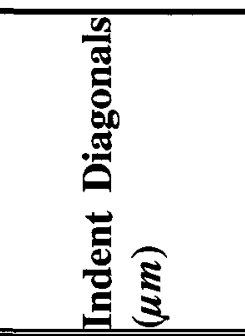 } & \multirow[t]{2}{*}{ 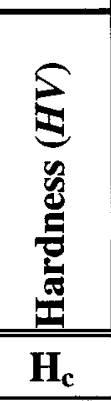 } & & \\
\hline $\mathbf{P}$ & $d_{1}$ & $\mathbf{d}_{2}$ & & $d_{1}$ & $d_{2}$ & & d & $\mathbf{H}_{\mathbf{c}}$ \\
\hline 50 & 9.67 & 9.71 & 987 & 9.65 & 9.62 & 999 & 9.66 & 993.1 \\
\hline 50 & 9.32 & 9.34 & 1065 & 9.36 & 9.40 & 1054 & 9.36 & 1059.5 \\
\hline 50 & 9.44 & 9.51 & 1033 & 9.49 & 9.60 & 1018 & 9.51 & 1025.2 \\
\hline 50 & 9.46 & 9.44 & 1038 & 9.50 & 9.55 & 1022 & 9.49 & 1030.1 \\
\hline 50 & 9.49 & 9.56 & 1021 & 9.56 & 9.55 & 1016 & 9.54 & 1018.8 \\
\hline 100 & 14.85 & 14.73 & 848 & 14.87 & 14.58 & 855 & 14.76 & 851.5 \\
\hline 100 & 14.39 & 14.02 & 919 & 14.43 & 14.18 & 906 & 14.26 & 912.6 \\
\hline 100 & 14.37 & 14.33 & 901 & 14.37 & 14.46 & 892 & 14.38 & 896.5 \\
\hline 100 & 14.45 & 14.31 & 897 & 14.47 & 14.26 & 898 & 14.37 & 897.7 \\
\hline 100 & 14.40 & 14.53 & 886 & 14.37 & 14.28 & 904 & 14.40 & 894.9 \\
\hline
\end{tabular}

Table 3.9 (cont.) 


\begin{tabular}{|c|c|c|c|c|c|c|c|c|}
\hline \multirow[b]{3}{*}{ 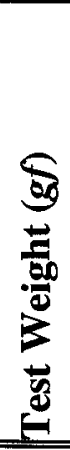 } & \multicolumn{6}{|c|}{ Measurement } & \multirow[b]{3}{*}{ 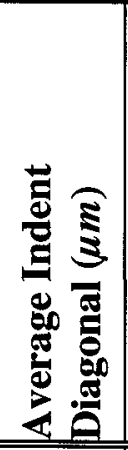 } & \multirow{3}{*}{ 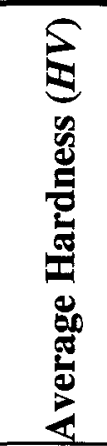 } \\
\hline & \multicolumn{3}{|c|}{1} & \multicolumn{3}{|c|}{2} & & \\
\hline & \multicolumn{2}{|c|}{ 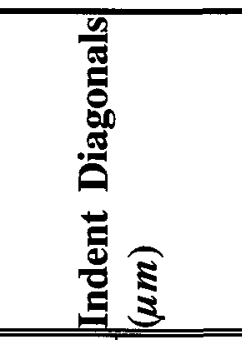 } & \multirow[t]{2}{*}{ 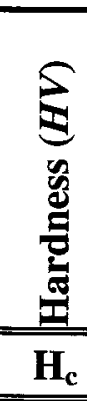 } & \multicolumn{2}{|c|}{ 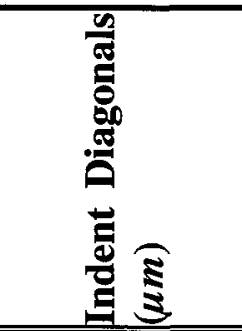 } & \multirow[t]{2}{*}{ 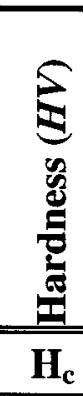 } & & \\
\hline $\mathbf{P}$ & $d_{1}$ & $d_{2}$ & & $d_{1}$ & $d_{2}$ & & $\overline{\text { d }}$ & $\overline{\mathbf{H}_{\mathrm{c}}}$ \\
\hline 200 & 21.17 & 21.19 & 827 & 21.13 & 21.10 & 832 & 21.15 & 829.3 \\
\hline 200 & 21.13 & 21.15 & 830 & 21.15 & 21.20 & 827 & 21.16 & 828.5 \\
\hline 200 & 21.08 & 21. & 831 & 88 & 21.31 & 82 & 21.16 & 828.3 \\
\hline 200 & 21.17 & 21.13 & 829 & 21.25 & 21.19 & 824 & 21.19 & 826.4 \\
\hline 200 & 21.06 & 20.98 & 840 & 21.04 & 21.01 & 839 & 21.02 & 839.2 \\
\hline 300 & 27.47 & 27.01 & 750 & 27.27 & 27.21 & 750 & 27.24 & 749.7 \\
\hline 300 & 27.48 & 27.77 & 729 & 27.41 & 27.80 & 730 & 27.62 & 729.5 \\
\hline 300 & 26.48 & 26.69 & 787 & 26.17 & 26.32 & 808 & 26.42 & 797.3 \\
\hline 500 & 34.50 & 34.88 & 770 & 34.80 & 34.79 & 766 & 34.74 & 768.2 \\
\hline 500 & 35.57 & 35.57 & 733 & 35.73 & 35.35 & 734 & 35.56 & 733.5 \\
\hline 500 & 35.55 & 35.86 & 727 & 35.66 & 35.77 & 727 & 35.71 & 727.1 \\
\hline
\end{tabular}

Table 3.9 (cont.) 


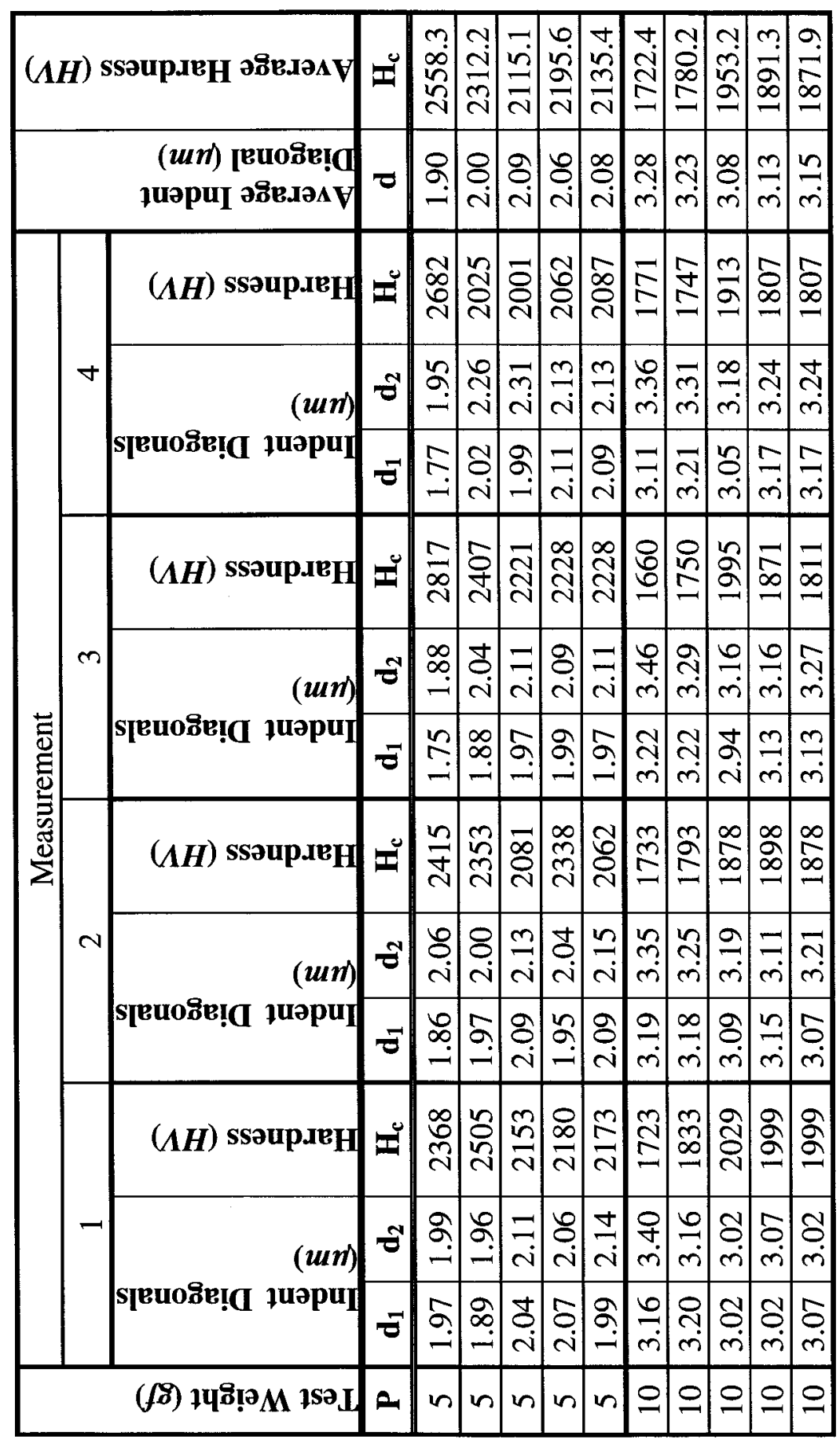




\begin{tabular}{|c|c|c|c|c|c|c|c|c|}
\hline \multirow[b]{3}{*}{ 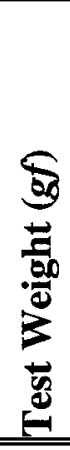 } & \multicolumn{6}{|c|}{ Measurement } & \multirow[b]{3}{*}{ 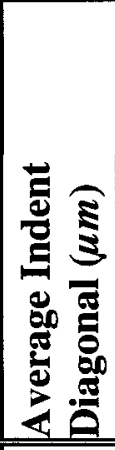 } & \multirow{3}{*}{ 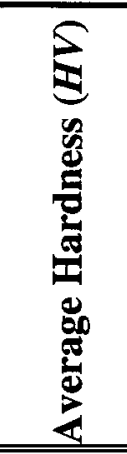 } \\
\hline & \multicolumn{3}{|c|}{1} & \multicolumn{3}{|c|}{2} & & \\
\hline & \multicolumn{2}{|c|}{ 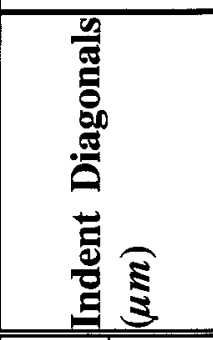 } & \multirow[t]{2}{*}{ 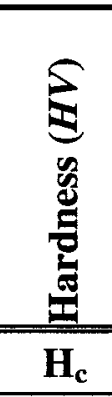 } & \multicolumn{2}{|c|}{ 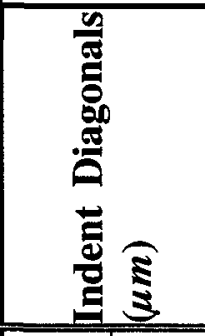 } & \multirow[t]{2}{*}{ 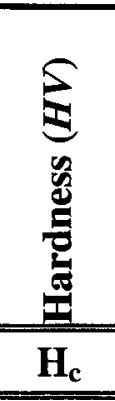 } & & \\
\hline $\mathbf{P}$ & $\mathbf{d}_{1}$ & $\mathbf{d}_{2}$ & & $d_{1}$ & $\mathbf{d}_{2}$ & & d & $\mathbf{H}_{\mathbf{c}}$ \\
\hline 15 & 4.11 & 4.22 & 1602 & 4.13 & 4.09 & 1648 & 4.14 & 1624.9 \\
\hline 15 & 4.13 & 4.21 & 1600 & 4.22 & 4.19 & 1575 & 4.19 & 1586.3 \\
\hline 15 & 4.22 & 4.21 & 1565 & 4.14 & 4.11 & 1635 & 4.17 & 1599.6 \\
\hline 15 & 4.09 & 4.17 & 1632 & 4.22 & 4.17 & 1585 & 4.16 & 1605.4 \\
\hline 15 & 4.09 & 4.06 & 1674 & 4.16 & 4.22 & 1585 & 4.13 & 1628.8 \\
\hline 25 & 5.36 & 5.44 & 1589 & 5.38 & 5.43 & 1585 & 5.40 & 1588.4 \\
\hline 25 & 5.52 & 5.57 & 1507 & 5.49 & 5.56 & 1518 & 5.54 & 1513.2 \\
\hline 25 & 5.82 & 5.81 & 1370 & 5.74 & 5.81 & 1390 & 5.80 & 1380.5 \\
\hline 25 & 5.47 & 5.37 & 1578 & 5.41 & 5.42 & 1582 & 5.42 & 1579.6 \\
\hline 25 & 5.48 & 5.46 & 1550 & 5.43 & 5.43 & 1572 & 5.45 & 1560.8 \\
\hline
\end{tabular}

Table 3.10 (cont.) 


\begin{tabular}{|c|c|c|c|c|c|c|c|c|}
\hline \multirow[b]{3}{*}{ 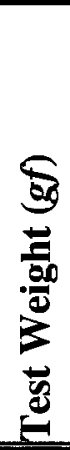 } & \multicolumn{6}{|c|}{ Measurement } & \multirow[b]{3}{*}{ 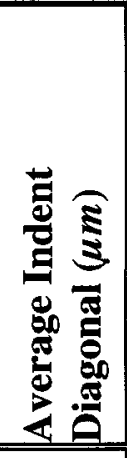 } & \multirow{3}{*}{ 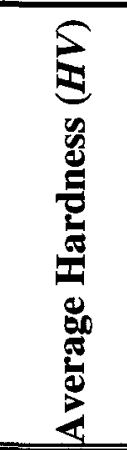 } \\
\hline & \multicolumn{3}{|c|}{1} & \multicolumn{3}{|c|}{2} & & \\
\hline & \multicolumn{2}{|c|}{ 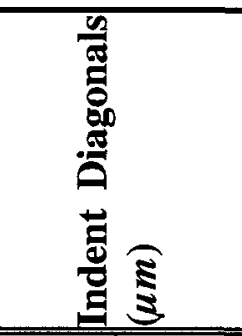 } & \multirow[t]{2}{*}{ 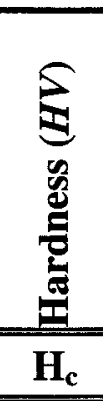 } & \multicolumn{2}{|c|}{ 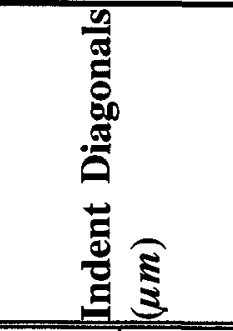 } & \multirow[t]{2}{*}{ 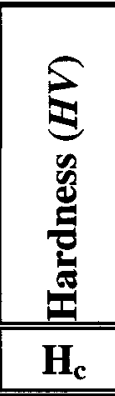 } & & \\
\hline $\mathbf{P}$ & $d_{1}$ & $\mathbf{d}_{2}$ & & $d_{1}$ & $\mathbf{d}_{2}$ & & d & $\mathbf{H}_{\mathrm{c}}$ \\
\hline 50 & 9.26 & 9.27 & 1080 & 9.27 & 9.26 & 1081 & 9.27 & 1080.1 \\
\hline 50 & 9.10 & 9.11 & 1119 & 9.03 & 9.08 & 1131 & 9.08 & 1124.6 \\
\hline 50 & 9.12 & 9.22 & 1103 & 9.09 & 9.22 & 1107 & 9.16 & 1104.4 \\
\hline 50 & 9.06 & 9.21 & 1111 & 9.13 & 9.07 & 1120 & 9.12 & 1115.4 \\
\hline 50 & 9.41 & 9.32 & 1057 & 9.41 & 9.52 & 1035 & 9.42 & 1046.0 \\
\hline 100 & 13.36 & 12.83 & 1082 & 13.49 & 12.77 & 1075 & 13.11 & 1078.5 \\
\hline 100 & 13.86 & 13.77 & 972 & 13.86 & 13.73 & 974 & 13.81 & 973.0 \\
\hline 100 & 13.48 & 13.78 & 998 & 13.72 & 13.89 & 973 & 13.72 & 985.5 \\
\hline 100 & 13.54 & 13.52 & 1013 & 13.90 & 13.83 & 965 & 13.70 & 988.4 \\
\hline 100 & 13.42 & 13.69 & 1009 & 13.52 & 13.50 & 1017 & 13.53 & 1012.6 \\
\hline
\end{tabular}

Table 3.10 (cont.) 


\begin{tabular}{|c|c|c|c|c|c|c|c|c|}
\hline \multirow[b]{3}{*}{ 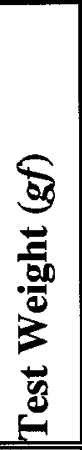 } & \multicolumn{6}{|c|}{ Measurement } & \multirow[b]{3}{*}{ 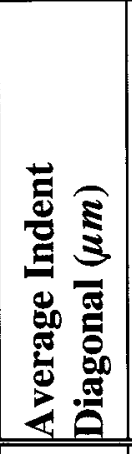 } & \multirow{3}{*}{ 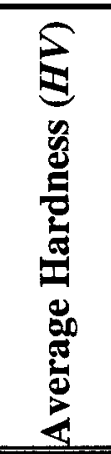 } \\
\hline & \multicolumn{3}{|c|}{1} & \multicolumn{3}{|c|}{2} & & \\
\hline & \multicolumn{2}{|c|}{ 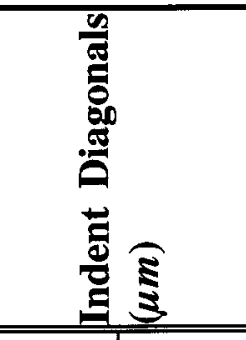 } & \multirow[t]{2}{*}{ 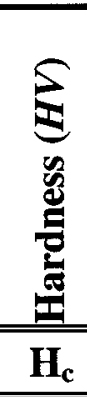 } & \multicolumn{2}{|c|}{ 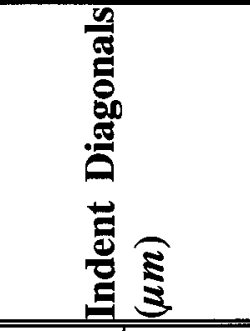 } & \multirow[t]{2}{*}{ 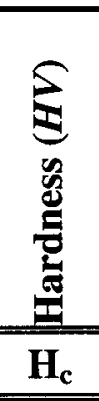 } & & \\
\hline $\mathbf{P}$ & $\mathbf{d}_{1}$ & $\mathbf{d}_{2}$ & & $d_{1}$ & $\mathbf{d}_{2}$ & & d & $\mathbf{H}_{\mathrm{c}}$ \\
\hline 200 & 20.23 & 20.73 & 884 & 20.61 & 21.23 & 848 & 20.70 & 865.6 \\
\hline 200 & 20.41 & 20.84 & 872 & 20.79 & 20.84 & 856 & 20.72 & 863.9 \\
\hline 200 & 20.95 & 20.83 & 850 & 20.90 & 21.05 & 843 & 20.93 & 846.4 \\
\hline 200 & 20.59 & 20.68 & 871 & 20.64 & 20.73 & 866 & 20.66 & 868.9 \\
\hline 200 & 20.65 & 20.64 & 870 & 20.59 & 20.72 & 869 & 20.65 & 869.7 \\
\hline 300 & 26.30 & 26.39 & 802 & 26.47 & 26.19 & 802 & 26.34 & 802.0 \\
\hline 300 & 26.16 & 26.23 & 811 & 26.40 & 26.22 & 804 & 26.25 & 807.2 \\
\hline 300 & 25.74 & 25.96 & 833 & 26.42 & 26.22 & 803 & 26.09 & 817.6 \\
\hline 500 & 34.15 & 34.21 & 794 & 34.06 & 34.12 & 798 & 34.14 & 795.7 \\
\hline 500 & 34.53 & 34.22 & 785 & 34.48 & 34.35 & 783 & 34.40 & 783.8 \\
\hline 500 & 34.18 & 34.18 & 794 & 34.32 & 34.52 & 783 & 34.30 & 788.1 \\
\hline
\end{tabular}

Table 3.10 (cont.) 


\begin{tabular}{|c|c|}
\hline Motor speed & $1100 \mathrm{rpm}$ \\
\hline Test duration & $120 \mathrm{~s}$ \\
\hline Ball diameter & $25.38 \mathrm{~mm}$ \\
\hline Abrasive & 0.1 micron (bleu) diamond solution \\
\hline
\end{tabular}

Table 3.11: Calotest paramters

\begin{tabular}{|c|c|c|}
\hline & $\mathbf{5 7 X}$ & $\mathbf{X 7}$ \\
\hline \hline $\mathbf{x}(\boldsymbol{\mu m})$ & 97.95 & 116.8 \\
\hline $\mathbf{y}(\boldsymbol{\mu m})$ & 565.1 & 563.2 \\
\hline Diameter, D $(\mathrm{mm})$ & 25.38 & 25.38 \\
\hline Thickness, t $(\boldsymbol{\mu m})$ & 2.18 & 2.59 \\
\hline
\end{tabular}

Table 3.12: Calotest crater measurements and thicknesses of $57 X$ and $X 7$ 


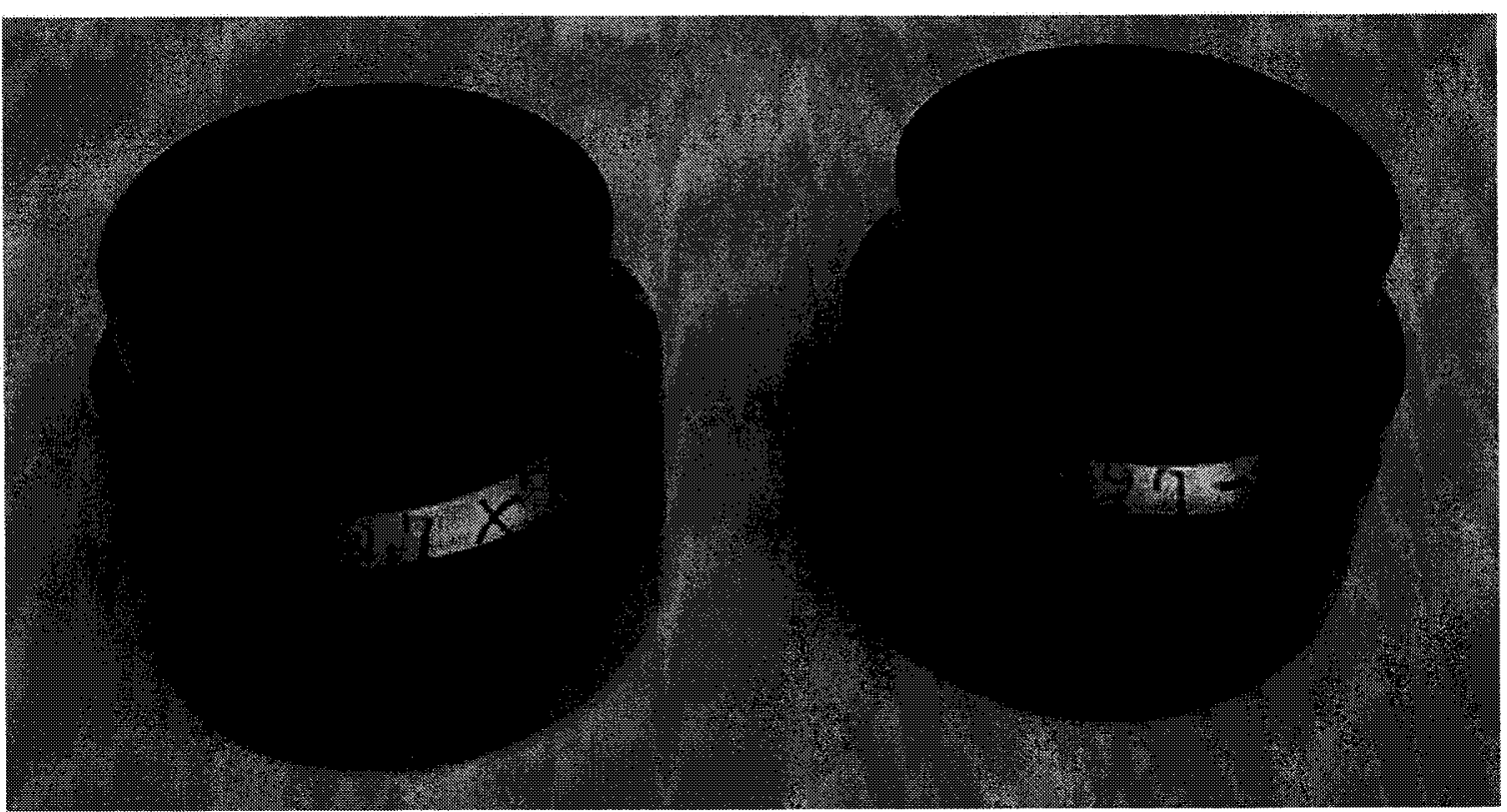

Figure 3.1: Test dies 57X and $X 7$ polished to mirror-like surface 


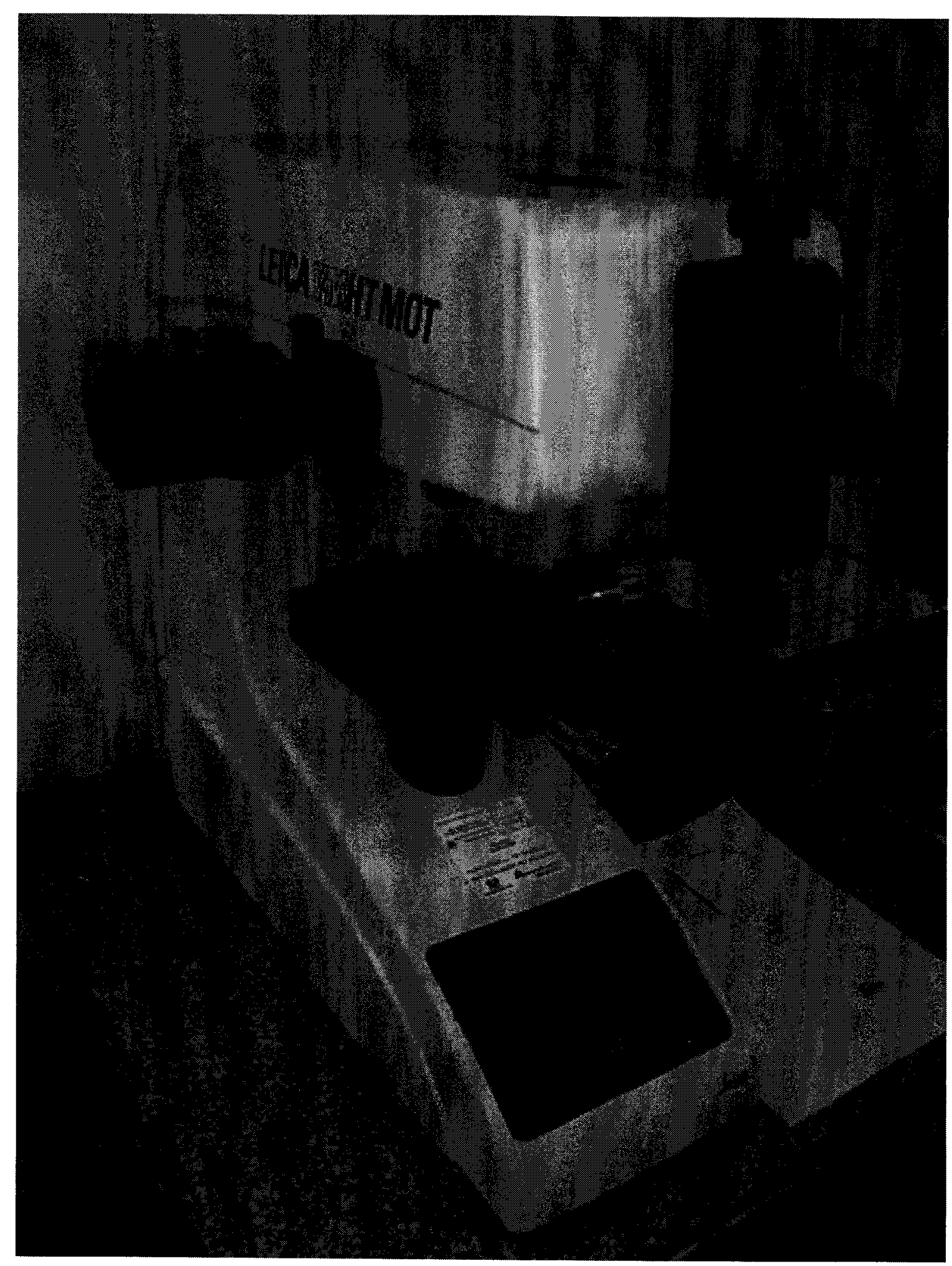

Figure 3.2: Micro-indentation apparatus 


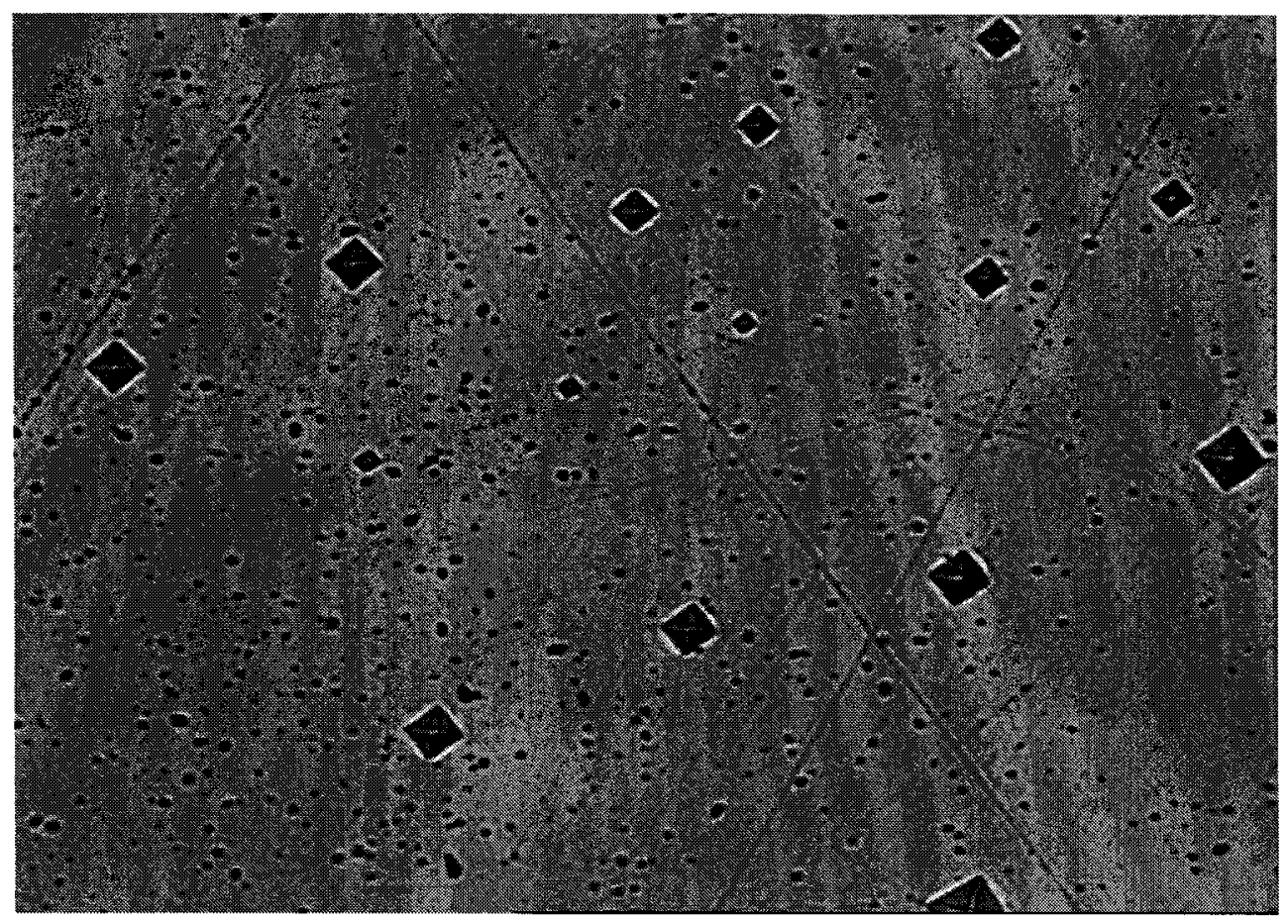

Figure 3.3: Sample micro-indentation test field from uncaoted 57X

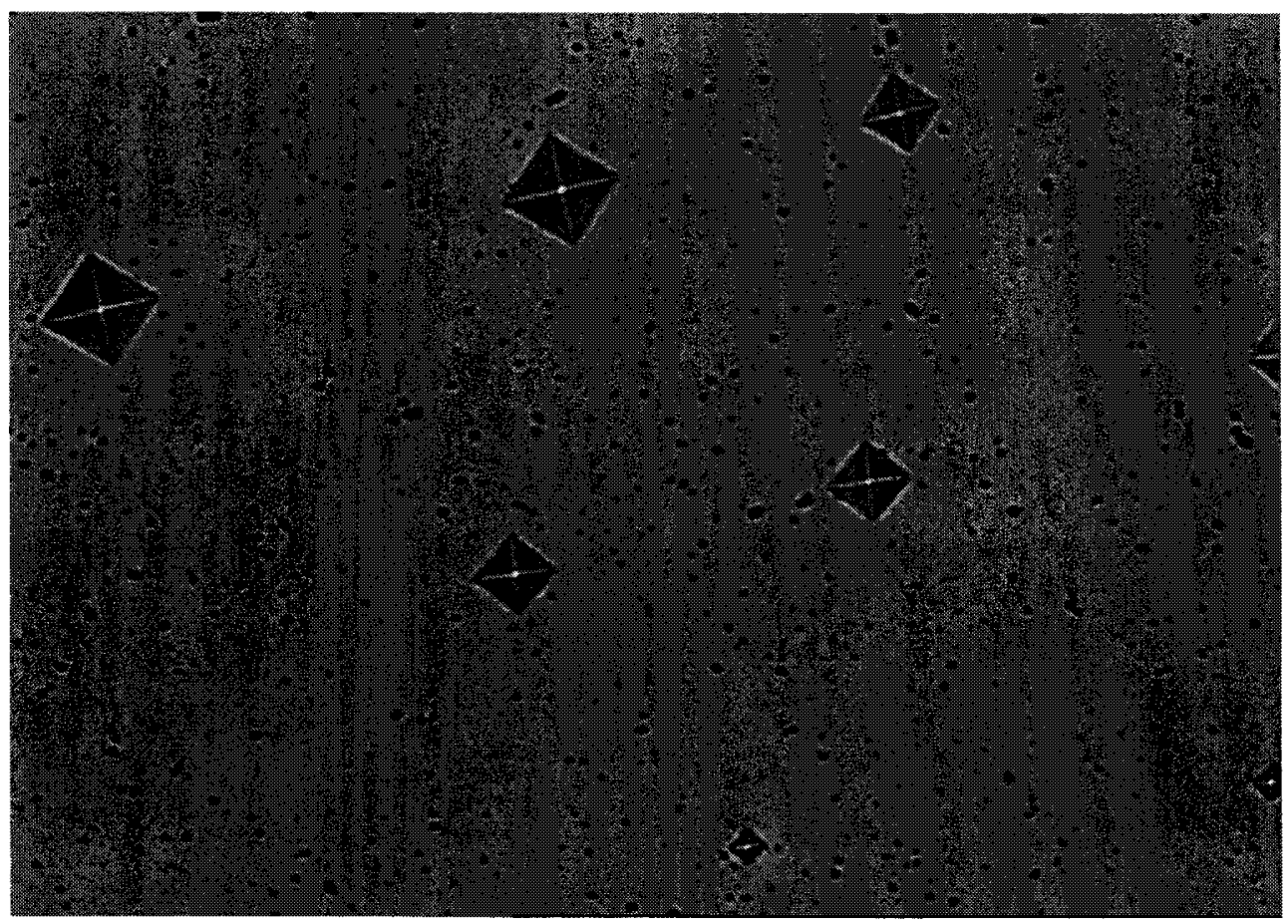

Figure 3.4: Sample micro-indentation test field from uncoated X7 


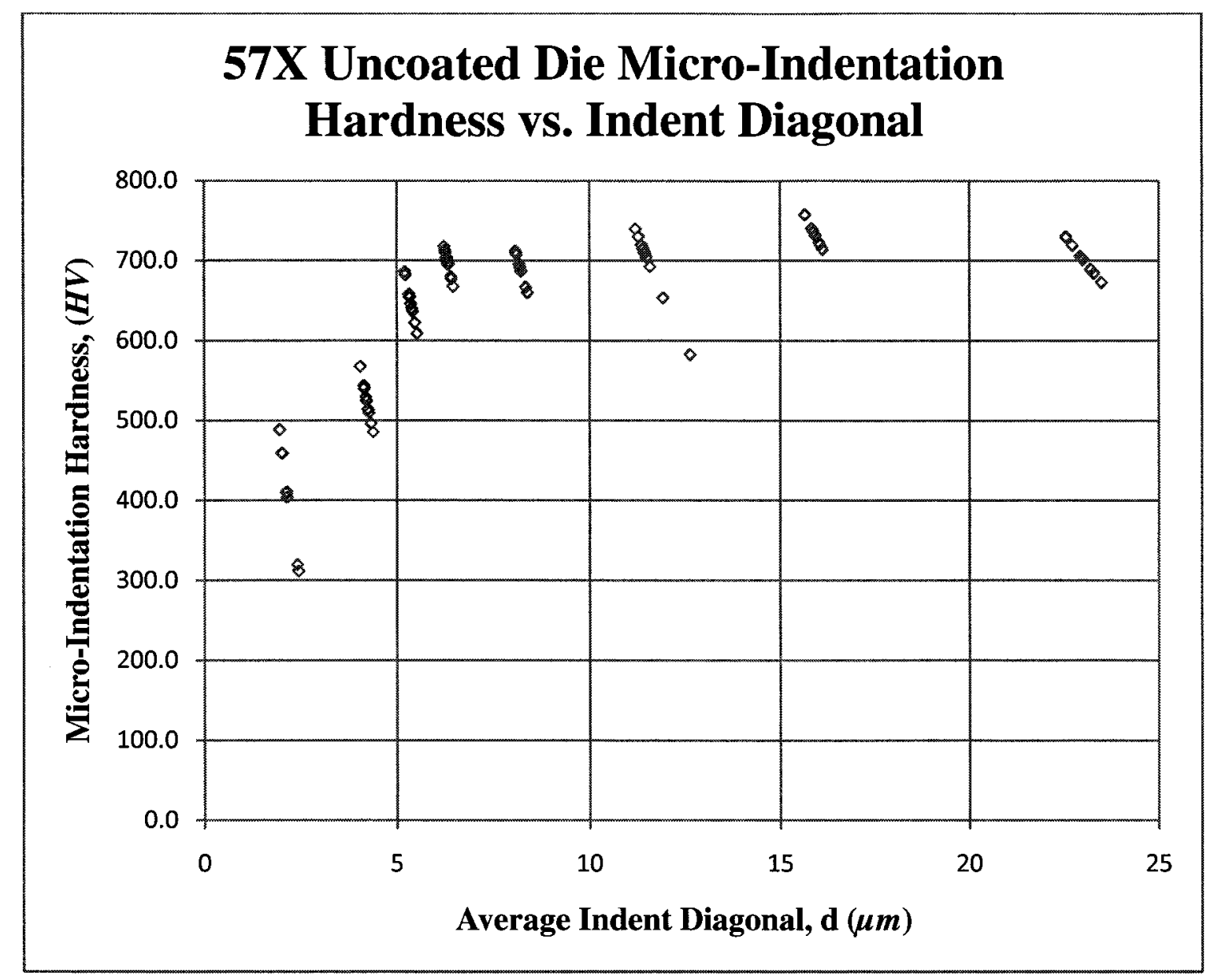

Figure 3.5: Measured substrate hardness of 57X displayed against indent diagonal 


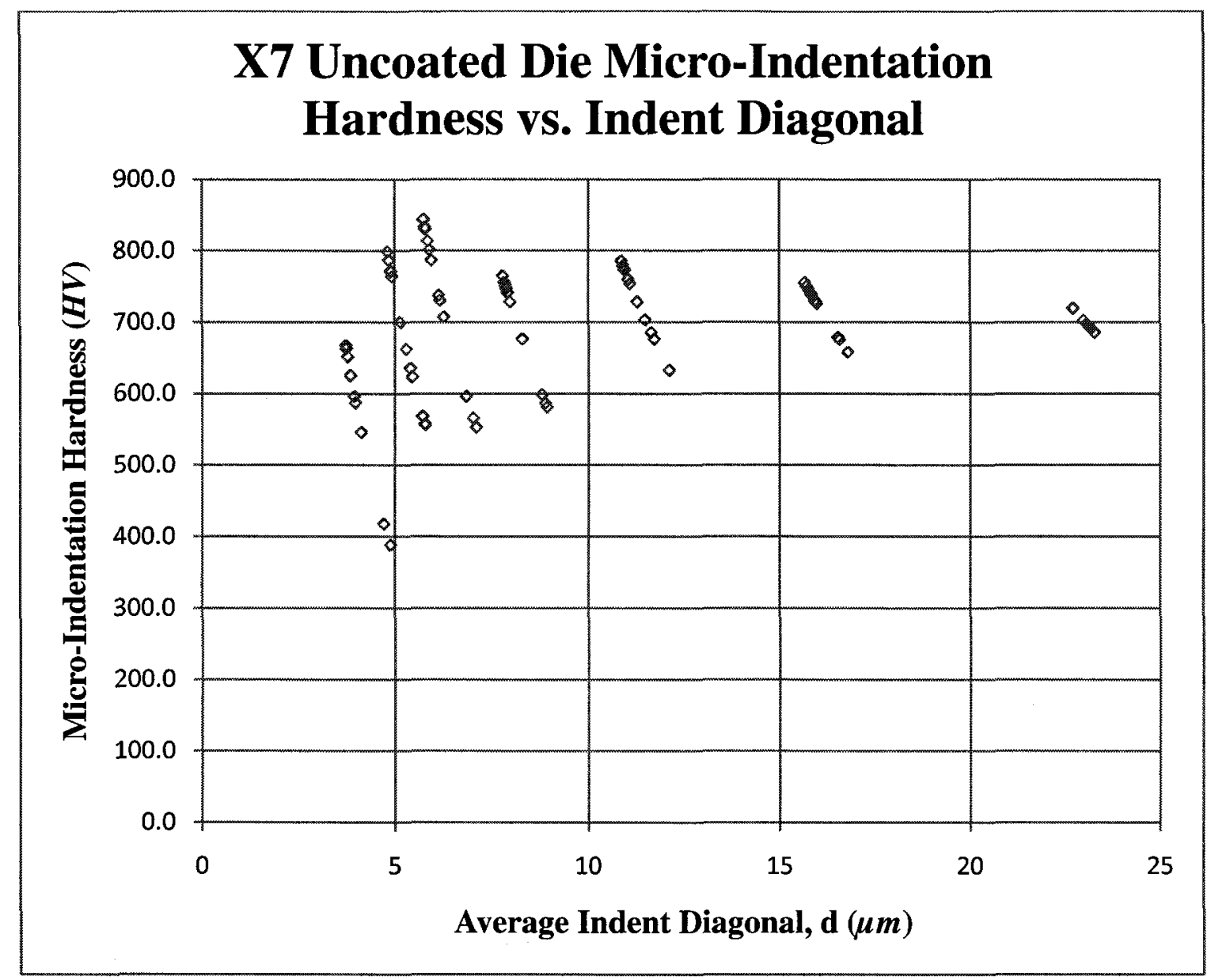

Figure 3.6: Measured substrate hardness of $\mathrm{X} 7$ displayed against indent diagonal 


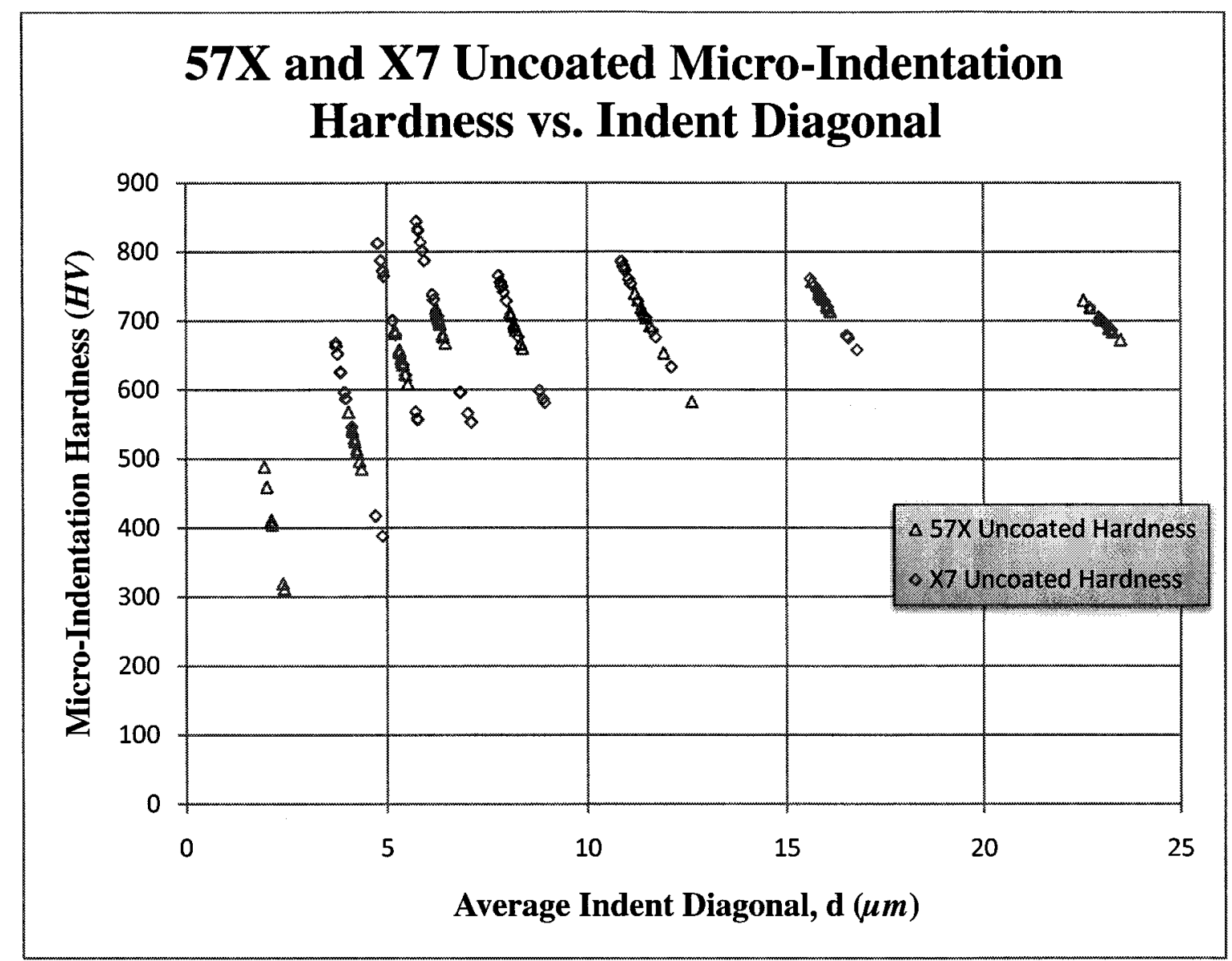

Figure 3.7: Comparison of substrate hardness data for $57 \mathrm{X}$ and $\mathrm{X} 7$ showing similar trend and magnitude 


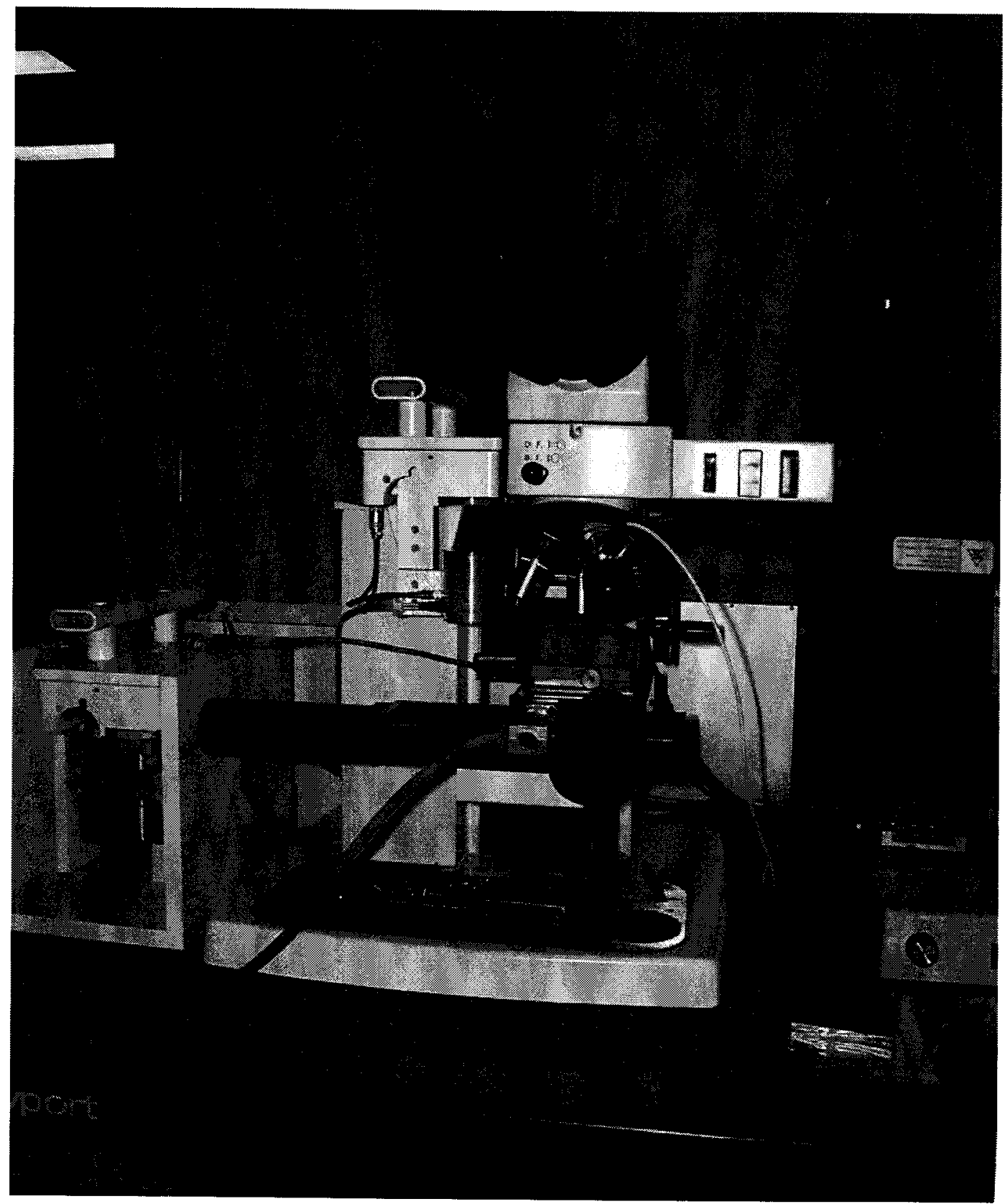

Figure 3.8: CSM Instruments nano-indentation tester resting on a vibration isolation table 


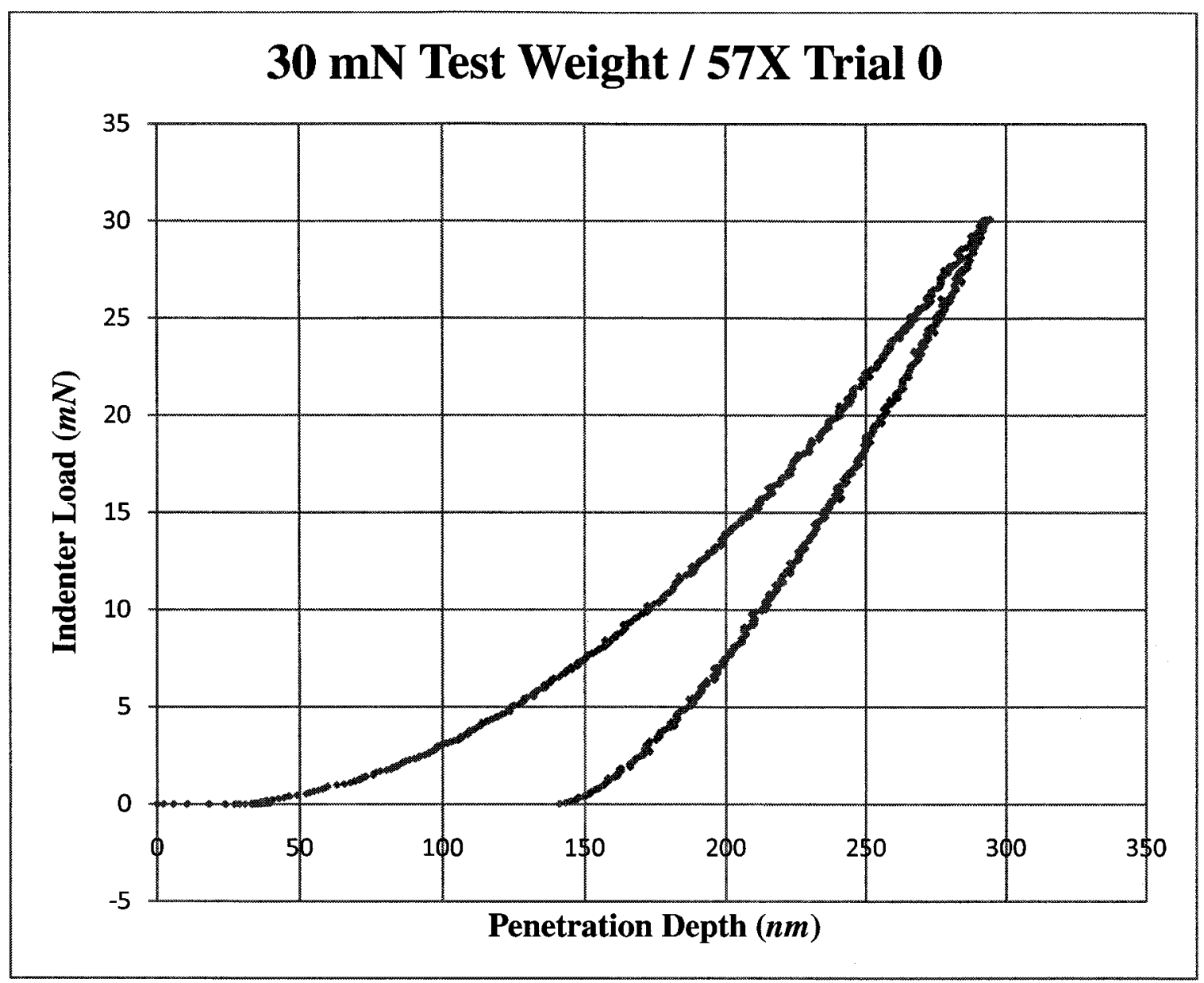

Figure 3.9: Load vs. penetration curve for $57 \mathrm{X}$ tested at $30 \mathrm{mN}$ 

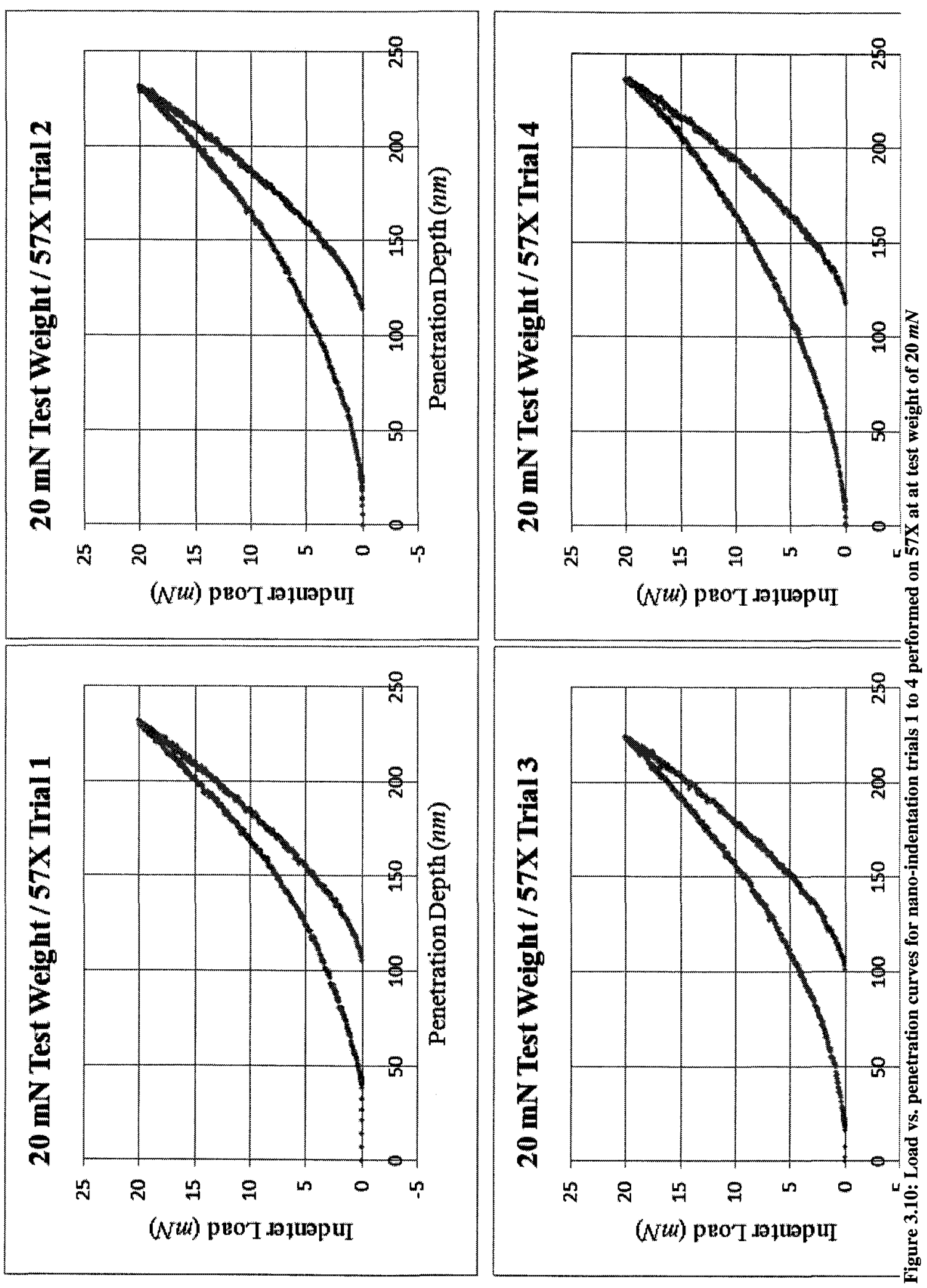

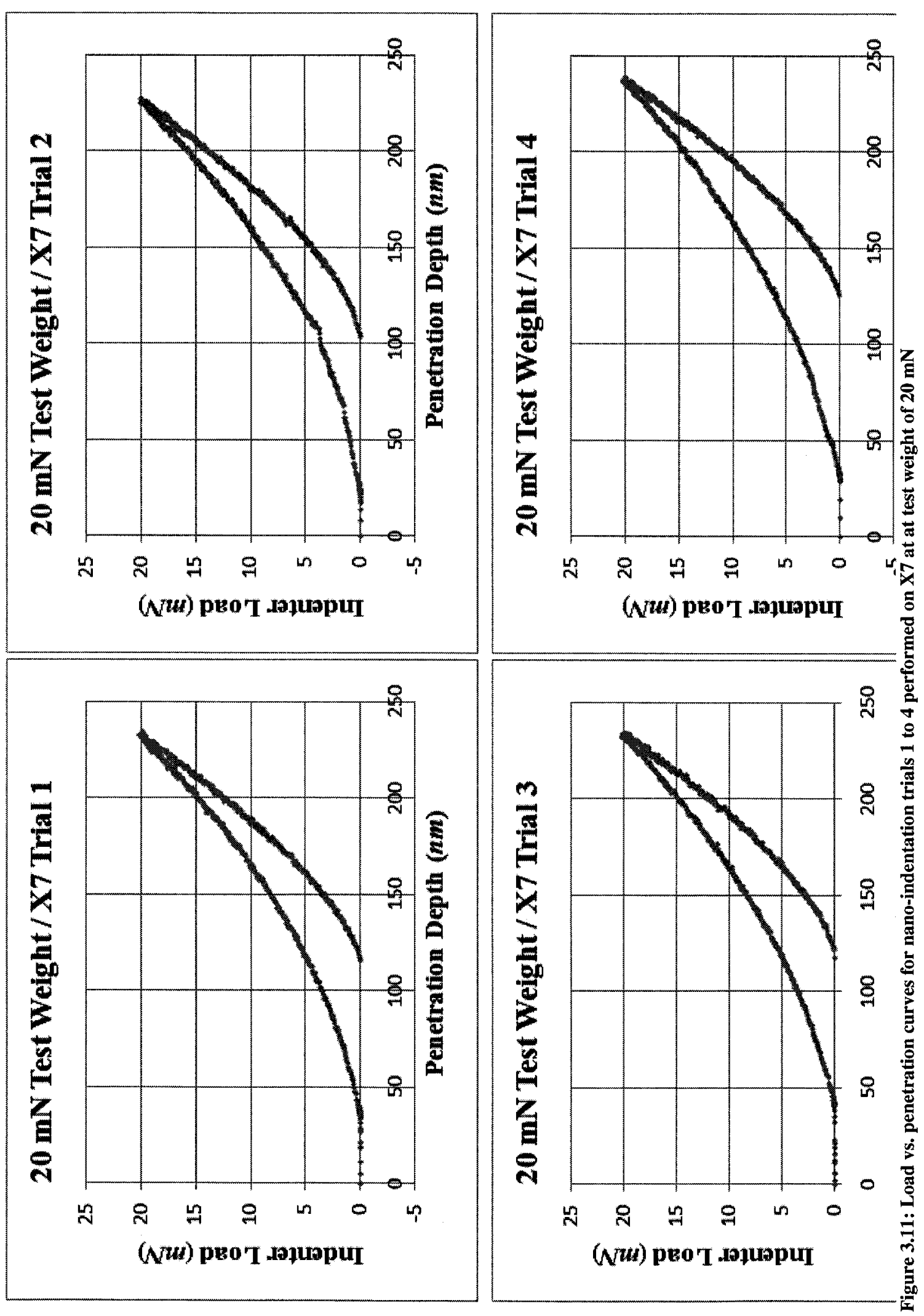


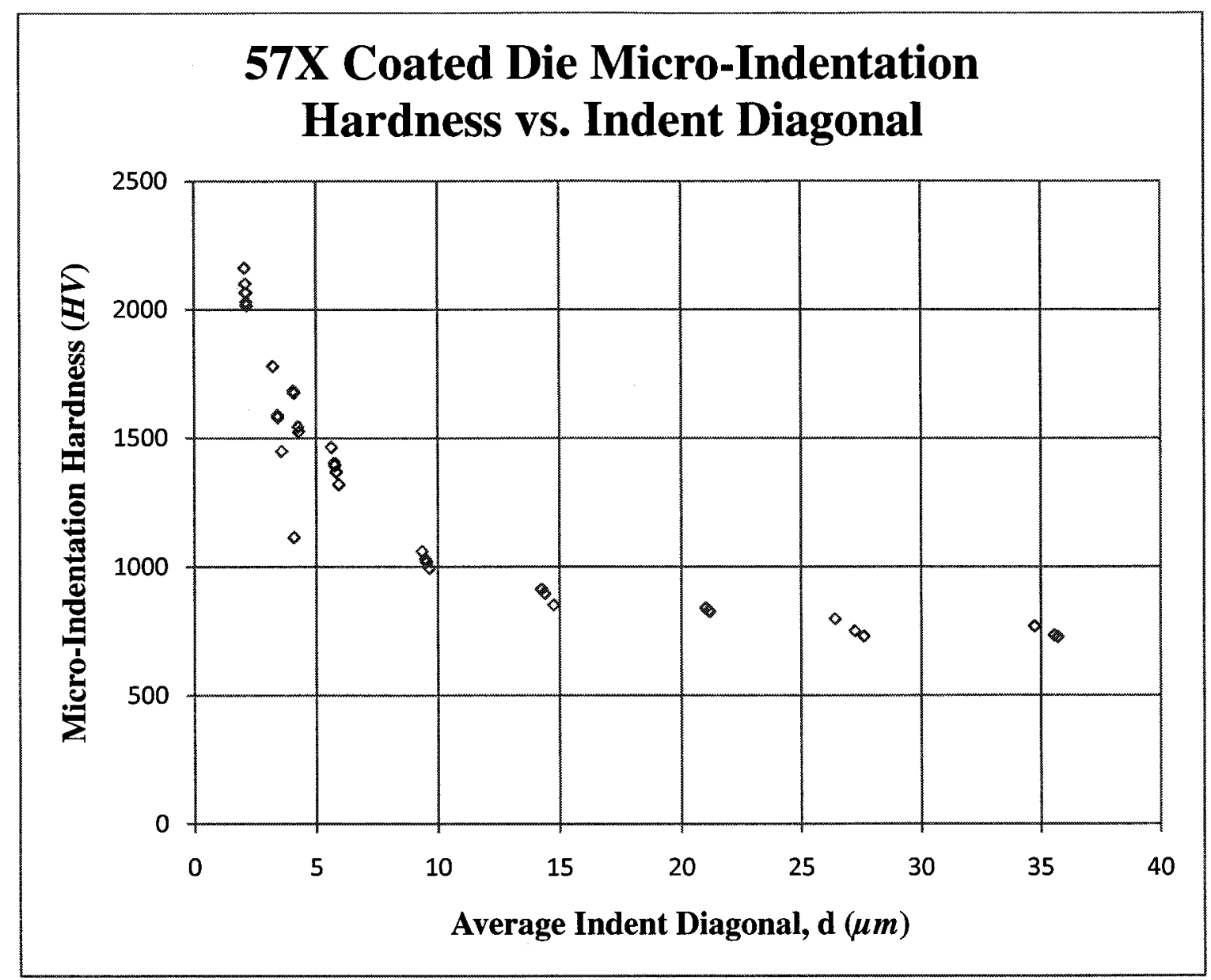

Figure 3.12: Measured micro-indentation hardness of $57 \mathrm{X}$ plotted against indent size

Notes for Figure 3.12:

- Here $\mathrm{H}_{\mathrm{c}}$ is plotted against the average indent diagonal (d) from Equation 2.7

- Groupings of data points (along lines from upper left to lower right) are performed at the same loading conditions

- This plot shows the change in measured hardness of the system in relation to the indent size and the difficulty in determining a specific value of the film hardness using micro-indentation test techniques 


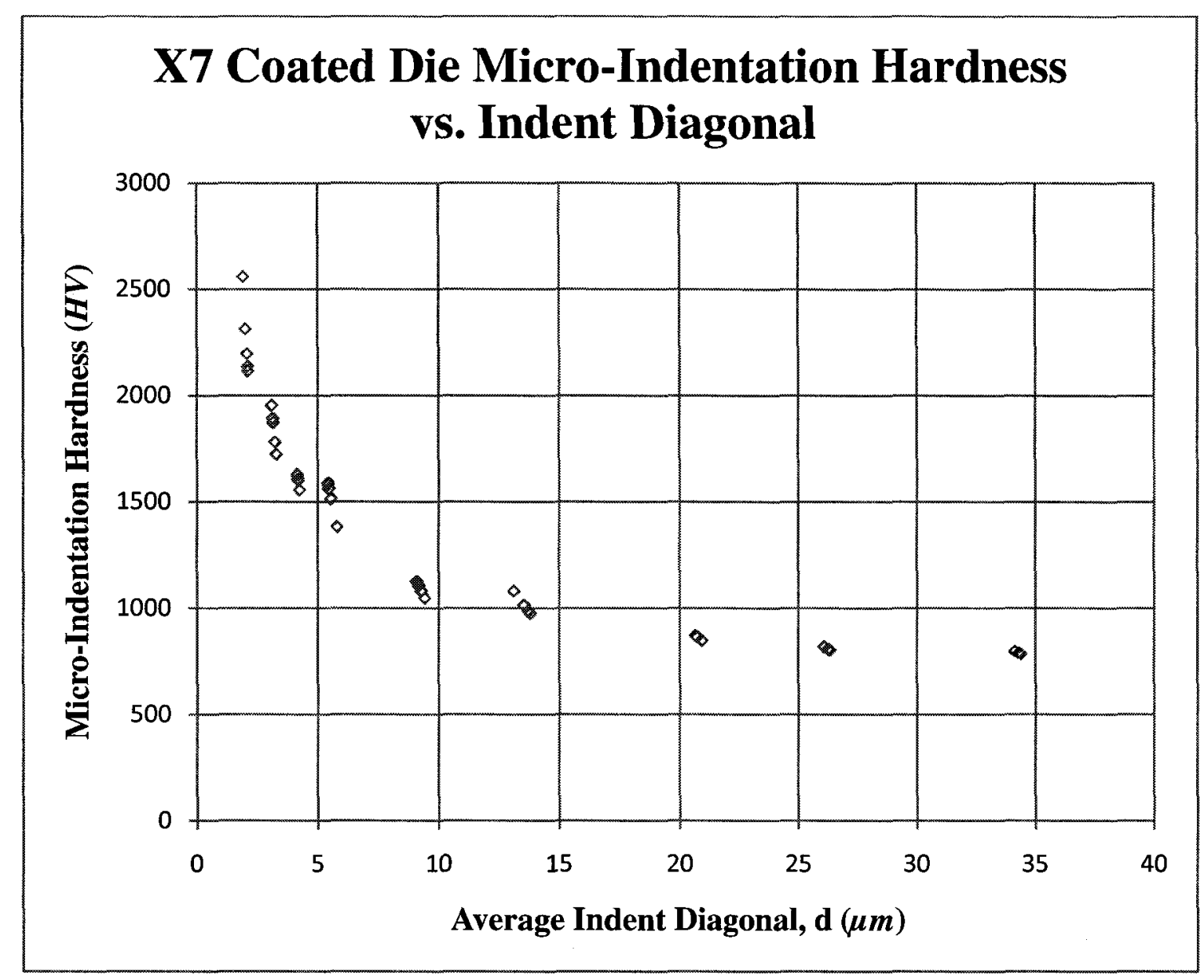

Figure 3.13: Measured micro-indentation hardness of $X 7$ plotted against indent size 


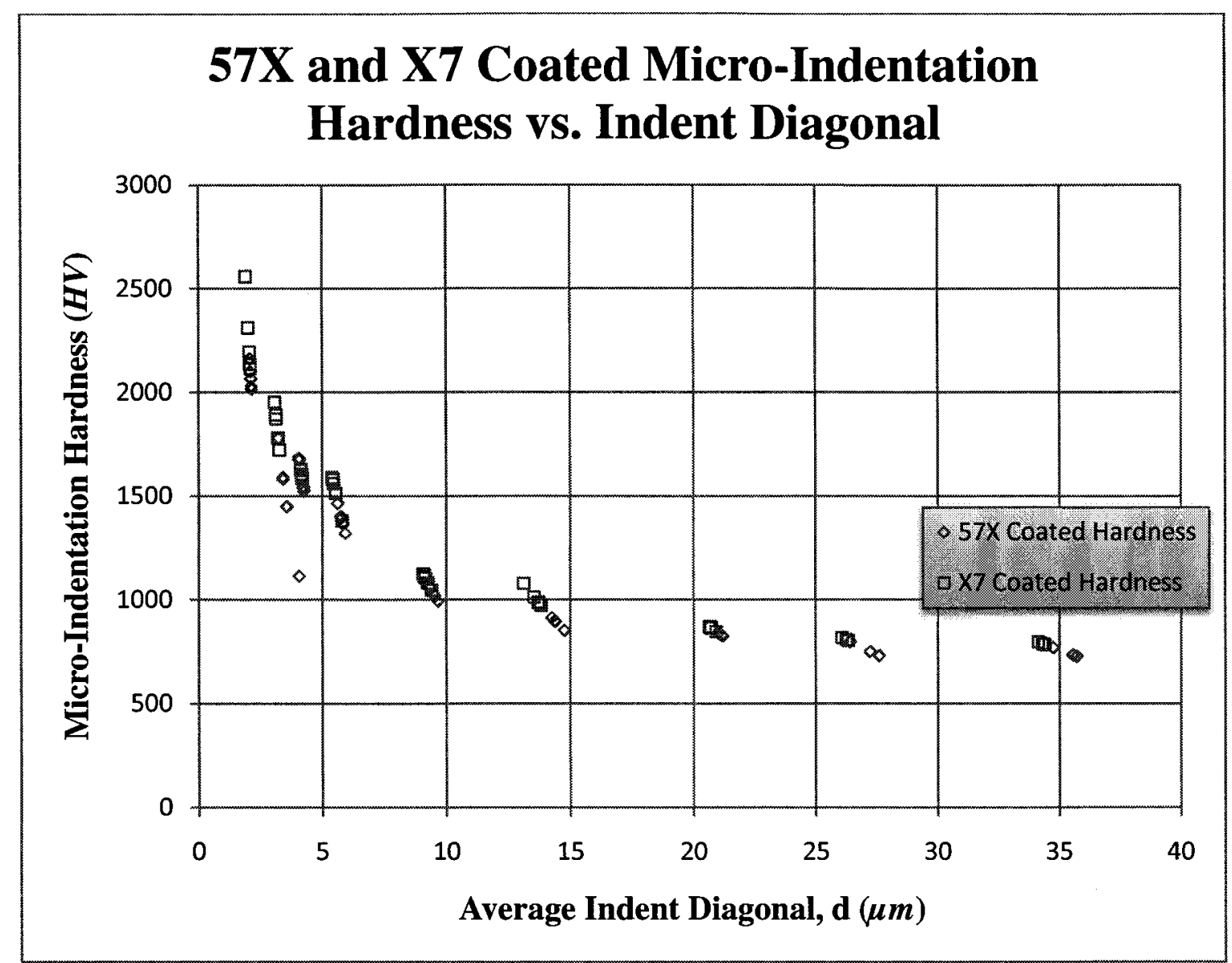

Figure 3.14: Measured micro-indentation hardness of $57 \mathrm{X}$ and $\mathrm{X} 7$ plotted against indent size showing a similar trend and magnitude throughout indentation range

Notes for Figure 3.14:

- Three of the $10 \mathrm{~g} f$ indentations for $57 \mathrm{X}$ are significantly lower than those for X7. Additionally, these indentations do not fall where expected from the smooth curved described by the rest of the $57 \mathrm{X}$ data.

- The hardness of 57X with indentation diagonals near 15,27 and $35 \mu \mathrm{m}$ spaced a little bit more widely than $\mathrm{X} 7$ and a little further to the right. This again indicates that hardness measurements of $57 \mathrm{X}$ were regularly lower than $\mathrm{X} 7$. 


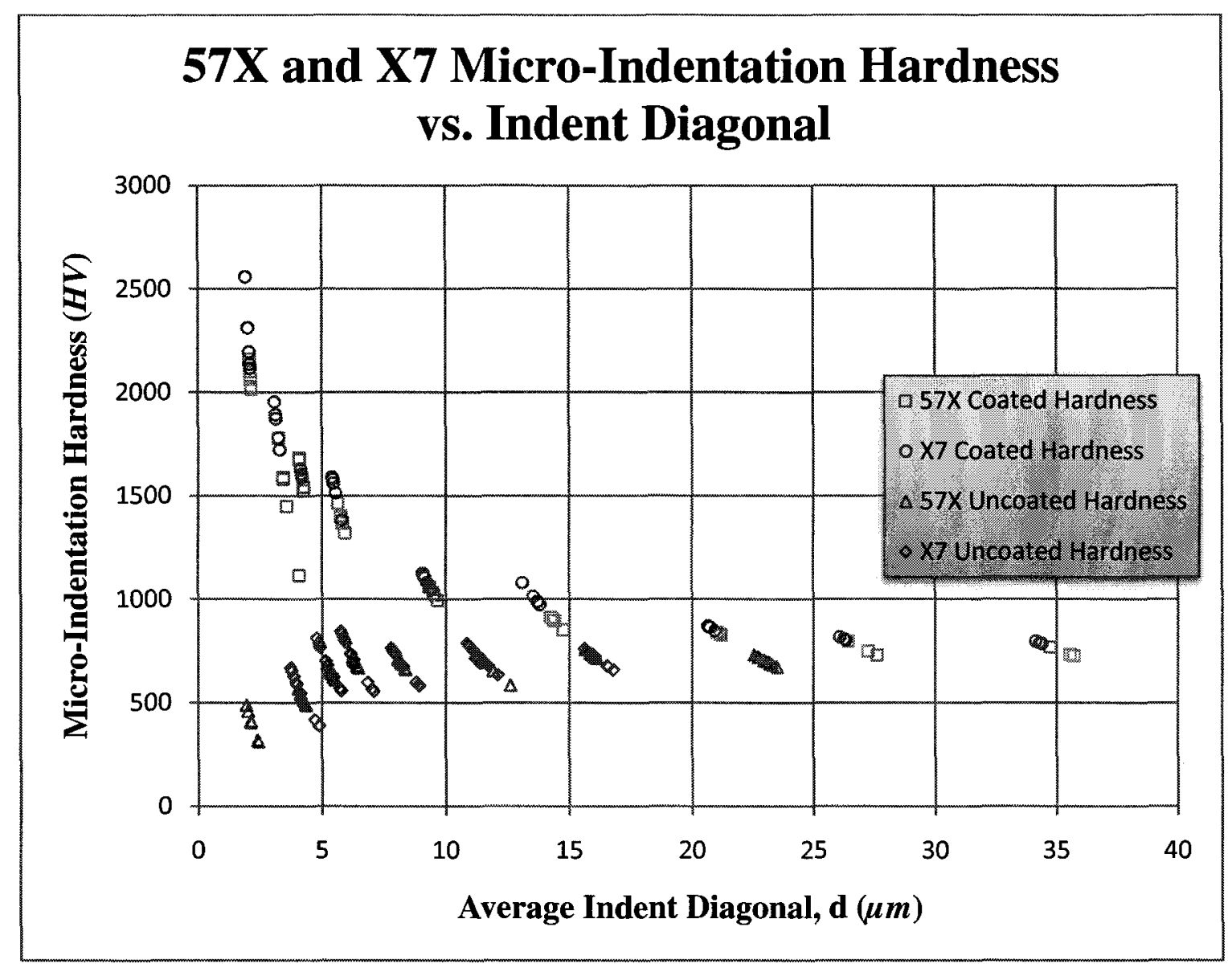

Figure 3.15: Coated and uncoated hardness plotted against indent diagonal showing the hardness values converging at high indent sizes 


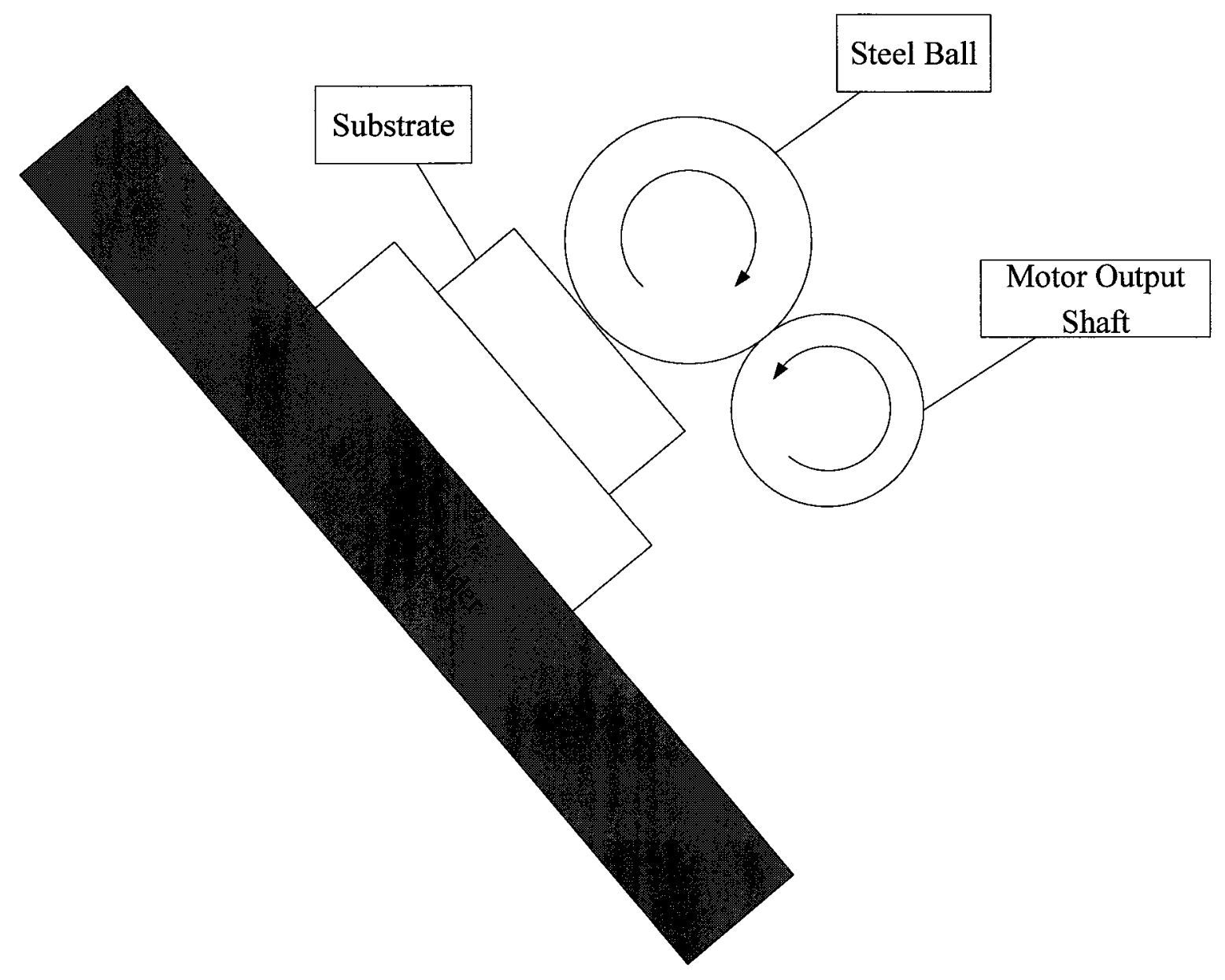

Figure 3.16: Steel ball position relative to the motor output shaft and specimen surface 


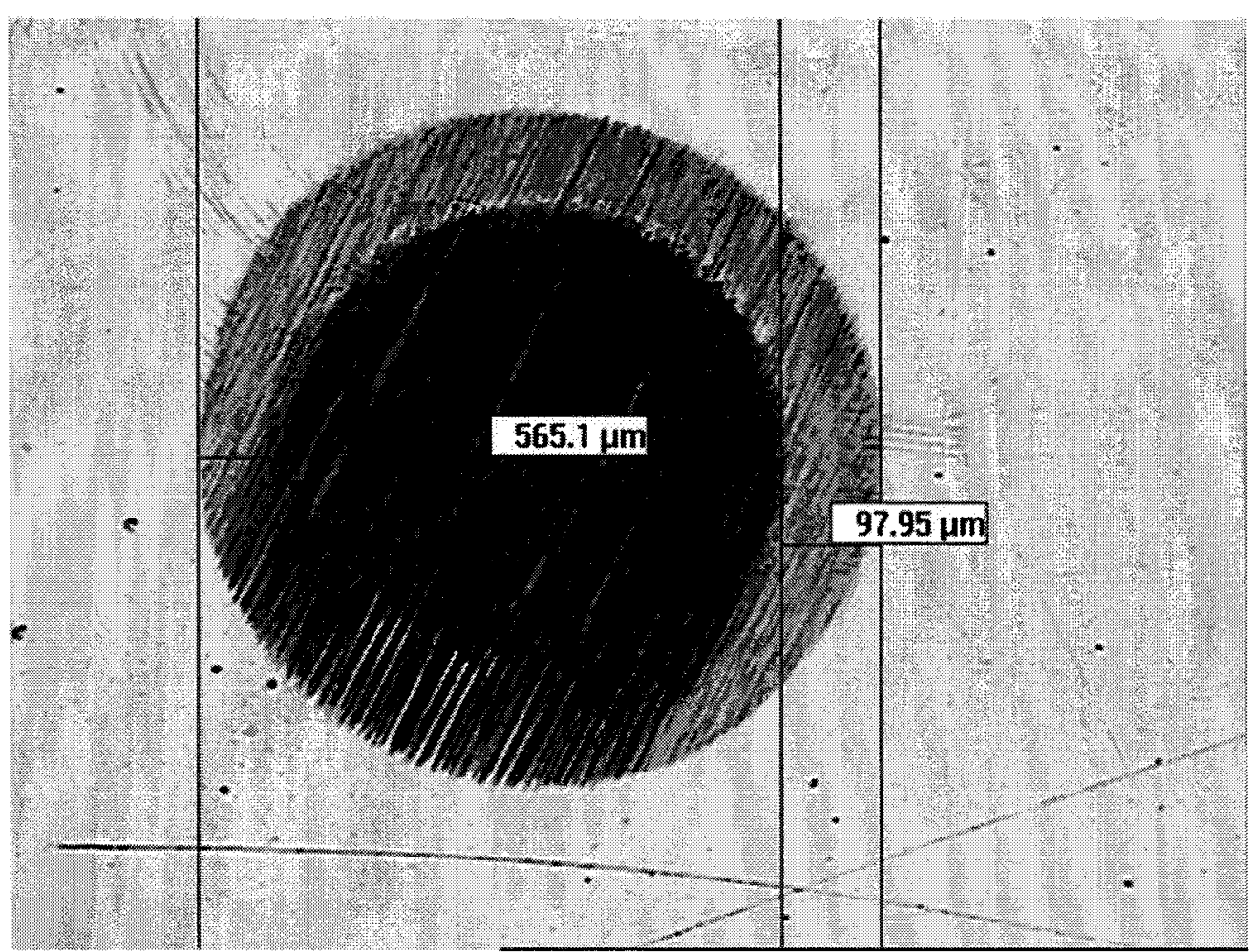

Figure 3.17: Crater on 57X resulting from calotest showing abraded film and substrate with measurements 


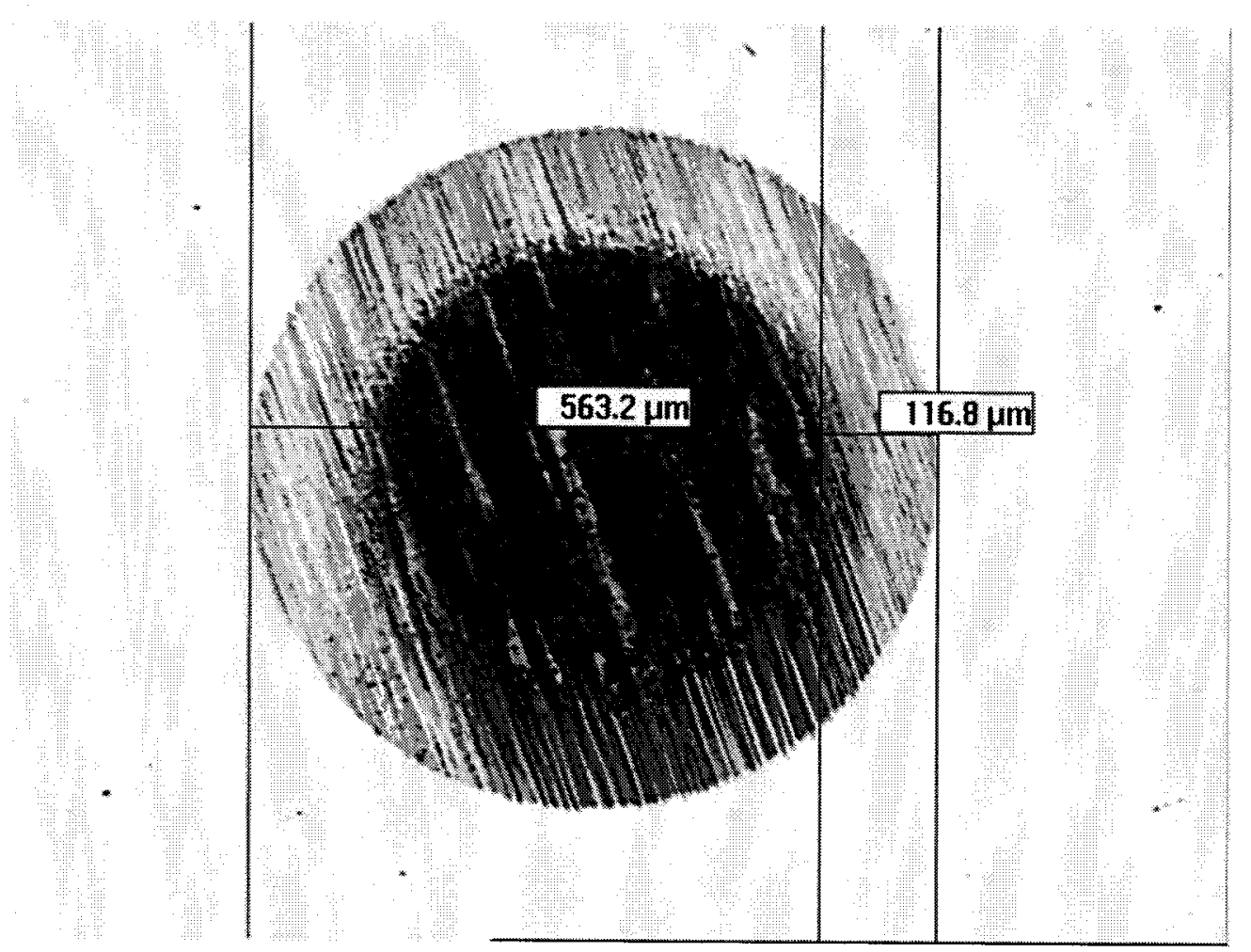

Figure 3.18: Crater on $\mathrm{X} 7$ resulting from calotest showing abraded film and substrate with measurement 


\section{Chapter 4 : Characterisation of the Sputter Coating}

In this chapter, the results of the hardness testing performed on the thin-film systems $57 \mathrm{X}$ and $\mathrm{X} 7$ are analysed. The aim of this chapter is to determine the hardness of the film and assess the use of the thin-film hardness models for estimating the film hardness from the micro-indentation data alone. Before analysing the coated system, the substrate hardness properties are analysed to minimise the number of unknowns in the thin-film system. The film hardness is determined using a computer algorithm and both the microindentation (VMHT) and nano-indentation test (NHT) data. The algorithm simultaneously determines the model parameters and film hardness from the indentation data. Based on the success of the calibrations, the most suitable models are used to predict the film hardness when only micro-indentation data is available. Finally, the predictive method outlined in this chapter is demonstrated using a sample of two dies from the RCM.

\subsection{Model Selection}

There are two types of models examined in this thesis. The thin-film hardness models presented in Section 2.3.1 describe the behaviour of the coated system and the indentation size effect (ISE) models presented in Section 2.3.2 describe the behaviour of the substrate or film phases individually. This section describes the selection of thin-film hardness models and ISEs that were used to analyse the VMHT and NHT data. The models are reduced to a single form and analysed in groups with similar characteristics. The models and ISEs which are most appropriate for the analysis of an uncharacterised thin film were selected based on their versatility and simplicity. 


\subsubsection{Hardness Models}

Several models which approximate the behaviour of a thin-film coating on a substrate have been proposed in the literature (see Section 2.3.1). These models are summarized below where $H_{c}, H_{s}, H_{f}$ are the hardness values of the composite (apparent hardness), substrate and film respectively. All of the models are written in the same form as Bückle's theory (Equation 4.1). Bückle originally defined the parameter $a$, the fraction of the film involved, as an empirical value for the particular film-substrate system being modelled. The thin film hardness models proposed by other authors (see Section 2.3.1) can be reduced to unique definitions of the parameter $a$ as shown below.

\begin{tabular}{|c|c|}
\hline Bückle & $H_{c}=H_{s}+a\left(H_{f}-H_{s}\right.$ \\
\hline Jönsson \& Hogmark & $a_{J H}=2 C \frac{t}{D}-C^{2}\left(\frac{t}{D}\right)$ \\
\hline Burnett \& Rickerby & $a_{B R}=3\left(\frac{H_{f}}{E_{f}}\right)^{\frac{1}{2}} \frac{t}{d} \tan ^{\frac{1}{3}}$ \\
\hline Chicot \& Lessage & $a_{C L}=\frac{3 t}{2 d}\left[\left(\frac{H_{f}}{E_{f}}\right)^{\frac{1}{2}}+\left(\frac{H_{s}}{E_{s}}\right)^{\frac{1}{2}}\right]$ \\
\hline Bykov et al. & $a_{B}=1-\frac{(D-t)^{2}}{D^{2}}$ \\
\hline Korsunsky & $a_{K}=\frac{1}{1-k_{K} \beta^{X_{K}}}$ \\
\hline Puchi-Cabrera & $a_{P C}=e^{-k_{P C} \beta^{X_{P C}}}$ \\
\hline
\end{tabular}

By substituting the appropriate value of $a$ (Equations 4.2-7) into Equation 4.1, we can model the apparent hardness of the thin-film system. The parameters in Equations 4.2 to 4.7 have been defined in Section 2.3.1. The models listed above are plotted together in Figure 4.1 to show their general behaviour. It was necessary to estimate some of the film parameters in order to demonstrate the models' behaviour. The estimated film parameters are summarised in Table 4.1 and were chosen to be similar to the RCM film in question. The assumed values for the other required model parameters are shown in Table 4.2. From Figure 4.1, it can be seen that the behaviours of the models fall into three categories. The models exhibiting similar characteristics are discussed below. 


\section{Jönsson \& Hogmark (JH) and Bykov et al. (B)}

The JH and B models both suffer from a dramatic decrease in hardness as the indent diagonal becomes small. The authors in both cases have coincidentally suggested that their models are accurate for relative indentation depths $(\beta)$ greater than 1 (see Section 2.3.1). The $\mathrm{JH}$ model can be adjusted slightly by selecting the $\mathrm{C}$ for plastic or brittle deformation modes of the film. As can be seen on the JH curve in Figure 4.1, there is a discontinuity where the $\mathrm{C}$ value was changed at an arbitrarily chosen relative indentation depth of 1 . This discontinuity was not observed in the test data although cracking was observed on the surface as the test load was increased. The apparent hardness in the $\mathrm{B}$ model peaks at the film hardness value at a relative indentation depth of 1 which is inappropriate for the current research. Further to this it does not seem to approach the substrate hardness value as quickly as any of the other models. The B model cannot be adjusted in any way as its parameter is based only on the film thickness $(t)$ and indentation depth $(D)$. Both of these models are limited in their ability to model different film and substrate combinations.

\section{Chicot \& Lessage (CL) and Burnett \& Rickerby $(B R)$}

In contrast to the $\mathrm{JH}$ and $\mathrm{B}$ models, the $\mathrm{CL}$ and $\mathrm{BR}$ models instead suffer from a dramatic increase in measured hardness at smaller indents. It is not expected that the measured hardness will significantly exceed the film hardness at any point. As with the B model, these two models cannot be adjusted as they are based solely on properties of the thinfilm system $\left(t, E_{f}, E_{s}\right)$, the indenter semi-angle $(\xi)$ and the indent diagonal $(d)$. Both models require extra information about the film properties, namely the Young's modulus, which is not available at this time. 


\section{Korsunsky (K) and Puchi-Cabrera (PC)}

The $\mathrm{K}$ and PC models both exhibit saturated behaviour at small and large relative indentation depths as would be reasonably expected. Both models also converge to the same hardness values at small and large relative indentation depths. In Figure 4.1, the $\mathrm{K}$ model offers a smoother transition between film and substrate hardness however both models include parameters which control the curve characteristics. The effect of varying the controlling parameters of the $\mathrm{K}$ model, $k_{K}$ and $X_{K}$, is shown in Figure 4.2. The same is shown for the PC model by varying $k_{P C}$ and $X_{P C}$ in Figure 4.3. The slope and position of the transitional portion of the curve can be satisfactorily controlled for both models. Additionally, the $\mathrm{K}$ and PC models exhibit the best $r^{2}$ values in the literature with the $\mathrm{K}$ model often having a marginally better fit than PC.

Based on the above considerations, the Korsunsky and Puchi-Cabrera models were selected for further analysis. They exhibit the most appropriate characteristics for the entire range of indentations possible and have shown superior ability to fit hardness data in previous research.

\subsubsection{Indentation Size Effect (ISE)}

The three ISEs presented in this thesis were developed by: Thomas, Meyer and Nix \& Gao. The equations describing these models are written below in Equation 4.8 to Equation 4.10.

$\begin{array}{cr}\text { Thomas } & H=H_{0}+\frac{b}{d} \\ \text { Meyer } & H=H_{0} d^{n-2} \\ \text { Nix \& Gao } & \frac{H}{H_{0}}=\sqrt{1+\frac{h^{*}}{h_{c}}} \\ \text { (Strain Gradient Plasticity) } & \end{array}$




$$
\begin{gathered}
h^{*}=\frac{81}{2} b \alpha^{2} \tan ^{2} \theta\left(\frac{\mu}{H_{0}}\right)^{2} \\
H_{0}=3 \sqrt{3} \alpha \mu b \sqrt{\rho_{s}}
\end{gathered}
$$

The strain gradient plasticity model developed by Nix \& Gao will not be used because it requires several pieces of information about the microstructure of the film which are beyond the scope of the present work. The other two models require no additional information about the film or substrate and have already been used and suggested by researchers in this area. The parameters for the ISEs shown above have been defined in Section 2.3.2.

\subsubsection{Summary}

Based on the above discussions, the $\mathrm{K}$ and PC models are the most appropriate for the present work. Both models exhibit the expected trends over the entire range of indent sizes and incorporate adjusting parameters to accommodate the film in this thesis. The two models are expressed in full in the following two equations.

$$
\begin{array}{cl}
\text { Korsunsky } & H_{c}=H_{s}+\frac{1}{1+k_{K} \beta^{X_{K}}}\left(H_{f}-H_{s}\right) \\
\text { Puchi-Cabrera } & H_{c}=H_{s}+e^{-k_{P C} \beta^{X_{P C}}}\left(H_{f}-H_{s}\right)
\end{array}
$$

These two models will be used in their basic forms (as in Equation 4.11 and Equation 4.12) and in conjunction with the Thomas and Meyer ISEs. When used, the ISE applies to both the film and substrate. The hardness of the substrate $\left(H_{s}\right)$ and film $\left(H_{f}\right)$ according to the Meyer and Thomas ISEs are shown explicitly below in Equation 4.13 to 4.16.

Meyer

$$
H_{s}=H_{0 s} d^{n_{s}-2}
$$

$$
H_{f}=H_{0 f} d^{n_{f}-2}
$$


Thomas

$$
\begin{aligned}
& H_{s}=H_{0 s}+\frac{b_{s}}{d} \\
& H_{f}=H_{0 f}+\frac{b_{f}}{d}
\end{aligned}
$$

Combining the models and ISEs, there are a total of 6 combinations that will be used to fit the data. The models combined with ISEs are obtained by substituting Equation 4.13 to Equation 4.16 into the models described by Equation 4.11 and Equation 4.12. The 6 combinations are shown explicitly below.

$$
\begin{array}{lc}
\text { K/No ISE } & H_{c}=H_{s}+\frac{1}{1+k_{K} \beta^{X_{K}}}\left(H_{f}-H_{s}\right) \\
\text { K/Meyer } & H_{c}=\left(H_{0 s} d^{n_{s}-2}\right)+\frac{1}{1+k_{K} \beta^{X_{K}}}\left[\left(H_{0 f} d^{n_{f}-2}\right)-\left(H_{0 s} d^{n_{s}-2}\right)\right] \\
\text { K/Thomas } & H_{c}=\left(H_{0 s}+\frac{b_{s}}{d}\right)+\frac{1}{1+k_{K} \beta^{X_{K}}}\left[\left(H_{0 f}+\frac{b_{f}}{d}\right)-\left(H_{0 s}+\frac{b_{s}}{d}\right)\right] \\
\text { PC/No ISE } & H_{c}=H_{s}+e^{-k_{P C} \beta^{X_{P C}}}\left(H_{f}-H_{s}\right) \\
\text { PC/Meyer } & H_{c}=\left(H_{0 s} d^{n_{s}-2}\right)+e^{-k_{P C} \beta^{X_{P C}}}\left[\left(H_{0 f} d^{n_{f}-2}\right)-\left(H_{0 s} d^{n_{s}-2}\right)\right] \\
\text { PC/Thomas } & H_{c}=\left(H_{0 s}+\frac{b_{s}}{d}\right)+e^{-k_{P C} \beta^{X_{P C}}}\left[\left(H_{0 f}+\frac{b_{f}}{d}\right)-\left(H_{0 s}+\frac{b_{s}}{d}\right)\right]
\end{array}
$$

In the above equations, the indent diagonal $(d)$ is also used to calculate the relative indent depth $(\beta=d / 7 t)$. For the remainder of this chapter, the subscripts $K, P C, N, M, T$ in all equations denote Korsunsky, Puchi-Cabrera, No ISE, Meyer ISE and Thomas ISE respectively. 


\subsection{Substrate Hardness}

Before the thin-film system data can be analysed to determine the film hardness, the substrate hardness properties must be determined. This section outlines the analysis of the substrate hardness data obtained from the micro-indentation testing performed in Section 3.1. In particular, the substrate parameters of the ISEs described in Section 4.1.3 must be determined. The test data used for this analysis is taken from Table 3.1 and Table 3.2 for $57 \mathrm{X}$ and $\mathrm{X} 7$ respectively. The hardness parameters are determined for the No ISE, Meyer and Thomas cases.

\subsubsection{Hardness Using No Indentation Size Effect}

When not using an ISE, a constant, representative hardness for the material is used. According to the ASTM micro-indentation testing standards, the hardness measured at larger indentations are most consistent and encounter fewer errors (ASTM, 2002). The representative hardness of the substrate was taken as the average of the micro-indentation hardness values at the highest test load performed (200 gf test load for each $57 \mathrm{X}$ and X7). The average substrate hardness values are in agreement at $697.6 H V_{200 g f}$ and 697.0 $H V_{200 g f}$ for $57 \mathrm{X}$ and $\mathrm{X} 7$ respectively.

\subsubsection{Hardness Using the Meyer or Thomas Indentation Size Effect}

Two parameters are used to describe the hardness profile using Meyer and Thomas ISEs. For Meyer, the absolute substrate hardness $H_{O s}$ and the exponent $n_{s}$ can be determined from the measured data using Equation 4.13 where $H_{s}$ is the measured substrate hardness and $d_{i}$ the corresponding indent diagonal. An error function $\left(\varphi_{M}\right)$ was defined for the Meyer ISE so that the parameters could be determined by solving the derivatives in Equation 4.24 and Equation 4.25. Here, $N$ is the number of data points that exist for the substrate ( 78 for $57 \mathrm{X}$ and 80 for $\mathrm{X} 7$ ). 


$$
\begin{gathered}
\varphi_{M}=\sum_{i=1}^{N}\left(H_{s}-H_{0 s} d_{i}^{n_{s}-2}\right)^{2} \\
\frac{\partial \varphi_{M}}{\partial H_{0 s}}=0=\sum_{i=1}^{N} 2\left(H_{s}-H_{0 s} d_{i}^{n_{s}-2}\right)\left(-d_{i}^{n_{s}-2}\right) \\
\frac{\partial \varphi_{M}}{\partial n_{s}}=0=\sum_{i=1}^{N} 2\left(H_{s}-H_{0 s} d_{i}^{n_{s}-2}\right)\left[-H_{0 s} \ln \left(d_{i}\right) d_{i}^{n_{s}-2}\right]
\end{gathered}
$$

Using an initial guess for the parameters $H_{O s}$ and $n_{s}$ of $700 \mathrm{HV}$ and 2 respectively, Equation 2.24 and Equation 2.25 were applied recursively to determine the best combination of parameters for the $57 \mathrm{X}$ and $\mathrm{X} 7$ substrates. As seen in Table 4.3 and Figure 4.4 , the values predicted for $57 \mathrm{X}$ and $\mathrm{X} 7$ are very different despite the similarity of the measured data points. Since hardness values of about $700 \mathrm{HV}$ are expected at even higher indent sizes, a reasonably flat line is expected for both dies. Also, the majority of the hardness testing on the film is performed where the data points level out and the effect of a film layer on the substrate ISE is unknown. Although the fit provided for X7 encounters more error at small indent sizes, it also provides accurate level readings at higher indent sizes. For these reasons, the absolute hardness of $702.63 \mathrm{HV}$ and film parameter of 2.003 will be used for both $57 \mathrm{X}$ and $\mathrm{X} 7$ to emulate the consistent hardness value expected for the majority of the indent diagonal range.

The parameters in Thomas's ISE were similarly determined. Equation 4.15 was used to define the error function $\varphi_{T}$ seen in Equation 2.26. The derivatives of Equation 2.26 are shown in Equation 2.27 and Equation 2.28 and were used to recursively solve for the parameters $H_{0 s}$ and $b_{s}$. Initial guesses of $700 \mathrm{HV}$ and $0 \mathrm{HVm}$ were made for $H_{0 s}$ and $b_{s}$ respectively.

$$
\begin{gathered}
\varphi_{T}=\sum_{i=1}^{N}\left[H_{s}-\left(H_{0 s}+\frac{b_{s}}{d_{i}}\right)\right]^{2} \\
\frac{\partial \varphi_{T}}{\partial H_{0 S}}=0=\sum_{i=1}^{N} 2\left[H_{s}-\left(H_{0 s}+\frac{b_{s}}{d_{i}}\right)\right](-1)
\end{gathered}
$$




$$
\frac{\partial \varphi_{T}}{\partial b_{s}}=0=\sum_{i=1}^{N} 2\left[H_{s}-\left(H_{0 s}+\frac{b_{s}}{d_{i}}\right)\right]\left(-\frac{1}{d_{i}}\right)
$$

The algorithm returned an absolute hardness of $762.6 \mathrm{HV}$ and parameter $b_{s}$ of $-0.00074338 \mathrm{HVm}$ for $57 \mathrm{X} . \quad H_{0 s}$ and $b_{s}$ were determined to be $738.1 \mathrm{HV}$ and $-0.00034308 \mathrm{HVm}$ for $\mathrm{X} 7$ respectively. The results of the calibration for both substrates using the Thomas ISE are summarised in Table 4.4. Both parameters are consistent for both $57 \mathrm{X}$ and $\mathrm{X} 7$. The hardness profiles described by Thomas for $57 \mathrm{X}$ and $\mathrm{X} 7$ are shown in Figure 4.5 and Figure 4.6 respectively.

\subsubsection{Summary of Substrate Hardness Values}

The hardness of the substrate has been characterised using 3 different methods. The parameters for each model have been determined for use with the Korsunsky and PuchiCabrera thin-film hardness models in Equation 4.11 and Equation 4.12. The hardness parameters for each model are summarised together are in Table 4.5 exactly as used in the analysis.

\subsection{Calibration of the Film Parameters Using Nano- and Micro-Indentation Test Data}

This section describes the analysis of the NHT data in combination with the VMHT data to simultaneously calibrate the thin-film hardness model parameters and the film hardness. In order to perform the analysis using the computer algorithm, the NHT and VMHT data must be refined. Using the refined input data, the algorithm autonomously searches for appropriate model parameters. The film hardness determined from this analysis represents the actual hardness of the film. 


\subsubsection{Preparation of Data}

For each indent, the input to the program included the average indent diagonal ( $d$ in meters), relative indentation depth $(\beta)$ and measured hardness $\left(H_{c}\right.$ in Vickers Hardness Number). The average indent diagonal was calculated from the average of all diagonals measured for a single indent. The relative indentation depth was calculated from the average indent diagonal using Equation 2.5 and the film thickness as determined in Section 2.1.4 $(\beta=d / 7 t)$. The measured hardness was calculated using the average indent diagonal, test weight $(P)$ and Equation 2.7. The refined input data from the microindentation tests for $57 \mathrm{X}$ and $\mathrm{X} 7$ is shown in Table 4.6 and Table 4.7 respectively.

The same inputs were refined from the NHT data so that it could be included in the analysis. Using Equation 2.8 for the Berkovich indenter, the indent diagonal was determined from the indent depth. The indent depth $(D)$ for each indent was taken directly from Table 3.6 and Table 3.7 for $57 \mathrm{X}$ and $\mathrm{X} 7$ respectively (shown in the tables as $H_{0}$ ). The relative indentation depth was simply determined from the ratio of penetration depth to film thickness $(D / t)$. The Vickers hardness was available directly from the nanoindentation test results. The input data from the nano-indentation tests are shown in Table 4.8 for $57 \mathrm{X}$ and Table 4.9 for X7. A total of 46 indents were used for $57 \mathrm{X}$ ( 41 VMHT and 5 NHT) while 45 were used for X7 (41 VMHT and 4 NHT).

\subsubsection{Algorithm}

The flowchart shown in Figure 4.7 outlines the algorithm designed to calibrate the model parameters using the VMHT and NHT data. Before performing the analysis, the following points were defined or considered:

- Input data includes:

- Indentation data $\left(d, \beta H_{c}\right)$

- Film thickness $(t)$

- Substrate hardness parameters $\left(H_{s}\right.$ or $H_{0 s}, n_{s}$ or $\left.b_{s}\right)$

- Define controlling parameters (see Appendix $\mathrm{C}$ for program documentation)

- Select the desired model and ISE. 
- Define an initial search space for the model parameters $\left(k_{K}\right.$ and $X_{K}$ or $k_{P C}$ and $X_{P C}$ ).

- Define a desired precision for each model parameter (ie. $\leq 0.01$ ).

- Define a search interval for the film hardness $\left(H_{f}\right.$ or $\left.H_{0 f}\right)$ and indentation size effect parameter $\left(n_{f}\right.$ or $\left.b_{f}\right)$.

The full code is presented in Appendix $\mathrm{C}$ with the above points selected for the case of Korsunsky with No ISE and using 57X data. The other options available to the user and user-defined variables are also explained in Appendix C. The program steps through different combinations of model parameters $k$ and $X$ within the search space defined. For each combination of model parameters, the program solves for the film parameters that minimize the sum of the squares of the errors. When not using an ISE, the film hardness $H_{f}$ is the third parameters required. If using an ISE the absolute hardness $H_{\text {of }}$ and the ISE parameter, $n_{f}$ or $b_{f}$ must be determined in place of $H_{f}$. The unknown parameters which must be determined for each combination of model and ISE are summarised in Table 4.10. Objective functions were defined based on the sum of the squares of the errors in order to facilitate solving for the film parameters. The objective functions for each combination of model and ISE are shown below in Equation 4.29 to Equation 4.34.

$$
\begin{gathered}
\varphi_{K, N}=\sum_{i=1}^{N}\left[H_{c}-\left(H_{s}+\frac{1}{1+k_{K} \beta^{X_{K}}}\left(H_{f}-H_{s}\right)\right)\right]^{2} \\
\varphi_{K, M}=\sum_{i=1}^{N}\left[H_{c}-\left(H_{0 s} d_{i}^{n_{s}-2}+\frac{1}{1+k_{K} \beta^{X_{K}}}\left(H_{0 f} d_{i}^{n_{f}-2}-H_{0 s} d_{i}^{n_{s}-2}\right)\right)\right]^{2} \\
\varphi_{K, T}=\sum_{i=1}^{N}\left[H_{c}-\left(\left(H_{0 s}+\frac{b_{s}}{d_{i}}\right)+\frac{1}{1+k_{K} \beta^{X_{K}}}\left[\left(H_{0 f}+\frac{b_{f}}{d_{i}}\right)-\left(H_{0 s}+\frac{b_{s}}{d_{i}}\right)\right]\right)\right]^{2} \\
\varphi_{P C, M}=\sum_{i=1}^{N}\left[H_{c}-\left(H_{0 s} d_{i}^{n_{s}-2}+e^{-k_{P C} \beta^{X_{P C}}}\left(H_{0 f} d_{i}^{n_{f}-2}-H_{0 s} d_{i}^{n_{s}-2}\right)\right)\right]^{2} \\
\left.\varphi_{P C, T}=\sum_{i=1}^{N}\left[H_{c}-\left(H_{s}+e^{-k_{P C} \beta^{X_{P C}}}\left(H_{f}-H_{s}\right)\right)\right]^{2}\left(\left(H_{0 s}+\frac{b_{s}}{d_{i}}\right)+e^{-k_{P C} \beta^{X_{P C}}}\left[\left(H_{0 f}+\frac{b_{f}}{d_{i}}\right)-\left(H_{0 s}+\frac{b_{s}}{d_{i}}\right)\right]\right)\right]^{2}
\end{gathered}
$$


The film parameters are determined by solving the derivative of the objective function being equal to zero. The derivatives which will be used to solve for the film hardness are given in Equation 4.35 to Equation 4.40 below.

$$
\begin{aligned}
& \frac{\partial \varphi_{K, N}}{\partial H_{f}}=\sum_{i=1}^{N} 2\left[H_{c}-\left(H_{s}+\frac{1}{1+k_{K} \beta^{X_{K}}}\left(H_{f}-H_{s}\right)\right)\right]\left[-\frac{1}{1+k_{K} \beta^{X_{K}}}\right] \\
& \frac{\partial \varphi_{K, M}}{\partial H_{0 f}}=\sum_{i=1}^{N} 2\left[H_{c}-\left(H_{0 s} d_{i}^{n_{s}-2}+\frac{\left(H_{0 f} d_{i}^{n_{f}-2}-H_{0 s} d_{i}^{n_{s}-2}\right)}{1+k_{K} \beta^{X_{K}}}\right)\right]\left[-\frac{d_{i}^{n_{f}-2}}{1+k_{K} \beta^{X_{K}}}\right] \\
& \frac{\partial \varphi_{K, T}}{\partial H_{0 f}}=\sum_{i=1}^{N} 2\left[H_{c}-\left(\left(H_{0 s}+\frac{b_{s}}{d_{i}}\right)+\frac{\left[\left(H_{0 f}+\frac{b_{f}}{d_{i}}\right)-\left(H_{0 s}+\frac{b_{s}}{d_{i}}\right)\right]}{1+k_{K} \beta^{X_{K}}}\right)\right]\left(-\frac{1}{1+k_{K} \beta^{X_{K}}}\right) \\
& \frac{\partial \varphi_{P C, N}}{\partial H_{f}}=\sum_{i=1}^{N} 2\left[H_{c}-\left(H_{s}+e^{-k_{P C} \beta^{X_{P C}}}\left(H_{f}-H_{s}\right)\right)\right]\left(-e^{-k_{P C} \beta^{X}{ }}\right) \\
& \frac{\partial \varphi_{P C, M}}{\partial H_{0 f}}=\sum_{i=1}^{N} 2\left[H_{C}\right. \\
& -\left(H_{0 s} d_{i}^{n_{s}-2}\right. \\
& \left.\left.+e^{-k_{P C} \beta^{X_{P C}}}\left(H_{0 f} d_{i}^{n_{f}-2}-H_{0 S} d_{i}^{n_{s}-2}\right)\right)\right]\left(-d_{i}^{n_{f}-2} e^{-k_{P C} \beta^{X_{P C}}}\right) \\
& \frac{\partial \varphi_{P C, T}}{\partial H_{0 f}}=\sum_{i=1}^{N} 2\left[H_{c}\right. \\
& -\left(\left(H_{0 s}+\frac{b_{s}}{d_{i}}\right)\right. \\
& \left.\left.+e^{-k_{P C} \beta^{X_{P C}}}\left[\left(H_{0 f}+\frac{b_{f}}{d_{i}}\right)-\left(H_{0 s}+\frac{b_{s}}{d_{i}}\right)\right]\right)\right]\left(-e^{-k_{P C} \beta^{X_{P C}}}\right)
\end{aligned}
$$

The equations for the derivatives required to solve for the ISE film parameters $n_{f}$ and $b_{f}$ are shown below in Equation 4.41 to Equation 4.44. There is no additional parameter for the case when there is no ISE so only the models combined with Meyer and Thomas ISEs are shown below. 


$$
\begin{aligned}
& \frac{\partial \varphi_{K, M}}{\partial n_{f}}=\sum_{i=1}^{N} 2\left[H_{c}-\left(H_{0 s} d_{i}^{n_{s}-2}+\frac{H_{0 f} d_{i}^{n_{f}-2}-H_{0 s} d_{i}^{n_{s}-2}}{1+k_{K} \beta^{X_{K}}}\right)\right]\left(-\frac{H_{0 f} d_{i}^{n_{f}-2} \ln d_{i}}{1+k_{K} \beta^{X_{K}}}\right) \\
& \frac{\partial \varphi_{K, T}}{\partial b_{f}}=\sum_{i=1}^{N} 2\left[H_{c}-\left(\left(H_{0 s}+\frac{b_{s}}{d_{i}}\right)+\frac{\left(H_{0 f}+\frac{b_{f}}{d_{i}}\right)-\left(H_{0 s}+\frac{b_{s}}{d_{i}}\right)}{1+k_{K} \beta^{X_{K}}}\right)\right]\left(-\frac{1}{d_{i}} \frac{1}{1+k_{K} \beta^{X_{K}}}\right) \\
& \frac{\partial \varphi_{P C, M}}{\partial n_{f}}=\sum_{i=1}^{N} 2\left[H_{c}\right. \\
& -\left(H_{0 s} d_{i}^{n_{s}-2}\right. \\
& \left.\left.+e^{-k_{P C} \beta^{X_{P C}}}\left(H_{0 f} d_{i}^{n_{f}-2}-H_{0 s} d_{i}^{n_{s}-2}\right)\right)\right]\left[-e^{-k_{P C} \beta^{X_{P C}}} H_{0 f} d_{i}^{n_{f}-2} \ln d_{i}\right] \\
& \frac{\partial \varphi_{P C, T}}{\partial b_{f}}=\sum_{i=1}^{N} 2\left[H_{c}\right. \\
& -\left(\left(H_{0 s}+\frac{b_{s}}{d_{i}}\right)\right. \\
& \left.\left.+e^{-k_{P C} \beta^{X_{P C}}}\left[\left(H_{0 f}+\frac{b_{f}}{d_{i}}\right)-\left(H_{0 s}+\frac{b_{s}}{d_{i}}\right)\right]\right)\right]\left(-e^{-k_{P C} \beta^{X_{P C}}} \frac{1}{d_{i}}\right)
\end{aligned}
$$

The algorithm is designed to keep track of the parameters which result in the best fit for the data determined by the $r^{2}$-value. As the search progresses, it refines the search space to look in the area of the current best set of values until the desired precision is reached.

\subsubsection{Calibration of the Model and Film Parameters}

The unknown model and film parameters of Equation 4.17 to Equation 4.22 were calibrated using the algorithm depicted in Figure 4.7 and described in Section 4.3.2 above. The precision and initial search space used for the model parameters are shown in Table 4.11. Large variations in film hardness outside of the expected range of about 2500 to $2800 H V$ were encountered when attempting calibration of the parameters using only the VMHT data. In order to reliably and consistently calibrate the model and film parameters, both the VMHT and NHT data were required. The resulting model and film 
parameters for all combinations are shown in Table 4.12 to Table 4.17. Small differences exist between the calibrated values for $57 \mathrm{X}$ and $\mathrm{X} 7$. It is interesting to note that the value of Meyer ISE parameter $n_{f}$ in all cases remains very close to 2 . As $n_{f}$ approaches 2 , the apparent film hardness approaches the value of the absolute film hardness $H_{0 f}$ which effectively negates the use of the ISE. The average film hardness values predicted using the Korsunsky models were all within the expected range whereas the average film hardness values predicted using the Puchi-Cabrera method were all in excess of $3000 \mathrm{HV}$. When comparing the fit of the curves, it can be seen that the $r^{2}$ value was also consistently better for the calibrations performed with the Korsunsky model as opposed to the Puchi-Cabrera model.

\subsubsection{Summary and Selection of Model and Indentation Size Effect}

The Korsunsky/No ISE and Korsunsky/Meyer combinations were selected from the 6 combinations considered to best represent the hardness data. The film hardness, determined by averaging the $57 \mathrm{X}$ and $\mathrm{X} 7$ values, is $2672 \mathrm{HV}$ from $\mathrm{K} / \mathrm{N}$ and $2691 \mathrm{HV}$ from K/M. The calibrated hardness profiles for $57 \mathrm{X}$ and $\mathrm{X} 7$, determined using the $\mathrm{K} / \mathrm{N}$ model, are shown in Figure 4.8 and Figure 4.9. The calibrated hardness profiles for $57 \mathrm{X}$ and X7 using the K/M model are depicted in Figure 4.10 and Figure 4.11. Both K/N and $\mathrm{K} / \mathrm{M}$ exhibit a saturated curve which closely follows the test data. Although the $\mathrm{K} / \mathrm{T}$ model provided both an excellent fit and a film hardness value within the expected range, the hardness profile did not exhibit the saturated behaviour expected for this situation. The PC models were eliminated not only because of the unexpectedly high calibrated film hardness, but also because the hardness profile did not conform to the saturated behaviour expected from the base models and test data. 


\subsection{Prediction of Film Hardness Using Micro-Indentation}

\section{Data}

The film hardness can be estimated from the VMHT data using the model and ISE parameters that were calibrated in the previous section. With the model parameters $k_{K}$ and $X_{K}$ known (and $n_{s}$ ), only the film hardness is unknown. The film hardness is again determined by minimising the sum of the squares of the errors of the fit with the measured hardness using the derivative of the appropriate error function from Section 4.3.2. Given the correct model and ISE parameters, the ability to predict the hardness based only on the VMHT data is verified by simply removing the NHT data and attempting to solve for the hardness of the same die. That is to say, use the VMHT and NHT data from one die to fully calibrate the parameters and then use the calibrated parameters without the NHT data to predict the film hardness of the same die. The calibrated parameters from one die are then used to predict the film hardness of the other die since the model parameters should be the same for the same film-substrate system. Finally, the hardness parameters are averaged and used to predict the film hardness of both test dies. The predicted film hardness for both $57 \mathrm{X}$ and $\mathrm{X} 7$ is shown in Table 4.18 using the $\mathrm{K} / \mathrm{N}$ combination. The predicted film hardness for $57 \mathrm{X}$ and $\mathrm{X} 7$ using Korsunsky/Meyer is shown in Table 4.19.

\subsubsection{Korsunsky/No Indentation Size Effect}

The calibrated values for the model parameters $k_{K}$ and $X_{K}$ are taken from Table 4.12 for both $57 \mathrm{X}$ and $\mathrm{X} 7$. Using the calibrated parameters from $57 \mathrm{X}\left(k_{K}=9.92, X_{K}=1.46\right)$ the film hardness of $57 \mathrm{X}$ was predicted to be $2777 \mathrm{HV}$ with only the VMHT data. This is very close to the calibrated film hardness of $2768 \mathrm{HV}$ determined in Section 4.3. The calibrated and predicted hardness profiles for $57 \mathrm{X}$ are plotted together in Figure 4.12. Similarly, using the calibrated parameters from $\mathrm{X} 7\left(k_{K}=7.33, X_{K}=1.61\right)$, the film hardness of $\mathrm{X} 7$ was predicted to be $2604 H V$ with only the VMHT data. The predicted film hardness for $\mathrm{X} 7$ is also close to its calibrated value of $2577 \mathrm{HV}$. The predicted and calibrated hardness profiles are shown in Figure 4.13 for X7. The predicted film 
hardness is 9 points higher for $57 \mathrm{X}$ and 27 points higher for $\mathrm{X} 7$ giving percent differences of $0.325 \%$ and $1.048 \%$ respectively. The small differences indicate that the film hardness can be successfully estimated from the VMHT data alone when the model parameters are available.

It was attempted to use the calibrated model parameters for $57 \mathrm{X}$ to predict the film hardness of $\mathrm{X} 7$, and vice-versa using only the VMHT data. This situation is particularly useful for the RCM as they will be attempting to quantify the film hardness of die samples in their quality control labs without the use of NHT data for calibrating the model parameters. Using the calibrated model parameters from $57 \mathrm{X}$, the film hardness of $\mathrm{X} 7$ is predicted to be $3069 \mathrm{HV}$, which is significantly higher than the calibrated film hardness of $2577 H V$. Similarly, using the calibrated model parameters from X7, the film hardness of $57 \mathrm{X}$ is predicted to be 2360,408 points lower than the calibrated value of $2768 \mathrm{HV}$. The percent differences in the predicted and calibrated film hardness values are $14.7 \%$ for $57 \mathrm{X}$ and $19.1 \%$ for $\mathrm{X} 7$. The differences here are large and show that the model parameters calibrated from one sample are not sufficient in this case to accurately predict the film hardness of another single sample.

In an attempt to reduce the error, the average calibrated model parameters from Table $4.12\left(k_{K}=8.63, X_{K}=1.53\right)$ were taken and used to predict the film hardness of $57 \mathrm{X}$ and $X 7$. The results of the film hardness prediction for both $57 \mathrm{X}$ and $\mathrm{X} 7$ are shown in Table 4.18. The predicted film hardness for $57 \mathrm{X}$ and $\mathrm{X} 7$ based on the average model parameters are $2559 H V$ and $2825 H V$ respectively (averaging $2692 H V$ together). This gives a percent difference of $7.6 \%$ and $9.6 \%$ between the predicted and calibrated hardness values for $57 \mathrm{X}$ and $\mathrm{X} 7$ respectively. The differences here are smaller however still large enough to be unable to directly predict the film hardness. The film hardness values predicted here suggest that the refinement of an average set of model parameters may be sufficient to verify that the film hardness is within an acceptable range for quality coin production. 


\subsubsection{Korsunsky/Meyer}

The results obtained using the K/M combination are very similar to the results obtained using the $\mathrm{K} / \mathrm{N}$ combination above. This is an expected outcome as the Meyer ISE parameters $n_{f}$ and $n_{s}$ are both close to 2, giving a weak dependence on the ISE. The film hardness is predicted to be $2803 H V$ and $2619 H V$ for $57 \mathrm{X}$ and X7 respectively by using the respective calibrated model parameters. The calibrated film hardness values are 2792 $H V$ and $2590 H V$ for $57 \mathrm{X}$ and $\mathrm{X} 7$ respectively, which gives a difference of 11 and 29 points between the predicted and calibrated hardness values $(0.39 \%$ and $1.12 \%$ difference). The predicted and calibrated hardness profiles are shown in Figure 4.14 for 57X and Figure 4.15 for $\mathrm{X} 7$. As with the $\mathrm{K} / \mathrm{N}$ combination, this shows that the film hardness can be successfully predicted using only VMHT data if the model parameters are accurate for the film-substrate system.

As before, the prediction of the $57 \mathrm{X}$ film hardness was attempted with the model parameters calibrated using $X 7$ and vice-versa. Similar results were encountered since the predicted film hardness of 57X was much lower and the predicted film hardness of $\mathrm{X} 7$ was much higher than their calibrated values. The predicted film hardness of $57 \mathrm{X}$ was $2375 H V$ (calibrated was $2792 H V$ ) while X7 was $3095 H V$ (calibrated was 2590 $H V$ ). These values represent a percent difference of $15.6 \%$ for the $57 \mathrm{X}$ hardness and $19.5 \%$ for X7. The differences here again indicate that the hardness of the film could not be determined by using the model parameters of one trial to predict the hardness of another single sample.

In an attempt to minimise the errors, the same prediction was attempted using the average of the model parameters for $\mathrm{K} / \mathrm{M}$ for both $57 \mathrm{X}$ and $\mathrm{X} 7$. Using the average parameters, the predicted film hardnesses of $2579 H V$ for $57 \mathrm{X}$ and $2846 H V$ for $\mathrm{X} 7$ along with the parameters used in the prediction are shown in Table 4.19. The errors are slightly reduced giving a percent difference between predicted and calibrated hardness values of $7.63 \%$ for $57 \mathrm{X}$ and $9.88 \%$ for $\mathrm{X} 7$. The average predicted hardness between $57 \mathrm{X}$ and $\mathrm{X} 7$ using average model parameters is $2712.5 \mathrm{HV}$. 


\subsection{Demonstration of the Predictive Method}

Two circulation dies made from the same materials and processes were used to demonstrate the use of the method described above. To be useful, the film hardness must be reasonably determined without the use of nano-indentation hardness testing on the coated surface. The two test dies, 100278-6X and 100278-7X, were cleaned using isopropyl alcohol and a lint-free cloth. Micro-indentation testing was performed for test weights of $5,10,15,25,50$ and $100 \mathrm{~g} f$ on each die. The measurements and algorithm input parameters can be seen in Table 4.20 and Table 4.21 for 100278-6X and 100278$7 \mathrm{X}$ respectively. The thickness of each die was also measured using a calotest and was found to be $1.35 \mu \mathrm{m}$ for 100278-6X and $1.58 \mu \mathrm{m}$ for 100278-7X. Because these dies were already coated, the substrate hardness was assumed to be $700 \mathrm{HV}$ as both $57 \mathrm{X}$ and $\mathrm{X} 7$ were consistently measured to be near this value. It is shown in Chapter 5 that $57 \mathrm{X}$ was found to have poor adhesion which affected the calibration of the model parameters. Previous testing at the RCM has found the coating to be consistently well-adhered so the model parameters from $X 7\left(k_{k}=7.33\right.$ and $\left.X_{k}=1.61\right)$ were selected for the demonstration. Further to this, the ISE was not used as it increased complexity without significantly improving the results. In other words, the demonstration was performed using $\mathrm{K} / \mathrm{N}$ with model parameters calibrated using X7. The resulting curves can be seen in Figure 4.16 and Figure 4.17 for 100278-6X and 100278-7X respectively. The film hardness was determined to be $2888 H V$ for $100278-6 \mathrm{X}$ with an $r^{2}$-value of 0.941 . The same values for 100278-7X were $2834 H V$ and 0.882 . One data point from 100278-7X can be seen to be away from the expected trend and contributes to the lower $r^{2}$-value. The hardness values here are consistent and are within an acceptable range of the calibrated hardness value of $2672 H V$.

\subsection{Summary and Conclusions}

A total of six different thin-film hardness models were investigated with three different indentation size effect models. From an initial analysis of the models and ISEs, two thinfilm hardness models and two ISEs were selected for further analysis. The thin-film models were used as written as well as in combination with the two ISEs giving a total of 
six combinations of model and ISE. The calibration of the model parameters for all six combinations of hardness model and ISE was successfully performed and $\mathrm{K} / \mathrm{N}$ and $\mathrm{K} / \mathrm{M}$ were selected as the best representation of the experimental data. The film hardness was determined from the average of each die to be $2672 H V$ by K/N and $2691 H V$ by K/M.

The calibrated model parameters were similar but different for the two dies which indicates the film-substrate system did not behave identically for each die. Because the calibrated model parameters were not the same, the prediction of the hardness of one die from the other's model parameters was unsuccessful. The average calibrated model parameters produced smaller errors when attempting to predict the film hardness of each die but still were not able to accurately predict the film hardness of either die. The prediction of the hardness was successful when the prediction was performed using the model parameters from the same die. This shows that the film hardness could be predicted using only the VMHT data if the model parameters are consistent for the filmsubstrate system.

Although the addition of the Meyer ISE to the Korsunsky model produced good results, the model accuracy was only minimally increased over the base Korsunsky model. From these results it is evident that the Korsunsky model is sufficient to model the thin-film hardness behaviour of the thin-film system analysed herein. The inclusion of the Meyer ISE is unnecessary as it increases the complexity of the analysis without significantly contributing to the accuracy of the results.

The method described in this chapter for predicting the film hardness using only microindentation test data has been demonstrated for two dies provided by the RCM. The method was shown to be consistent and accurate within an acceptable range. The model parameters are consistent between systems of the same composition such that calibrations using nano-indentation test data are not necessary. The hardness of the two dies used for this demonstration were determined to be $2888 \mathrm{HV}$ and $2834 \mathrm{HV}$. 


\begin{tabular}{|l||c||c|}
\hline Film Thickness & $t$ & $2.5 \mu \mathrm{m}$ \\
\hline Film Young's Modulus & $E_{f}$ & $300 \mathrm{GPa}$ \\
\hline Film Hardness & $H_{f}$ & $2500 \mathrm{HV}$ \\
\hline Substrate Young's Modulus & $E_{s}$ & $200 \mathrm{GPa}$ \\
\hline Substrate Hardness & $H_{s}$ & $750 \mathrm{HV}$ \\
\hline
\end{tabular}

Table 4.1: Sample material properties used for preparation of Figure 4.1 for model selection

\begin{tabular}{|c|c|c|}
\hline \multirow{2}{*}{$C$} & $\begin{array}{l}\text { *Arbitrarily decide that cracking initiates at } \\
\text { a relative indentation depth of } 1 \text { and assign } \\
\text { the appropriate value for } C \text { (see Section } \\
2.3 .1) .\end{array}$ \\
\cline { 2 - 3 } & $\beta<1$ & $C=C_{1}=\sin ^{2} 22^{\circ}$ \\
\cline { 2 - 3 } & $\beta \geq 1$ & $68^{\circ}=2 \sin ^{2} 11^{\circ}$ \\
\hline$\xi$ & 2 \\
\hline$k_{K}$ & 2 \\
\hline$X_{K}$ & 2 \\
\hline$k_{P C}$ & 2 \\
\hline$X_{P C}$ & \multicolumn{2}{|c|}{2} \\
\hline
\end{tabular}

Table 4.2: Sample model parameters used for preparation of Figure 4.1 for model selection 


\begin{tabular}{|c|c|c|}
\hline & $\begin{array}{c}\text { Absolute } \\
\text { Hardness }\end{array}$ & ISE Parameter \\
\hline \hline Die & $\mathbf{H}_{\mathbf{0 s}}(\boldsymbol{H V})$ & $\mathbf{n}_{\mathbf{s}}(\boldsymbol{H V m})$ \\
\hline \hline $\mathbf{5 7 X}$ & 1326.5 & 2.1503 \\
\hline $\mathbf{X 7}$ & 702.63 & 2.0030 \\
\hline
\end{tabular}

Table 4.3: Absolute hardness and ISE parameter from Meyer ISE

Notes for Table 4.3:

- X7 substrate hardness parameters will be used for $57 \mathrm{X}$ since the indentation data for each die is very similar and the curve represented by the $\mathrm{X} 7$ data is more representative of the actual data.

\begin{tabular}{|c|c|c|}
\hline & $\begin{array}{c}\text { Absolute } \\
\text { Hardness }\end{array}$ & ISE Parameter \\
\hline \hline Die & $\mathbf{H}_{\mathbf{0 s}}(\boldsymbol{H V})$ & $\mathbf{b}_{\mathbf{s}}(\boldsymbol{H} \boldsymbol{V m})$ \\
\hline \hline $\mathbf{5 7 X}$ & 762.61 & -0.00074338 \\
\hline $\mathbf{X 7}$ & 738.12 & -0.00034308 \\
\hline
\end{tabular}

Table 4.4: Absolute hardness and ISE parameter from Thomas ISE

\begin{tabular}{|c|c|c|c|}
\hline & No ISE & Meyer ISE & Thomas ISE \\
\hline 57X & $H_{s}=697.6 \mathrm{HV}_{200 g f}$ & $\begin{array}{c}H_{0 s}=702.63 \mathrm{HV} \\
n_{s}=2.0030\end{array}$ & $\begin{array}{c}H_{0 s}=762.61 \mathrm{HV} \\
b_{s}=-0.00074338\end{array}$ \\
\hline $\mathbf{X 7}$ & $H_{s}=697.0 \mathrm{HV}_{200 g f}$ & $\begin{array}{c}H_{0 s}=702.63 \mathrm{HV} \\
n_{s}=2.0030\end{array}$ & $\begin{array}{c}H_{0 s}=738.12 \mathrm{HV} \\
b_{s}=-0.00034308\end{array}$ \\
\hline
\end{tabular}

Table 4.5: Summary of substrate hardness model parameters being used in the thin-film analysis 


\begin{tabular}{|c|c|c|}
\hline Average Diagonal & Relative Indentation Depth & Calculated Hardness \\
\hline d $(m)$ & $\mathbf{\beta}$ & $\mathbf{H}_{\mathrm{c}}(\boldsymbol{H V})$ \\
\hline $2.07 \mathrm{E}-06$ & 0.1357 & 2161.3 \\
\hline $2.10 \mathrm{E}-06$ & 0.1377 & 2100.0 \\
\hline $2.14 \mathrm{E}-06$ & 0.1401 & 2029.4 \\
\hline $2.12 \mathrm{E}-06$ & 0.1388 & 2065.4 \\
\hline $2.15 \mathrm{E}-06$ & 0.1406 & 2015.2 \\
\hline $3.43 \mathrm{E}-06$ & 0.2245 & 1579.7 \\
\hline $4.08 \mathrm{E}-06$ & 0.2674 & 1114.0 \\
\hline $3.58 \mathrm{E}-06$ & 0.2344 & 1448.9 \\
\hline $3.42 \mathrm{E}-06$ & 0.2239 & 1588.9 \\
\hline $3.23 \mathrm{E}-06$ & 0.2116 & 1778.8 \\
\hline $4.07 \mathrm{E}-06$ & 0.2664 & 1683.3 \\
\hline $4.08 \mathrm{E}-06$ & 0.2670 & 1675.1 \\
\hline $4.25 \mathrm{E}-06$ & 0.2783 & 1541.8 \\
\hline $4.27 \mathrm{E}-06$ & 0.2800 & 1523.8 \\
\hline $4.25 \mathrm{E}-06$ & 0.2782 & 1543.6 \\
\hline $5.75 \mathrm{E}-06$ & 0.3768 & 1402.2 \\
\hline $5.82 \mathrm{E}-06$ & 0.3816 & 1367.5 \\
\hline $5.63 \mathrm{E}-06$ & 0.3688 & 1463.9 \\
\hline $5.77 \mathrm{E}-06$ & 0.3779 & 1393.7 \\
\hline $5.93 \mathrm{E}-06$ & 0.3884 & 1319.5 \\
\hline $9.66 \mathrm{E}-06$ & 0.6332 & 993.1 \\
\hline $9.36 \mathrm{E}-06$ & 0.6130 & 1059.5 \\
\hline $9.51 \mathrm{E}-06$ & 0.6232 & 1025.2 \\
\hline $9.49 \mathrm{E}-06$ & 0.6217 & 1030.1 \\
\hline $9.54 \mathrm{E}-06$ & 0.6252 & 1018.8 \\
\hline $1.48 \mathrm{E}-05$ & 0.9671 & 851.5 \\
\hline $1.43 \mathrm{E}-05$ & 0.9341 & 912.6 \\
\hline $1.44 \mathrm{E}-05$ & 0.9425 & 896.5 \\
\hline $1.44 \mathrm{E}-05$ & 0.9418 & 897.7 \\
\hline $1.44 \mathrm{E}-05$ & 0.9433 & 894.9 \\
\hline $2.11 \mathrm{E}-05$ & 1.3858 & 829.3 \\
\hline $2.12 \mathrm{E}-05$ & 1.3865 & 828.5 \\
\hline $2.12 \mathrm{E}-05$ & 1.3866 & 828.3 \\
\hline $2.12 \mathrm{E}-05$ & 1.3883 & 826.4 \\
\hline $2.10 \mathrm{E}-05$ & 1.3776 & 839.2 \\
\hline $2.72 \mathrm{E}-05$ & 1.7851 & 749.7 \\
\hline $2.76 \mathrm{E}-05$ & 1.8096 & 729.5 \\
\hline $2.64 \mathrm{E}-05$ & 1.7310 & 797.3 \\
\hline $3.47 \mathrm{E}-05$ & 2.2767 & 768.2 \\
\hline $3.56 \mathrm{E}-05$ & 2.3299 & 733.5 \\
\hline $3.57 \mathrm{E}-05$ & 2.3401 & 727.1 \\
\hline
\end{tabular}

Table 4.6: Micro-indentation input data for $57 \mathrm{X}$ 


\begin{tabular}{|c|c|c|}
\hline Average Diagonal & Relative Indentation Depth & Calculated Hardness \\
\hline $\mathbf{d}(\boldsymbol{m})$ & $\boldsymbol{\beta}$ & $\mathbf{H}_{\mathbf{c}}(H V)$ \\
\hline $1.90 \mathrm{E}-06$ & 0.1050 & 2558.3 \\
\hline $2.00 \mathrm{E}-06$ & 0.1105 & 2312.2 \\
\hline $2.09 \mathrm{E}-06$ & 0.1155 & 2115.1 \\
\hline $2.06 \mathrm{E}-06$ & 0.1133 & 2195.6 \\
\hline $2.08 \mathrm{E}-06$ & 0.1149 & 2135.4 \\
\hline $3.28 \mathrm{E}-06$ & 0.1810 & 1722.4 \\
\hline $3.23 \mathrm{E}-06$ & 0.1780 & 1780.2 \\
\hline $3.08 \mathrm{E}-06$ & 0.1700 & 1953.2 \\
\hline $3.13 \mathrm{E}-06$ & 0.1727 & 1891.3 \\
\hline $3.15 \mathrm{E}-06$ & 0.1736 & 1871.9 \\
\hline $4.14 \mathrm{E}-06$ & 0.2282 & 1624.9 \\
\hline $4.23 \mathrm{E}-06$ & 0.2333 & 1554.6 \\
\hline $4.17 \mathrm{E}-06$ & 0.2300 & 1599.6 \\
\hline $4.16 \mathrm{E}-06$ & 0.2296 & 1605.4 \\
\hline $4.13 \mathrm{E}-06$ & 0.2279 & 1628.8 \\
\hline $5.40 \mathrm{E}-06$ & 0.2980 & 1588.4 \\
\hline $5.54 \mathrm{E}-06$ & 0.3053 & 1513.2 \\
\hline $5.80 \mathrm{E}-06$ & 0.3196 & 1380.5 \\
\hline $5.42 \mathrm{E}-06$ & 0.2988 & 1579.6 \\
\hline $5.45 \mathrm{E}-06$ & 0.3006 & 1560.8 \\
\hline $9.27 \mathrm{E}-06$ & 0.5110 & 1080.1 \\
\hline $9.08 \mathrm{E}-06$ & 0.5008 & 1124.6 \\
\hline $9.16 \mathrm{E}-06$ & 0.5054 & 1104.4 \\
\hline $9.12 \mathrm{E}-06$ & 0.5029 & 1115.4 \\
\hline $9.42 \mathrm{E}-06$ & 0.5193 & 1046.0 \\
\hline $1.31 \mathrm{E}-05$ & 0.7232 & 1078.5 \\
\hline $1.38 \mathrm{E}-05$ & 0.7614 & 973.0 \\
\hline $1.37 \mathrm{E}-05$ & 0.7566 & 985.5 \\
\hline $1.37 \mathrm{E}-05$ & 0.7555 & 988.4 \\
\hline $1.35 \mathrm{E}-05$ & 0.7464 & 1012.6 \\
\hline $2.07 \mathrm{E}-05$ & 1.1418 & 865.6 \\
\hline $2.07 \mathrm{E}-05$ & 1.1429 & 863.9 \\
\hline $2.09 \mathrm{E}-05$ & 1.1546 & 846.4 \\
\hline $2.07 \mathrm{E}-05$ & 1.1395 & 868.9 \\
\hline $2.07 \mathrm{E}-05$ & 1.1390 & 869.7 \\
\hline $2.63 \mathrm{E}-05$ & 1.4527 & 802.0 \\
\hline $2.63 \mathrm{E}-05$ & 1.4480 & 807.2 \\
\hline $2.61 \mathrm{E}-05$ & 1.4388 & 817.6 \\
\hline $3.41 \mathrm{E}-05$ & 1.8828 & 795.7 \\
\hline $3.44 \mathrm{E}-05$ & 1.8971 & 783.8 \\
\hline $3.43 \mathrm{E}-05$ & 1.8919 & 788.1 \\
\hline
\end{tabular}

Table 4.7: Micro-indentation input data for X7 


\begin{tabular}{|c|c|c|c|}
\hline $\begin{array}{c}\text { Indent } \\
\text { Depth }(\boldsymbol{m})\end{array}$ & $\begin{array}{c}\text { Equivalent } \\
\text { Indent } \\
\text { Diagonal } \\
(\boldsymbol{m})\end{array}$ & $\begin{array}{c}\text { Relative } \\
\text { Indentation } \\
\text { Depth }\end{array}$ & $\begin{array}{c}\text { Hardness } \\
(\boldsymbol{H} \boldsymbol{V})\end{array}$ \\
\hline \hline $\mathbf{D}\left(\mathbf{o r} \mathbf{H}_{\mathbf{0}}\right)$ & $\mathbf{d}$ & $\boldsymbol{\beta}$ & $\mathbf{H}_{\mathbf{c}}$ \\
\hline $1.47 \mathrm{E}-07$ & $1.27 \mathrm{E}-06$ & 0.0676 & 2417.2 \\
\hline $1.11 \mathrm{E}-07$ & $9.51 \mathrm{E}-07$ & 0.0508 & 2567.5 \\
\hline $1.17 \mathrm{E}-07$ & $1.01 \mathrm{E}-06$ & 0.0537 & 2472.6 \\
\hline $1.06 \mathrm{E}-07$ & $9.09 \mathrm{E}-07$ & 0.0485 & 2671.1 \\
\hline $1.23 \mathrm{E}-07$ & $1.05 \mathrm{E}-06$ & 0.0562 & 2352.9 \\
\hline
\end{tabular}

Table 4.8: Nano-indentation input data for $57 \mathrm{X}$

\begin{tabular}{|c|c|c|c|}
\hline $\begin{array}{c}\text { Indent } \\
\text { Depth }(\boldsymbol{m})\end{array}$ & $\begin{array}{c}\text { Equivalent } \\
\text { Indent } \\
\text { Diagonal } \\
(\boldsymbol{m})\end{array}$ & $\begin{array}{c}\text { Relative } \\
\text { Indentation } \\
\text { Depth }\end{array}$ & $\begin{array}{c}\text { Hardness } \\
(\boldsymbol{H} \boldsymbol{V})\end{array}$ \\
\hline \hline D (or H $)$ & $\mathbf{d}$ & $\boldsymbol{\beta}$ & $\mathbf{H}_{\mathbf{c}}$ \\
\hline \hline $1.19 \mathrm{E}-07$ & $1.02 \mathrm{E}-06$ & 0.0459 & 2466.6 \\
\hline $1.07 \mathrm{E}-07$ & $9.22 \mathrm{E}-07$ & 0.0414 & 2613.4 \\
\hline $1.23 \mathrm{E}-07$ & $1.06 \mathrm{E}-06$ & 0.0477 & 2372.4 \\
\hline $1.27 \mathrm{E}-07$ & $1.09 \mathrm{E}-06$ & 0.0492 & 2260.1 \\
\hline
\end{tabular}

Table 4.9: Nano-indentation input data for $X 7$ 


\begin{tabular}{|c|c|c|c|}
\hline & No ISE & With Meyer ISE & With Thomas ISE \\
\hline Korsunsky & $\mathrm{k}_{\mathrm{K}}, \mathrm{X}_{\mathrm{K}}, \mathrm{H}_{\mathrm{f}}$ & $\mathrm{k}_{\mathrm{K}}, \mathrm{X}_{\mathrm{K}}, \mathrm{H}_{0 \mathrm{f}}, \mathrm{n}_{\mathrm{f}}$ & $\mathrm{k}_{\mathrm{K}}, \mathrm{X}_{\mathrm{K}}, \mathrm{H}_{\mathrm{f}}, \mathrm{b}_{\mathrm{f}}$ \\
\hline Puchi-Cabrera & $\mathrm{k}_{\mathrm{PC}}, \mathrm{X}_{\mathrm{PC}}, \mathrm{H}_{\mathrm{f}}$ & $\mathrm{k}_{\mathrm{PC}}, \mathrm{X}_{\mathrm{PC}}, \mathrm{H}_{0 \mathrm{f}}, \mathrm{n}_{\mathrm{f}}$ & $\mathrm{k}_{\mathrm{PC}}, \mathrm{X}_{\mathrm{PC}}, \mathrm{H}_{\mathrm{f}}, \mathrm{b}_{\mathrm{f}}$ \\
\hline
\end{tabular}

Table 4.10: Summary of parameters to be calibrated simultaneously for all 6 selected combinations of model and indentation size effect

\begin{tabular}{|c|c|c|c|c|c|c|c|c|}
\hline \multirow{2}{*}{ Model } & \multicolumn{4}{|c|}{$k$} & \multicolumn{4}{|c|}{ X } \\
\cline { 2 - 9 } & Low & High & $\begin{array}{c}\text { Initial } \\
\text { Step Size }\end{array}$ & $\begin{array}{c}\text { Final } \\
\text { Precision }\end{array}$ & Low & High & $\begin{array}{c}\text { Initial } \\
\text { Step Size }\end{array}$ & $\begin{array}{c}\text { Final } \\
\text { Precision }\end{array}$ \\
\hline Korsunsky & 3 & 25 & 1 & $<=0.01$ & 1 & 5 & 0.25 & $<=0.01$ \\
\hline $\begin{array}{c}\text { Puchi- } \\
\text { Cabrera }\end{array}$ & 1 & 3 & 0.1 & $<=0.01$ & 0.5 & 1 & 0.1 & $<=0.01$ \\
\hline
\end{tabular}

Table 4.11: Initial search space used for calibration of the model parameters 


\begin{tabular}{|c|c|c|c|c|c|c|}
\hline Die & $\mathbf{k}_{\mathbf{K}}$ & $\mathbf{X}_{\mathbf{K}}$ & $\mathbf{H}_{\mathbf{f}}$ & $\mathbf{H}_{\mathbf{s}}$ & $\mathbf{t}$ & $\mathbf{r}^{\mathbf{2}}$ \\
\hline $\mathbf{5 7 X}$ & 9.92 & 1.46 & 2768 & 697.59 & $2.18 \mathrm{E}-06$ & 0.9739 \\
\hline $\mathbf{X 7}$ & 7.33 & 1.61 & 2577 & 696.98 & $2.59 \mathrm{E}-06$ & 0.9750 \\
\hline Average & 8.63 & 1.53 & 2672 & & & \\
\hline
\end{tabular}

Table 4.12: Calibrated parameters for $57 X$ and $X 7$ using Korsunsky/No ISE

\begin{tabular}{|c|c|c|c|c|c|c|}
\hline Die & $\mathbf{k}_{\mathbf{P C}}$ & $\mathbf{X}_{\mathbf{P C}}$ & $\mathbf{H}_{\mathbf{f}}$ & $\mathbf{H}_{\mathbf{s}}$ & $\mathbf{t}$ & $\mathbf{r}^{2}$ \\
\hline $\mathbf{5 7 X}$ & 2.76 & 0.64 & 3493 & 697.59 & $2.18 \mathrm{E}-06$ & 0.9727 \\
\hline $\mathbf{X 7}$ & 2.29 & 0.82 & 2880 & 696.98 & $2.59 \mathrm{E}-06$ & 0.9666 \\
\hline Average & 2.52 & 0.73 & 3186 & & & \\
\hline
\end{tabular}

Table 4.13: Calibrated parameters for $57 \mathrm{X}$ and $\mathrm{X} 7$ using Puchi-Cabrera/No ISE

\begin{tabular}{|c|c|c|c|c|c|c|c|c|}
\hline Die & $\mathbf{k}_{\mathbf{K}}$ & $\mathbf{X}_{\mathbf{K}}$ & $\mathbf{H}_{\mathbf{0 f}}$ & $\mathbf{n}_{\mathbf{f}}$ & $\mathbf{H}_{\mathbf{0 s}}$ & $\mathbf{n}_{\mathbf{s}}$ & $\mathbf{t}$ & $\mathbf{r}^{2}$ \\
\hline $\mathbf{5 7 X}$ & 9.24 & 1.41 & 2792 & 1.999998 & 702.63 & 2.003000 & $2.18 \mathrm{E}-06$ & 0.9740 \\
\hline $\mathbf{X 7}$ & 6.82 & 1.55 & 2590 & 2.000004 & 702.63 & 2.003000 & $2.59 \mathrm{E}-06$ & 0.9745 \\
\hline Average & 8.03 & 1.48 & 2691 & 2.000001 & & & & \\
\hline
\end{tabular}

Table 4.14: Calibrated parameters for $57 X$ and $X 7$ using Korsunsky/Meyer

\begin{tabular}{|c|c|c|c|c|c|c|c|c|}
\hline Die & $\mathbf{k}_{\mathbf{P C}}$ & $\mathbf{X}_{\mathbf{P C}}$ & $\mathbf{H}_{\mathbf{0 f}}$ & $\mathbf{n}_{\mathbf{f}}$ & $\mathbf{H}_{\mathbf{0 s}}$ & $\mathbf{n}_{\mathbf{s}}$ & $\mathbf{t}$ & $\mathbf{r}^{2}$ \\
\hline $\mathbf{5 7 X}$ & 2.69 & 0.62 & 3566 & 1.999999 & 702.63 & 2.003000 & $2.18 \mathrm{E}-06$ & 0.9723 \\
\hline $\mathbf{X 7}$ & 2.22 & 0.79 & 2907 & 1.999996 & 702.63 & 2.003000 & $2.59 \mathrm{E}-06$ & 0.9657 \\
\hline Average & 2.45 & 0.71 & 3236 & 1.999997 & & & & \\
\hline
\end{tabular}

Table 4.15: Calibrated parameters for 57X and X7 using Puchi-Cabrera/Meyer 


\begin{tabular}{|c|c|c|c|c|c|c|c|c|}
\hline Die & $\mathbf{k}_{\mathbf{K}}$ & $\mathbf{X}_{\mathbf{K}}$ & $\mathbf{H}_{\mathbf{~} \mathbf{f}}$ & $\mathbf{b}_{\mathbf{f}}$ & $\mathbf{H}_{\mathbf{0}}$ & $\mathbf{b}_{\mathbf{s}}$ & $\mathbf{t}$ & $\mathbf{r}^{2}$ \\
\hline $\mathbf{5 7 X}$ & 10.46 & 1.62 & 2739 & $5.28 \mathrm{E}-06$ & 762.61 & $-7.43 \mathrm{E}-04$ & $2.18 \mathrm{E}-06$ & 0.9727 \\
\hline $\mathbf{X 7}$ & 7.97 & 1.71 & 2569 & $-5.38 \mathrm{E}-06$ & 738.12 & $-3.43 \mathrm{E}-04$ & $2.59 \mathrm{E}-06$ & 0.9755 \\
\hline Average & 9.22 & 1.66 & 2654 & $-4.94 \mathrm{E}-08$ & & & & \\
\hline
\end{tabular}

Table 4.16: Calibrated parameters for $57 \mathrm{X}$ and $\mathrm{X7}$ using Korsunsky/Thomas

\begin{tabular}{|c|c|c|c|c|c|c|c|c|}
\hline Die & $\mathbf{k}_{\mathbf{P C}}$ & $\mathbf{X}_{\mathbf{P C}}$ & $\mathbf{H}_{\mathbf{~} \mathrm{f}}$ & $\mathbf{b}_{\mathbf{f}}$ & $\mathbf{H}_{\mathbf{0 s}}$ & $\mathbf{b}_{\mathbf{s}}$ & $\mathbf{t}$ & $\mathbf{r}^{2}$ \\
\hline $\mathbf{5 7 X}$ & 2.91 & 0.73 & 3556 & $-5.62 \mathrm{E}-07$ & 762.61 & $-7.43 \mathrm{E}-04$ & $2.18 \mathrm{E}-06$ & 0.9728 \\
\hline $\mathbf{X 7}$ & 2.42 & 0.89 & 2863 & $-1.25 \mathrm{E}-05$ & 738.12 & $-3.43 \mathrm{E}-04$ & $2.59 \mathrm{E}-06$ & 0.9677 \\
\hline Average & 2.67 & 0.81 & 3210 & $-6.52 \mathrm{E}-6$ & & & & \\
\hline
\end{tabular}

Table 4.17: Calibrated parameters for 57X and X7 using Puchi-Cabrera/Thomas 


\begin{tabular}{|l|c|c|c|c|}
\hline \multirow{2}{*}{ Method } & \multirow{2}{*}{$\mathbf{k}_{\mathbf{K}}$} & \multirow{2}{*}{$\mathbf{X}_{\mathbf{K}}$} & \multicolumn{2}{c|}{ Predicted Hardness, $\mathbf{H}_{\mathbf{f}}$} \\
\cline { 4 - 5 } & & & $\mathbf{5 7 X}$ & $\mathbf{X 7}$ \\
\hline \hline Calibrated with NHT data & & & 2768 & 2577 \\
\hline \hline Predicted using 57X parameters & 9.92 & 1.46 & 2777 & 3069 \\
\hline Predicted using X7 parameters & 7.33 & 1.61 & 2360 & 2604 \\
\hline Predicted using average parameters & 8.63 & 1.53 & 2559 & 2825 \\
\hline
\end{tabular}

Table 4.18: Predicted film hardness values for 57X and X7 using Korsunsky/No ISE

\begin{tabular}{|l|c|c|c|c|c|}
\hline \multirow{2}{*}{ Method } & \multirow{2}{*}{$\mathbf{k}_{\mathbf{K}}$} & \multirow{2}{*}{$\mathbf{X}_{\mathbf{K}}$} & \multirow{2}{*}{$\mathbf{n}_{\mathbf{f}}$} & \multicolumn{2}{|c|}{ Predicted Hardness, $\mathbf{H}_{\mathbf{0 f}}$} \\
\cline { 5 - 7 } & & & & $\mathbf{5 7 X}$ & $\mathbf{X 7}$ \\
\hline \hline Calibrated with NHT data & & & & 2792 & 2590 \\
\hline \hline Predicted using 57X parameters & 9.24 & 1.41 & 2.0000 & 2803 & 3095 \\
\hline Predicted using X7 parameters & 6.82 & 1.55 & 2.0000 & 2375 & 2619 \\
\hline Predicted using average parameters & 8.03 & 1.48 & 2.0000 & 2579 & 2846 \\
\hline
\end{tabular}

Table 4.19: Predicted film hardness values for $57 X$ and $X 7$ using Korsunsky/Meyer 


\begin{tabular}{|c|c|c|c|c|c|c|c|c|c|}
\hline \multirow[b]{3}{*}{ 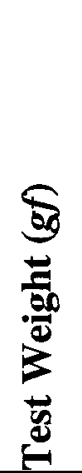 } & \multicolumn{6}{|c|}{ Measurement } & \multirow{2}{*}{\multicolumn{3}{|c|}{ Algorithm Input }} \\
\hline & \multicolumn{3}{|c|}{1} & \multicolumn{3}{|c|}{2} & & & \\
\hline & \multicolumn{2}{|c|}{ 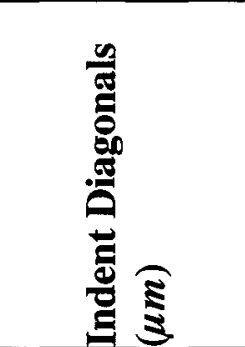 } & \multirow[t]{2}{*}{  } & \multicolumn{2}{|c|}{ 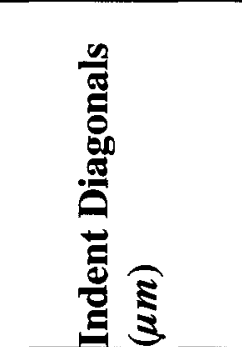 } & \multirow[t]{2}{*}{ 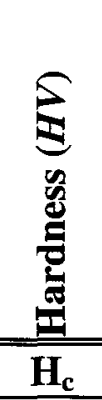 } & \multirow[t]{2}{*}{ 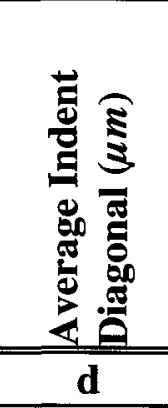 } & \multirow[t]{2}{*}{ 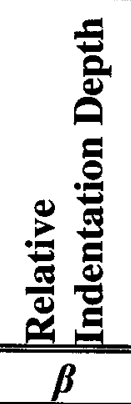 } & 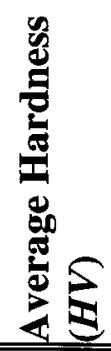 \\
\hline $\mathbf{P}$ & $d_{1}$ & $\overline{d_{2}}$ & & $d_{1}$ & $\overline{d_{2}}$ & & & & $\mathbf{H}_{c}$ \\
\hline$\overline{5}$ & 2.03 & 2.37 & 1914 & 1.94 & 2.35 & 2019 & $\overline{2.21 \mathrm{E}-06}$ & 0.2336 & 1903 \\
\hline 10 & 3.40 & 3.31 & 1648 & 3.39 & 3.53 & 1548 & $3.41 \mathrm{E}-06$ & 0.3606 & 1597 \\
\hline 15 & 4.27 & 4.11 & 1587 & 4.47 & 4.56 & 1359 & $4.35 \mathrm{E}-06$ & 0.4606 & 1468 \\
\hline 25 & 5.73 & 5.85 & 1384 & 6.22 & 6.10 & 1222 & $5.98 \mathrm{E}-06$ & 0.6323 & 1299 \\
\hline 50 & 9.29 & 9.54 & 1046 & 9.68 & 9.51 & 1007 & $9.51 \mathrm{E}-06$ & 1.0058 & 1026 \\
\hline 100 & 13.89 & 14.00 & 954 & 14.12 & 14.12 & 930 & $1.40 \mathrm{E}-05$ & 1.4849 & 942 \\
\hline
\end{tabular}

Table 4.20: Micro-indentation test data and algorithm input for 100278-6X

\begin{tabular}{|c|c|c|c|c|c|c|c|c|c|}
\hline \multirow[b]{3}{*}{ 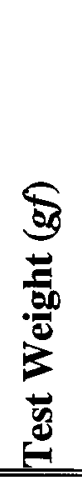 } & \multicolumn{6}{|c|}{ Measurement } & \multirow{2}{*}{\multicolumn{3}{|c|}{ Algorithm Input }} \\
\hline & \multicolumn{3}{|c|}{1} & \multicolumn{3}{|c|}{2} & & & \\
\hline & \multicolumn{2}{|c|}{ 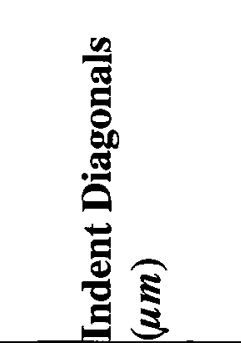 } & \multirow[t]{2}{*}{ 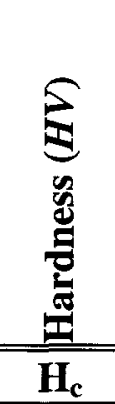 } & \multicolumn{2}{|c|}{ 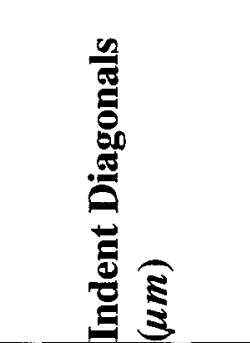 } & \multirow[t]{2}{*}{ 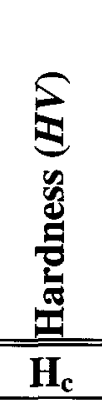 } & \multirow[t]{2}{*}{ 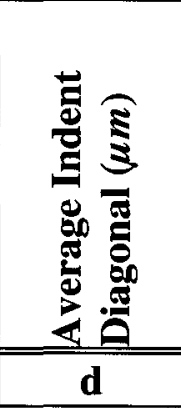 } & \multirow[t]{2}{*}{ 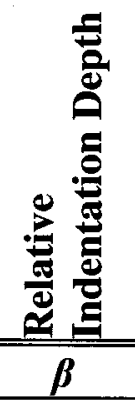 } & \multirow[t]{2}{*}{ 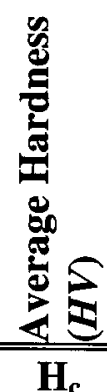 } \\
\hline $\mathbf{P}$ & $d_{1}$ & $\overline{d_{2}}$ & & $d_{1}$ & $\mathrm{~d}_{2}$ & & & & \\
\hline 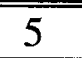 & 2.00 & 2.35 & 1965 & 2.15 & 2.23 & 1937 & $2.18 \mathrm{E}-06$ & 0.2051 & 1947 \\
\hline 10 & 3.53 & 3.54 & 1484 & 3.43 & 3.43 & 1577 & $3.48 \mathrm{E}-06$ & 0.3273 & 1529 \\
\hline 15 & 4.00 & 4.14 & 1679 & 4.12 & 4.14 & 1630 & $4.10 \mathrm{E}-06$ & 0.3853 & 1655 \\
\hline 25 & 5.71 & 5.59 & 1451 & 5.83 & 5.54 & 1435 & $5.67 \mathrm{E}-06$ & 0.5327 & 1443 \\
\hline 50 & 8.97 & 9.17 & 1128 & 9.02 & 9.11 & 1129 & $9.07 \mathrm{E}-06$ & 0.8522 & 1128 \\
\hline 100 & 14.25 & 14.30 & 910 & 14.20 & 14.33 & 911 & $1.43 \mathrm{E}-05$ & 1.3412 & 911 \\
\hline
\end{tabular}

Table 4.21: Micro-indentation test data and algorithm input for 100278-6X 
1) 

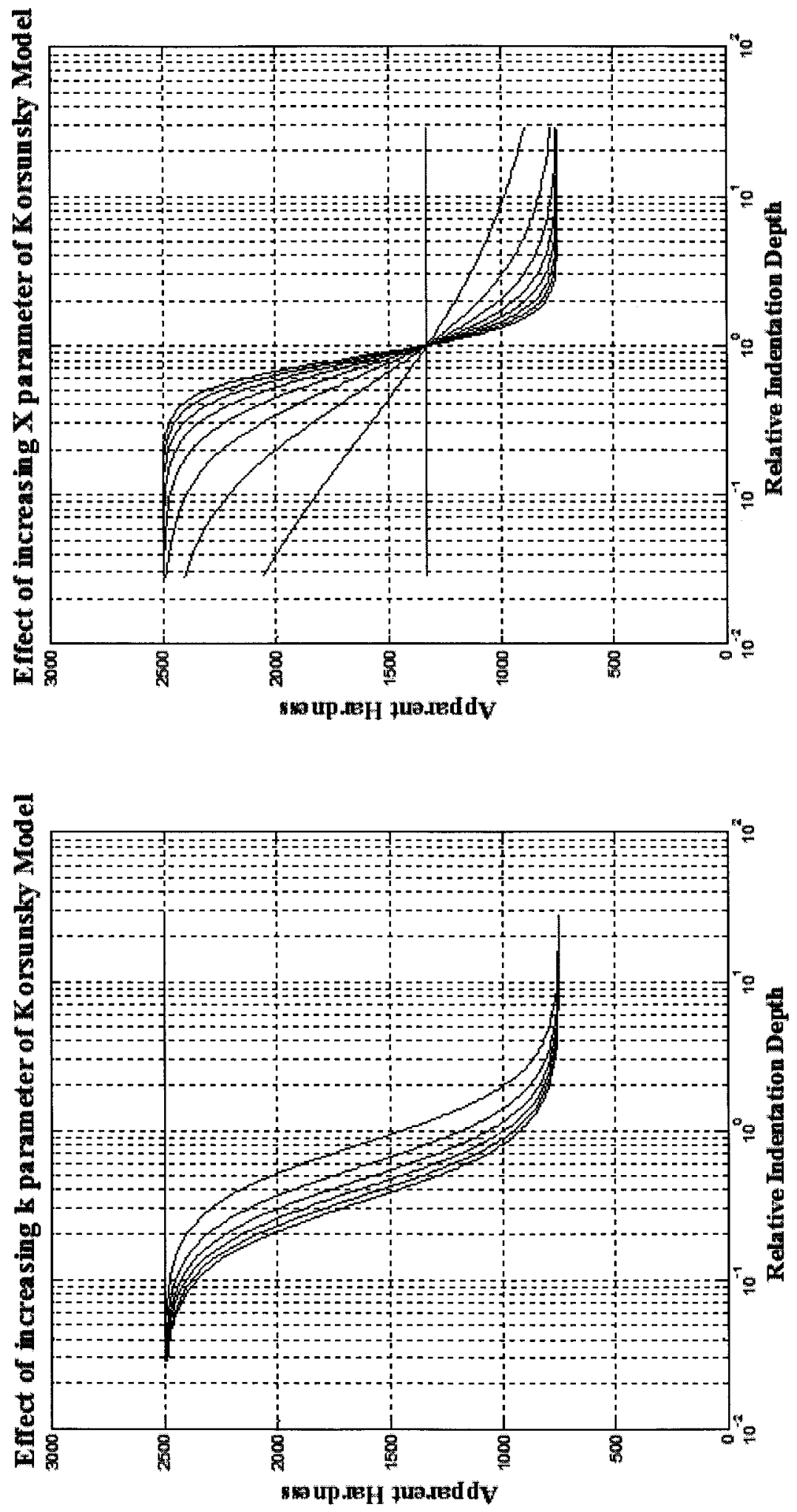

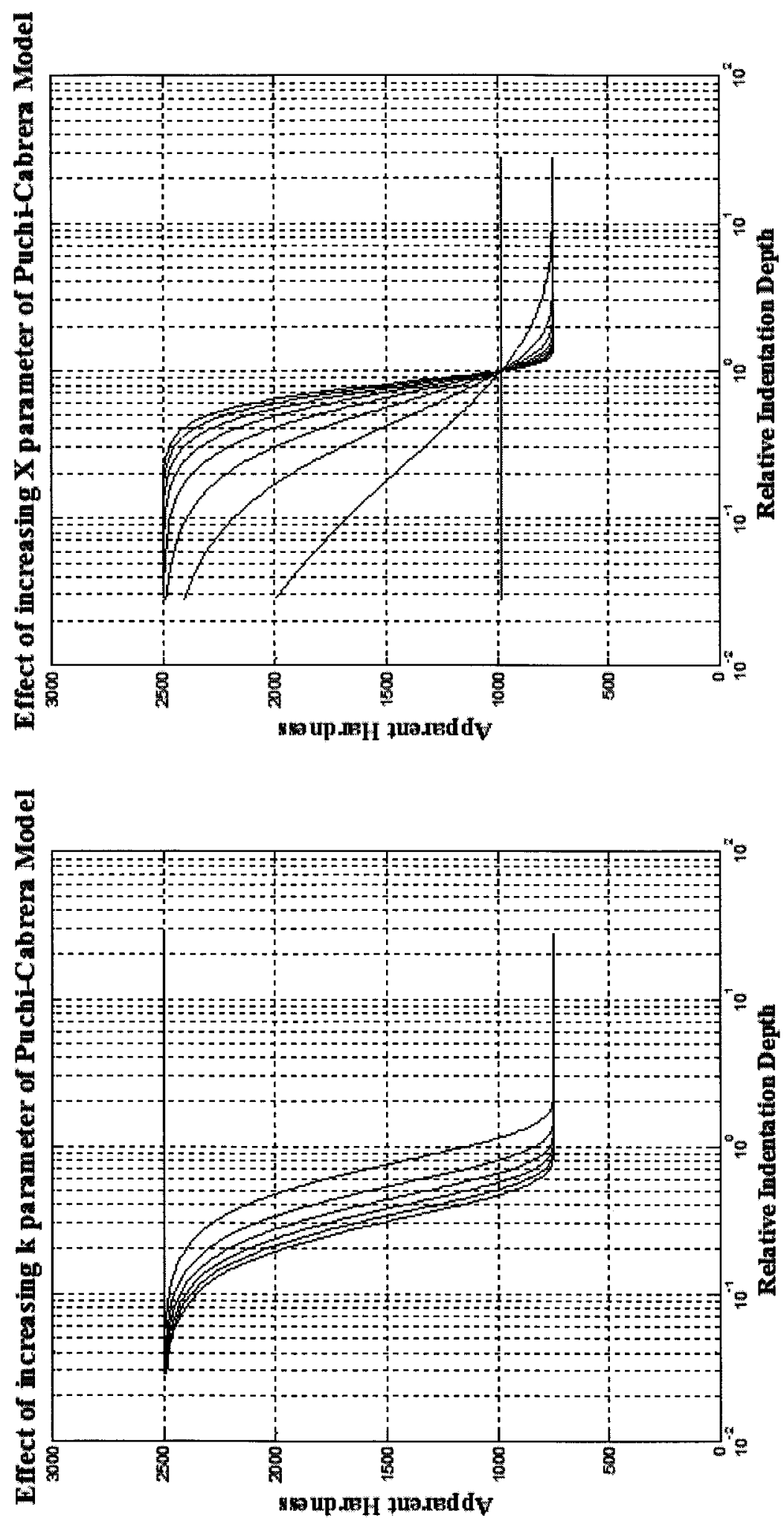


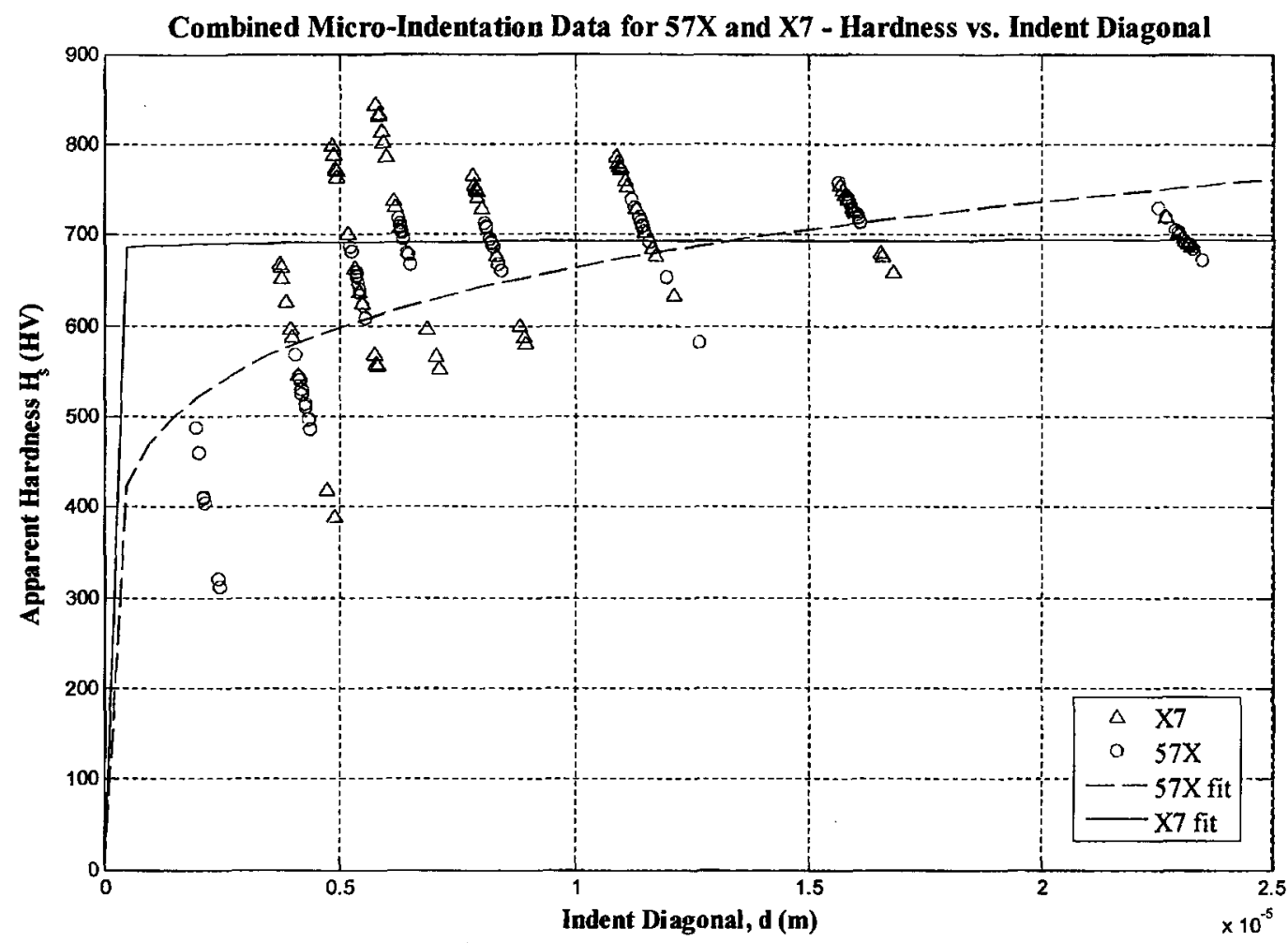

Figure 4.4: Combined micro-indentation data for 57X and X7 showing fit of Meyer ISE for both sets of data 


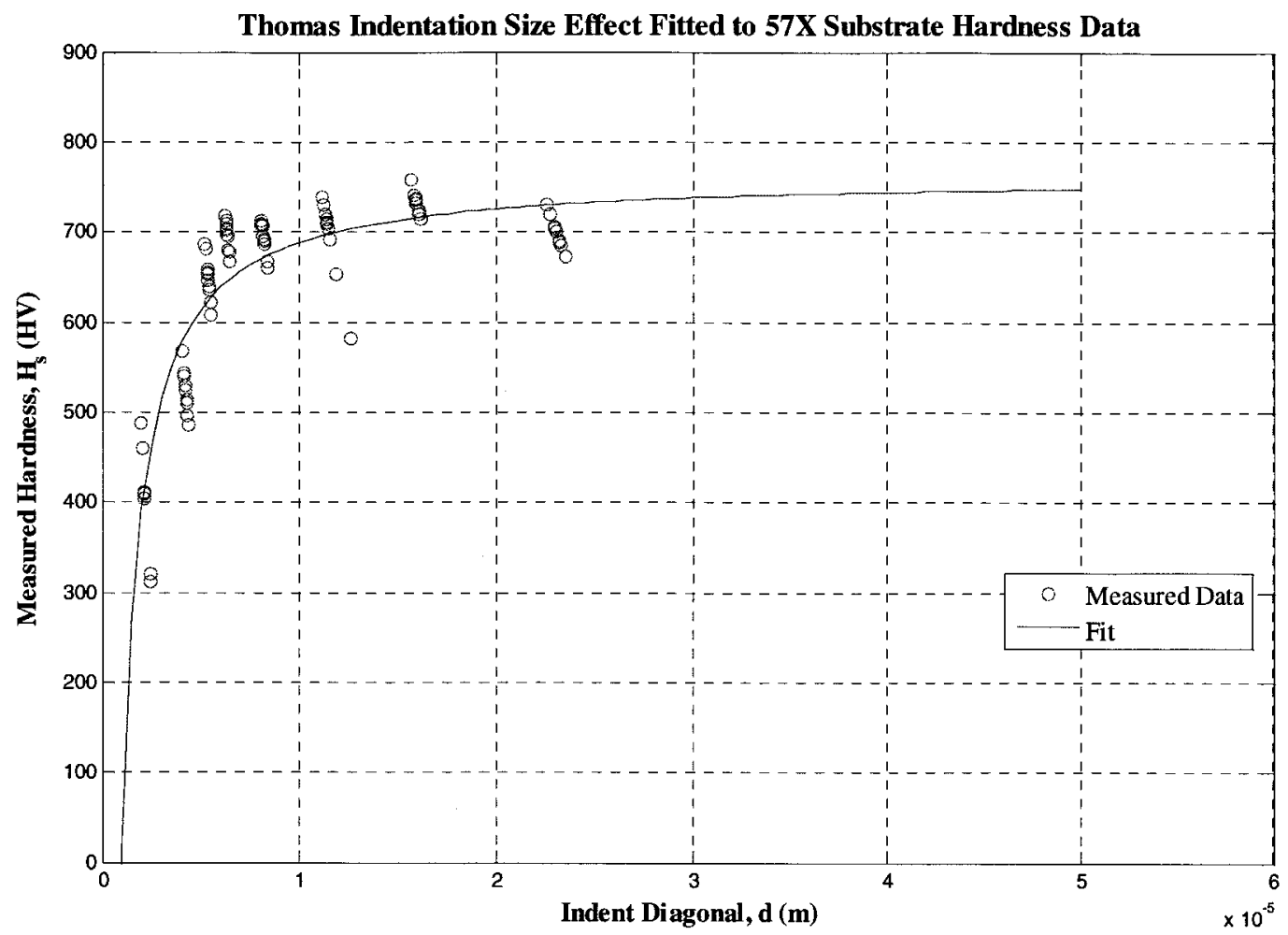

Figure 4.5: Thomas indentation size effect representation of the substrate hardness profile for 57X 


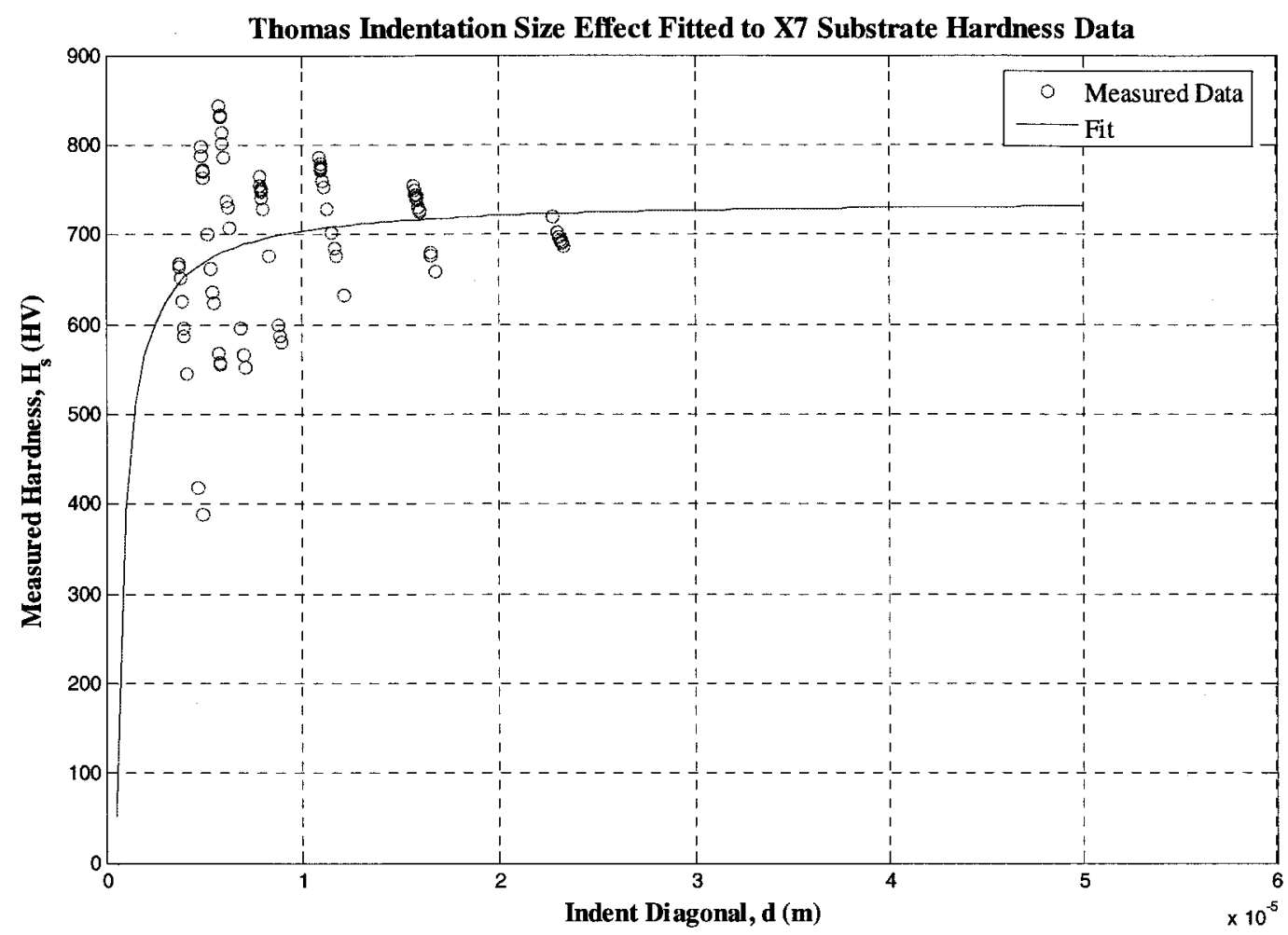

Figure 4.6: Thomas indentation size effect representation of the substrate hardness profile for $\mathrm{X} 7$ 


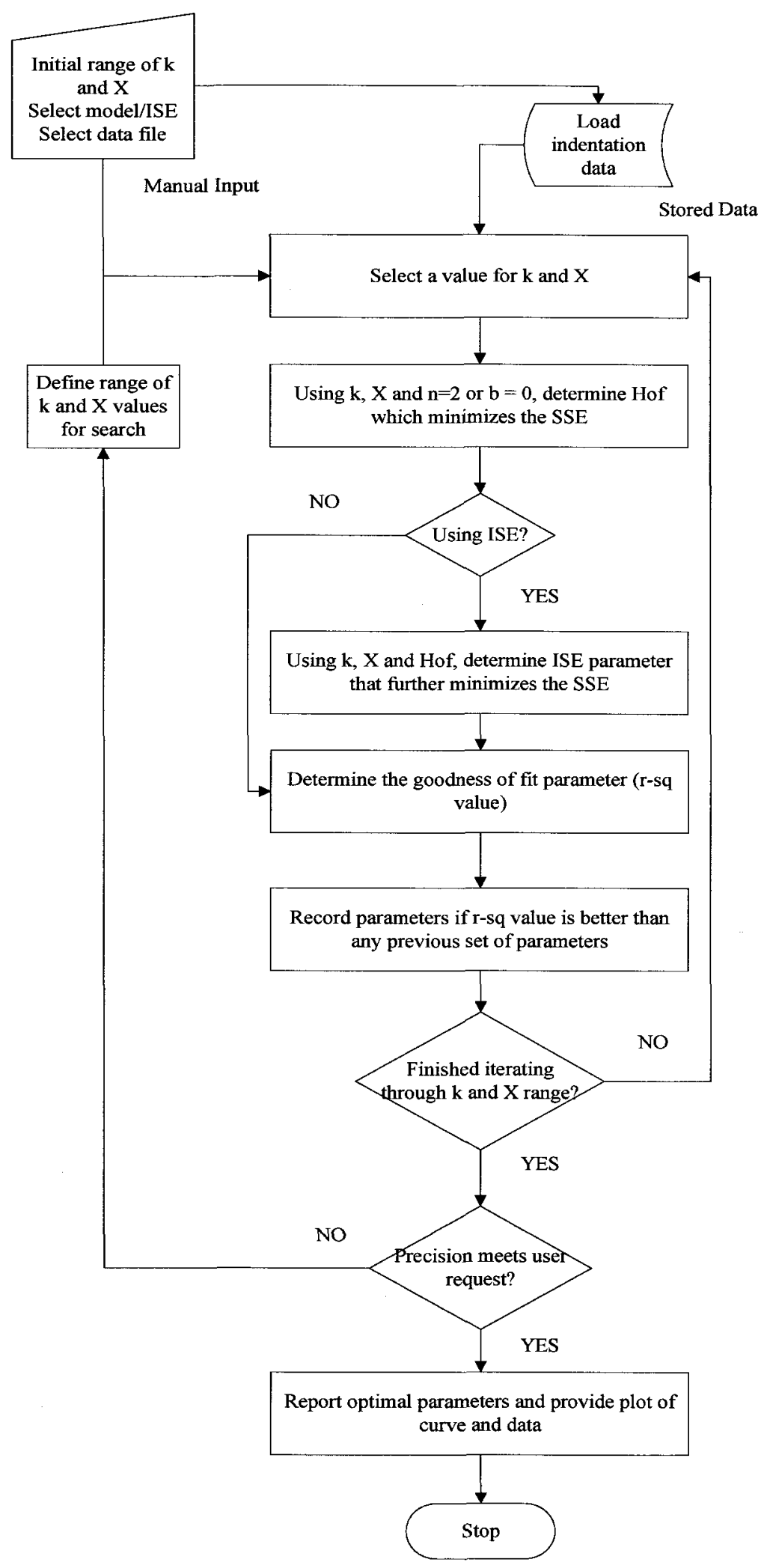

Figure 4.7: Flowchart illustrating the process for calibrating the model and film parameters using nano- and micro-indentation test data 


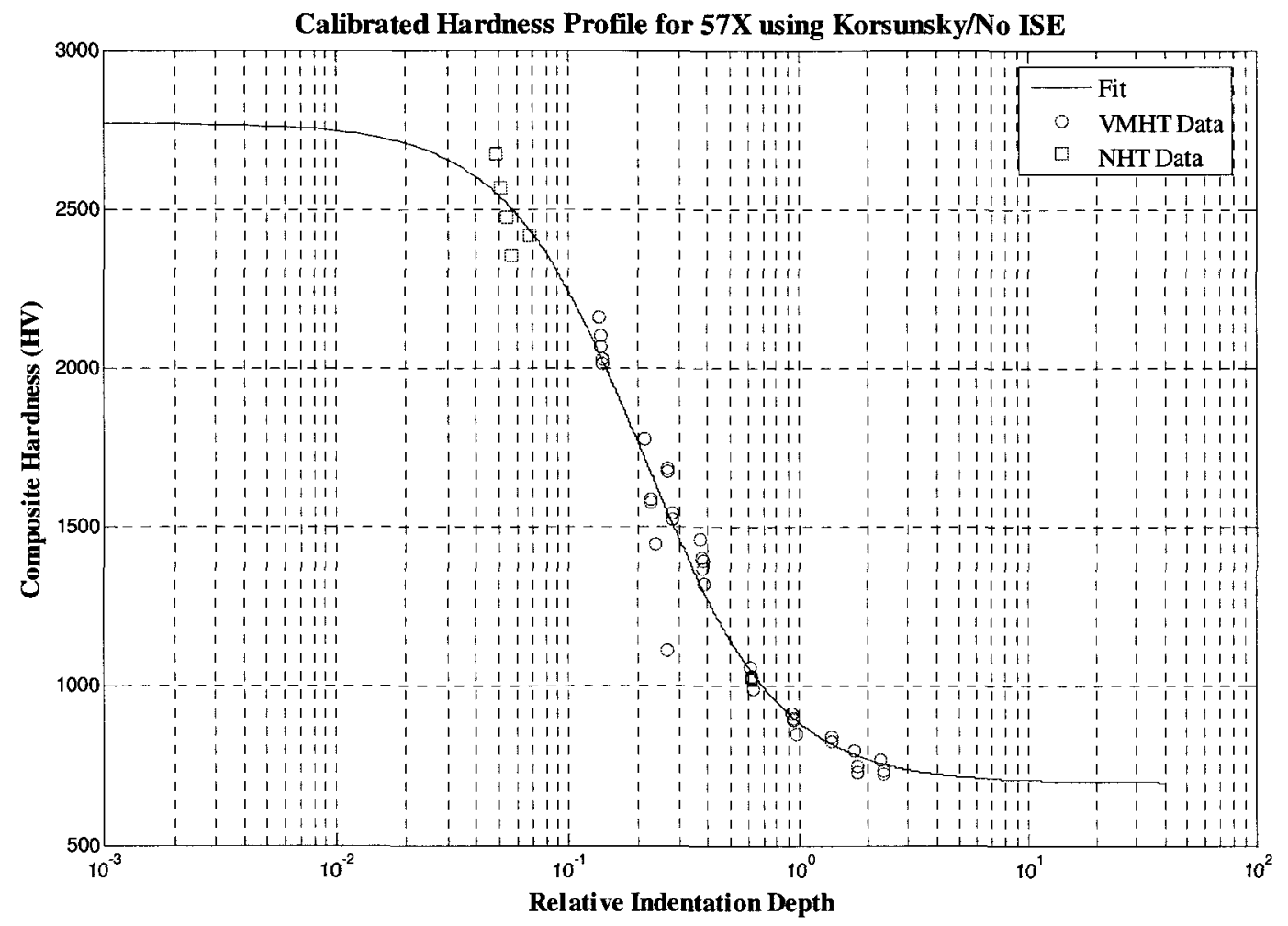

Figure 4.8: Korsunsky/No ISE calibrated hardness profile for 57X 


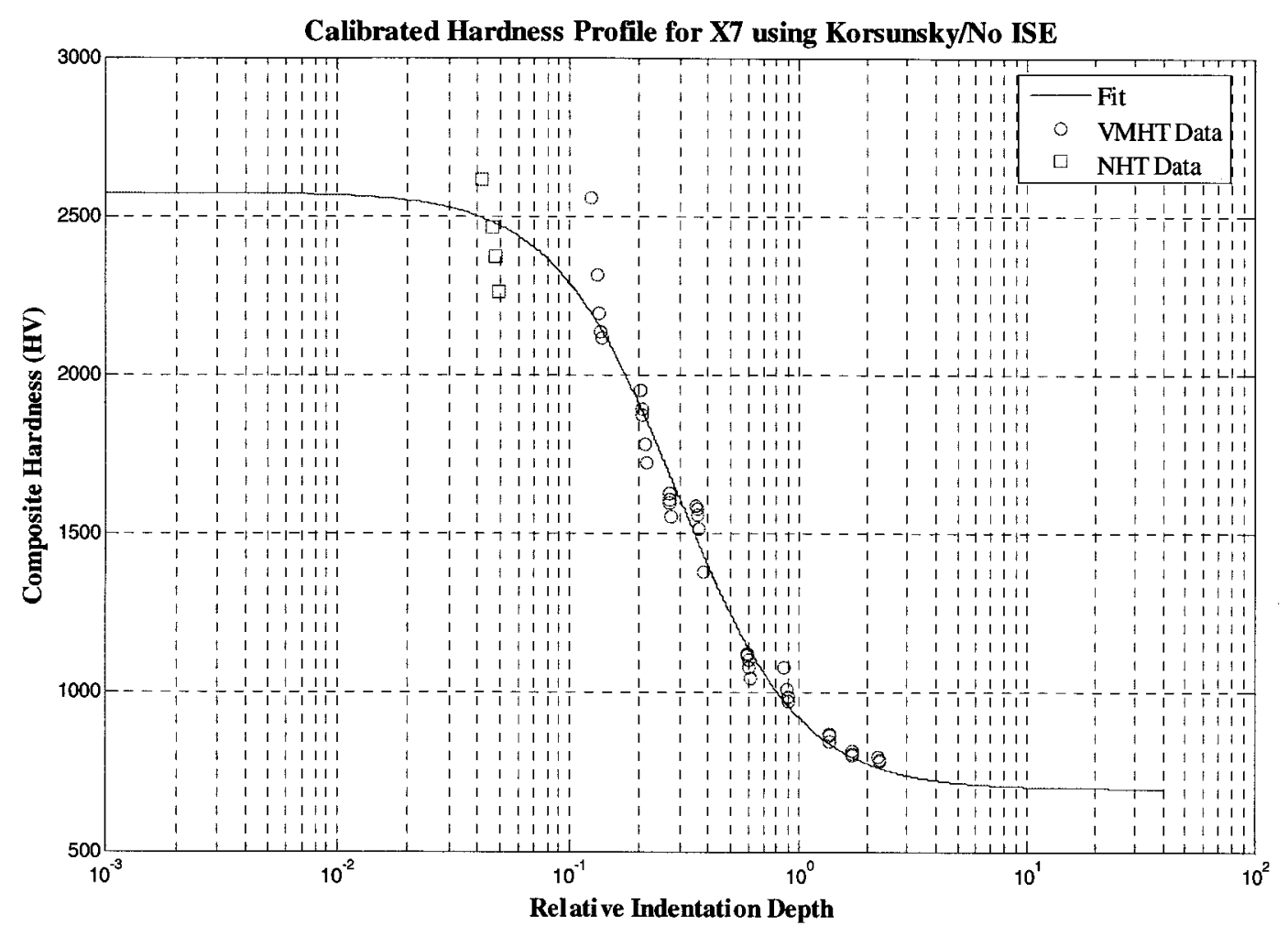

Figure 4.9: Korsunsky/No ISE calibrated hardness profile for X7 


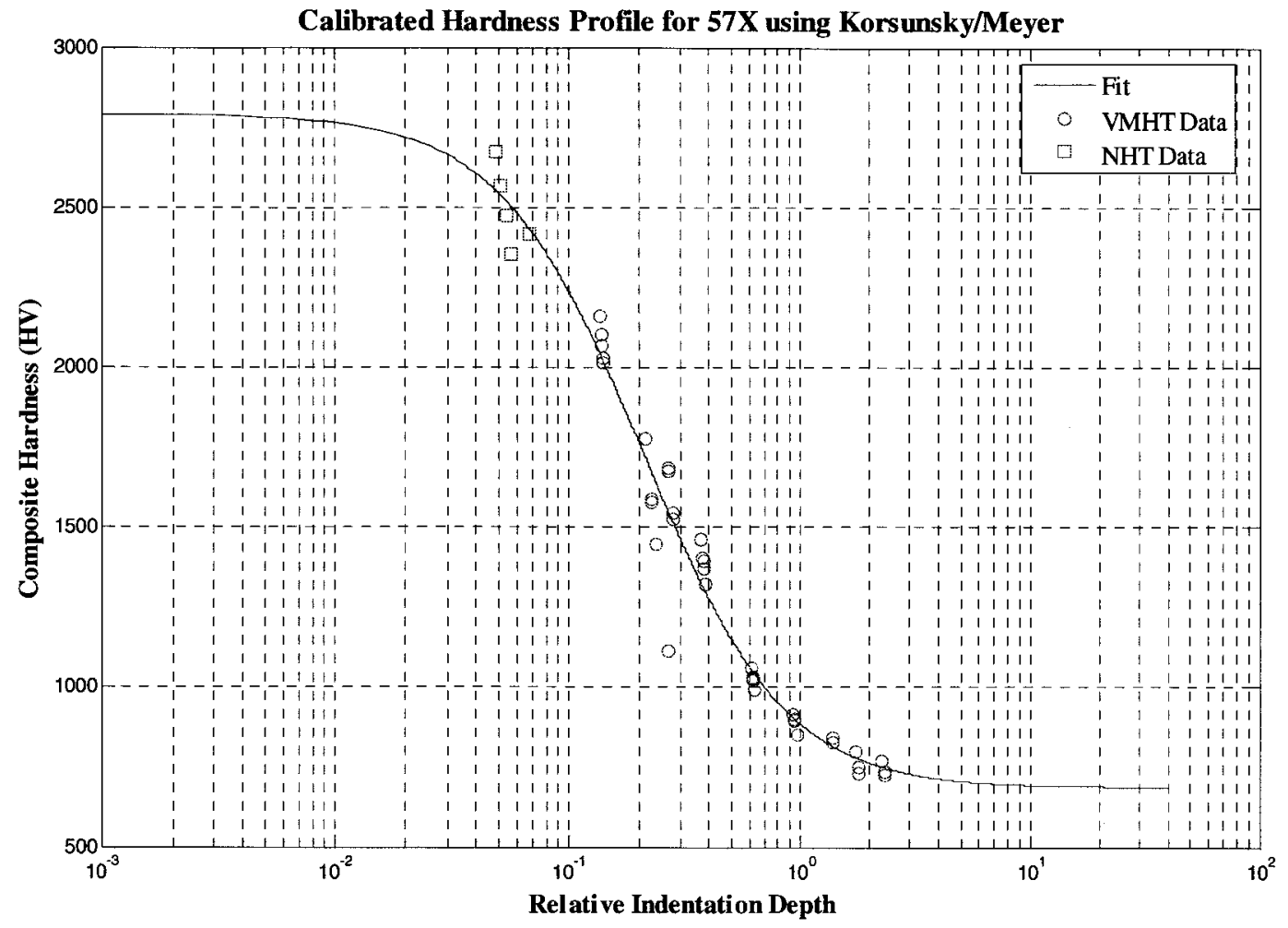

Figure 4.10: Korsunsky/Meyer calibrated hardness profile for 57X 


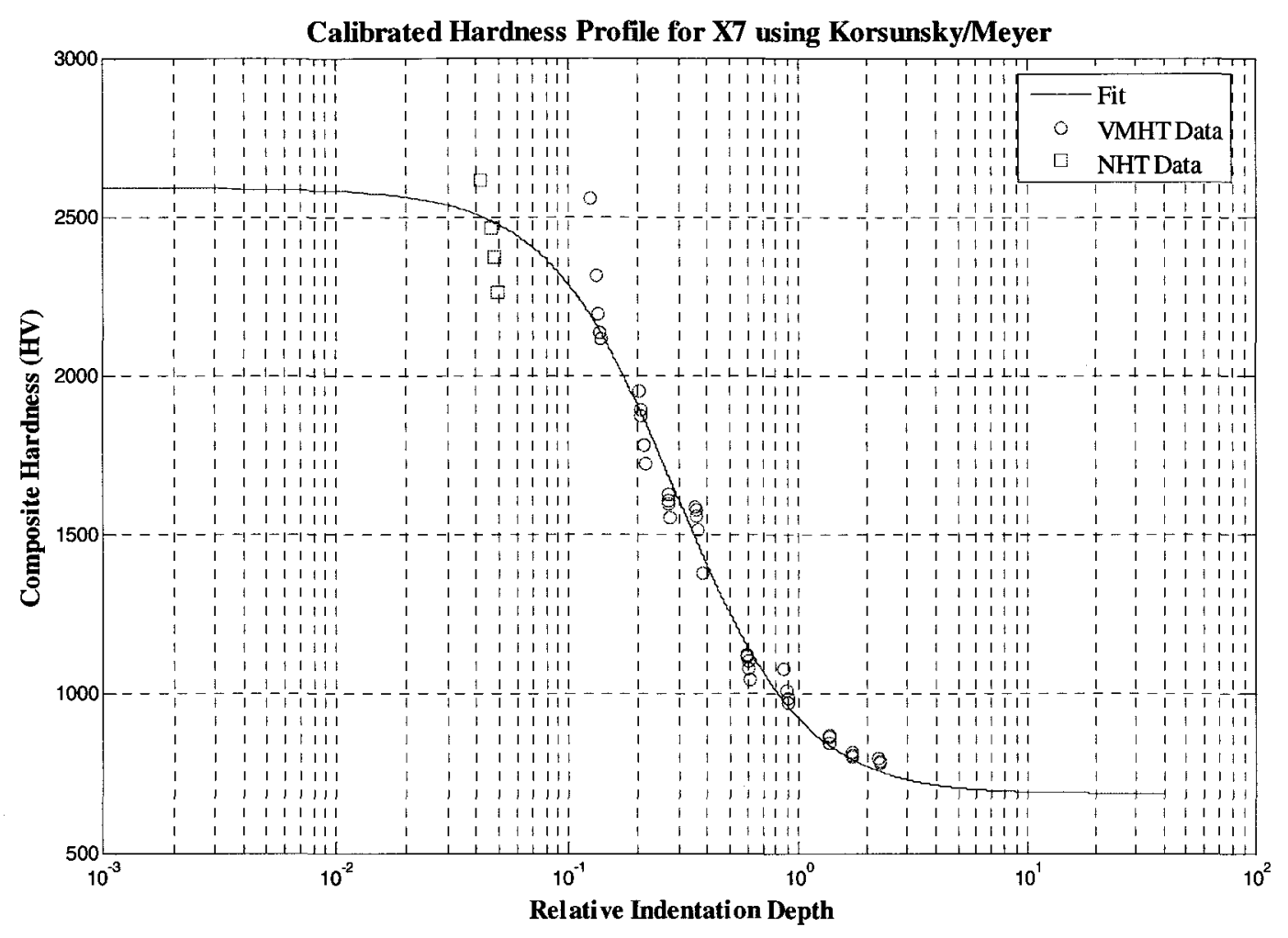

Figure 4.11: Korsunsky/Meyer calibrated hardness profile for X7 


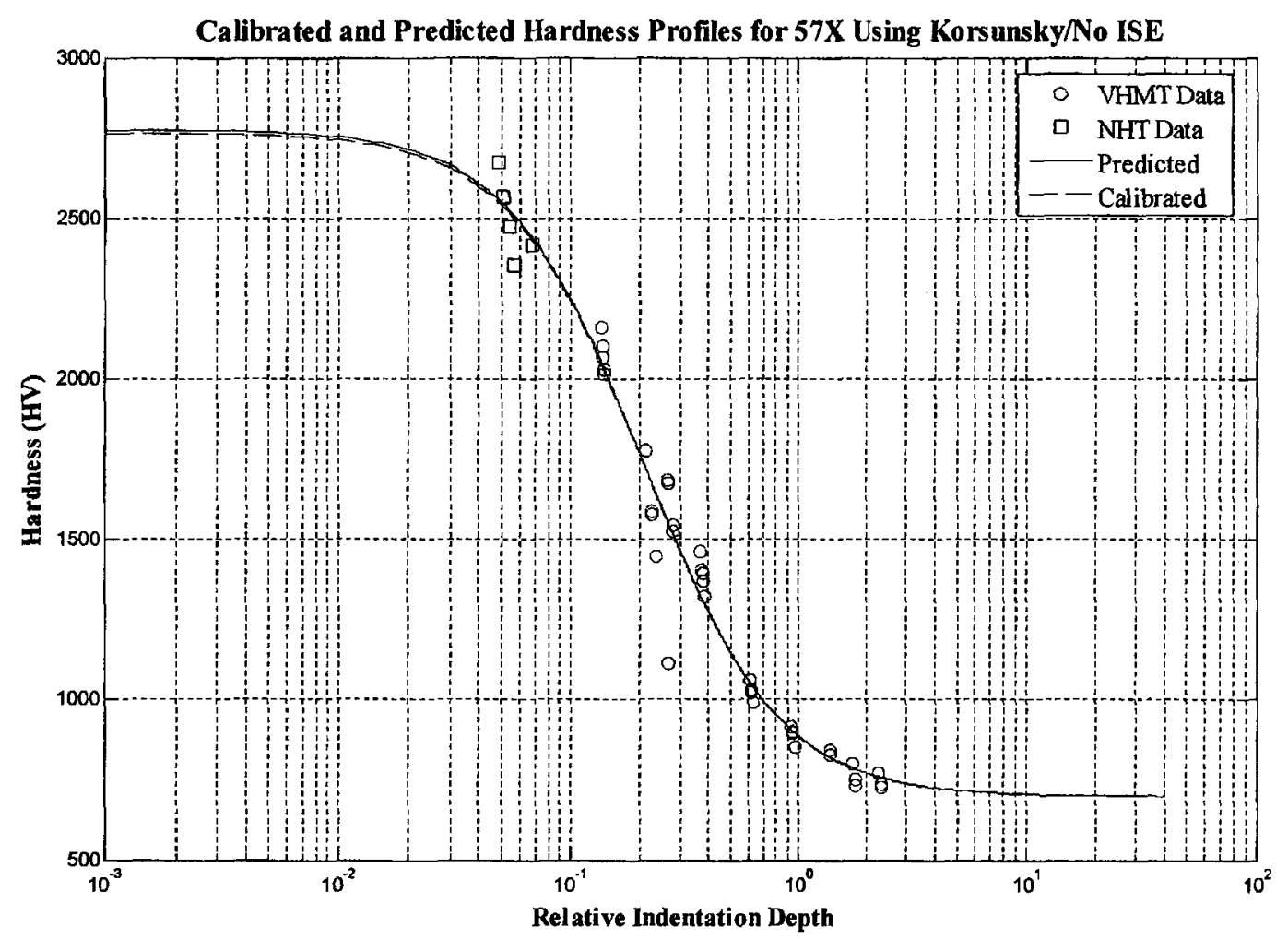

Figure 4.12: Calibrated and predicted hardness profiles for 57X using Korsunsky/No ISE showing close agreement despite removal of nano-indentation test data 


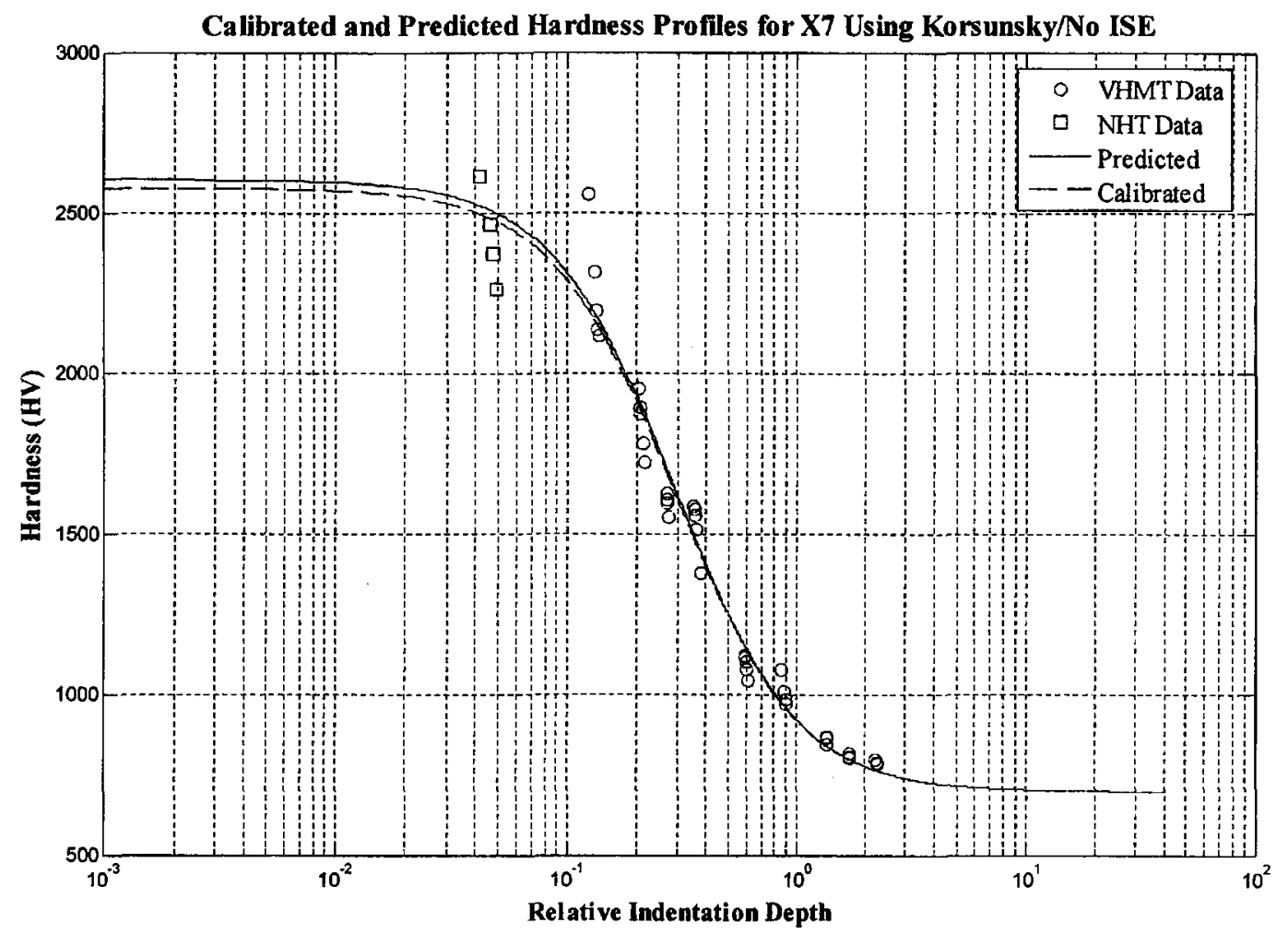

Figure 4.13: Calibrated and predicted hardness profiles for X7 using Korsunsky/No ISE showing close agreement despite removal of nano-indentation test data 


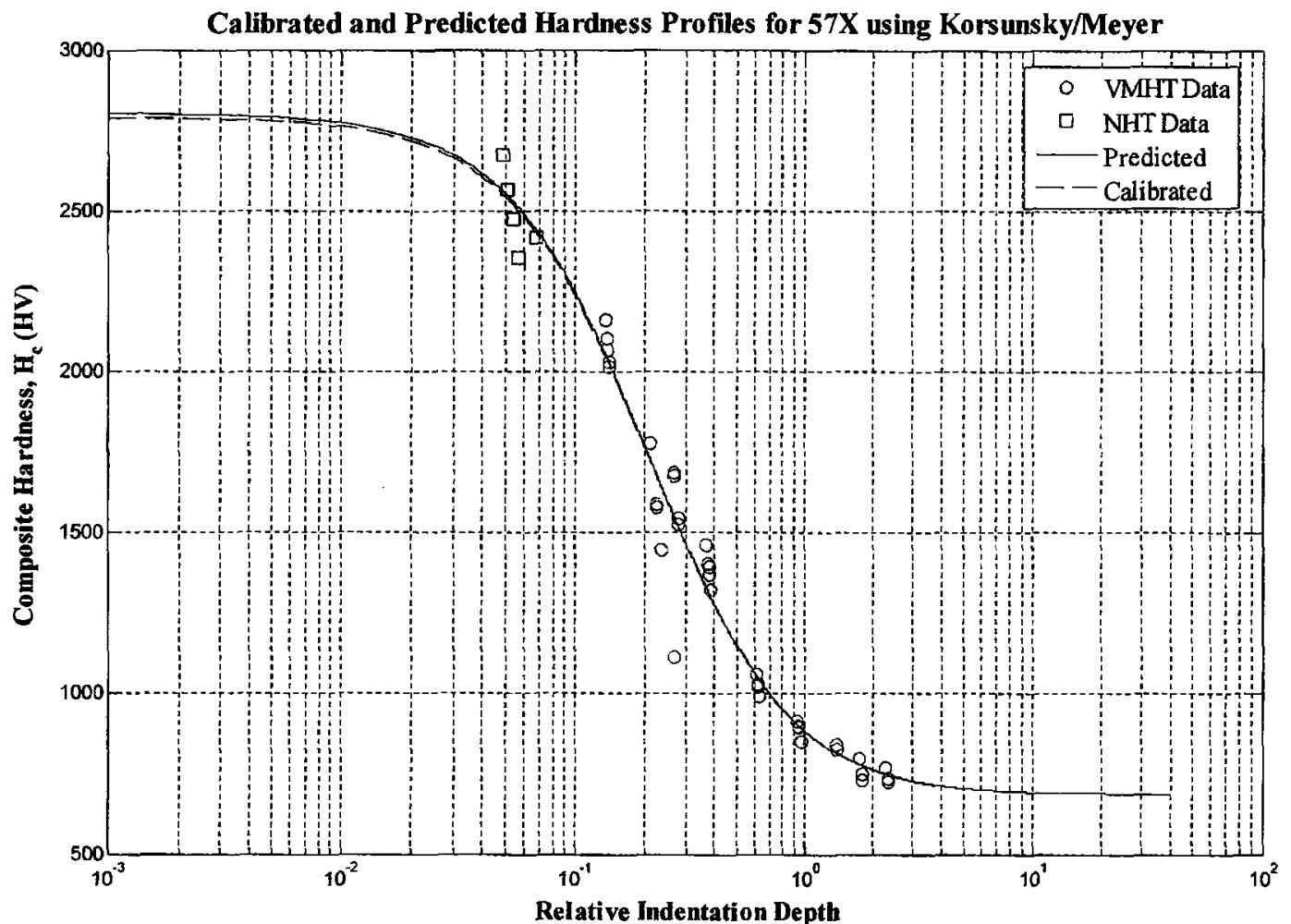

Figure 4.14: Calibrated and predicted hardness profiles for 57X using Korsunsky/Meyer showing close agreement between the two curves despite the removal of the nano-indentation data for the predicted curve 


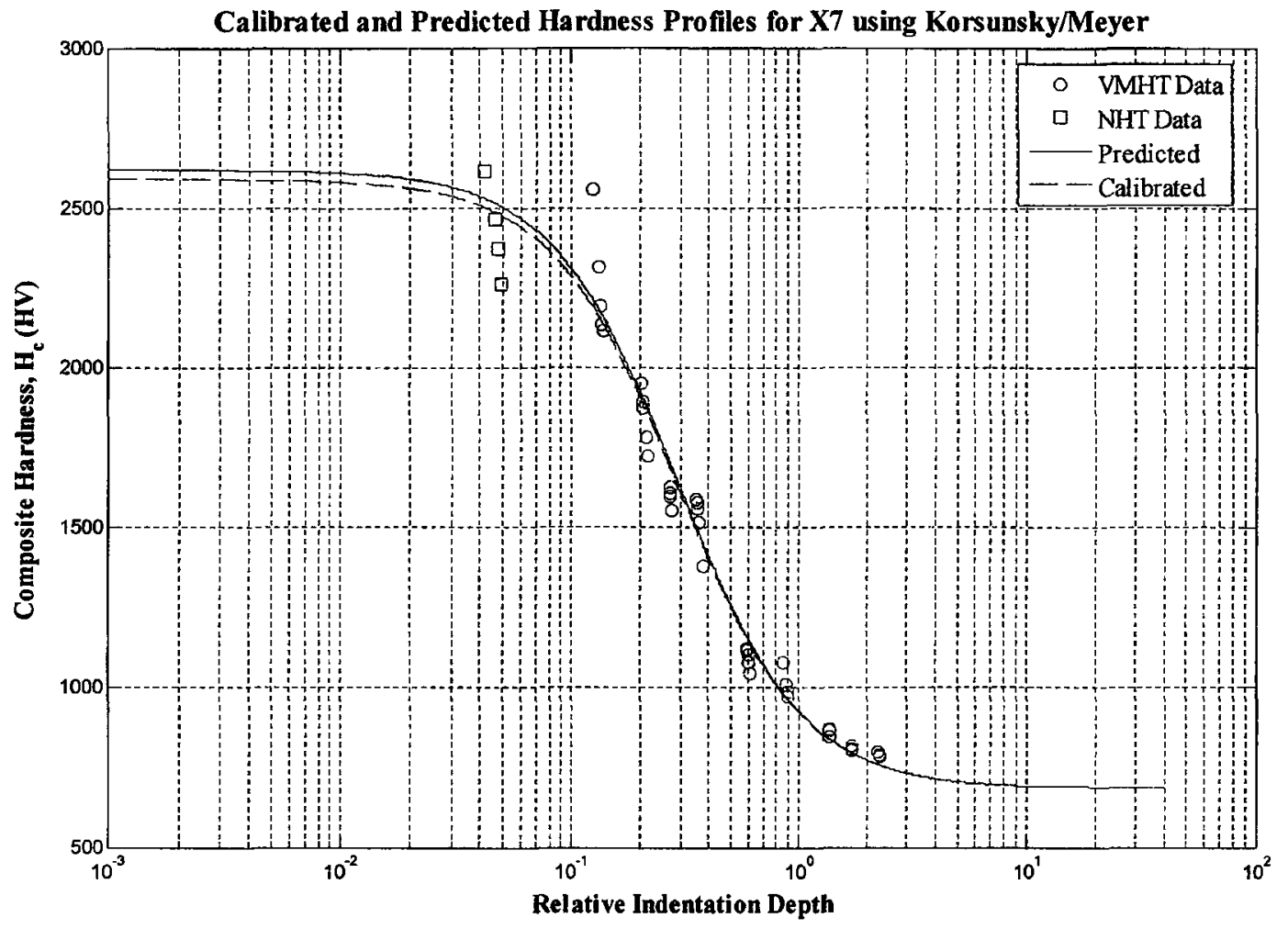

Figure 4.15: Calibrated and predicted hardness profiles for $X 7$ using Korsunsky/Meyer showing close agreement between the two curves despite the removal of the nano-indentation data for the predicted curve 


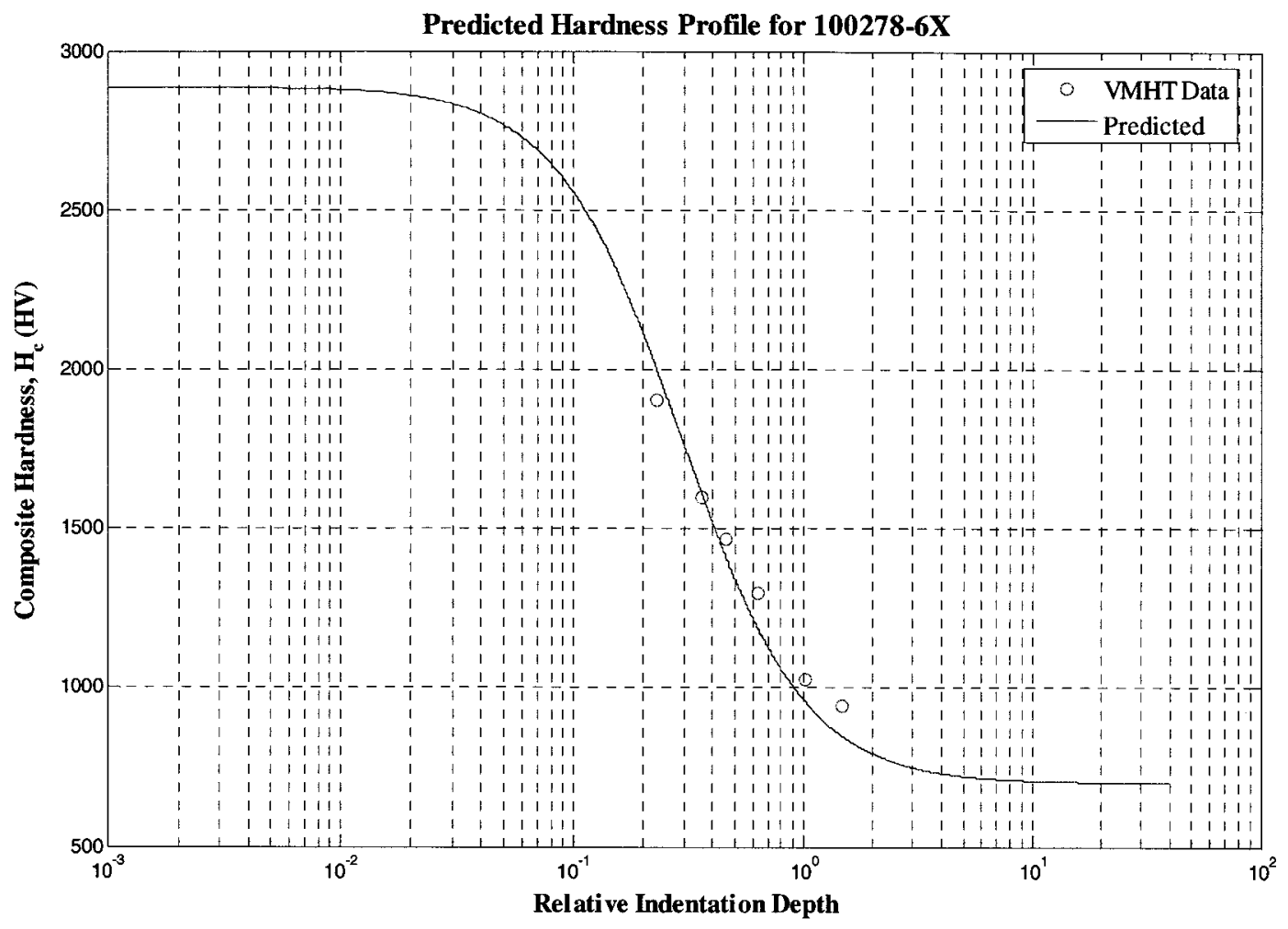

Figure 4.16: Predicted hardness profile for 100278-6X when using model parameters calibrated from X7 


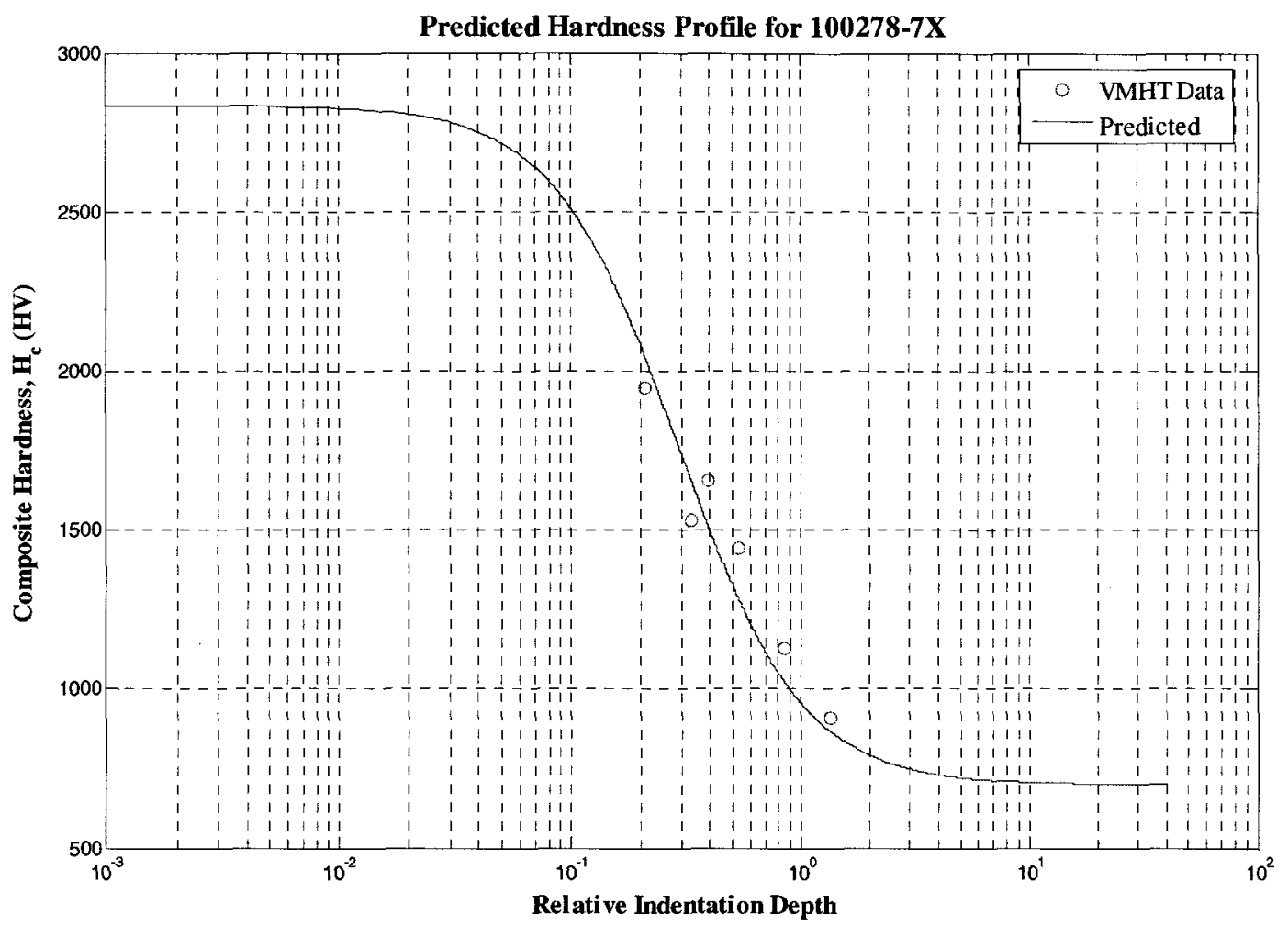

Figure 4.17: Predicted hardness profile for 100278-7X when using model parameters calibrated from X7 


\section{Chapter 5 : Performance}

Although the primary focus of this thesis is the determination of the film hardness and the validation of the thin-film hardness models, some other factors regarding the performance and quality of the film were analysed. The test dies $57 \mathrm{X}$ and $\mathrm{X} 7$ were further analysed for effects of the film quality on the hardness profiles determined in Chapter 4. In particular, the film adhesion of the test dies was qualified and linked to the hardness performance. Observations of cracking on the film made during the micro-indentation hardness testing are also discussed in terms of their correlation with the hardness profiles of the two dies. In order to analyse the practical performance and wear of the film, 3 numismatic coin dies were selected and analysed. This chapter discusses both the effects of the film performance on the hardness measurement and the observation of wear in practical coining operations.

\subsection{Film Adhesion}

The film adhesion is an important factor in the performance of the thin-film system. This section outlines the experimental procedure and results of the adhesion tests. The adhesion was tested for test dies $57 \mathrm{X}$ and $\mathrm{X} 7$ using a Rockwell-C hardness test. The indents created by the Rockwell-C hardness test are far too large to detect any effect of the film hardness so it was not used to evaluate the hardness. Instead, this test was only used to create a large deformation relative to the film thickness on the die surface to assess the film adhesion. The adhesion results are discussed with main focus on their relation to the results of the hardness analysis performed in Chapter 4.

\subsubsection{Experimental Setup and Procedure}

The Rockwell-C hardness test apparatus used to perform the adhesion tests is shown in Figure 5.1. The apparatus was set up to apply the maximum load to the sample. The test 
die was placed on the sample holder and the hardened steel ball Rockwell-C indenter tip was selected. The sample holder was then adjusted upwards until the test die surface was in contact with the indenter tip. The holder was further adjusted so that the force between the indenter tip and test die aligned the small needle with the black dot representing the test start position. The large needle, measuring the hardness, was then set to zero by adjusting the gauge face. The test was performed by tipping the lever which applied the full test weight to the specimen surface. When the indenter had finished moving, the weight was removed and set to its original position. Two indents were performed on each die. The indents were then observed under a Carl Zeiss Axiovert 200 Max inverted microscope equipped with a Sony ExwaveHAD video camera attached to a computer. The microscope and camera are shown in Figure 5.2. Several images of the indent craters were recorded for each die and can be seen in Figure 5.3 to Figure 5.10 for X7 and Figure 5.11 to Figure 5.18 for $57 \mathrm{X}$.

\subsubsection{Observations}

It is immediately obvious from the images in Figure 5.3 to Figure 5.18 that the adhesion of the film is much better for $\mathrm{X} 7$ than it is for $57 \mathrm{X}$. Looking first at $\mathrm{X} 7$, cracking is seen throughout the vicinity of the indent crater with only a few isolated chips of the film lifting from the substrate at the lip of the crater. Long deep cracks are seen outside of the crater where there is mild deformation due to pile-up. The cracks on the surface outside of the crater align themselves along a particular direction for both test sites (from top-left to bottom-right). The cracks are reasonably spread out and independent and the film does not appear to have separated from the substrate. Inside the indent, several small circumferential cracks are seen as intense deformation occurred during the indentation. Despite the excessive deformation, the film has remained adhered to the substrate and followed the contour of the substrate by cracking to relieve stresses. For the film on X7, the film is more likely to crack than to separate from the substrate to relieve the stresses. Many of the same observations can be made for 57X (Figure 5.11 to Figure 5.18). 57X experiences the same cracking on the surface outside of the crater indent with the cracks being aligned in the left to right direction. These cracks are also well spaced with no 
evidence of separation of the film from the substrate. Inside the crater the circumferential cracks are also seen due to the progression of the indenter into the surface. 57X differs from X7 in that the coating at the lip of the crater shows a near complete failure to adhere to the substrate. The excessive flaking seen at the lip indicates that the film would delaminate from the surface to relieve stresses before cracking to follow the contour of the substrate.

Figure 5.19 shows the hardness profiles of $57 \mathrm{X}$ and $\mathrm{X} 7$ that were previously calibrated in Chapter 4. Although there is a difference in the hardness of the film as indicated by the curve crossing the $y$-axis, there is also a slight difference in the location of the transient section of the curve. We can see that the 57X hardness profile undergoes a decrease in hardness with increasing relative indentation depth $(\beta)$ slightly earlier than does X7. Although there are only two specimens in this analysis, it is possible that the film adhesion plays a role in maintaining the composite hardness at higher relative indentation depths (and higher loads). The rate of change of the composite hardness with increasing $\beta$ in this transient range remains similar between the two profiles.

\subsection{Surface Cracking Observed During Indentation Testing}

During micro-indentation testing presented in Chatper 3, cracks on the film surface was observed and recorded. Cracks were observed on the film both inside and outside of the indent. Figure 5.20 illustrates the typical cracking that was observed during microindentation hardness testing. The degree to which cracking occurred was related to the test weight used for the indent. Cracking was first observed on 57X at the edge of one of the indents performed at $10 \mathrm{gf}$. The first clear observation of cracking inside the indent on $57 \mathrm{X}$ was made at a test weight of only $15 \mathrm{gf}$. At a test weight of $50 \mathrm{~g} f$, the cracks inside the indent on $57 \mathrm{X}$ reached the maximum observed severity. The first observation of cracking on $\mathrm{X} 7$ was not made until a test weight of $15 \mathrm{gf}$. In contrast to $57 \mathrm{X}$, only minor cracking was observed on $\mathrm{X} 7$ at this test weight. The consistent cracking that was observed in the $57 \mathrm{X}$ surface at $15 \mathrm{~g}$ was not observed on $\mathrm{X} 7$ until test weights of $50 \mathrm{gf}$ 
were applied. No flaking of the film was observed for any of the indents on either test specimen.

A complex stress state is set up between the indenter and the film surface during indentation. The situation is further complicated by the effect of the constraining force applied by the substrate on the film due to film adhesion. When cracking occurs during indentation testing, the section of film enclosed by cracking is no longer supporting a portion of the indenter load; it is simply transferring the load directly to the substrate. It is expected that the early onset of cracking would coincide with an early decrease in measured hardness. Although an analysis of the stresses involved here is not within the scope of this thesis, it is fair to note that the later onset of cracking observed for X7 coincides with the superior film adhesion noted in the previous section and the delayed decay of the composite hardness seen in Figure 5.19.

\subsection{Performance of the Film Surface in Numismatic Coining Operations}

Thus far, the two test dies $57 \mathrm{X}$ and $\mathrm{X} 7$ have been used to analyse several different aspects of the thin film's performance including film hardness and adhesion. Although these two factors offer both quantitative and qualitative measurement of the film's performance, they do not assess the actual performance of the film in daily coining operations. In order to further assess the performance, several numismatic coin dies were analysed after use in the coining operations at the Ottawa branch of the RCM. The surfaces of these dies were analysed for changes in the surface quality after usage. The surface quality was observed using a Carl Zeiss Axiovert 200 Max inverted microscope seen in Figure 5.2. This section describes the numismatic dies, how they were used and the observations made regarding the performance of the film. 


\subsubsection{Samples}

Three different Gold Maple Leaf (GML) reverse dies were selected for comparison of the film surface at different stages in the dies' lifetimes. The three stages selected were: newly manufactured, used but not yet failed and failed due to the die surface. The newly manufactured die was used as a control when observing the surfaces of the dies at the other two stages. The dies are shown in Figure 5.21 and listed as labelled below.

- 104819X8 (hereafter X8)

- Die was newly manufactured for surface analysis and had never been used. Images taken of X8 surface are seen in Figure 5.22 to Figure 5.28.

- 104819-26X (hereafter 26X)

- Die was used for the production of the GML coin and had failed when the die struck the collar during coining rather than from the wear failure of the surface. Images taken of $26 \mathrm{X}$ surface are seen in Figure 5.29 to Figure 5.35. The die had been used to strike a total of 16,220 coins.

- 104819-7X (hereafter 7X, not to be confused with X7 from previous experiments)

- Die was used for the production of the GML coin and was removed from service due to surface wear. Images taken of $7 \mathrm{X}$ surface are seen in Figure 5.36 to Figure 5.41. The die had been used to strike a total of 41,598 coins. It had been reworked 3 times after producing $236,18,817$ and 3291 coins. After the final rework, the die struck 19,254 coins before being removed.

The three GML dies were hobbed and finished before heat and surface treatments to produce the relief seen in Figure 5.21. The dies were then treated using the same heat treatment and coating process as test dies $57 \mathrm{X}$ and X7. Both 26X and 7X were inserted into the daily numismatic coining operations at the RCM so that the surface wear could be observed. During coining, the dies were frequently inspected and wiped clean by the operators to minimise debris which could mar the surface of the die and coin. The operators were responsible for recording the number of coins struck by each die as well as determining when the die had to be removed from coin production. 


\subsubsection{Observations and Surface Wear}

The observation of the surfaces of the three GML dies mentioned above revealed three distinct points of interest. The three points are: the coverage of the film, changes in the surface and damage to the surface. The varying coverage of the film on the substrate is shown especially on X8 (which had not been used) while the other two dies show the changes in the film texture as well as damage encountered during normal use.

The first feature to notice is the texture of the as-coated film in Figure 5.22 and Figure 5.23. The surface texture does not appear to be perfectly smooth given the appearance of circular outlines and difficulty in focussing the entire field under the microscope. In nearly all of the images of the flat surface of the die there are alternating dark and light regions running in lines from the top to the bottom of the images. This is a result of the designed texture used for that area of the die. In Figure 5.24 and Figure 5.25 we can see how the coating has covered the flat surface of the die right up to the edge of the recessed 'F'. In Figure 5.25 we can even see that the coating was at least somewhat successful in coating the recessed details of the die face. Based on the appearance of Figure 5.40, some corrosion is visible in the recessed area of a ' 9 ' on $7 \mathrm{X}$ where the coating may or may not have completely coated the area prior to use. Figure 5.28 shows an area inside the sunken region of the maple leaf where the surface appears relatively smooth with a bright mirror-like finish.

The second feature to notice is the apparent change in the surface texture after having been used. The surfaces of both $26 \mathrm{X}$ and $7 \mathrm{X}$ in Figure 5.29 and Figure 5.36 show the same alternating dark and light regions due to the design of the die. Due to surface wear, they both lack the clear circular outlines observed on the unused die (X8). In Figure 5.30 we can see what appears to be the substrate through small holes abraded in the film surface. The surfaces of the used dies appear smoother than the unused die however the rate at which this transformation occurs is not evident from the data analysed here.

The final feature to notice is the damage found on both of the used die surfaces. In particular, deep gouges, starburst scratches, adhesions and cracks were found on both 
dies. Figure 5.31 of $26 \mathrm{X}$ shows an example of deep gouges that were found on both dies. Several of these deep gouges appeared together aligned in the same direction indicating foreign debris, or inclusions in the blank, being forced along the surface of the die. Although starburst scratches were most easily discoverable at the edges of recessed detail as in Figure 5.32 and near the '9's as in Figure 5.37, some groupings of starburst scratches were found in the areas without detail as in Figure 5.33. Surface adhesions were most evident on $26 \mathrm{X}$ while adhesions on $7 \mathrm{X}$ were primarily found lodged into a crack in the surface. Figure 5.34 shows one instance of the coin material adhering to the flat surface of $26 \mathrm{X}$ while Figure 5.38 and Figure 5.39 show coin material inside two different cracks found on the surface of $7 \mathrm{X}$ at two different tips of the maple leaf. The cracks on $7 \mathrm{X}$ were severe enough to cause the removal of the die from coin production. Some small cracks in the film were also found on the $26 \mathrm{X}$ surface but did not cause the die's removal from service. A crack on $26 \mathrm{X}$ is shown in Figure 5.35 while cracks on $7 \mathrm{X}$ are shown in Figure 5.38, Figure 5.39 and Figure 5.41. A significant increase in the surface damage was observed for $7 \mathrm{X}$ over $26 \mathrm{X}$ where the surfaces shown had produced 19,254 and 16,220 respectively. The difference may be attributed to either the extra 3000 coins struck by the $7 X$ surface or the fatigue wear of the substrate after producing 41,598 for $7 \mathrm{X}$ against only 16,220 for $26 \mathrm{X}$.

\subsection{Summary and Conclusions}

The quality and performance of the thin film was observed in several different ways. Specifically, the adhesion and cracking of the film during indentation testing was observed on test dies $57 \mathrm{X}$ and $\mathrm{X} 7$ and linked with the hardness profiles determined in Chapter 4. Better adhesion of the film to the substrate delays the onset of decay of the composite hardness. The superior adhesion performance of the film on X7 demonstrates this as the hardness profile decays at larger indentation depths as compared with $57 \mathrm{X}$ which showed poor adhesion performance. The film cracking observed during microindentation testing further supports this conclusion as cracks in the film (and loss of film support) were less evident for $\mathrm{X} 7$ than they were for $57 \mathrm{X}$. 
The wear characteristics were observed for the 3 numismatic dies presented in this chapter. Although the majority of the die surface was well coated, a few small weakly coated areas were found. The used numismatic dies both exhibited typical damage for coining operations including: starburst scratches, gouges in the surface, adhesion of blank material to the die surface and cracks. No problems were found with the adhesion of the coating to the substrate even in the areas where cracks existed. Blank material adhesion on the surfaces of the dies was minimal for both dies. Finally, the majority of the scratching and gouging occurred in or near details on the die rather than in the wide flat areas where they would be more easily noticed on the coin. 


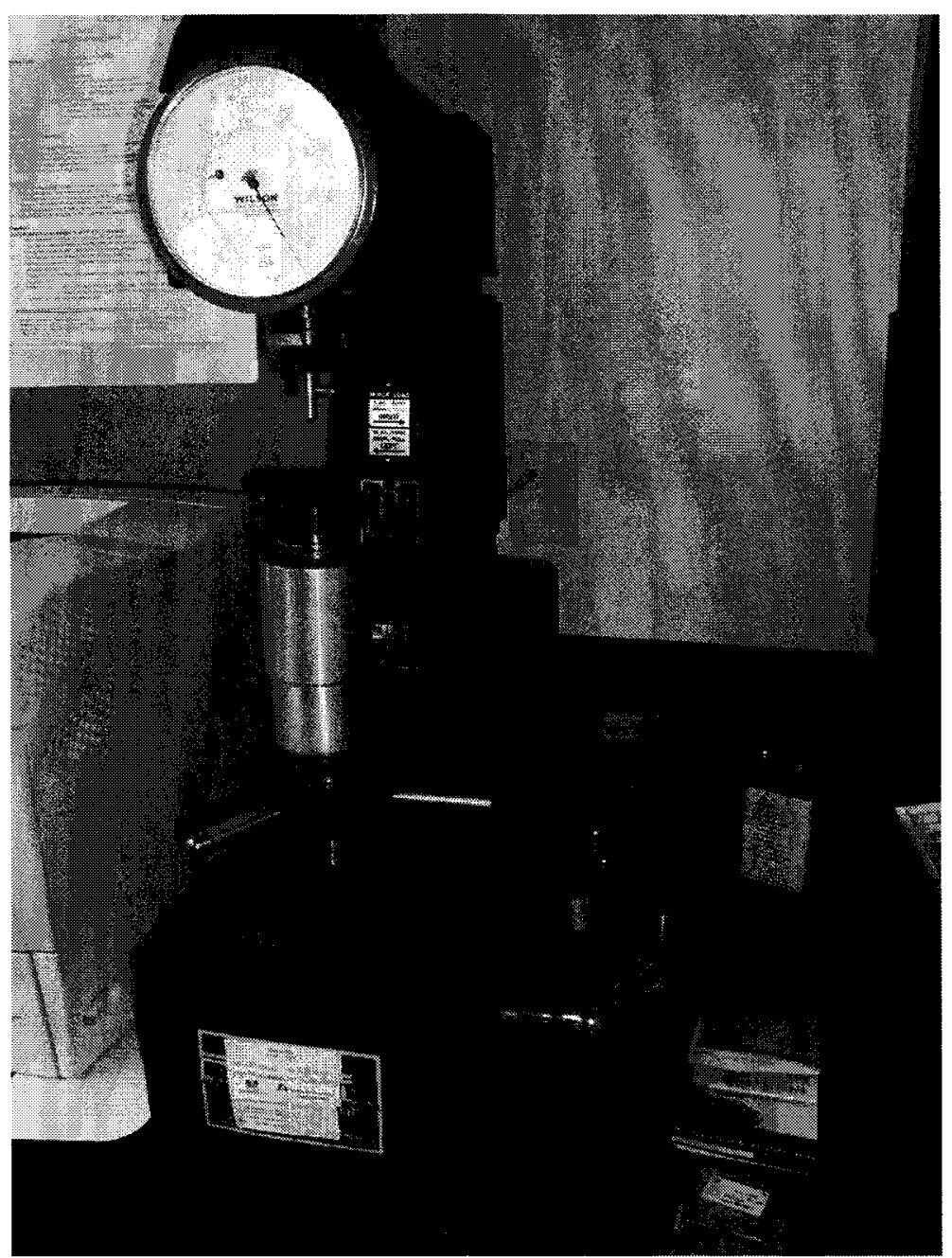

Figure 5.1: Rockwell-C indenter 
138

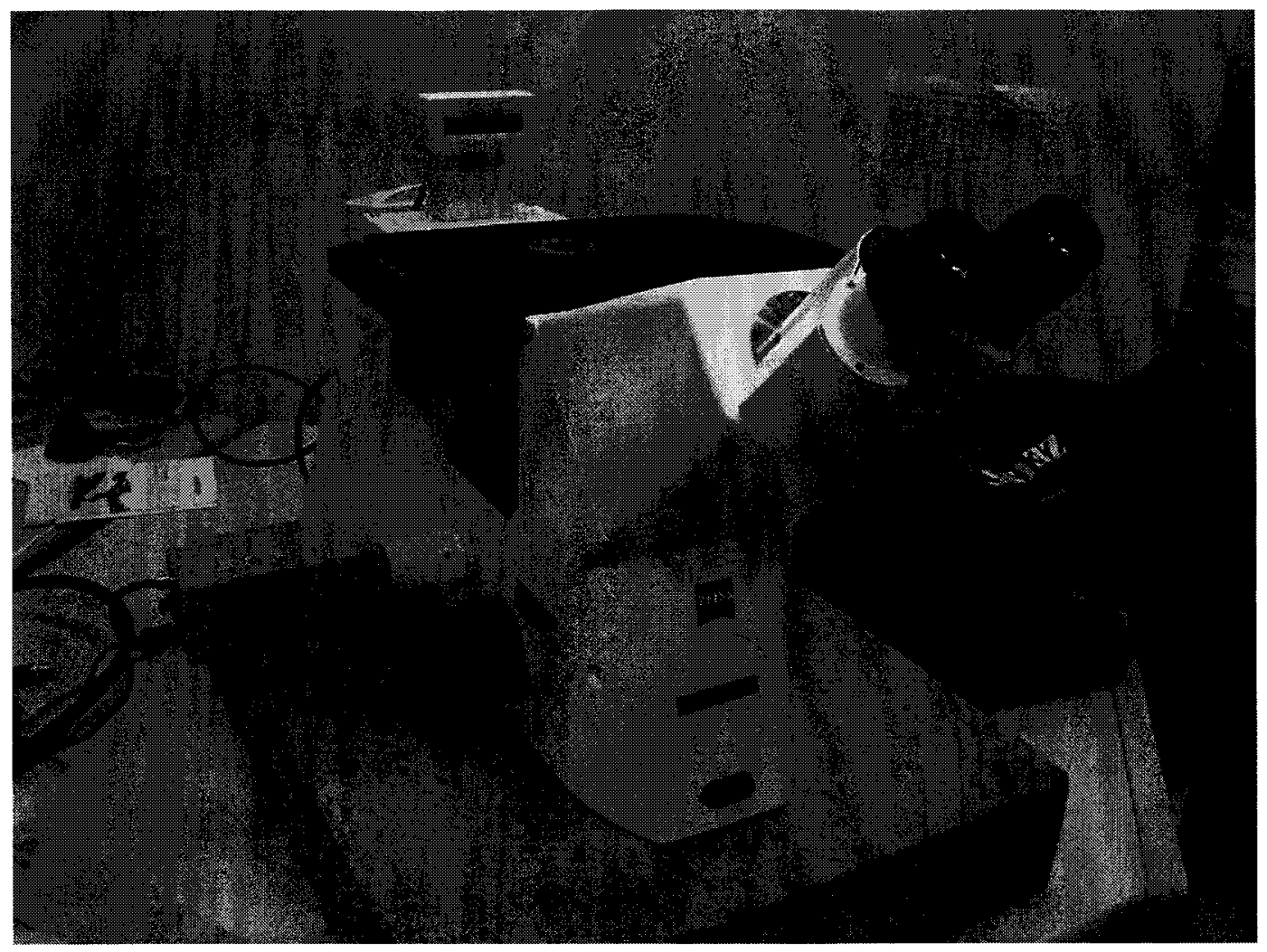

Figure 5.2: Carl Zees Axiovert 200 Max inverted microscope equipped with Sony ExwaveHAD video camera 


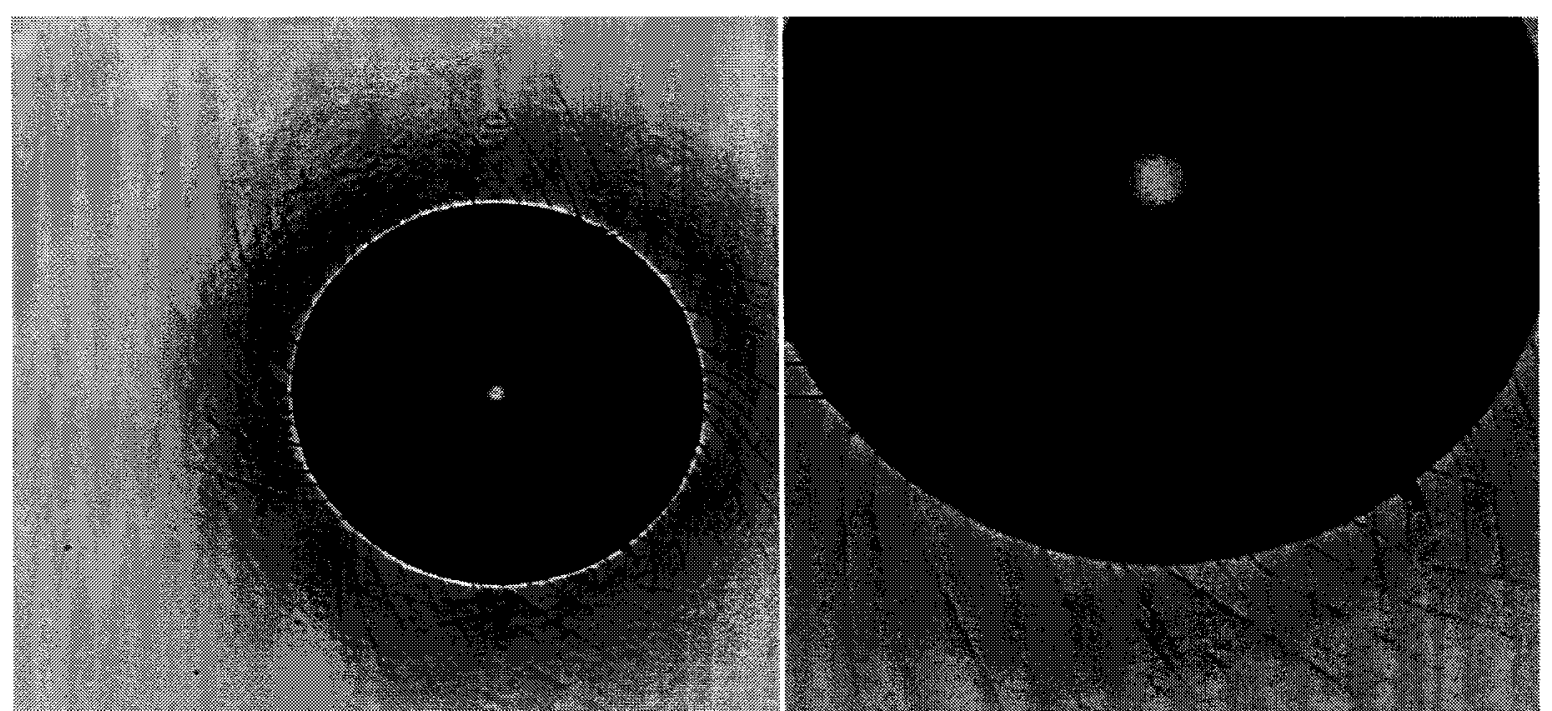

Figure 5.3: Rockwell-C indent \#1 on X7 showing good adhesion (5x magnification)

Figure 5.4: Rockwell-C indent \#1 on $X 7$ showing good adhesion and a small chip in the lower right (10x magnification)

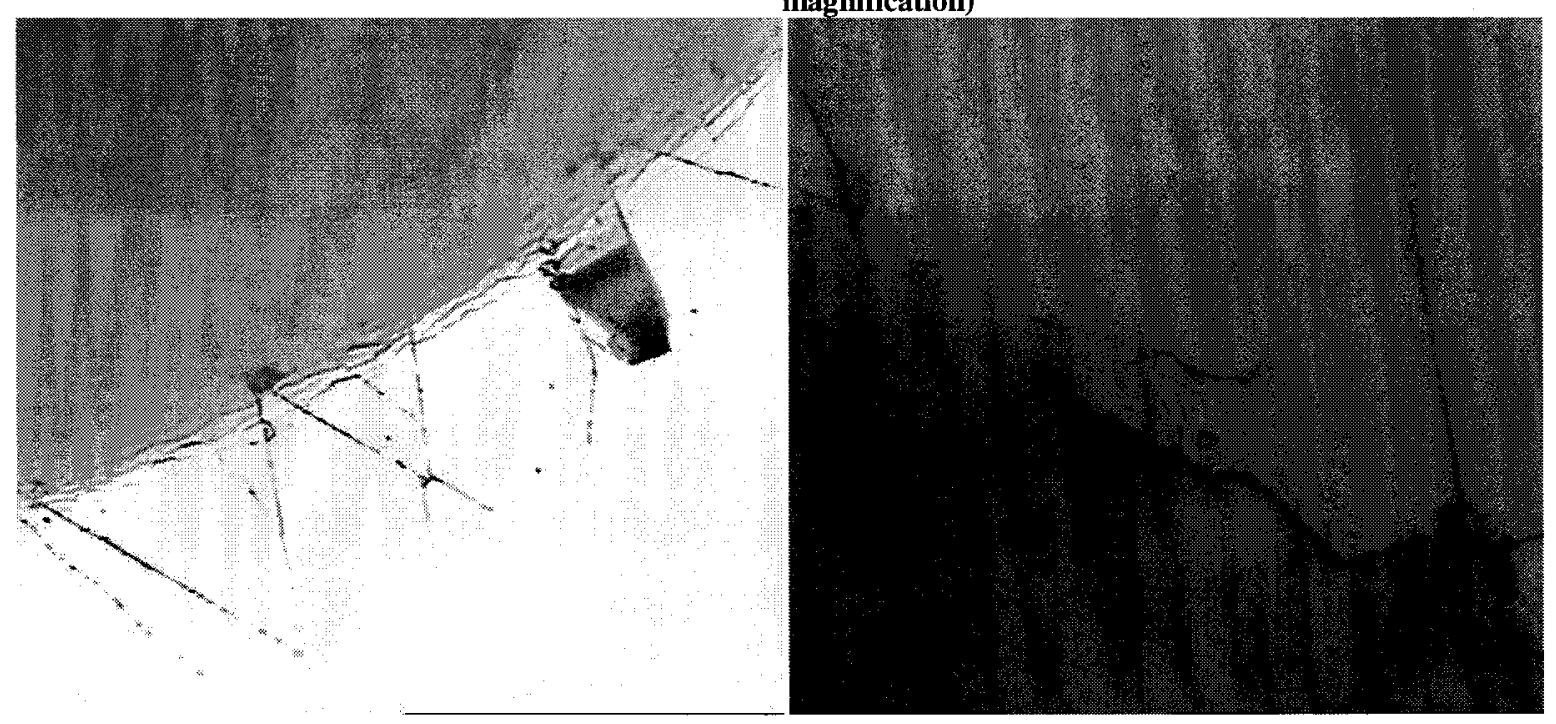

Figure 5.5: Rockwell-C indent \#1 on $X 7$ close-up of chip at bottom right of indent crater and showing circumferential cracking (50x magnification)

Figure 5.6: Rockwell-C indent \#1 on $X 7$ close-up of damage at upper right edge of indent crater (100x magnification) 

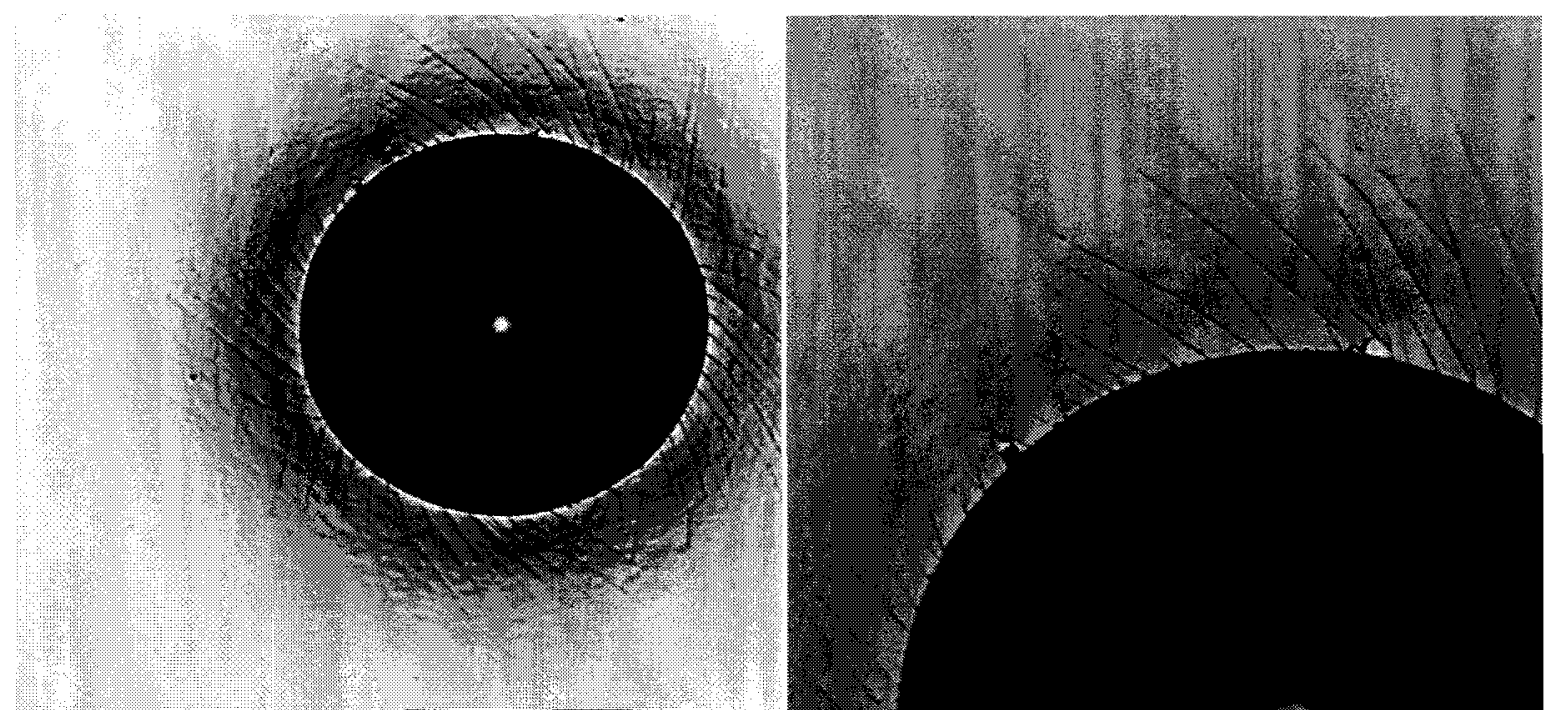

Figure 5.7: Rockwell-C indent \#2 on X7 showing good adhesion ( $5 x$ magnification)

Figure 5.8: Rockwell-C indent \#2 on X7 showing good adhesion and a small chip in the upper left (10x magnification)

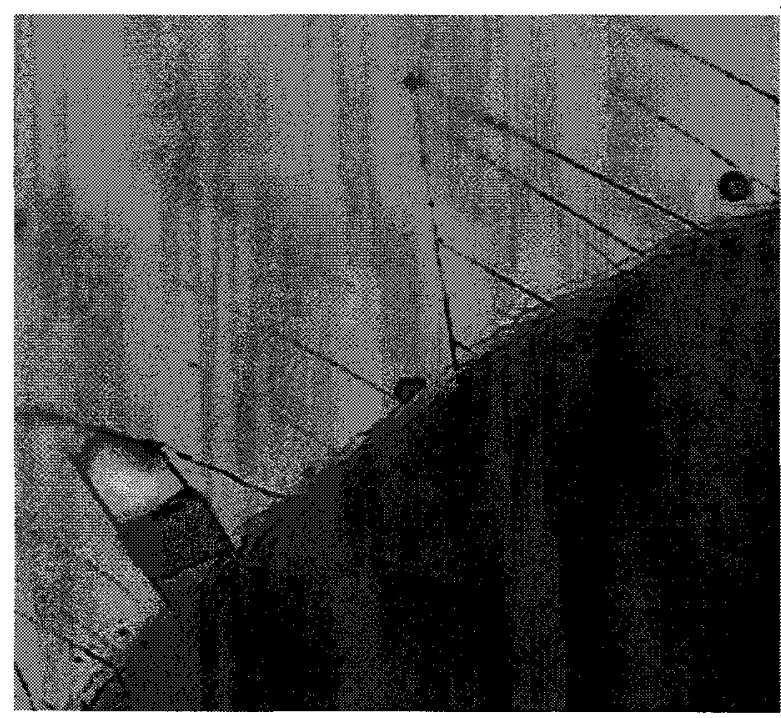

Figure 5.9: Rockwell-C indent \#2 on $X 7$ close-up of chip at upper left of indent crater and showing circumferential cracking (50x magnification)
Figure 5.10: Rockwell-C indent \#2 on X7 close-up of damage at upper edge of indent crater $(100 x$ magnification) 


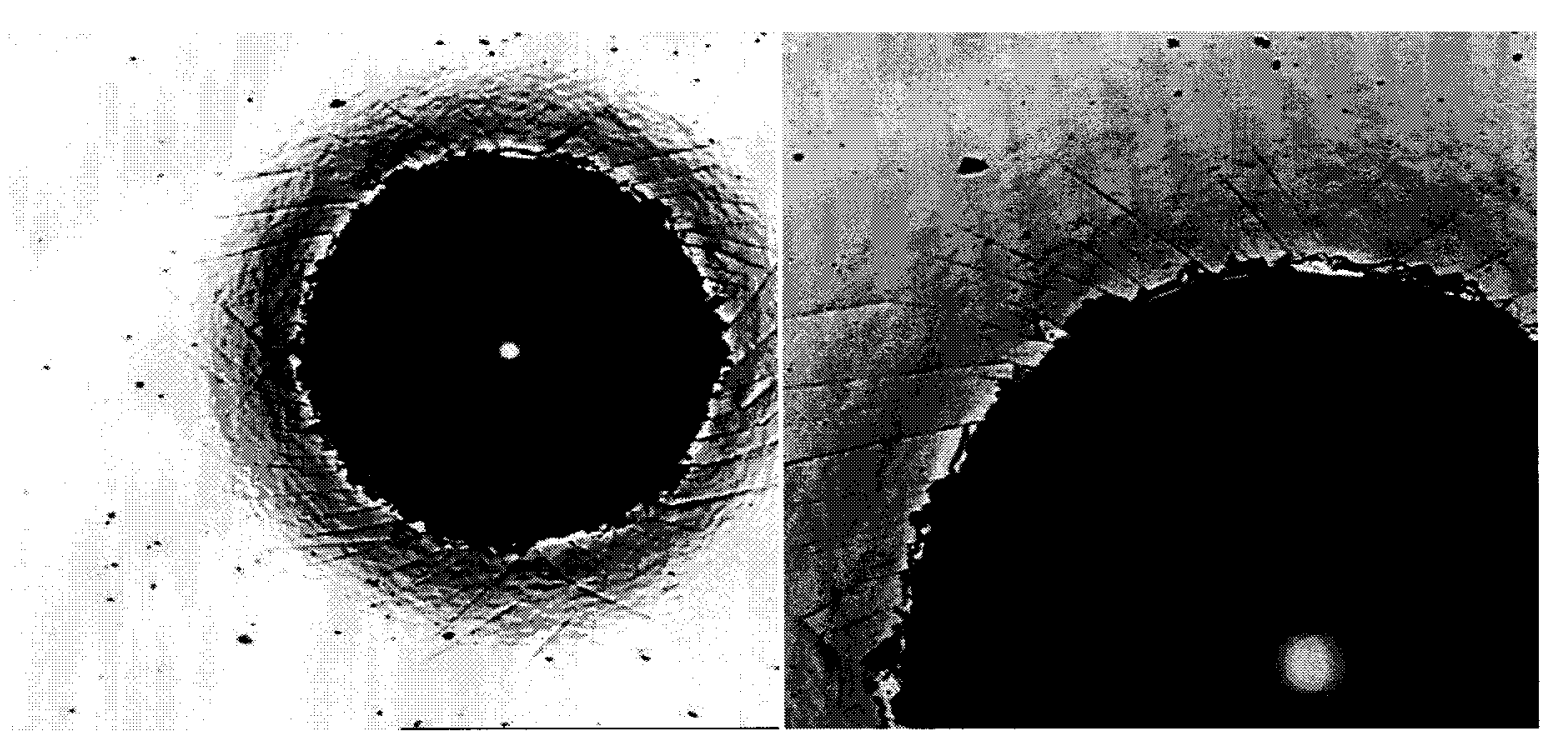

Figure 5.11: Rockwell-C indent \#1 on 57X showing poor film adhesion ( $5 \mathrm{x}$ magnification)

Figure 5.12: Rockwell-C indent \#1 on 57X showing the film lifting from the substrate near the edge of the indent crater (10x magnification)

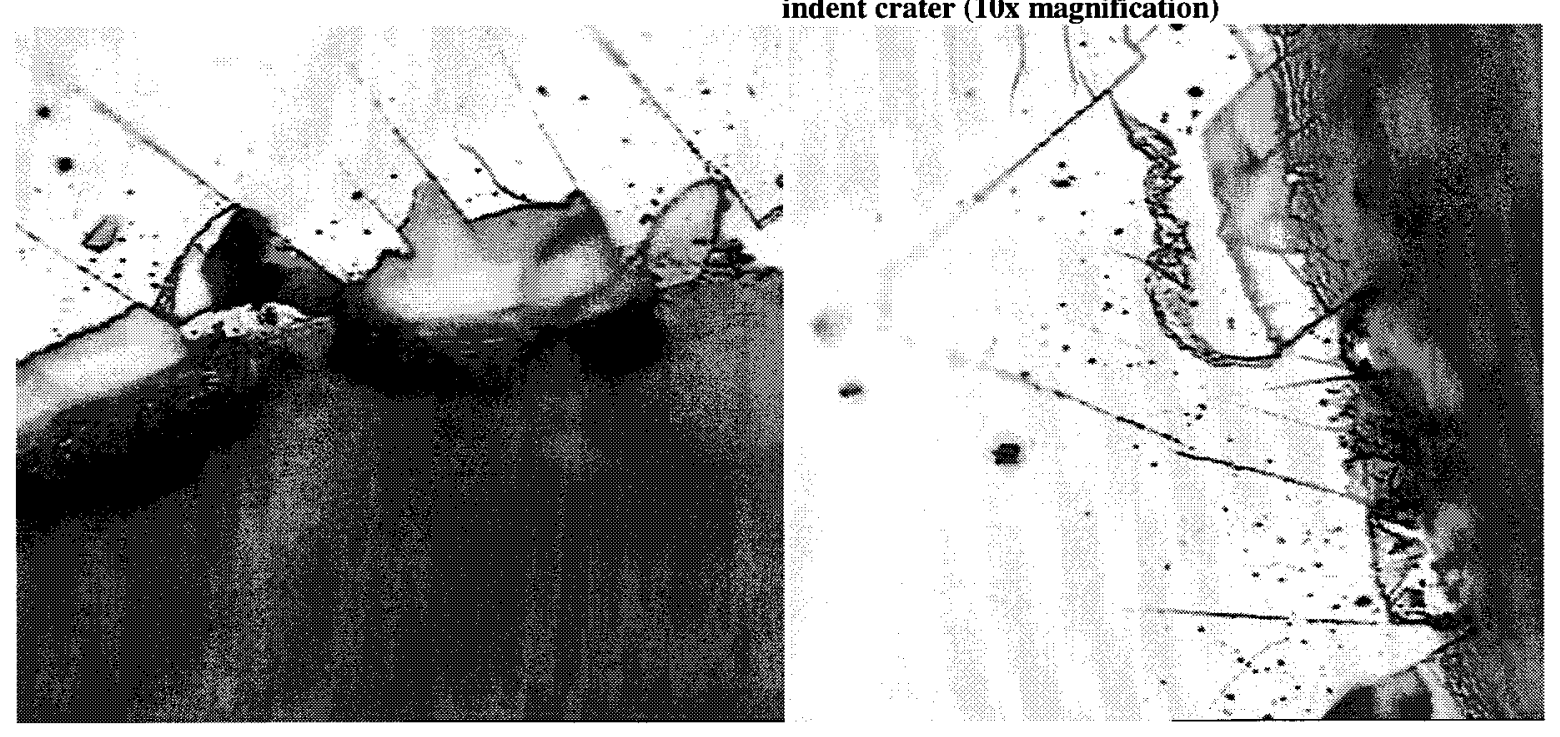

Figure 5.13: Rockwell-C indent \#1 on 57X showing area at upper edge of crater where coating has circumferential cracking and film delaminating from

Figure 5.14: Rockwell-C indent \#1 on 57X showing delaminated from the substrate under high the substrate (50x magnification) deformation (50x magnification) 


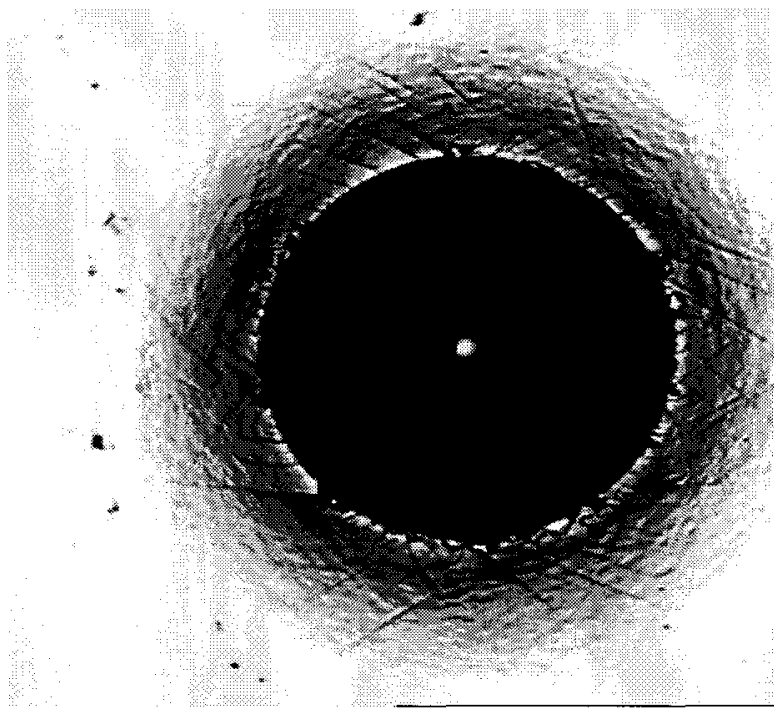

Figure 5.15: Rockwell-C indent \#2 on 57X showing primarily poor film adhesion ( $5 x$ magnification)

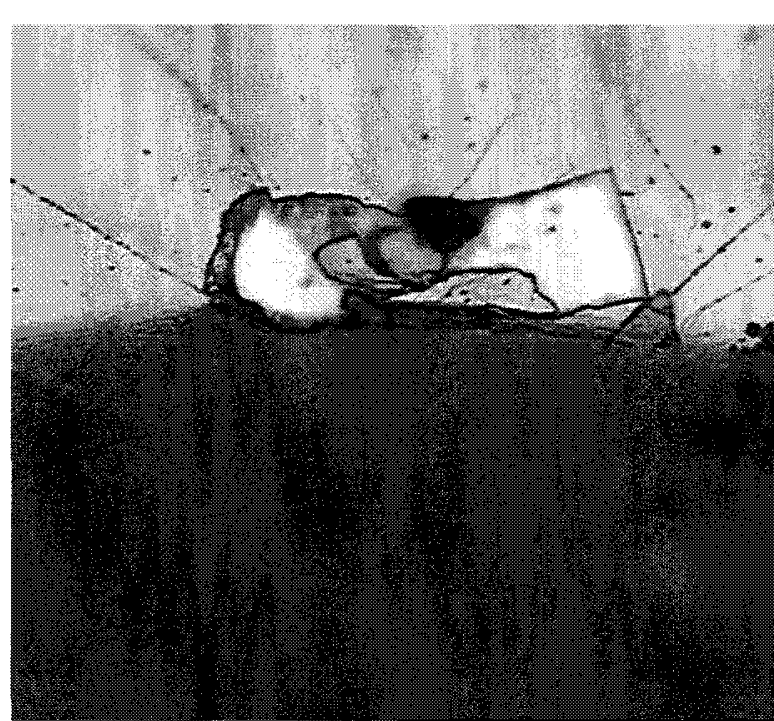

Figure 5.17: Rockwell-C indent \#2 on $57 \mathrm{X}$ showing some well-adhered coating with circumferential cracking and some chipping of the coating (50x magnification)

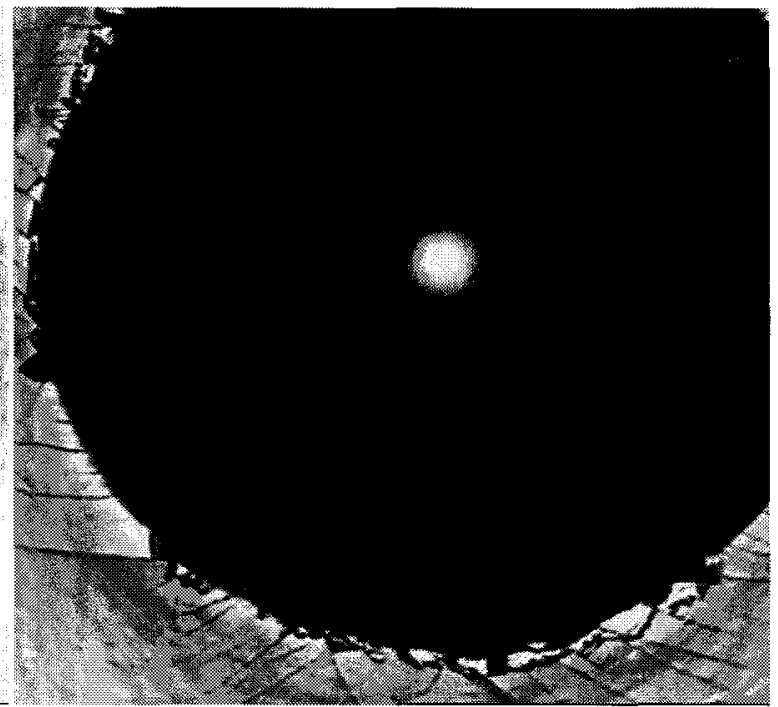

Figure 5.16: Rockwell-C indent \#2 on 57X primarily poor adhesion with a small section of well-adhered coating near the left side (10x magnification)

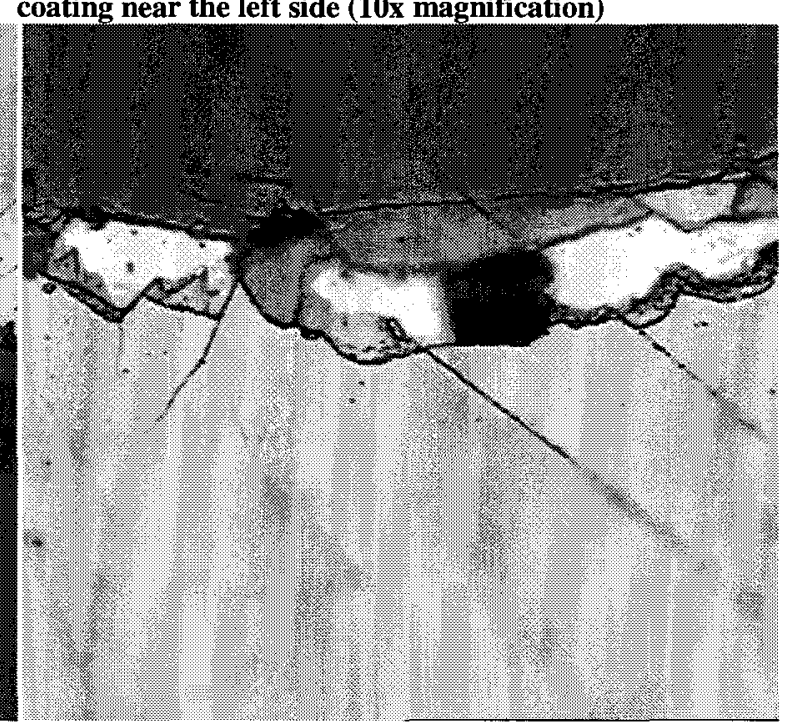

Figure 5.18: Rockwell-C indent \#2 on 57X showing chipping of the coating at the edge of crater with coating visible within the crater (50x magnification) 


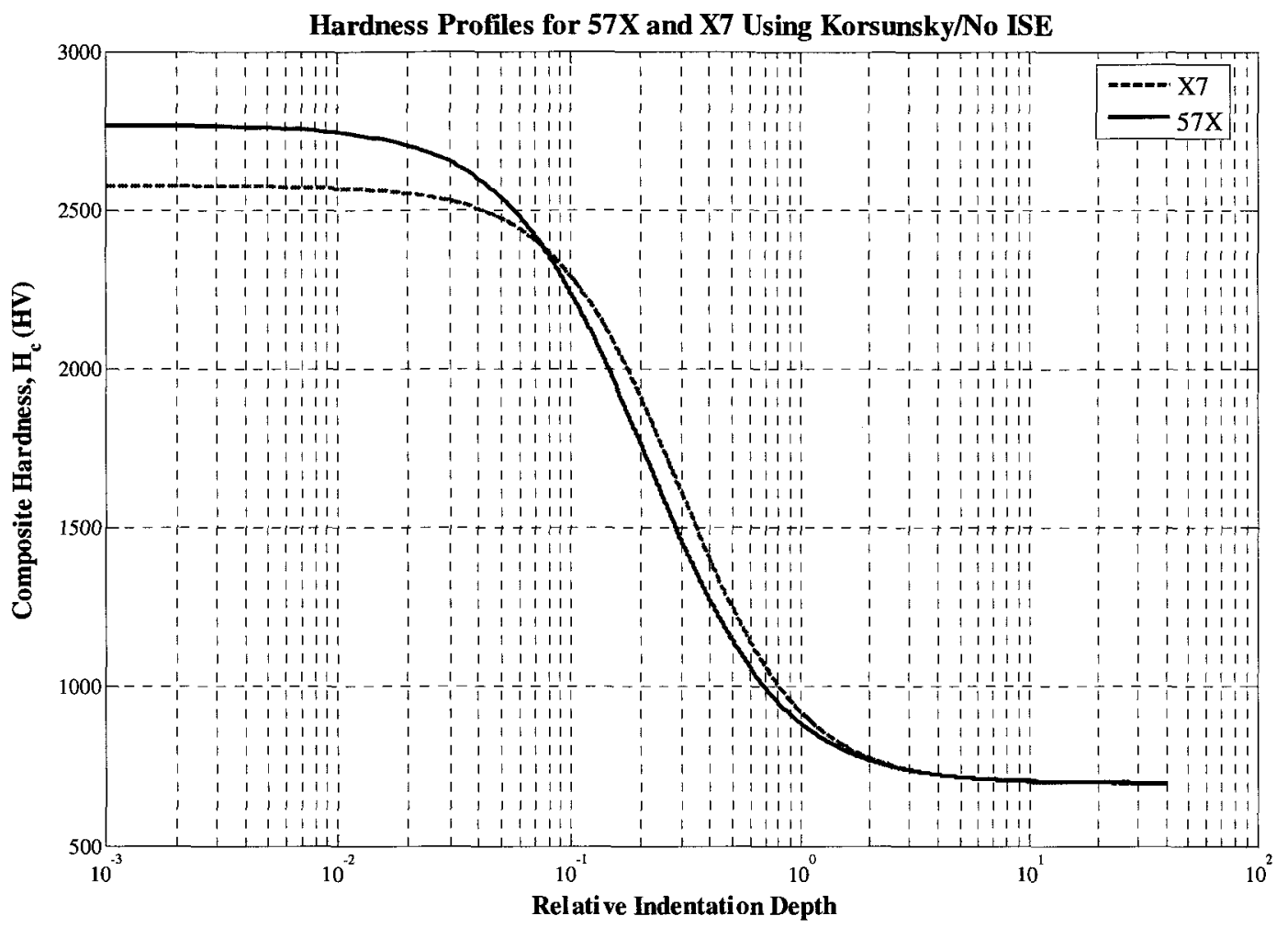

Figure 5.19: Calibrated hardness profiles for $57 X$ and $X 7$ using Korsunsky/No ISE and shown on the same plot 


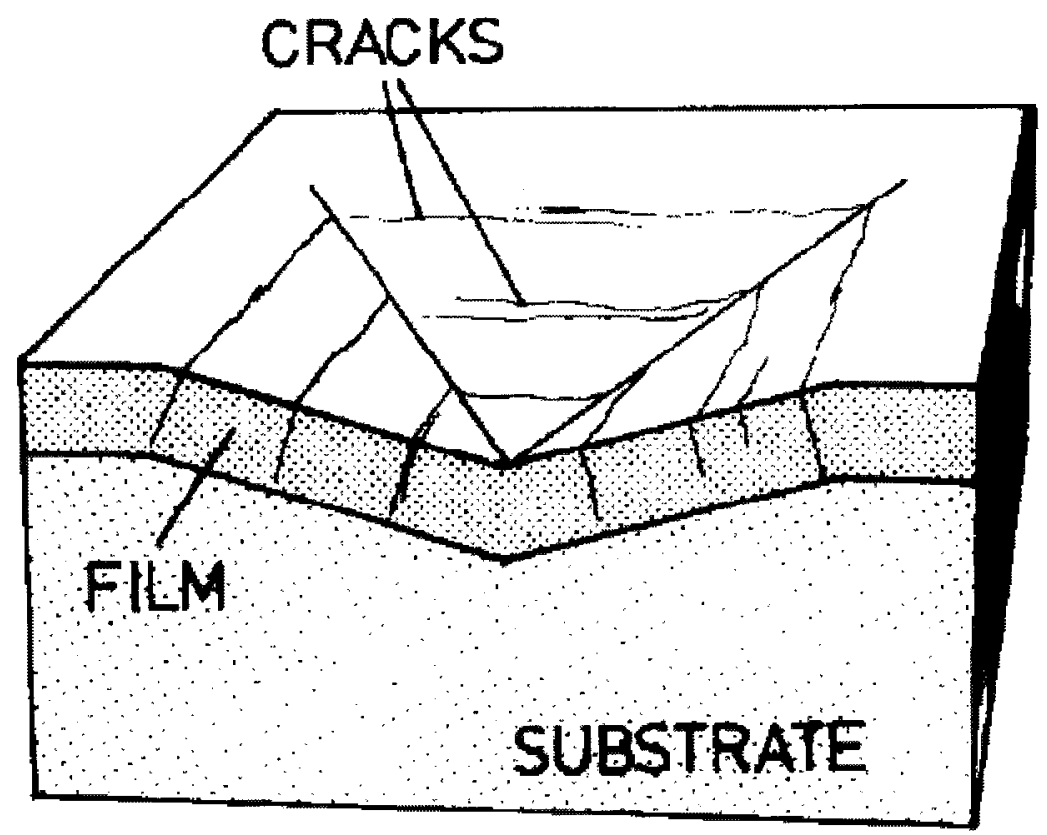

Figure 5.20: Cracking occurring inside indent performed during micro-indentation testing of the thin-film system (Jönsson, et al., 1984)

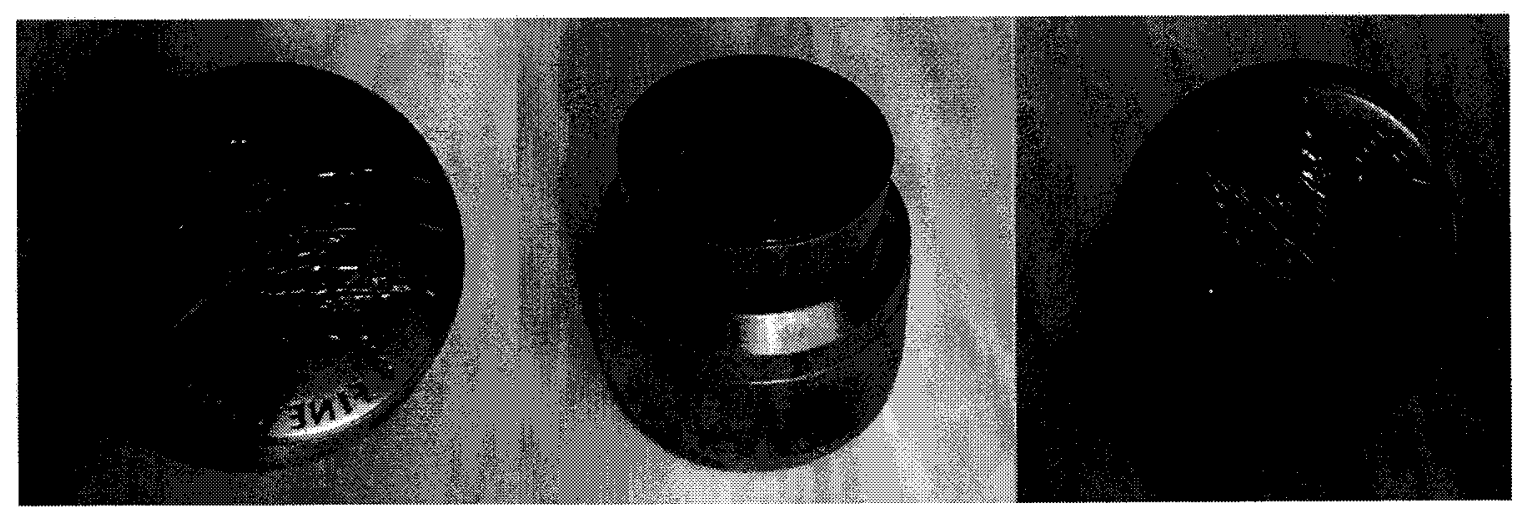

Figure 5.21: GML dies use for surface analysis [from left to right: new and unused die (104819X8), failed die due to striking collar (104819-26X), failed die due to surface wear (104819-7X)] 

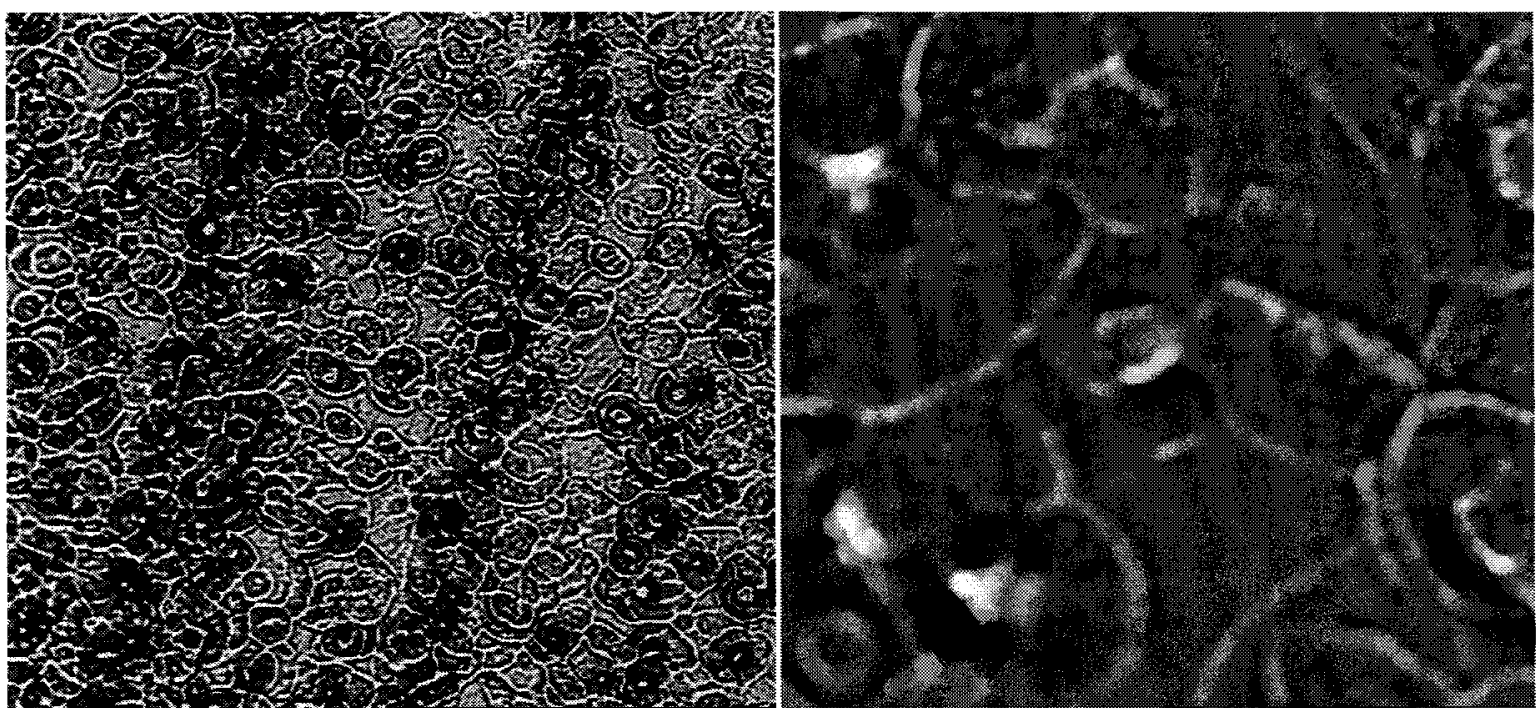

Figure 5.22: Flat surface of X8 (10x magnification)

Figure 5.23: Flat surface of X8 (100x magnification)

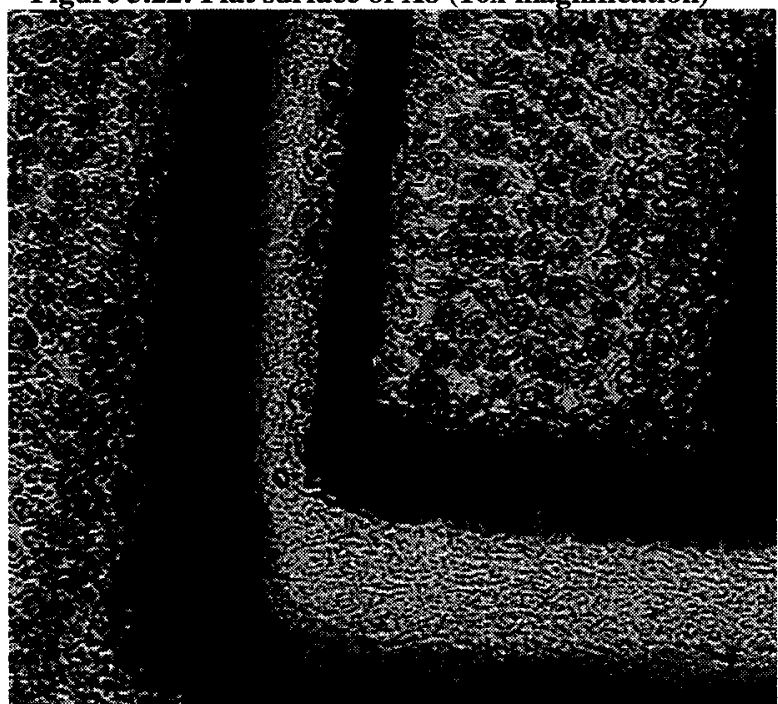

Figure 5.24: Recessed ' $F$ ' of $X 8$ showing film fully Figure 5.25: Recessed ' $F$ ' of $X 8$ showing some clearly covering flat surface up to the edges ( $5 x$ magnification) visible film inside recessed area (10x magnification) 


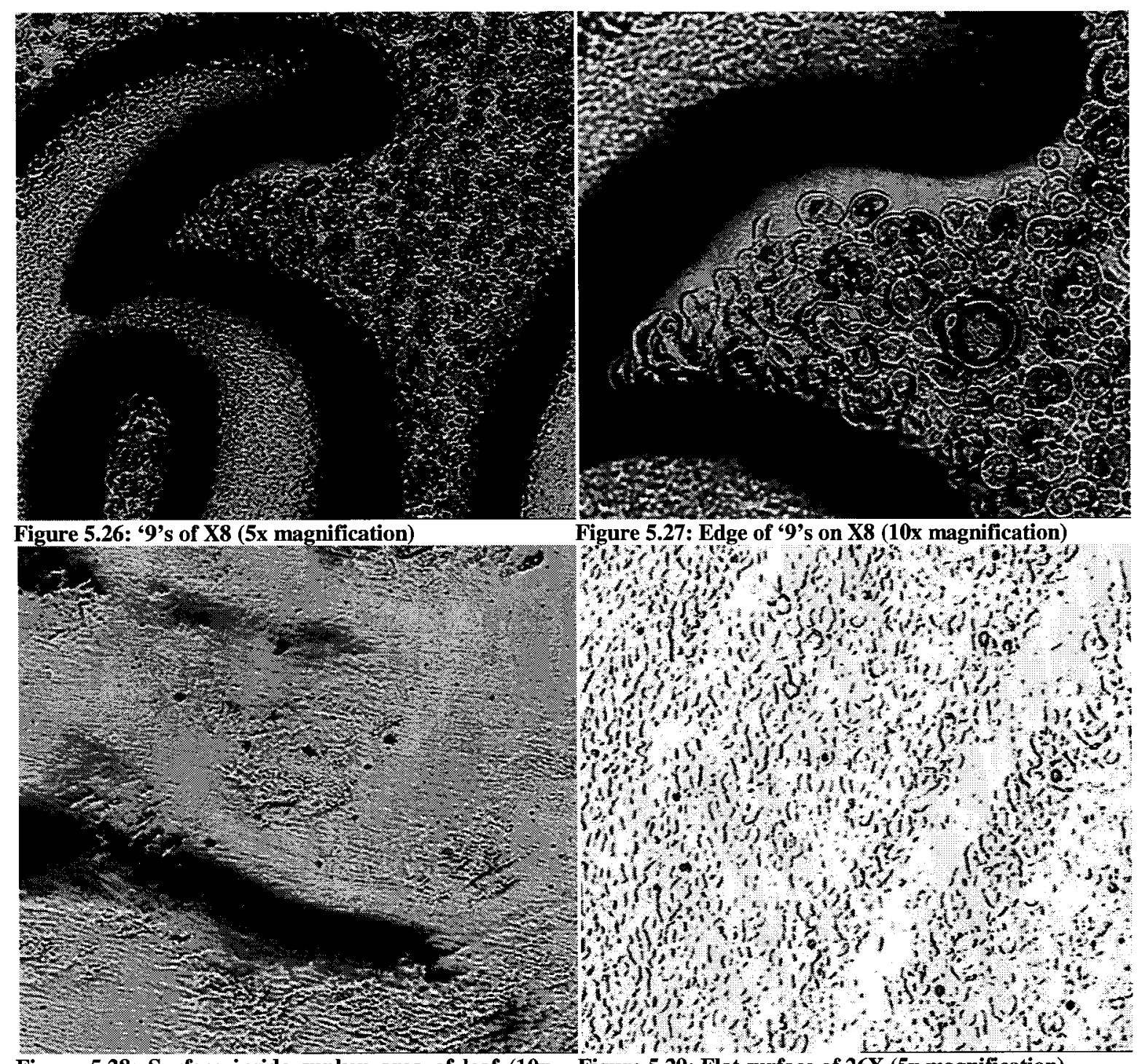

Figure 5.28: Surface inside sunken area of leaf (10x Figure 5.29: Flat surface of $26 X$ (5x magnification) magnification) 


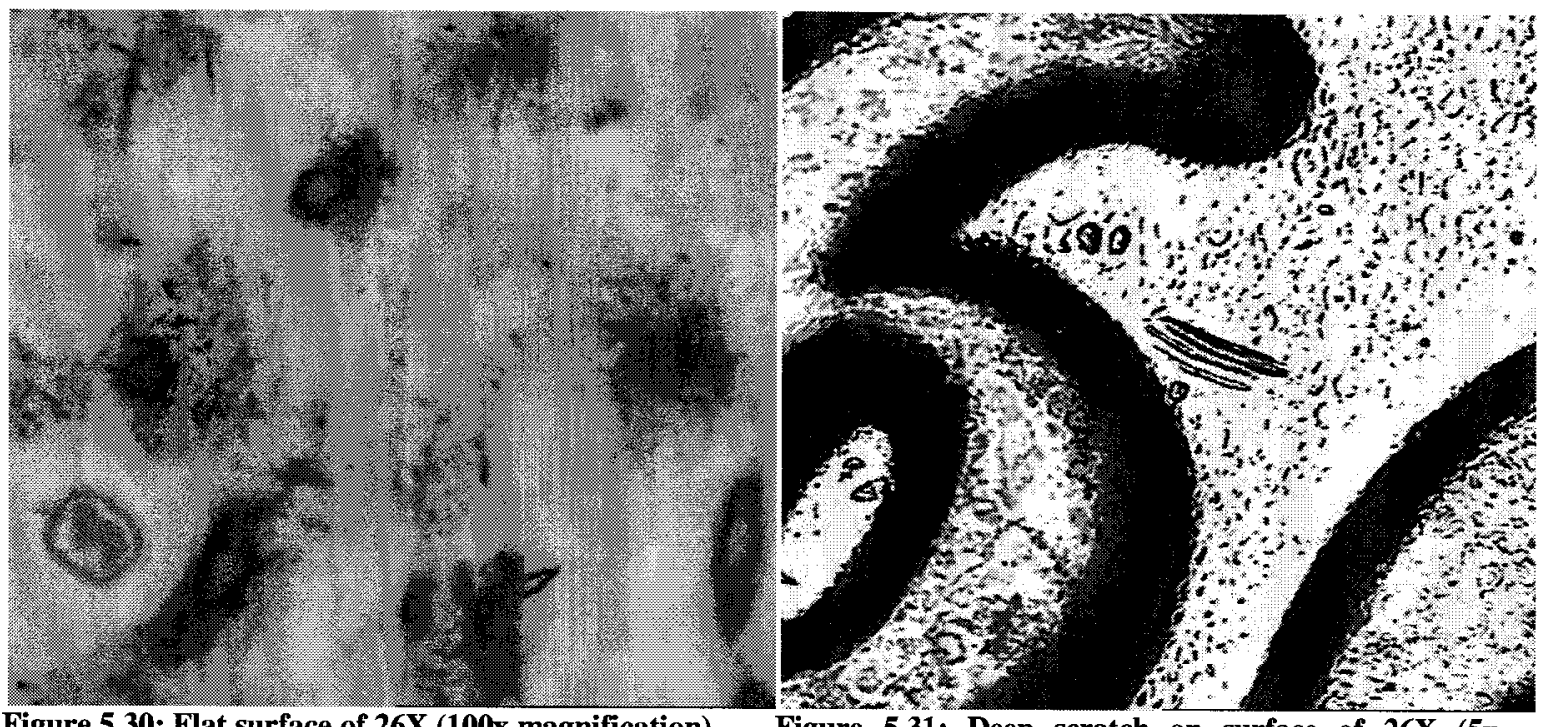

Figure 5.30: Flat surface of $26 \mathrm{X}$ (100x magnification)

Figure 5.31: Deep scratch on surface of $26 \mathrm{X}(5 \mathrm{x}$

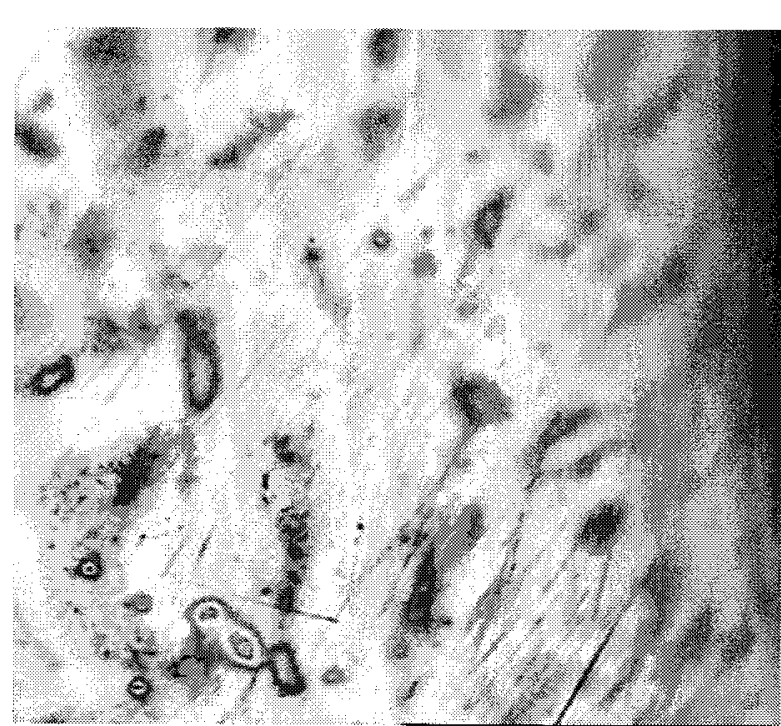
magnification)

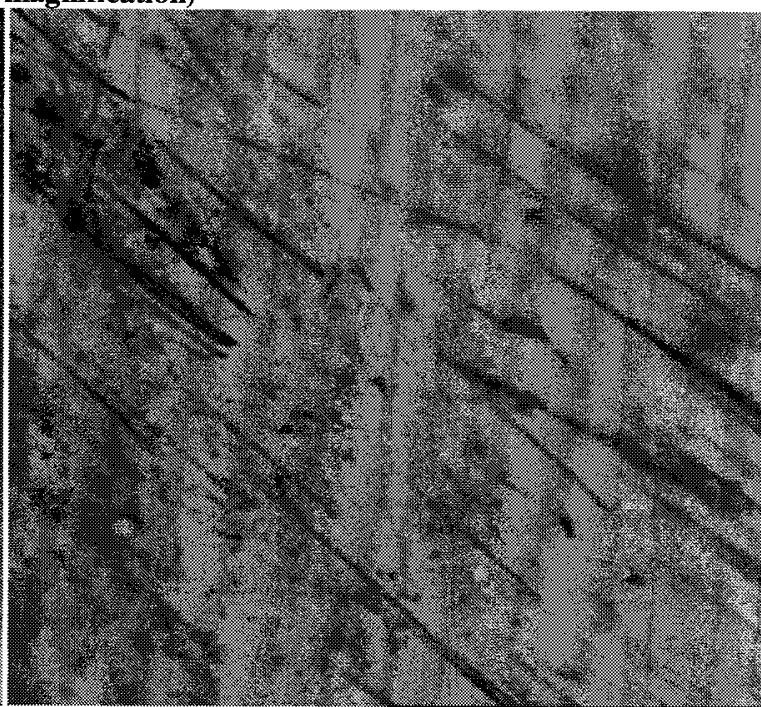

magnification)

Figure 5.33: Starburst scratches visible on the flat surface of $26 \mathrm{X}$ (100x magnification) 


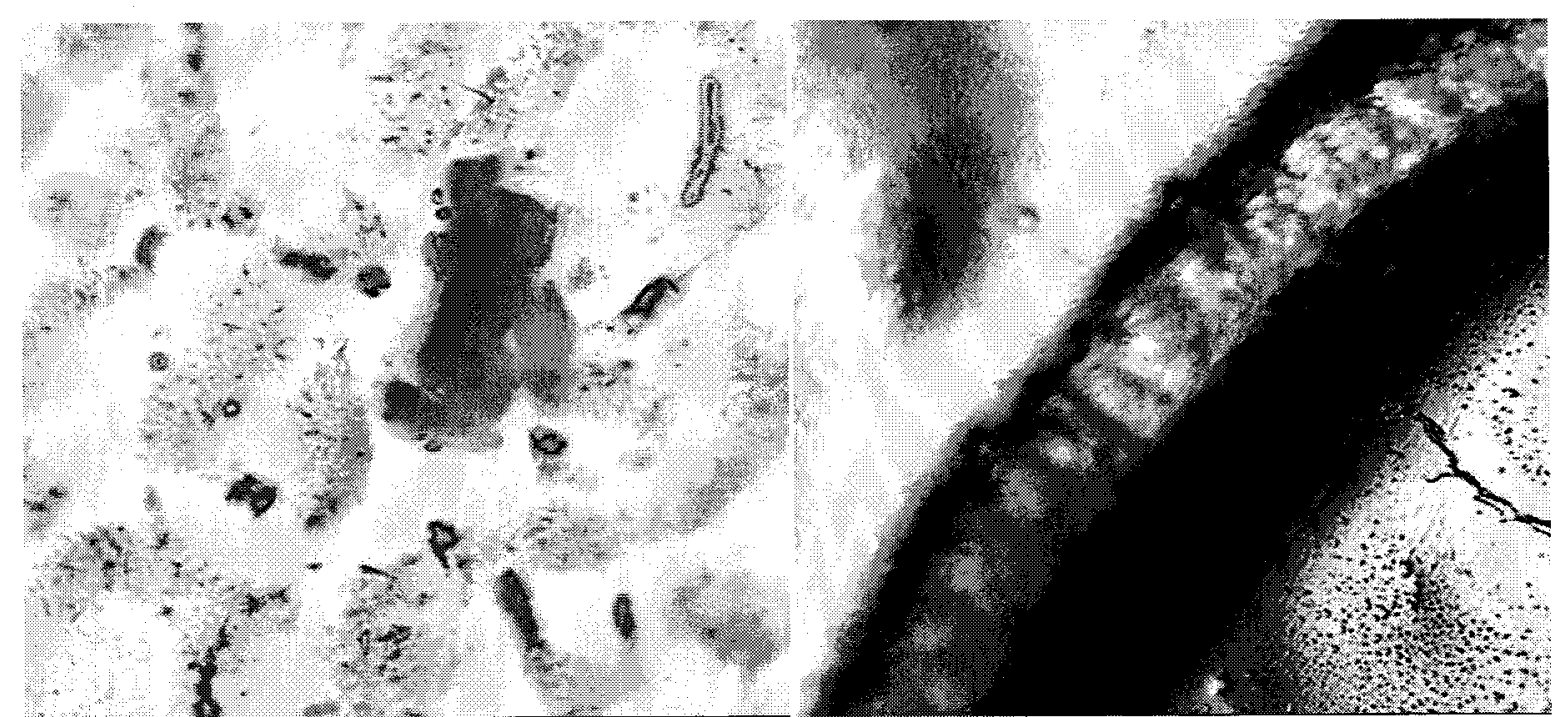

Figure 5.34: Coin material adhering to the flat surface of $26 \mathrm{X}$ ( $50 \times$ magnification)

Figure 5.35: Crack at a vein in the recessed leaf of $26 \mathrm{X}$

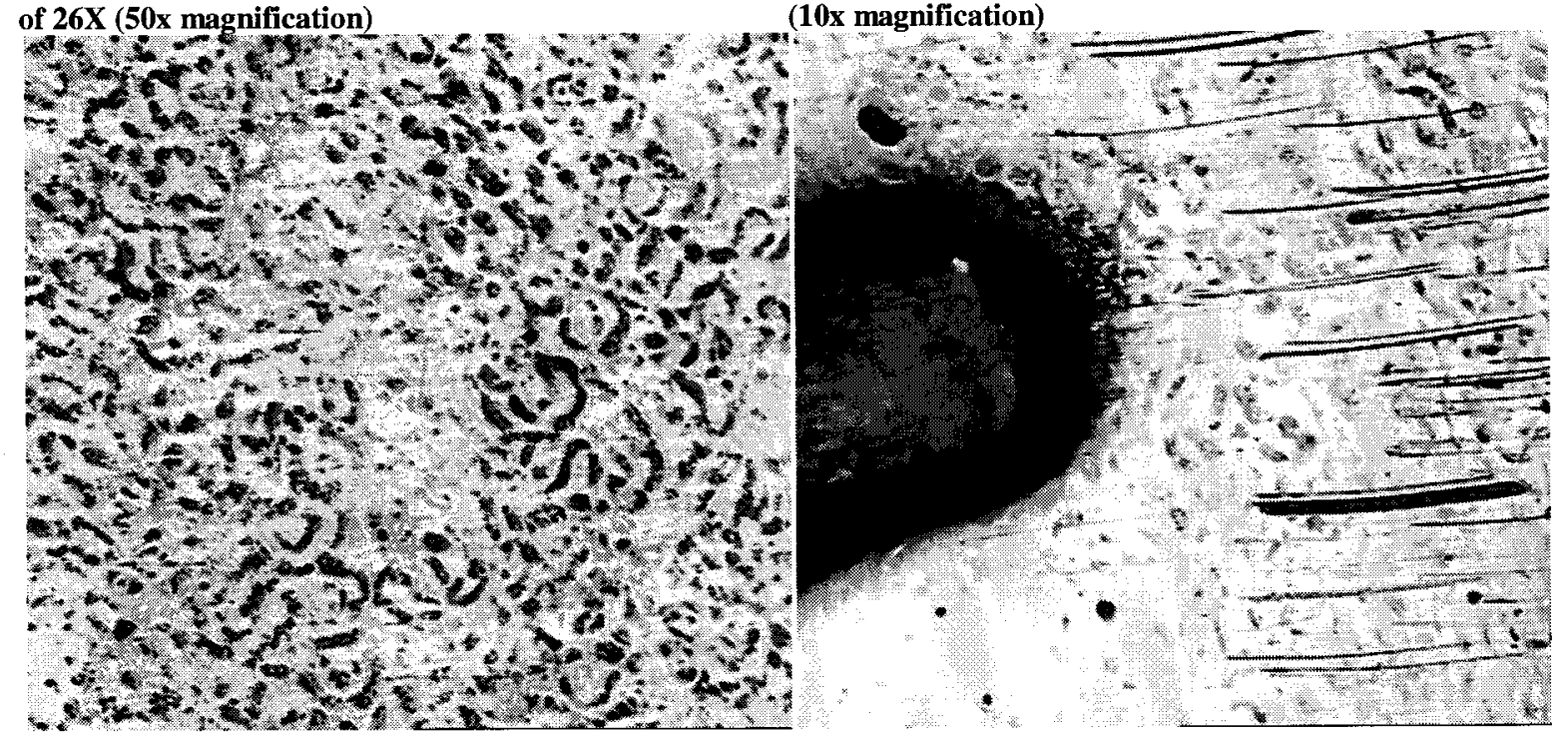

Figure 5.36: Flat surface of $7 \times$ (10x magnification)

Figure 5.37: Starburst scratches and corrosion near '9's of $7 \mathrm{X}$ (10x magnification) 




Figure 5.38: Crack at leaf tip of $7 \mathrm{X}$ causing removal of die from coin production (10x magnification)

Figure 5.39: Crack in film at leaf tip on $7 X$ showing

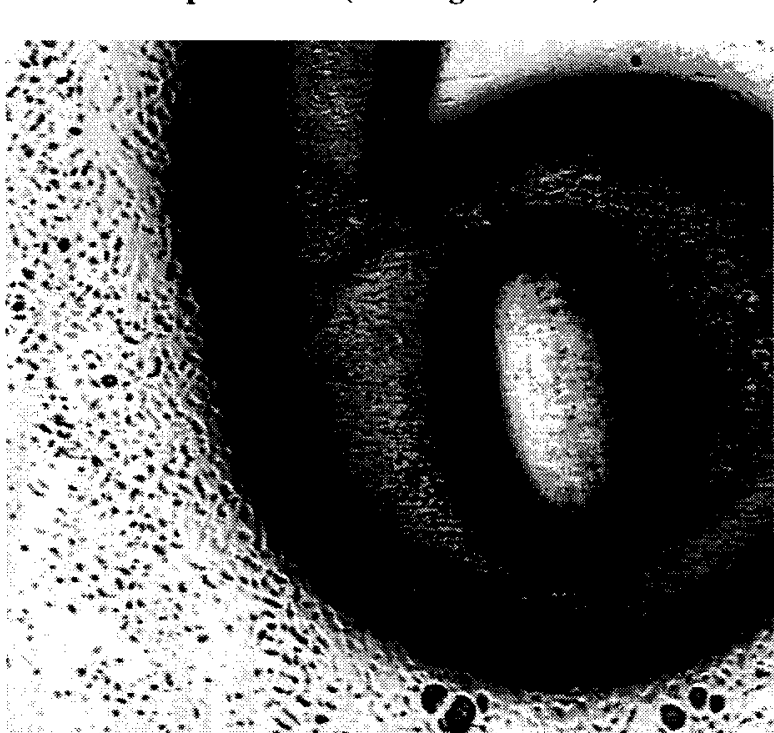
corrosion of substrate and adhesion of coin material (50x magnification)

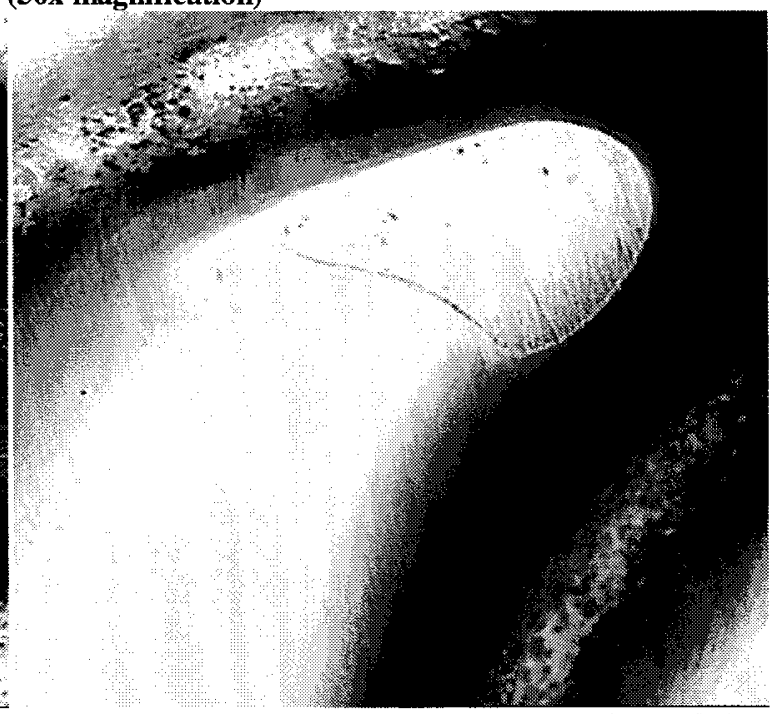

Figure 5.40: Corrosion at the bottom of recessed '9' on $7 \mathrm{X}$ where the film poorly covered the substrate or has been worn away ( $5 \mathrm{x}$ magnification)

5.41: Surface inside recessed leaf on $7 X$ showing small crack near leaf vein and smooth bright surfaces (10x magnification) 


\section{Chapter 6 : Conclusions and Recommendations}

In this study, the hardness of the RCM's hard PVD coating and a predictive method for determining the film hardness were examined using two test dies. The wear of the film on 3 production dies was also observed for normal numismatic coining operations and related to the hardness properties of the film. This section presents the main conclusions that can be drawn from the test results. Recommendations for supplementary study to the current research are also offered.

\subsection{Conclusions}

- Of the 6 thin-film hardness models and 2 indentation size effects (ISE) studied, two combinations were selected to best represent the measured hardness data. These were the basic Korsunsky model and the Korsunsky model combined with the Meyer ISE.

- Using the basic Korsunsky hardness model, the average film hardness of the two test dies was determined to be $2672 H V$. Using the Korsunsky model with the Meyer ISE, the average film hardness was determined to be $2691 \mathrm{HV}$.

- The inclusion of the Meyer ISE increases complexity but was not found to significantly increase the goodness of fit to the data so the basic Korsunsky model is sufficient for modelling the thin-film examined in this thesis.

- The selected thin-film hardness models can be used to simultaneously determine the model parameters and film properties when using both micro- and nanoindentation test data. The use of micro-indentation test data alone was found to be insufficient for this simultaneous calibration. Because the model parameters 
are consistent when using the same materials and processes, this calibration is only required when a new material or process is introduced.

- The method presented in this thesis is able to predict the hardness of the film using only micro-indentation test data. This was shown by using the calibrated model parameters from one die and predicting the hardness using the microindentation data from that die. It was then demonstrated that the calibrated model parameters from one die could be used to predict the hardness of two other dies.

- Poor adhesion of the film to the substrate on test die 57X coincides with the early onset of cracking noticed during indentation testing and the earlier deterioration of the measured hardness.

\subsection{Recommendations for Further Study}

The method discussed in this thesis for determining the hardness of a thin film has been demonstrated and has shown promise. The film hardness for both test dies (57X and X7) were very similar however the model parameters differed enough to offset the composite hardness curve. As noted, one die suffered from poor adhesion while the other did not. The experiments performed in this thesis could be repeated for additional samples with consistent adhesion to refine the model parameters. In addition to this, a statistical analysis should be carried out to evaluate the statistical significance and range of accuracy of the results. 


\section{Appendix A}

The closed-field unbalanced magnetron sputter ion plating (CFUBMSIP) technique used by the RCM is a particular type of physical vapour deposition (PVD) coating. This process has been enjoying increasing popularity due to its exceptional versatility (Kelly, et al., 2000),(Cooke, et al., 2003). The four main types of PVD coatings as reported by Sproul (1996) are: low voltage electron beam evaporation, cathodic arc deposition, triode high voltage electron beam evaporation and balanced and unbalanced magnetron sputtering. All of these methods evaporate and ionize the metallic targets in order to transport and deposit the material on the substrate. The major difference between these methods is the way that the target material is vaporised. The CFUBMSIP process is performed at low pressures $(<0.1 \mathrm{~Pa})$ (Cooke, et al., 2003) with an inert gas fed into the chamber to ensure the removal of other reactive gasses. The process can also be performed in the presence of a reactive gas, like nitrogen, to deposit the coating reactively.

\section{The Closed-Field Unbalanced Magnetron Sputter Ion Plating Process}

The CFUBMSIP process is composed of two different stages. As in other PVD coating methods, the first step is cleaning the substrate surface of contaminants and oxides using ion bombardment (Sproul, 1996). In all PVD methods, proper cleaning of the substrate surface is exceptionally important for coating adhesion (Cooke, et al., 2003). For CFUBMSIP, argon is ionized while the substrate is held at a negative potential in order to facilitate ion bombardment. The second step is the actual sputter coating of the substrates and includes four key components: targets, magnetron configuration, substrates and reactive gasses. One of the main advantages of this method is that the coating can be applied at temperatures as low as $150^{\circ} \mathrm{C}$ (Teer, et al., 2006). 


\section{Targets}

The targets are the raw materials which will be deposited on the substrate as a coating. Each target is a plate which is positioned in front of a magnetron at some distance away from the substrate. The distance between the substrate and target is dictated by the strength of the magnetron; however newer apparatuses allow the magnetron strength to be adjusted during the process for versatile coating. All together, the targets are evenly spaced surrounding the substrate holder.

\section{Magnetron Configuration}

A magnetron consists of a set of magnets placed behind a target. The magnets are arranged such that one pole is in the centre of the target and the opposite pole is near the edges as in Figure A.1 (Sproul, 1996). Each magnetron sets up a "racetrack" of trapped electrons which strike and ionize argon atoms creating plasma in front of the target (Teer, et al., 2006). During operation, the plasma in the vicinity of the target glows as electrons in the argon atoms are being excited and dropping back to lower energy shells (Ltd09). Figure A.2 shows a magnetron in operation. A conventional magnetron is one where the inner and outer magnets are of the same strength (Kelly, et al., 2000). An unbalanced magnetron is one where either the inner or outer set of magnets is stronger that the other. Type-II magnetrons, where the outer set of magnets is stronger than the inner (Sproul, 1996) are the most common (Type-I has stronger inner magnets). The Type-II configuration is used so that the magnetic field extends towards the substrate as in Figure A. 3 to ensure the plasma also exists next to the substrate so that high deposition rates can be obtained on the substrate. The magnetrons are arranged in the chamber such that the magnetron's polarity is opposite to its neighbour so that the magnetic field lines will be closed as in Figure A.4 (Kelly, et al., 2000). Charged particles are then trapped within the working area. When the magnetron drives are turned on, the target is negatively 
charged in order to attract positive argon ions (Ltd09). The ejected target atoms are uncharged and proceed directly out of the magnetic trap towards the substrates. For a four magnetron system as used in the Teer Coatings UDP650/4 system, the magnetrons are arranged at $90^{\circ}$ angles as shown in Figure A.4 to close the field. Other closed field configurations are also possible (Cooke, et al., 2004) and are shown in Figure A.5. Magnetron power can be set and adjusted by the operator.

\section{Substrates}

The substrates are the items to be coated, commonly a metallic tool requiring some surface enhancement. A typical coating machine has a substrate holder located in the centre of the arrangement of magnetrons. The substrate holder can rotate the substrates past each magnetron in order for the substrates to be coated with the various target materials. The rate of rotation can be set by the operator based on the coating required.

\section{Reactive Gasses}

Reactive gasses may be fed into the chamber depending on the magnetron configuration. The flow of the gas can be controlled to obtain graded coating composition and properties (Kelly, et al., 2000). Nitrogen is regularly used as the reactive gas in order to deposit nitride coatings. A commonly used coating TiN can be sputtered effectively in both cases by selecting pure $\mathrm{Ti}$ targets (reactive sputtering) or TiN targets (non-reactive sputtering) (Mayrhofer, et al., 2002). 


\section{Overview of Unbalanced Magnetron Sputtering of Minting Dies}

Once the die is hobbed, heat treated and finished, it is ready for the hard PVD coating. Before coating, the dies are cleaned using argon ion bombardment. The sputter coating is applied when the magnetrons are turned on and electrons begin their motion around the 'racetrack' set up in front of the target. Electrons strike and ionize argon atoms creating plasma in front of the target. Charged argon atoms accelerate towards and strike the charged target, ejecting target atoms as well as secondary electrons (Kelly, et al., 2000). The sputtered target atoms are uncharged and travel out of the magnetic trap towards the substrate (Ltd09). The secondary electrons are trapped by the magnetic field and replenish the plasma in both target and substrate regions (Kelly, et al., 2000),(Ltd09). The sputtered target atoms then react with the reactive gasses in the chamber and condense on the substrate surface forming the coating. Once the coating is completed, a final buffing is performed to remove surface asperities and ensure a smooth die. 


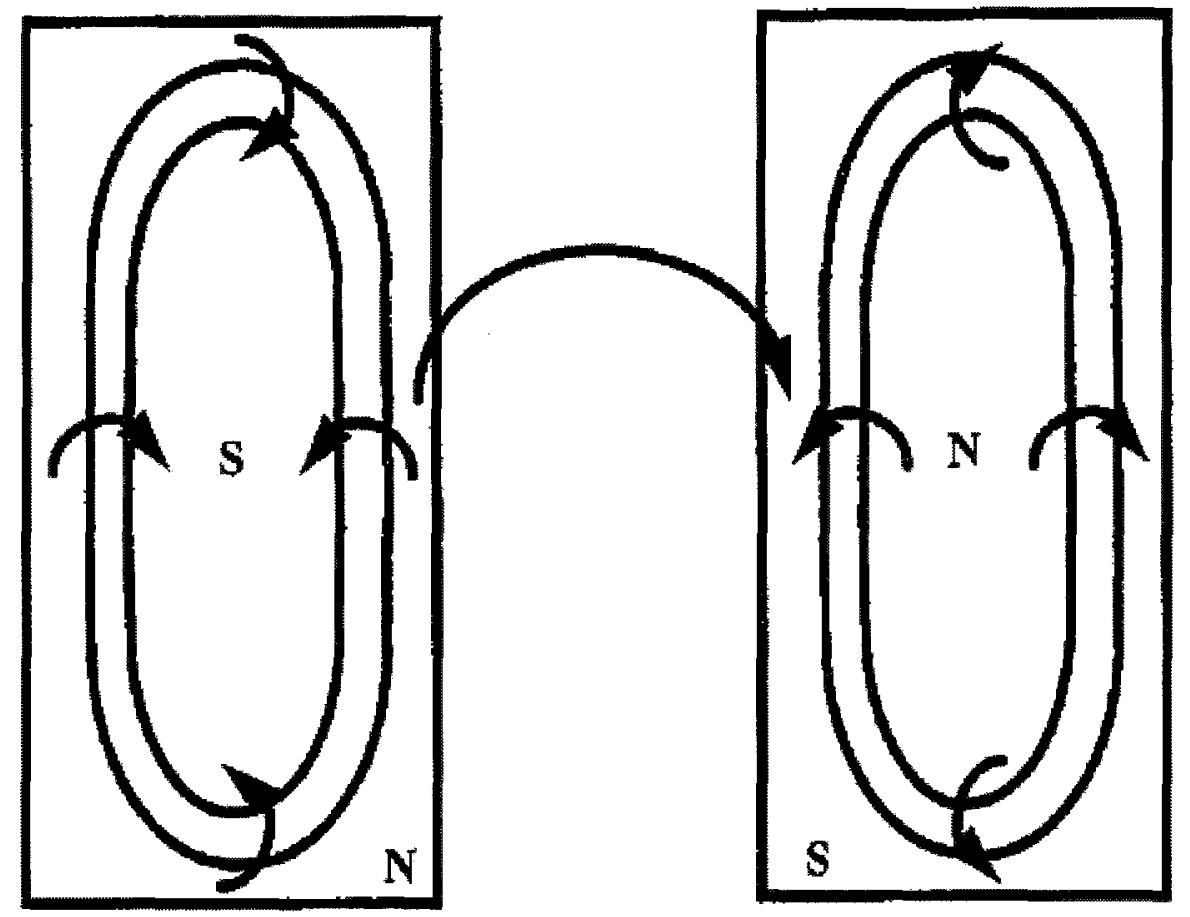

Figure A.1: Arrangement of magnets in a magnetron (Sproul, 1996)

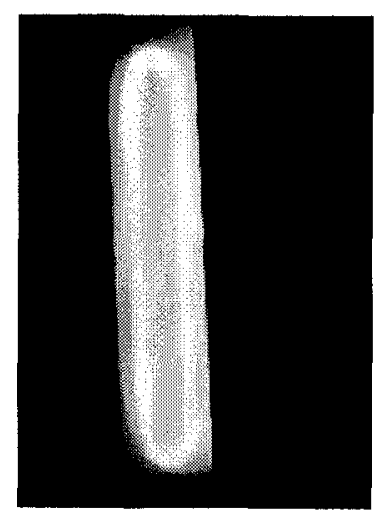

Figure A.2: Magnetron in operation (Ltd09) 

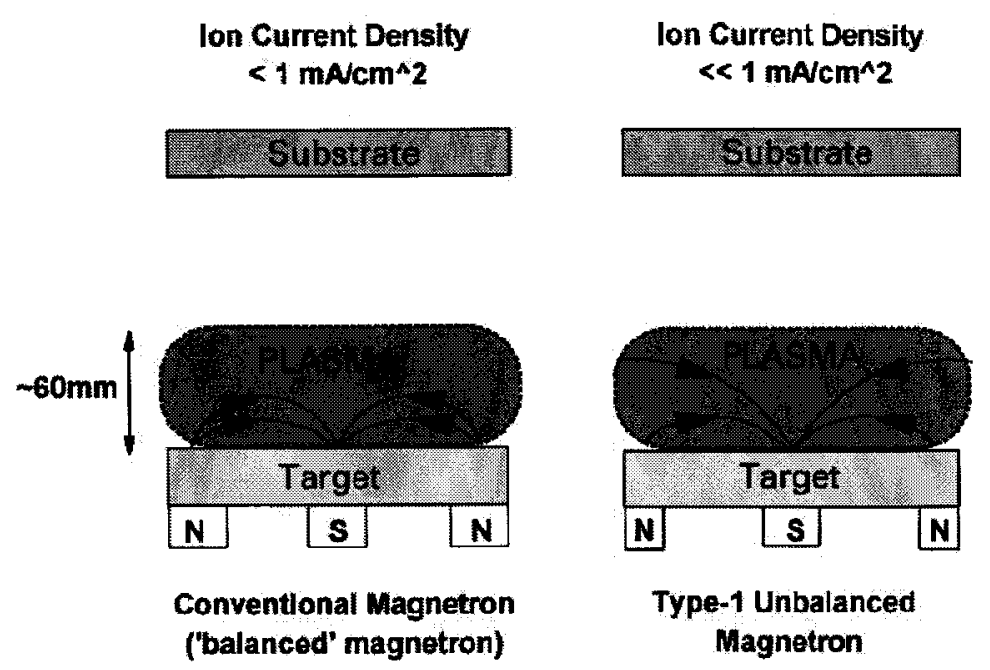
Ion Current Density
2-10 $\mathrm{mA}^{\mathrm{cm}}{ }^{\wedge} 2$

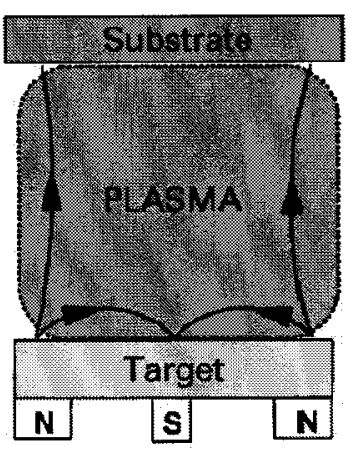

Type-2 Unbalanced Magnetron

Figure A.3: Distribution of plasma for various magnetron configurations (Kelly, et al., 2000)

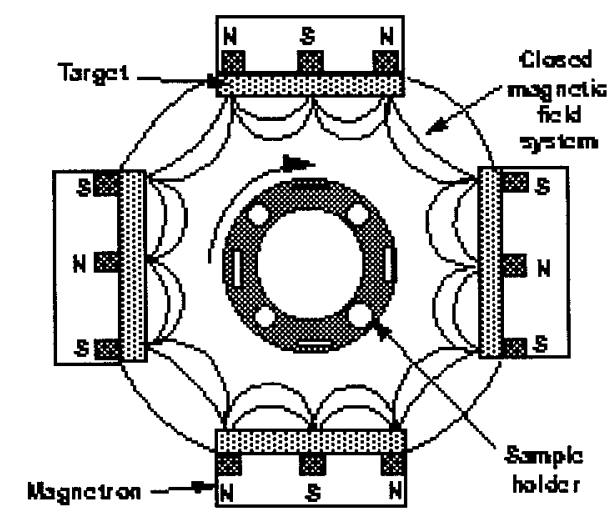

Figure A.4: Four magnetron closed field arrangement (Ltd09) 


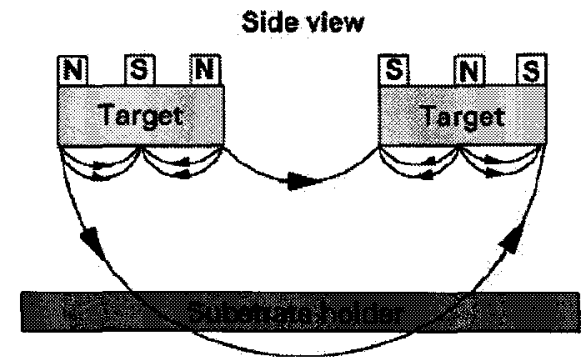

Closed-fleld conflguration (co-planar)
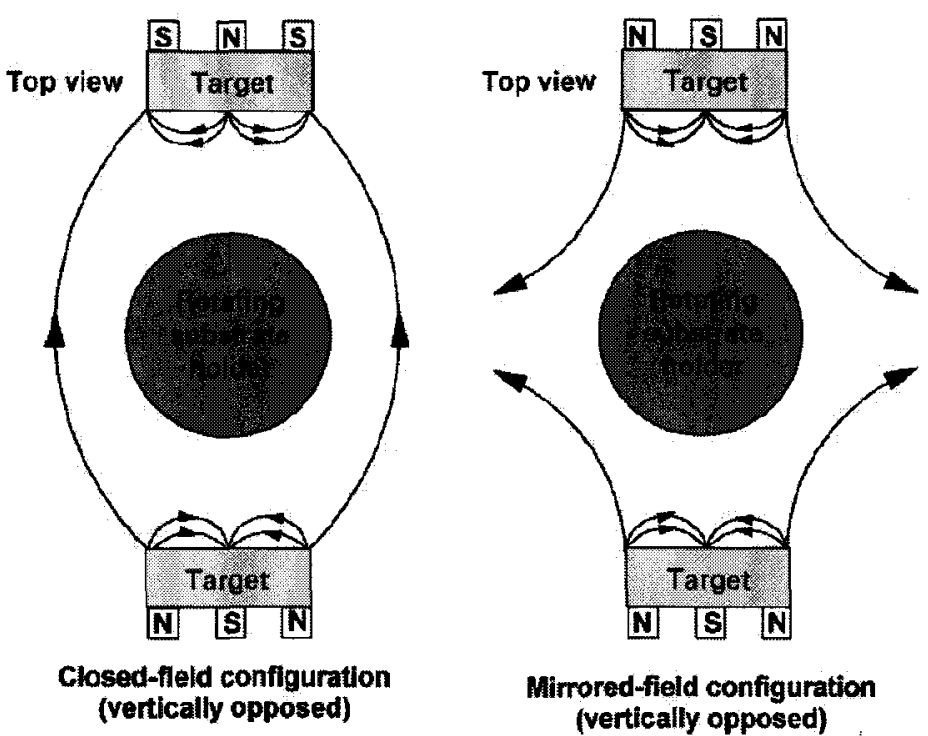

Mirrored-field configuration (vertically opposed)

Figure A.5: Various magnetron configurations (Kelly, et al., 2000) 


\section{Appendix B}

This section is intended to define some of the terminology used in this document. In particular it will cover the terminology specific to minting and metrics used to evaluate the performance and failure of dies. (Costello, 2009)

\section{Blank}

A blank is a small, flat metal alloy disc that has not yet been struck to produce a coin.

\section{Die}

A die is a tool with the negative impression to be imparted on another object. Minting dies come in pairs: obverse and reverse.

\section{Obverse}

The obverse is the "front" of the coin. The obverse carries the principal design of the coin which is generally the figurehead. The Queen is represented on the obverse of Canadian coins.

\section{Reverse}

The reverse is the "back" of the coin. The reverse often carries the year the coin was struck, the coin's denomination and an artistic design.

\section{Numismatic Die}

A numismatic die is a die used for producing collector's quality (or numismatic) coins. 


\section{Circulation Die}

A circulation die is a die used for producing circulation coinage. The quality of circulation coinage, while important, is not nearly as critical as numismatic coinage.

\section{Striking}

Striking is the application of force by the dies on a blank in order to imprint the blank with the design on the die. The blank may be struck several times before it is a finished coin.

\section{Die Crash}

Die crash occurs when two dies are struck together without a blank in between.

\section{Die Life}

The die life is measured using the total number of coins struck, or total number of strikes from the die, before failure of the die based on the quality of struck coins. 


\section{Appendix C}

This section is intended to present the MATLAB source code used to produce the results discussed in this thesis. The source code is presented in 6 different sections:

- Input data

- User controls

- Supporting functions

- Substrate calibration

- Coated die calibration

- Coated die prediction

\section{Input Data}

In order to use the program, the user must prepare a MATLAB data file (*.mat) for each die to be analysed. The data file must contain the following pieces of information:

\begin{tabular}{|c|c|l|}
\hline Variable Name & Data Type & \multicolumn{1}{c|}{ Description } \\
\hline NHT_data & $\begin{array}{c}\text { N by } 3 \text { array of } \\
\text { double }\end{array}$ & $\begin{array}{l}\text { Array containing coated system nano-indentation test } \\
\text { data for N indents. First column contains mean indent } \\
\text { diagonal (in m). Second column contains relative } \\
\text { indentation depth. Third column contains Vickers } \\
\text { hardness number. }\end{array}$ \\
\hline VMHT_data & $\begin{array}{c}\text { N by } 3 \text { array of } \\
\text { double }\end{array}$ & $\begin{array}{l}\text { Array containing coated system micro-indentation test } \\
\text { data for N indents. First column contains mean indent } \\
\text { indentation depth. Third column contains Vickers } \\
\text { hardness number. }\end{array}$ \\
\hline subData & $\begin{array}{l}\text { N by } 3 \text { array of } \\
\text { double }\end{array}$ & $\begin{array}{l}\text { Array containing substrate micro-indentation test data } \\
\text { for N indents. First column contains mean indent }\end{array}$ \\
\hline
\end{tabular}




\begin{tabular}{|c|c|c|c|c|}
\hline & & $\begin{array}{l}\text { diagonal (in m). Secon } \\
\text { indentation depth. Thirc } \\
\text { hardness number. }\end{array}$ & column & $\begin{array}{l}\text { ins relative } \\
\text { ns Vickers }\end{array}$ \\
\hline \multirow{4}{*}{ subResults } & \multirow{4}{*}{$\begin{array}{c}3 \text { by } 2 \text { array of } \\
\text { double }\end{array}$} & \multicolumn{3}{|c|}{$\begin{array}{l}\text { Array containing hardness information for the } \\
\text { substrate. }\end{array}$} \\
\hline & & $\mathrm{H}_{0 \mathrm{~s}, \text { Meyer }}$ & $\mathrm{n}_{\mathrm{s}}$ & \\
\hline & & $\mathrm{H}_{0 \mathrm{~s} \text {,Thomas }}$ & $\mathrm{b}_{\mathrm{s}}$ & \\
\hline & & $\mathrm{H}_{\mathrm{s}}$ & Not used & \\
\hline $\mathrm{t}$ & double & \multicolumn{3}{|l|}{ Thickness of the film (in m). } \\
\hline
\end{tabular}

\section{User Controls}

The user is able to control how the program analyses the data file by selecting the values for the variables listed in the table below.

\begin{tabular}{|c|c|c|}
\hline Variable & Options & Description \\
\hline dataFile & & $\begin{array}{l}\text { User defined string corresponding to the data file to } \\
\text { be analysed. File extension (.mat) not required. }\end{array}$ \\
\hline XLS_BOOK & & $\begin{array}{l}\text { User defined string corresponding to the Microsoft } \\
\text { Excel (97-2003) file where the output data will be } \\
\text { recorded. File extension (.xls) not required. }\end{array}$ \\
\hline MODEL & $\begin{array}{c}\text { KORSUNSKY } \\
\text { PUCHI_CABRERA }\end{array}$ & $\begin{array}{l}\text { Selects the thin-film model to be used for the } \\
\text { analysis. }\end{array}$ \\
\hline ISE & $\begin{array}{c}\text { NO_ISE } \\
\text { MEYER_ISE } \\
\text { THOMAS_ISE }\end{array}$ & $\begin{array}{l}\text { Selects the ISE to be combined with the thin-film } \\
\text { model. }\end{array}$ \\
\hline what & $\begin{array}{l}\text { VMHT } \\
\text { NHT } \\
\text { BOTH }\end{array}$ & $\begin{array}{l}\text { Selects the coated indentation data to be used from } \\
\text { the input file. VMHT loads indentation data from } \\
\text { only VMHT_data, NHT from NHT_data and BOTH } \\
\text { loads both sets of data. }\end{array}$ \\
\hline$\overline{\text { k_acc }}$ & $0<\mathrm{k} \_$acc & Program searches for parameter $\mathrm{k}$ to within $\pm \mathrm{k} \_\mathrm{acc}$. \\
\hline
\end{tabular}




\begin{tabular}{|c|l|l|}
\hline X_acc & $0<X \_a c c$ & $\begin{array}{l}\text { Program searches for parameter X to within } \pm \\
\text { X_acc. }\end{array}$ \\
\hline displayRange & true/false & $\begin{array}{l}\text { If true, program displays current search range on } \\
\text { screen with current selected parameters. }\end{array}$ \\
\hline displayResults & true/false & $\begin{array}{l}\text { If true, program displays full results on screen at the } \\
\text { end. }\end{array}$ \\
\hline recordResults & true/false & $\begin{array}{l}\text { If true, program records full results in user specified } \\
\text { XLS_BOOK. }\end{array}$ \\
\hline $\begin{array}{l}\text { k_LOW } \\
\text { k_STEP } \\
\text { k_HIGH }\end{array}$ & & $\begin{array}{l}\text { Specifies the initial search space for model } \\
\text { parameter } k .\end{array}$ \\
\hline $\begin{array}{l}\text { X_LOW } \\
\text { X_STEP } \\
\text { X_HIGH }\end{array}$ & & Specifies the initial search space for model \\
\hline
\end{tabular}

\section{Supporting Functions}

The following are functions which support the operation of the main program. They are displayed in alphabetical order by function name without regard to the particular program in which they are called.

\section{function [success] = curvePlot(MODEL, ISE, params, lineOptions)}

$\%$ curvePlot takes a set of model and ISE parameters and plots the resulting

$\%$ curve on a semilog axis. Can be used with

load('Controls');

success = false; \% Dummy return value

$\%$ Assign parameters

$k=\operatorname{params}(1) ; X=\operatorname{params}(2)$; 


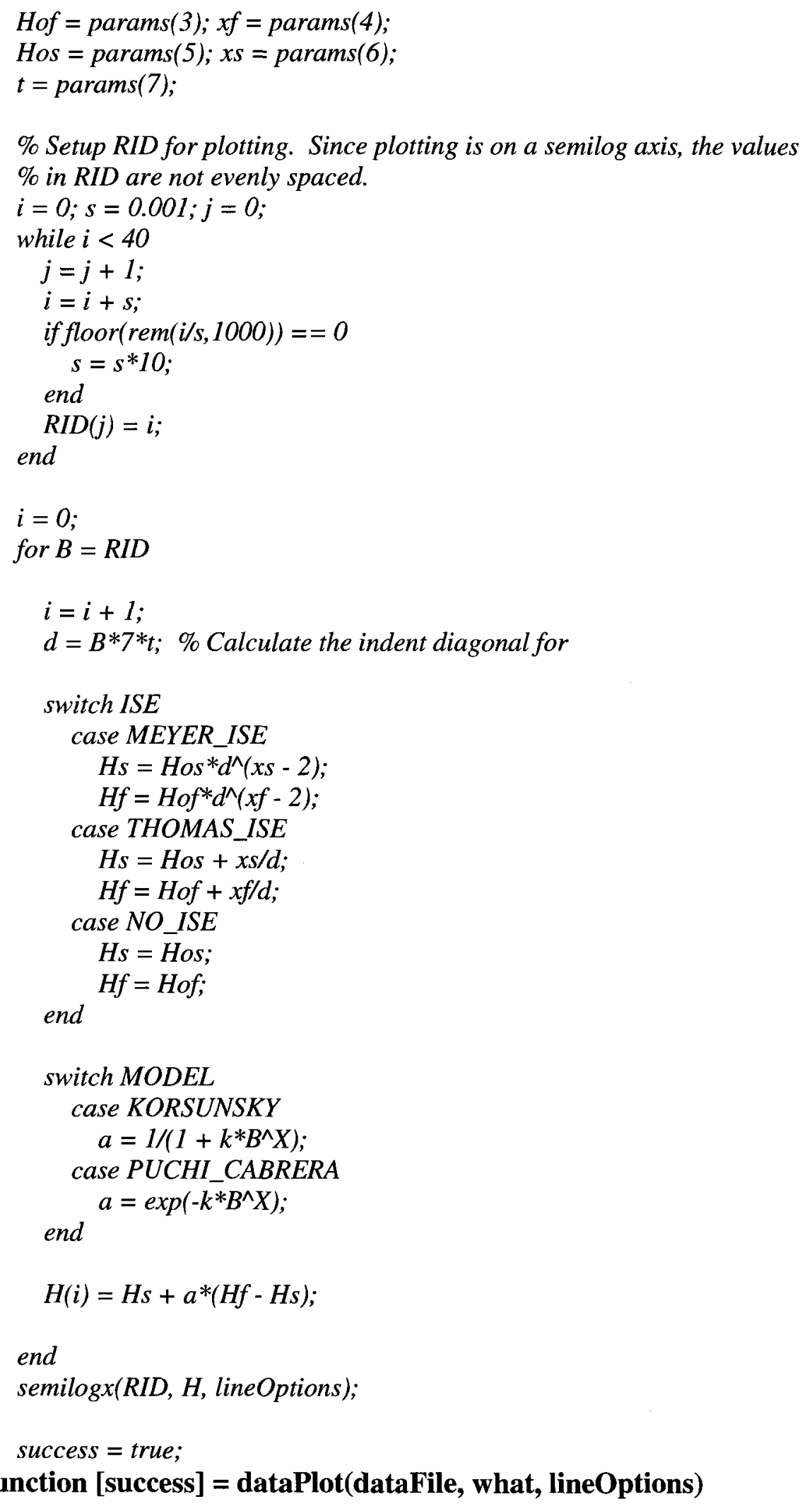

$\%$ Plots the actual data recorded from testing on a semilog plot. 
load('Controls');

data = getData (dataFile, what $) ; \%$ Load data

semilogx(data(:, B_COL), data(:, H_COL), lineOptions);

success $=$ true;

\section{function $[\mathrm{dpdHo}]=$ dPhi dHo(ISE, Ho, $\mathbf{x}$, data);}

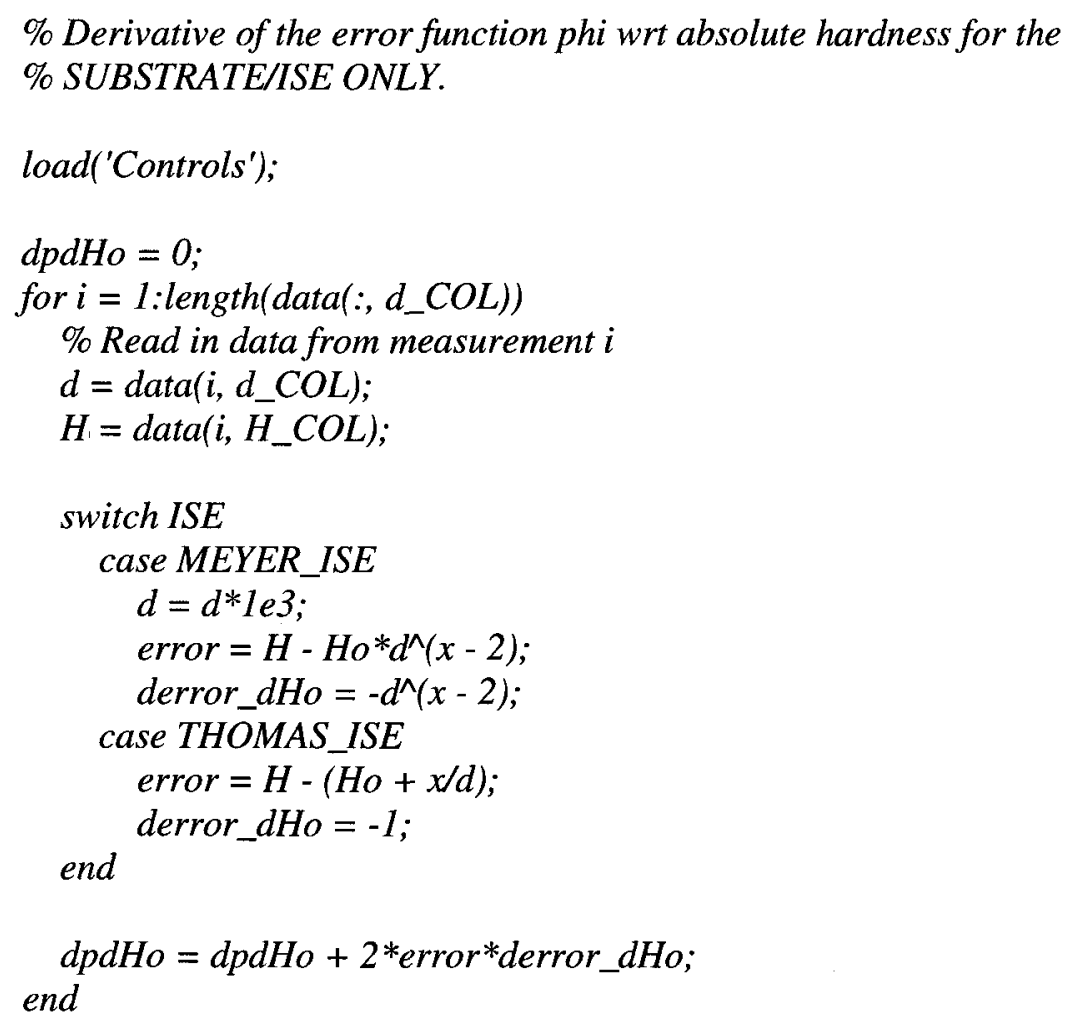

\section{function [dpdHof] = dPhi_dHof(MODEL, ISE, k, X, Hof, xf, Hos, xs, data);}

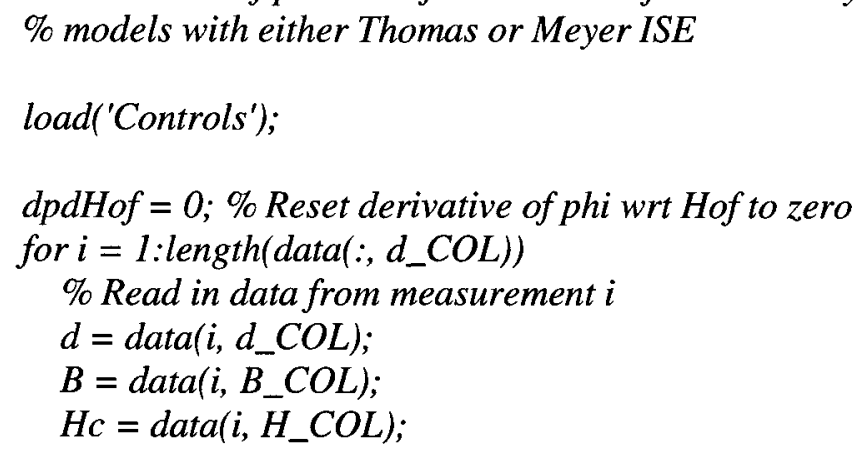




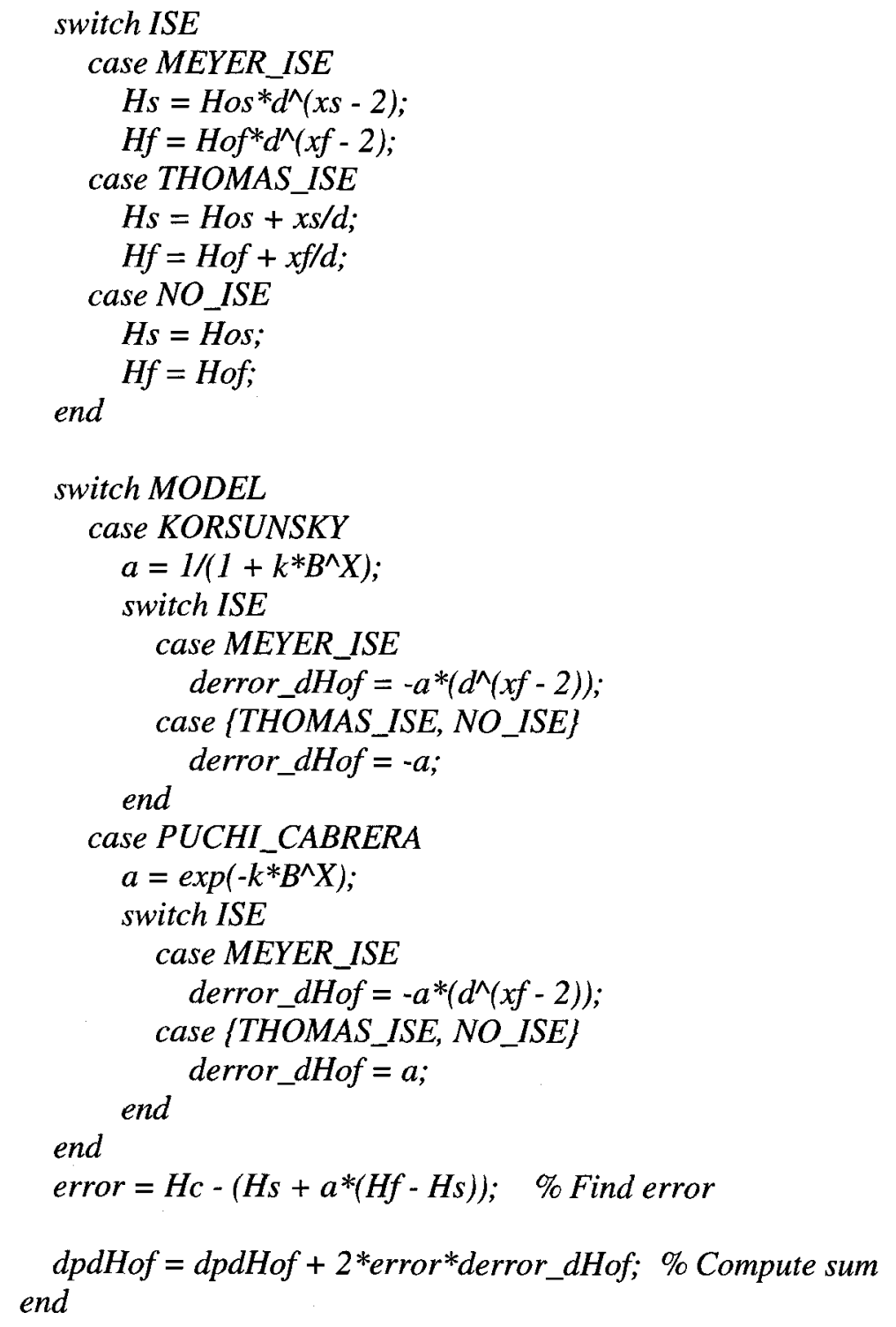

\section{function [dpdx] = dPhi_dx(ISE, Ho, x, data);}

$\%$ Function returns the sum of the derivative of the error funtion phi wrt $\%$ the ISE parameter ( $n$ or $b$ ) for the SUBSTRATE/ISE only.

load('Controls');

$d p d x=0$

for $i=1:$ length $\left(\right.$ data $\left.\left(:, d \_C O L\right)\right)$

$\%$ Read in data from measurement $i$

$d=$ data $\left(i, d \_C O L\right)$;

$H=$ data $\left(i, H_{-} C O L\right)$; 


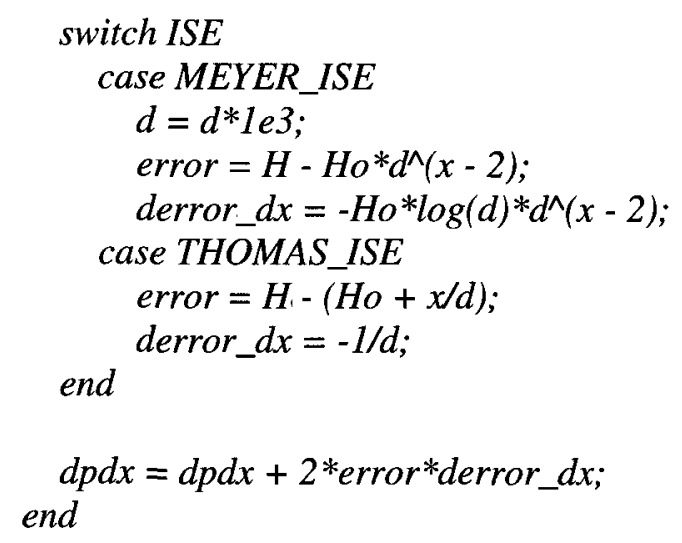

\section{function [dpdxf] = dPhi_dxf(MODEL, ISE, k, X, Hof, xf, Hos, xs, data);}

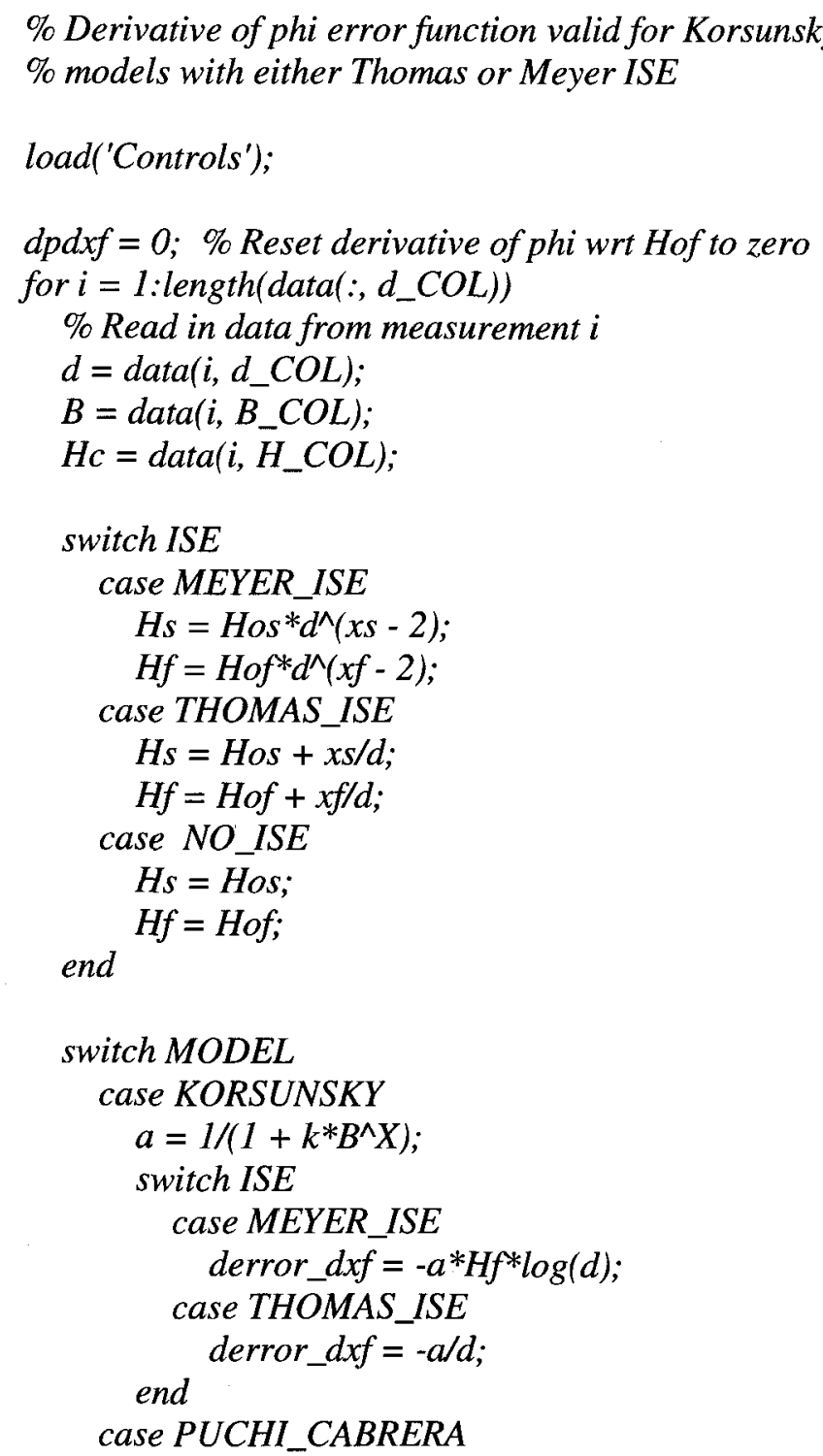




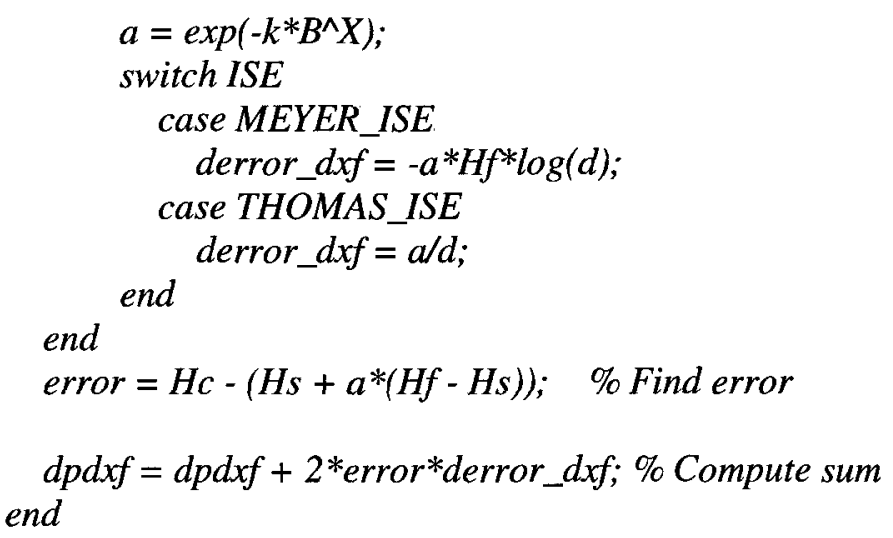

function [data, $\mathrm{t}]$ = getData(dataFile, what);

$\%$ Function loads requested subset of indentation data

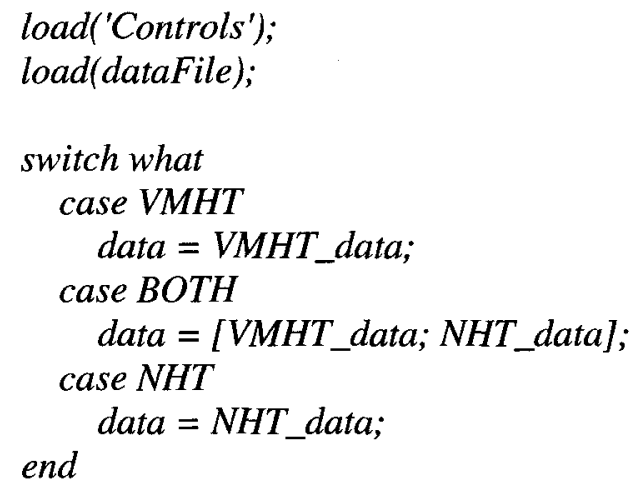

\section{function [Hos, xs] = getSubData(dataFile, ISE);}

\% Function retums requested calibrated substrate parameters

load('Controls');

load(dataFile);

Hos $=$ subResults $(I S E, 1)$;

$x s=\operatorname{subResults}(I S E, 2)$;

\section{function [sse] = phi(ISE, Ho, x, data);}

\% Function returns the sum of the squares of the errors of the hardness of $\%$ the SUBSTRATE compared with the appropriate ISE.

load('Controls'); 


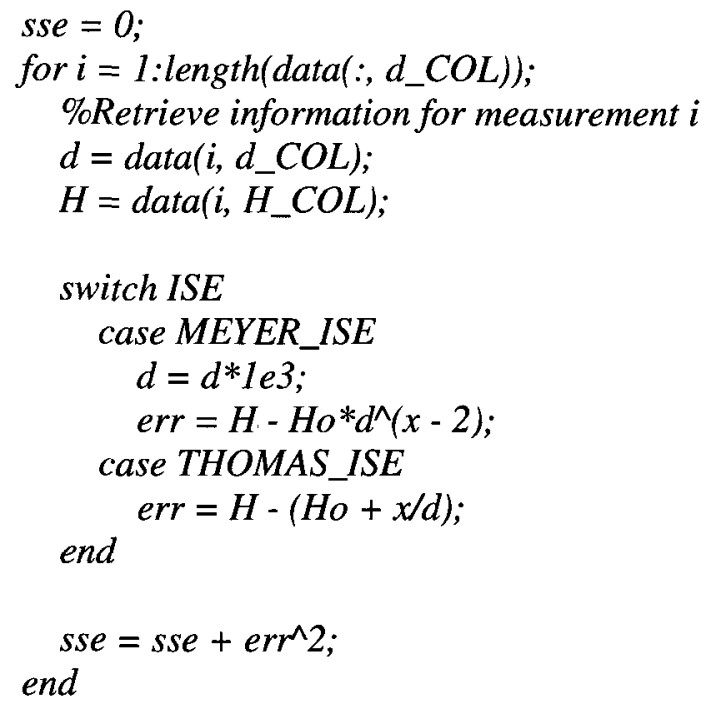

\section{function [sse] = phi(MODEL, ISE, k, X, Hof, xf, Hos, xs, data);}

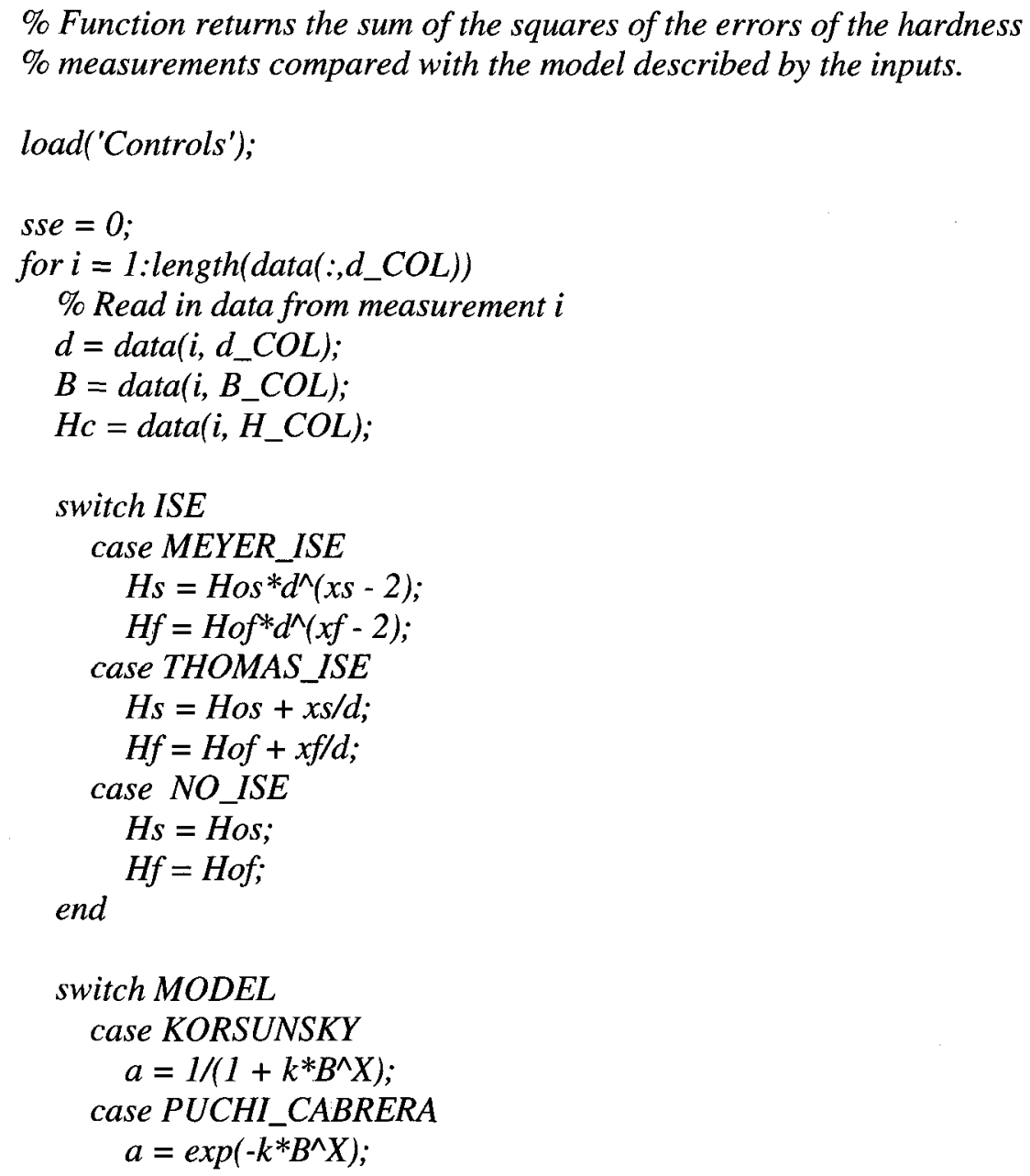

switch MODEL case KORSUNSKY 


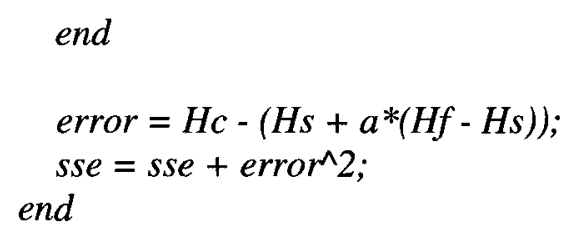

\section{Substrate Calibration}

The following program code was used to calibrate the absolute hardness and ISE parameters ( $\mathrm{n}$ and $\mathrm{b}$ ) for the uncoated substrate data. The results from the calibration using Meyer and Thomas ISEs were entered into the data file (*.mat) manually.

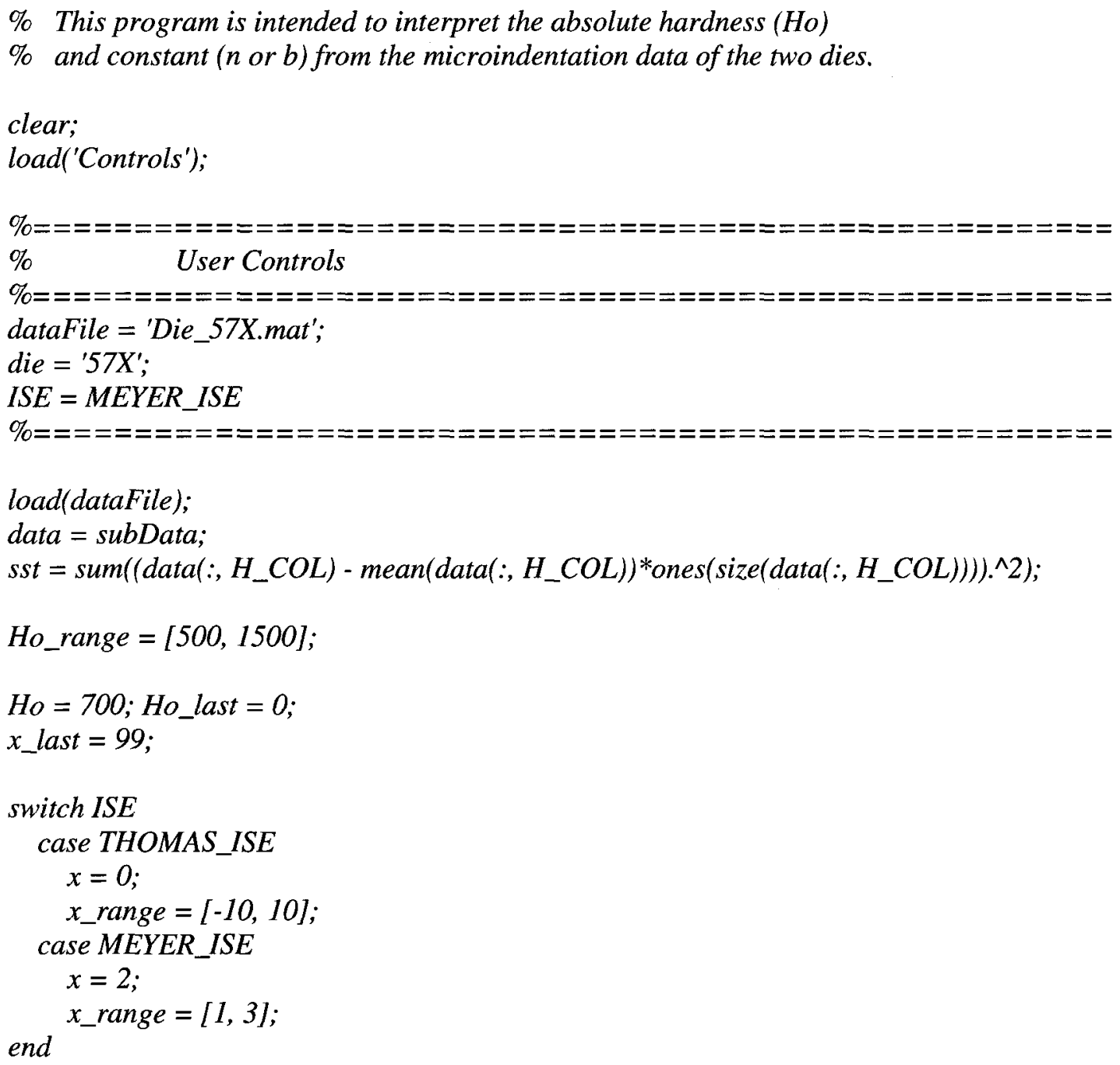




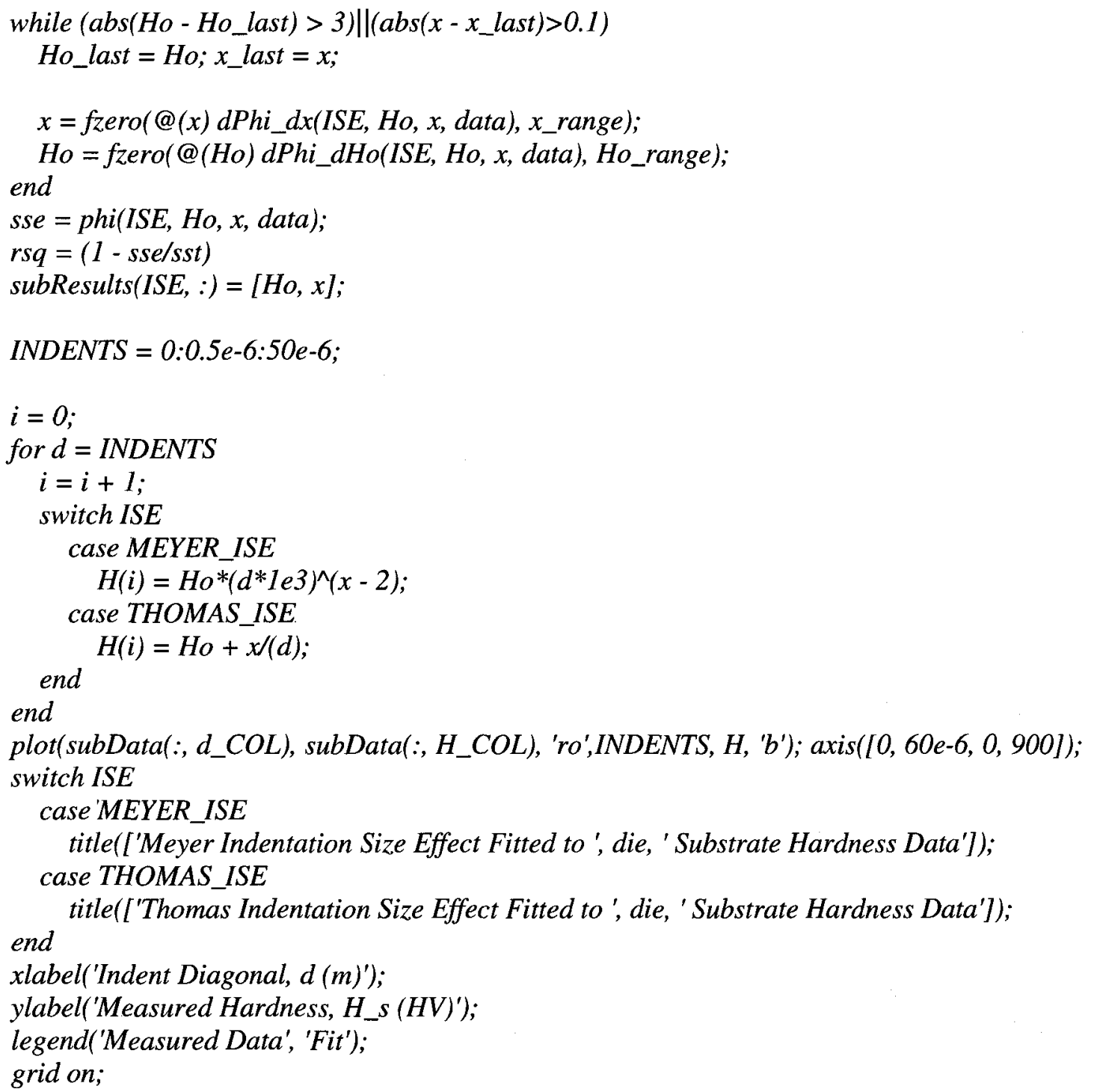

\section{Coated Die Calibration}

The following program code was used to calibrate the model and ISE parameters for each of the dies. It is set up for calibrating 57X using the Korsunsky thin-film model without using an ISE. The user controls are explained above. 


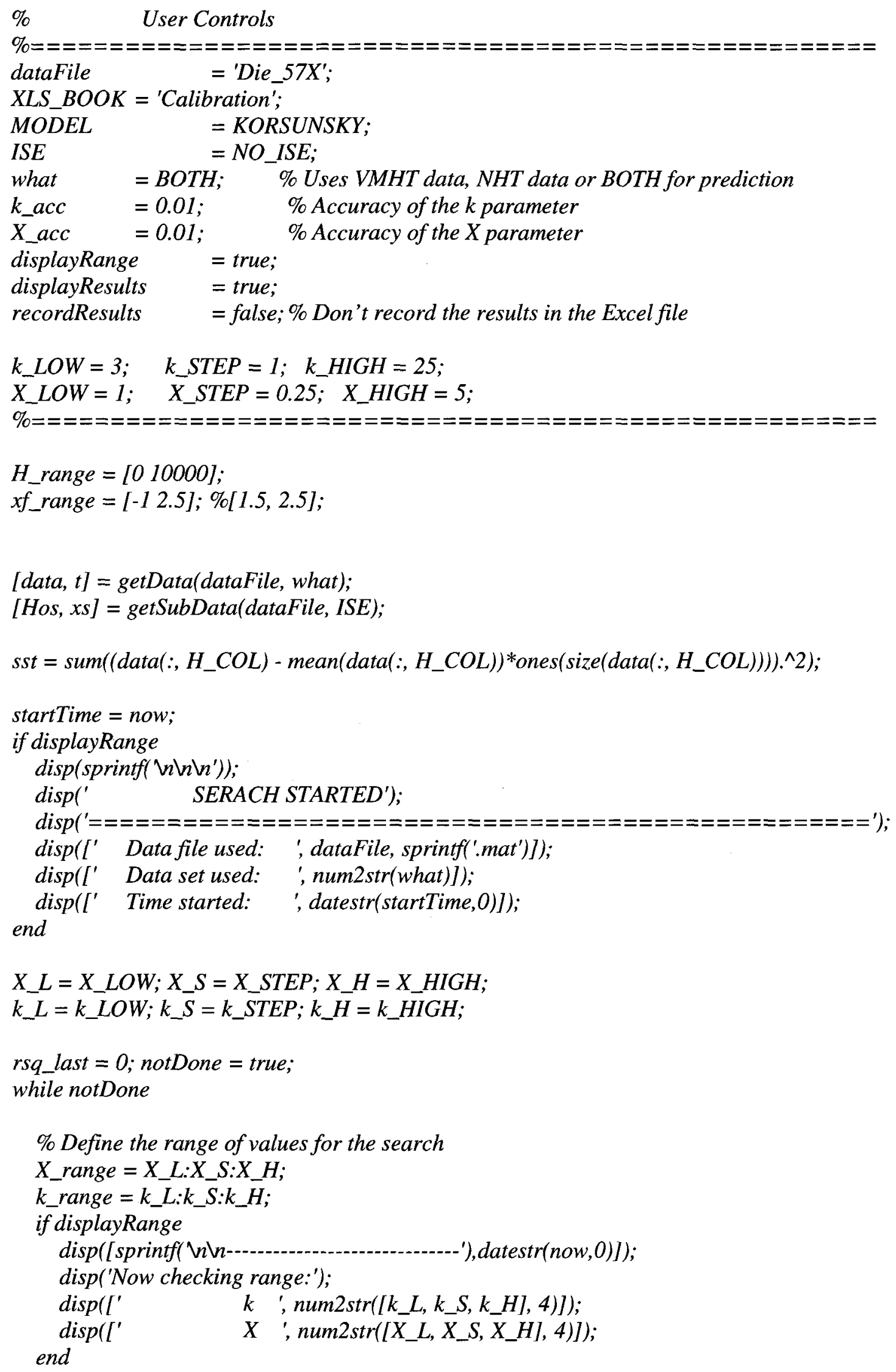




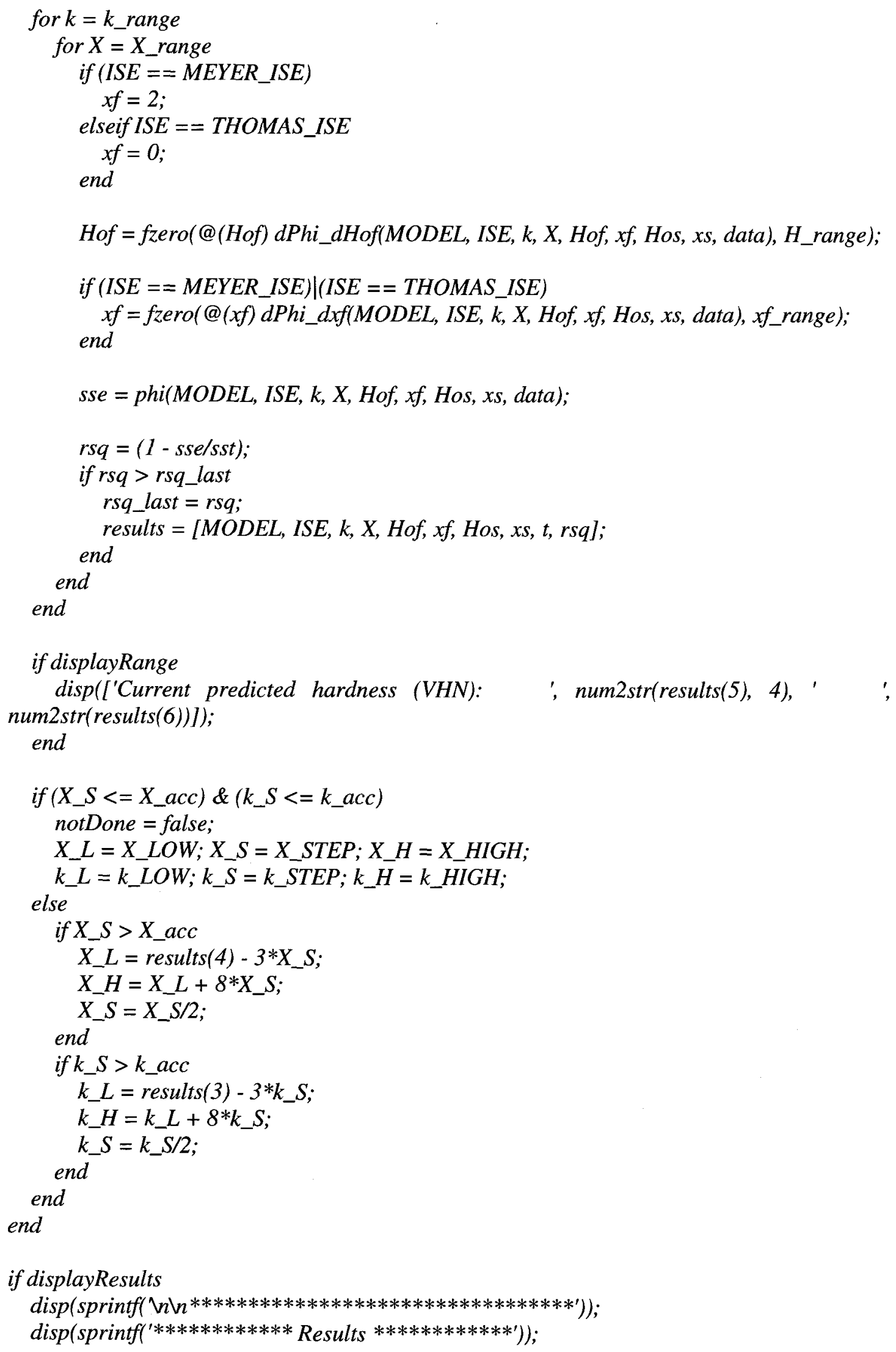




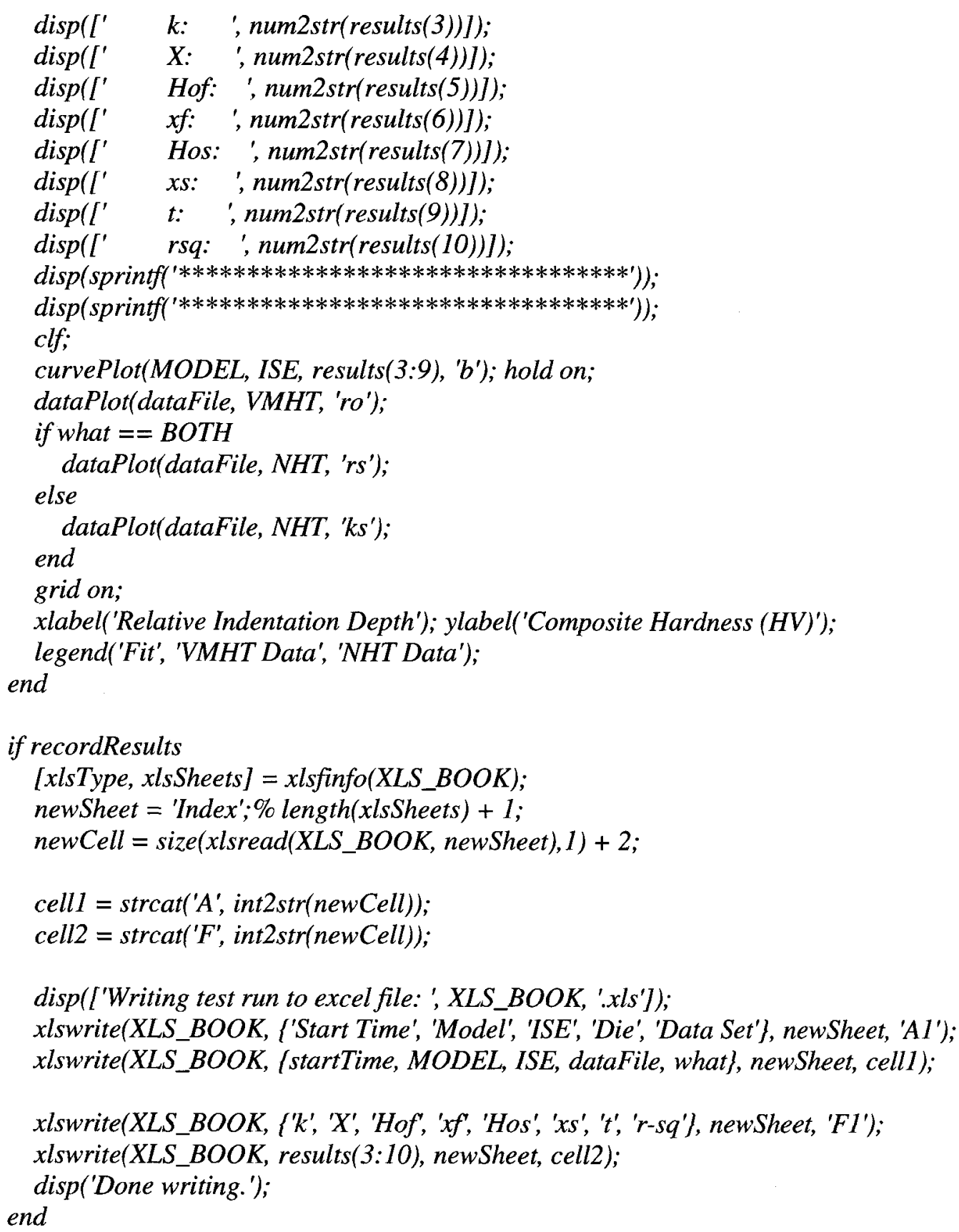

\section{Calibrated Die Prediction}

The following program code was used for predicting the hardness of the thin-film using only micro-indentation data. The model parameters are input by the user and the film hardness is determined along with the $r^{2}$ value of the fit. 
$\%$ This program takes a user-defined/pre-determined set of model parameters

$\%$ and calculates the film hardness that best fits the given data. It

$\%$ reports the fit ( $r$-sq value) of the model to the data and plots the model

$\%$ against the data.

clear;

load('Controls');

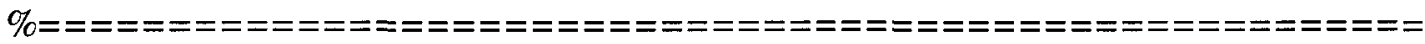

$\% \quad$ User Controls

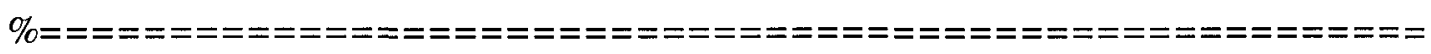
dataFile $\quad=$ 'Die_57X';

what $\quad=$ BOTH;

MODEL $\quad=$ KORSUNSKY;

ISE $\quad$ MEYER_ISE;

$X L S \_B O O K=$ = 'Prediction.xls';

makeRecord $\quad=$ true;

dataTag $\quad=' K / M-57 X$ Verify $(\text { Both })^{\prime} ; \quad \%$ Note recorded with results

$\%$ Set model parameters

$k=6.8203$;

$X=1.5547$;

$x f=2.0000$;

Hof_range $=[10005000]$

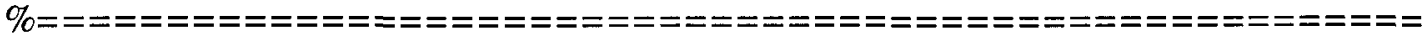

\% Load the data

[Hos, xs] = getSubData(dataFile, ISE);

[data, $t]=$ getData (dataFile, what $)$;

\% Solve for film hardness

Hof=fzero(@(Hof)dPhi_dHof(MODEL, ISE, $k, X$, Hof, xf, Hos, xs, data), Hof_range); 
$\%$ Calculate the fit

$s s t=\operatorname{sum}\left(\left(\right.\right.$ data $\left(:, H \_C O L\right)-$ mean $\left(d a t a\left(:, H \_C O L\right)\right) *$ ones $\left(\right.$ size $\left.\left.\left.\left(d a t a\left(:, H \_C O L\right)\right)\right)\right) \cdot \wedge 2\right)$;

$s s e=p h i(M O D E L$, ISE, $k, X$, Hof, xf, Hos, xs, data);

$r s q=(1-s s e / s s t)$;

results $=[k, X$, Hof, $x f$, Hos, $x s, t$, sst, sse, rsq $]$

clf;

dataPlot(dataFile, VMHT, 'ro'); hold on;

dataPlot(dataFile, NHT, 'ks');

curvePlot(MODEL, ISE, results(1:7), ' $b$ '); grid on;

xlabel('Relative Indentation Depth'); ylabel('Composite Hardness, $\left.H_{-} c(H V)^{\prime}\right)$;

legend('VMHT Data', 'NHT Data', 'Predicted');

hold off;

$\%$ Record important results to excel file

if makeRecord

disp('Writing test run to excel file...');

new Sheet $=$ 'Index';

temp $=x l s r e a d\left(X L S \_B O O K\right)$;

writeStart $=\operatorname{strcat}\left('{ }^{\prime}\right.$, , num 2 str $($ size $($ temp, 1$\left.)+2)\right)$;

xlswrite(XLS_BOOK, ['Model/ISE', 'Die', 'Model', 'ISE', 'Data Set', 'k', 'X', 'Hof', 'xf', 'Hos', 'xs', 't', 'rsq'], newSheet, 'Al');

xlswrite (XLS_BOOK, (dataTag, dataFile, MODEL, ISE, what, $k, X$, Hof, xf, Hos, xs, $t, r s q$ ), newSheet, writeStart);

end 


\section{References}

ASTM Standard Test Method for Microindentation Hardness of Materials [Report]. West Conshohocken : ASTM International, 2002. - E 384-99.

Beegan D., Chowdhury S. and Laugier M. T. Modification of composite hardness models to incorporate indentation size effects in thin films [Journal] // Thin Solid Films. [s.l.] : Elsevier, 2008. - Vol. 516. - pp. 3813-3817.

Burnett P J and Rickerby D S The Mechanical Properties of Wear-Resistant Coatings I: Modelling of Hardness Behaviour [Journal] // Thin Solid Films. - Netherlands : Elsevier Sequoia, 1987. - Vol. 148. - pp. 41-50.

Bykov Yu. A. [et al.] Measurement of the hardness of thin films [Journal] // Metal Science and Heat Treatment. - 2003. - 9-10 : Vol. 45. - pp. 396-399. - Translated from Metallovedenie i Termicheskaya Obrabotka Metallov.

Callister William (Jr.) D Materials Science and Engineering: An Introduction [Book] / ed. Anderson Wayne. - [s.1.] : John Wiley \& Sons Inc., 2000. - 5th Edition.

Chicot $\mathbf{D}$ and Lesage $\mathbf{J}$ Absolute Hardness fo Films and Coatings [Journal] // Thin Solid Films. - [s.1.] : Elsevier, 1995. - Vol. 254. - pp. 123-130.

Conran Graham W The Evaluation and Heat Treatment fo Steels for the Manufacture of Coining Dies and their Subsequent Surface Coating [Journal] // Surface and Coatings Technology. - [s.1.] : Elsevier, 1995. - Vol. 71. - pp. 98-101.

Cooke K E [et al.] Multilayer Nitride Coatings by Closed Field Unbalanced Magnetron Sputter Ion Plating [Journal] // Surface and Coatings Technology. - [s.1.] : Elsevier, 2003. - Vol. 162. - pp. 276-287.

Cooke K E [et al.] The Industrian Application of Pulsed DC Bias Power Supplies in Closed Field Unbalanced Magnetron Sputter Ion Plating [Journal]// Surface and Coatings Technology. - [s.1.] : Elsevier, 2003. - Vols. 177-178. - pp. 789-794. 
Cooke K, Hapmshire $\mathbf{J}$ and Teer D G Variations on the Closed Field Unbalanced Magnetron Sputter Ion Plating Configuration [Online]// Teer Coatings Ltd.. - Teer $\begin{array}{lllll}\text { Coatings } \quad \text { Ltd., } & \text { 2004. - } & \text { August } & \text { 2009. - }\end{array}$ http://www.teercoatings.co.uk/documents/Kevin3.pdf.

Costello Peter [Interview]. - Ottawa : [s.n.], March 24, 2009.

CSM-Instruments Coating Thickness by Calotest | CSM Instruments [Online]. - CSM Instruments, 2009. - July 28, 2009. - http://www.csm-instruments.com/Calotest.

CSM-Instruments Scratch Test | CSM Instruments [Online] // CSM Instruments. - CSM Instruments, 2009. - July 9, 2009. - http://www.csm-instruments.com/en/Scratch.

Huang $\mathbf{R}$ F [et al.] Wear-Resistant Multilayered Diamond-Like Carbon Coating Prepared by Pulse Biased Arc Ion Plating [Journal] // Diamond and Related Materials. [s.l.] : Elsevier, 2001. - Vol. 10. - pp. 1850-1854.

Jönsson B. and Hogmark S. Hardness measurements of thin films [Journal] // Thin Solid Films. - Uppsala : [s.n.], 1984. - Vol. 114. - pp. 257-269.

Kelly P J and Arnell R D Manetron Sputtering: A Review of Recent Developments and Applications [Journal] // Vacuum. - [s.1.] : Elsevier Science Ltd., 2000. - Vol. 56. - pp. 159-172.

King R B Elastic Analysis of Some Punch Problems for a Layered Medium [Journal] // Internation Journal of Solids and Structures. - Great Britain : Pergamon Journals Ltd., 1987. - 12 : Vol. 23. - pp. 1657-1664.

Korsunsky A M [et al.] On the hardness of coated systems [Journal] // Surface Coatings and Technology. - Newcastly upon Tyne : Elsevier, 1998. - Vol. 99. - pp. 171-183.

Leu Ming-Sheng [et al.] Diamond-Like Coatings Prepared by the Filtered Cathodic Arc Technique for Minting Application [Journal]// Surface Coatings and Technology. [s.1.] : Elsevier, 2004. - Vols. 177-178. - pp. 566-572. 
Lin W [et al.] The Failure Mechanism of Diamond Like Coatings Prepared by the Filtered Cathodic Arc Technique for Minting Application [Journal] // Surface Coatings and Technology. - [s.1.] : Elsevier, 2006. - Vol. 201. - pp. 4430-4435.

Magnetron Sputtering [Online] // Teer Coatings Ltd.. - Teer Coatings Ltd.. - August 5, 2009. - http://www.teercoatings.co.uk/index.php?page=magsput.

Martin P J, Gardiner $\mathbf{R}$ and Yasbandha $\mathbf{H}$ [Conference]// Mint Directory Conference. - South Africa : [s.n.], 2000.

Mayrhofer P $\mathbf{H}$ [et al.] A Comparative Study on Reactive and Non-Reactive Unbalanced Magnetron Sputter Deposition of TiN Coatings [Journal]// Thin Solid Films. - [s.1.] : Elsevier, 2002. - Vol. 415. - pp. 151-159.

Murata Toshi Plating of Proof Dies [Report]: Internal Report/ Research and Development Division ; Japan Mint. - 2008. - p. 7.

Nix William D and Gao Huajian Indentation Size Effects in Crystalline Materials: A Law for Strain Gradient Plasticity [Journal] // Journal of the Mechanics and Physics of Solids. - [s.1.] : Pergamon, 1998. - 3 : Vol. 46. - pp. 411-425.

Oliveira J C [et al.] The Structure and Hardness of Magnetron Sputteret Ti-Al-N Thin Films with Low N Contents ( $<42$ at.\%) [Journal] // Surface and Coatings Technology. [s.1.] : Elsevier, 2006. - Vol. 200. - pp. 6583-6587.

Pharr G M, Oliver W C and Brotzen F R On the Generality of the Relationship Among Contact Stiffness, Contact Area, adn Elastic Modulus During Indentation [Journal] // Journal of Materials Research. - [s.1.] : Materials Research Society, 1992. - 3 : Vol. 7. - pp. 613-617.

Puchi-Cabrera E S A new model for the computation of the composite hardness of coated systems [Journal] // Surface Coatings and Technology. - [s.l.] : Elsevier, 2002. Vol. 160. - pp. 177-186.

Puchi-Cabrera E S, Berríos J A and Teer D G On the computation of the hardness of thin solid films [Journal]. - [s.1.] : Elsevier, 2002. - Vol. 157. - pp. 185-196. 
Rodríguez Rafael J, Sanz Antonio $\mathbf{L}$ and Medrano Angel M The Search for New Applications for Ion Inplantation Treatments [Journal]// Surface and Coatings Technology. - [s.l.] : Elsevier, 1996. - Vol. 84. - pp. 594-599.

Selgin George Steam, Hot Air and Small Change: Matthew Boulton and the Reform of Britain's Coinage [Journal]// Economic History Review.- Oxford: Blackwell Publishing, 2003. - 3 : Vol. 56. - pp. 478-509.

Sneddon Ian $\mathbf{N}$ The Relation Between Load and Penetration in the Axisymmetric Boussinesq Problem for a Punch of Arbitrary Profile [Journal]. - [s.1.] : Pergamon Press, 1965. - Vol. 3. - pp. 47-57.

Sproul William D [et al.] Reactive unbalanced magnetron sputtering of the nitrides of Ti, Zr, Hf, Cr, Mo, Ti-Al, Ti-Zr and Ti-Al-V [Journal]// Surface and Coatings Technology. - [s.1.] : Elsevier Sequoia, 1993. - Vol. 61. - pp. 139-143.

Sproul William D Physical Vapor Deposition Tool Coatings [Journal] // Surface and Coatings Technology. - Evanston, $\Pi$ : Elsevier, 1996. - Vol. 81.

Stallard J, Poulat $\mathbf{S}$ and Teer D G The Study of Adhesion of a TiN Coating on Steel and Titanium Alloy Substrates Using a Multi-Mode Scratch Tester [Journal] // Tribology International. - [s.1.] : Elsevier, 2006. - Vol. 39. - pp. 159-166.

Teer D G and Li Xianyao Sputter Coatings for Collector's Quality Coining Dies. - 2006.

Tuck J R [et al.] Indentation Hardness Evaluation of Cathodic Arc Deposited Thin Hard Coatings [Journal] // Surface and Coatings Technology. - [s.1.] : Elsevier, 2001. - Vol. 139. - pp. 63-74.

Vlasveld A C [et al.] Characterisation and Performance of Partially Filtered Arc TiAlN Coatings [Journal] // Surface and Coatings Technology. - [s.1.] : Elsevier, 2002. - Vol. 149. - pp. 217-224.

Yang Q [et al.] Wear, Errosion and Corrosion Resistance of CrTiAlN Coating Deposited by Magnetron Sputtering [Journal] // Surface and Coatings Technology. - [s.l.] : Elsevier, 2008. - Vol. 202. - pp. 3886-3892. 
Yang Shicai, Cooke K E and Teer D G The Physical Properties and Performance of Chromium Titanium Aluminum Nitride Coatings Deposited by Closed Field Magnetron Sputter Ion Plating [Report]. - 2002.

Yasbandha H Selection of Suitable Numismatic Die/Tool Steels [Conference] // Mint Directors Conference Australia. - 2000. 